\title{
EFFECT OF DIFFERENT DESIGN PARAMETERS ON THE CYCLIC RESPONSE OF REDUCED BEAM SECTIONS (RBS) MOMENT CONNECTIONS
}

By

\section{Syed Asad Abbas Naqvi}

B.S. (Civil Engineering), SSUET Karachi, Pakistan, 2009

\author{
A major research project \\ presented to Ryerson University \\ in partial fulfillment of the \\ requirements for the degree of \\ Master of Engineering \\ in the program of \\ Civil Engineering \\ Toronto, Ontario, Canada, 2019 \\ (C) Syed Asad Abbas Naqvi, 2019
}




\section{AUTHOR'S DECLARATION}

I hereby declare that I am the sole author of this report. This is a true copy of the MRP, including any required final revisions.

I authorize Ryerson University to lend this MRP to other institutions or individuals for the purpose of scholarly research

I further authorize Ryerson University to reproduce this MRP by photocopying or by other means, in total or in part, at the request of other institutions or individuals for the purpose of scholarly research.

I understand that my MRP may be made electronically available to the public. 


\title{
EFFECT OF DIFFERENT DESIGN PARAMETERS ON THE CYCLIC RESPONSE OF REDUCED BEAM SECTIONS (RBS) MOMENT CONNECTIONS
}

By

\author{
Syed Asad Abas Naqvi \\ Master of Engineering (MEng.) in the Program of Civil Engineering \\ Ryerson University \\ 2019
}

\begin{abstract}
After the 1994 Northridge earthquake, research has been conducted to develop new types of beamcolumn moment connections, such as Reduced Beam Section (RBS) connections. This study performs a sensitivity analysis of the cyclic response of RBS connections using detailed finite element simulation. The significance of the effect of twenty-one factors is assessed using a statistical design of experiment method. The input factors are related to the material properties or the geometry of the beam-column connection. A two-level fractional factorial design is used to create factor combinations for the sensitivity analysis. The cyclic response of RBS connections is assessed in terms of five response variables, including: the total dissipated energy, initial stiffness, strength degradation rate, maximum moment capacity and rupture index at $7.5 \%$ storey drift. The sensitivity analysis results show that the beam depth has the greatest influence on the cyclic response of RBS connections.
\end{abstract}




\section{ACKNOWLEDGEMENTS}

I would like to acknowledge my supervisor Dr. Saber Moradi for his continuous guidance and support throughout the process of my experiment and completion of this project. I would also like to thank Dr. Thomas Duever for his valuable time and support in regards to his guidance about the design of experiments. It is necessary to mention about the resources that Ryerson University has provided me including all the research papers and tools to carry out my project such as ANSYS APDL that were necessary for this endeavour. 


\section{Table of Contents}

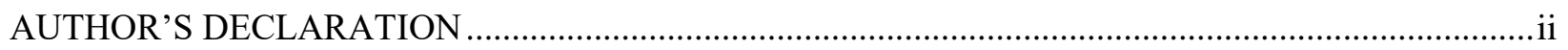

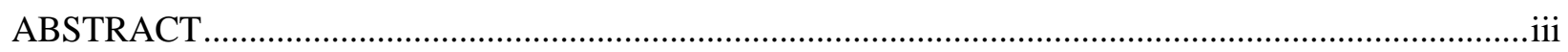

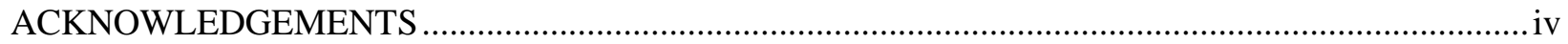

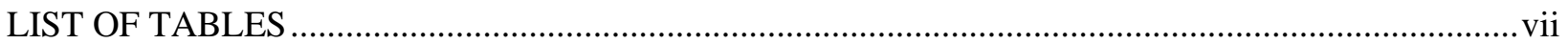

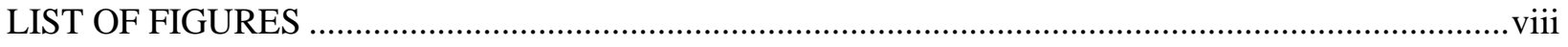

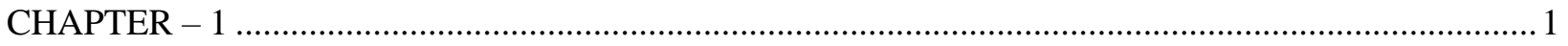

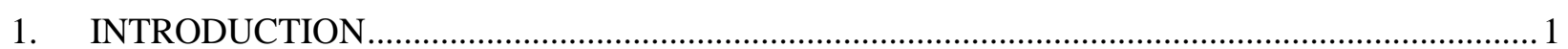

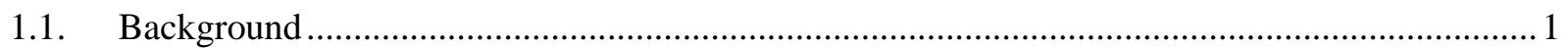

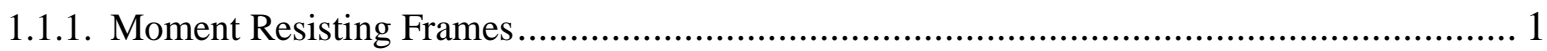

1.1.2. Need for Reduced Beam Sections (RBS) ................................................................ 2

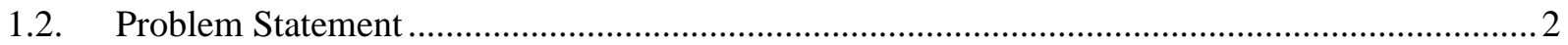

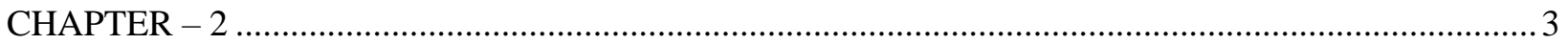

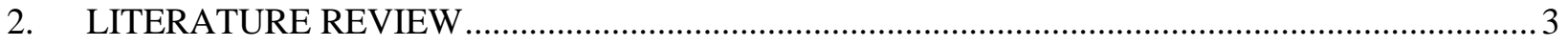

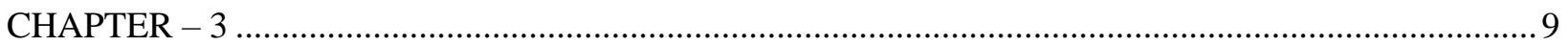

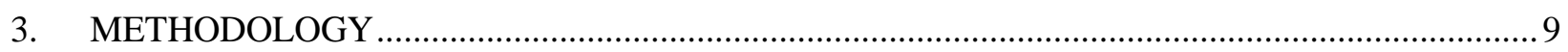

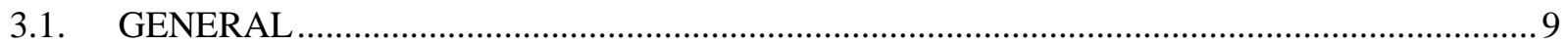

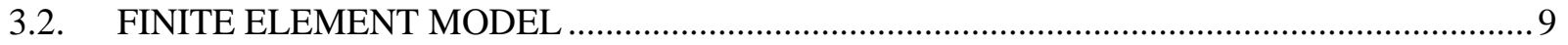

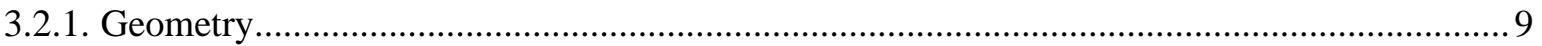

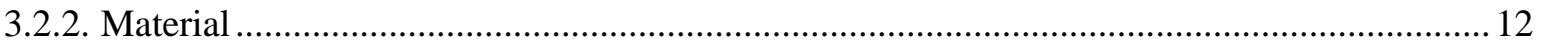

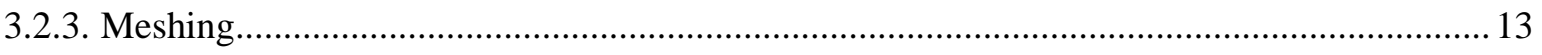

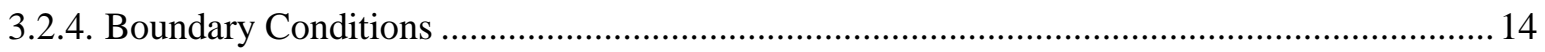

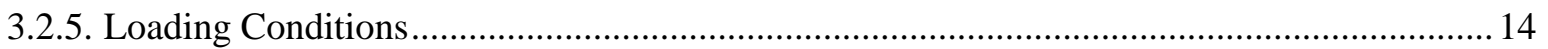

3.2.6. Validation of the Finite Element Model.............................................................................. 15

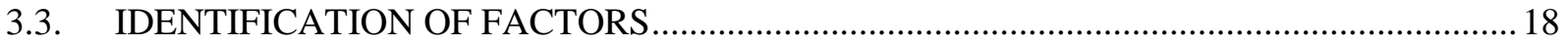

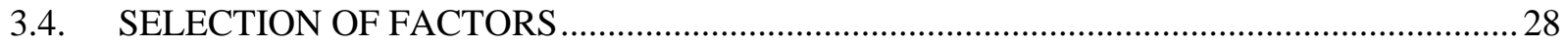

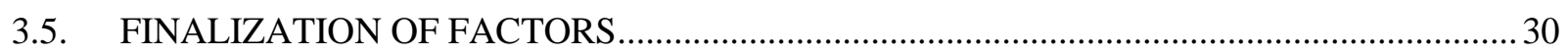

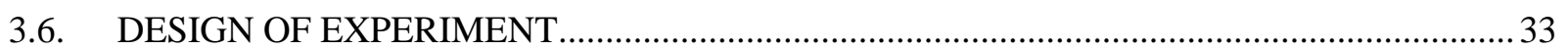

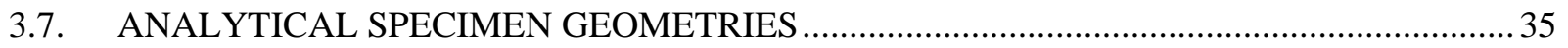

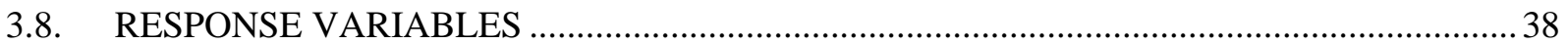

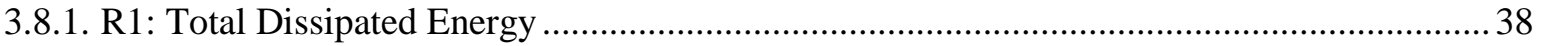

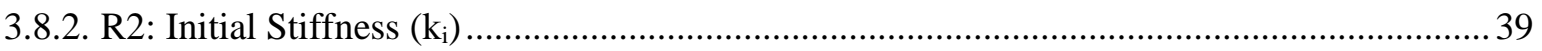

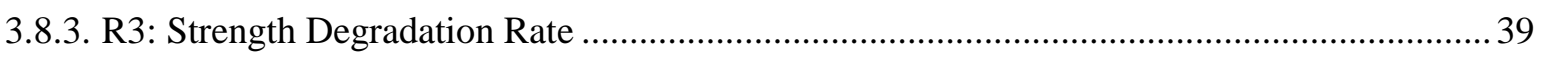

3.8.4. R4: Maximum Moment Resistance................................................................................. 39

3.8.5. R5: Rupture Index @ 7.5\% Total Storey Drift ....................................................................... 40 


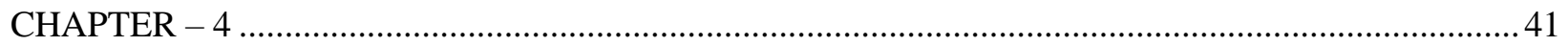

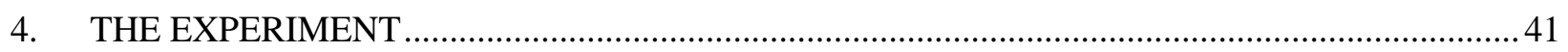

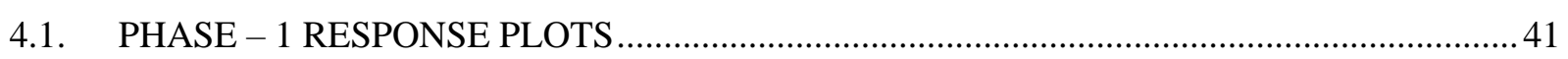

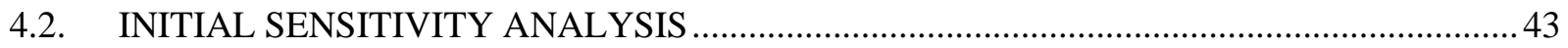

4.3. SEMI-FOLD OVER AUGMENTED DESIGN (PHASE-2) …...........................................51

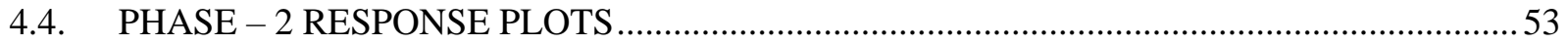

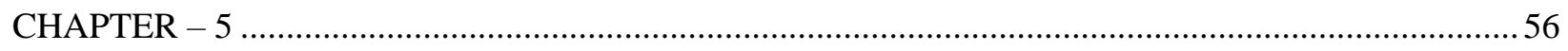

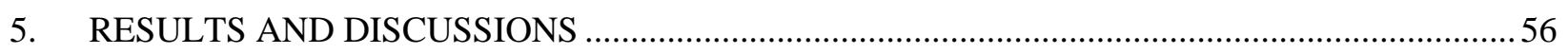

5.1. DEFLECTED GEOMETRIES OF FEA MODELS ..........................................................56

5.2. OVERALL SENSITIVITY ANALYSIS OF EFFECTS ….................................................5

5.2.1. For Response Variable R1 (Total Dissipated Energy) .......................................................... 60

5.2.2. For Response Variable R2 (Initial Stiffness) …................................................................. 71

5.2.3. For Response Variable R3 (Strength Degradation Rate) .................................................... 76

5.2.4. For Response Variable R4 (Maximum Moment Capacity) .................................................... 86

5.2.5. For Response Variable R5 (Rupture Index @ 7.5\% Total Storey Drift) .............................. 91

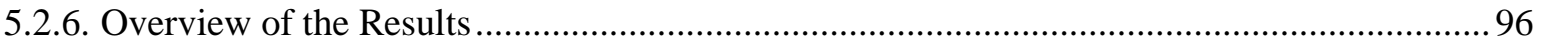

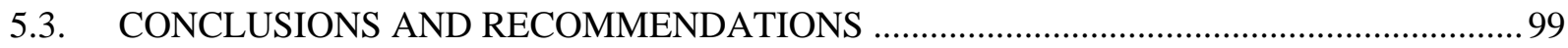

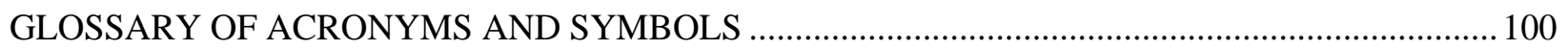

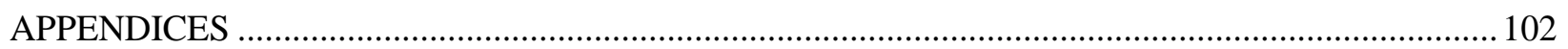

APPENDIX A: FEA Models

APPENDIX B: Response Plots

APPENDIX C: Deflected Geometries of Specimen

REFERENCES 


\section{LIST OF TABLES}

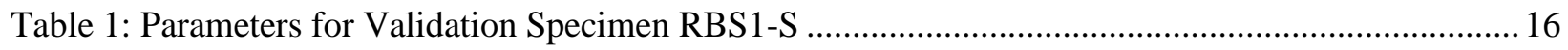

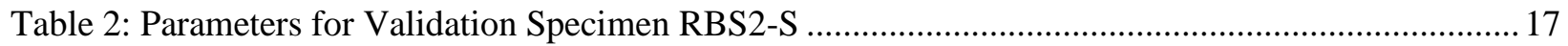

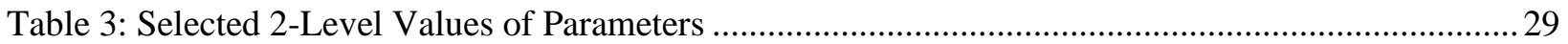

Table 4: Values of Parameters for Testing 2 Insignificant Factors .......................................................... 30

Table 5: Finalized 2-Level Values of Parameters ................................................................................... 33

Table 6: Coded Factor Combinations for Experiment Phase 1 .................................................................. 34

Table 7: ANOVA of Selected Model for Response R1, Phase-1 …...................................................... 46

Table 8: ANOVA of Selected Model for Response R2, Phase-1 …...................................................... 47

Table 9: ANOVA of Selected Model for Response R3, Phase-1 …...................................................... 48

Table 10: ANOVA of Selected Model for Response R4, Phase-1..........................................................49

Table 11: ANOVA of Selected Model for Response R5, Phase-1 .............................................................50

Table 12: Coded Factor Combinations for Experiment Phase 2 (Semi-Fold over) ..................................52

Table 13: Results from Both Phases of the Experiment .....................................................................5

Table 14: Coefficients of Model for Response R1 ..............................................................................6 60

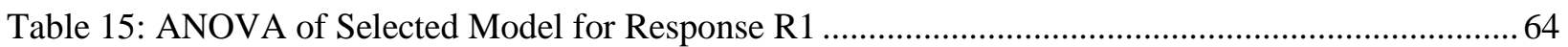

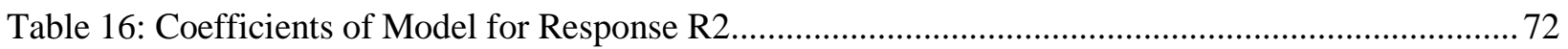

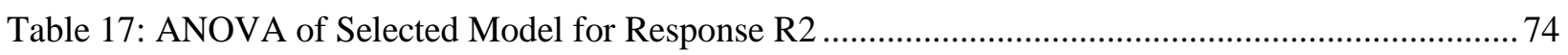

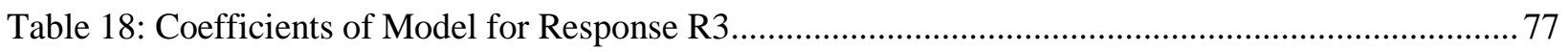

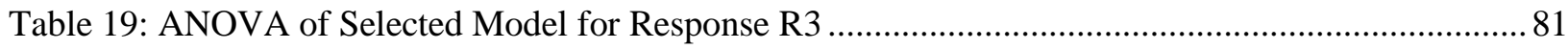

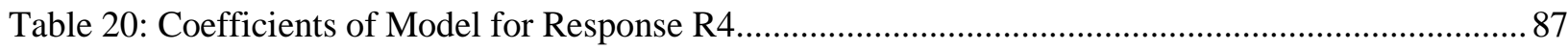

Table 21: ANOVA of Selected Model for Response R4 ..................................................................... 91

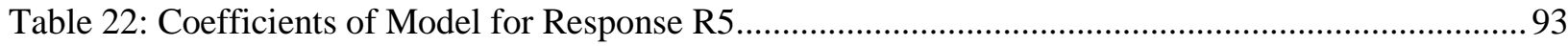

Table 23: ANOVA of Selected Model for Response R5 ................................................................... 96

Table 24: Summary of Contribution of Factors for All Responses ....................................................... 98

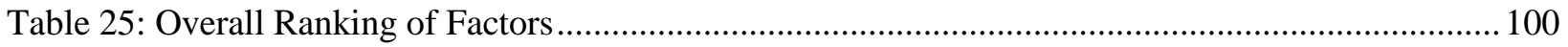




\section{LIST OF FIGURES}

Figure 1: A Conceptual Sketch of a Moment Resisting Frame (MRF) ................................................. 1

Figure 2: Type I - RBS with Continuity and Doubler Web Plates......................................................... 10

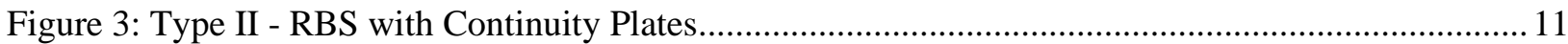

Figure 4: Type III - RBS with Doubler Web Plates.............................................................................. 11

Figure 5: Type IV - RBS without Continuity and Doubler Web Plates................................................... 12

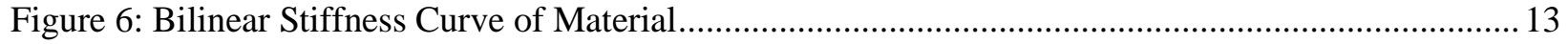

Figure 7: A Depiction of Model Meshing and Boundary Conditions .................................................... 14

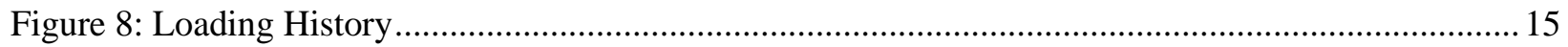

Figure 9: Response Comparison for RBS1-S (Tabar and Deylami 2005) .............................................. 16

Figure 10: Response Comparison for RBS2-S (Tabar and Deylami 2005) ............................................. 17

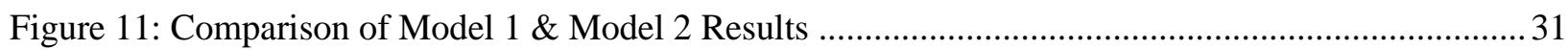

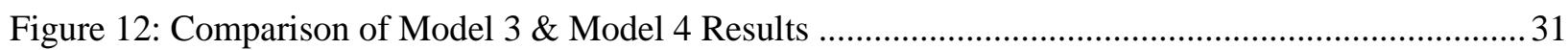

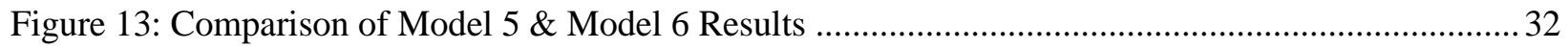

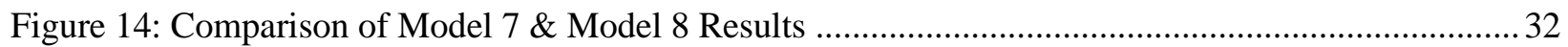

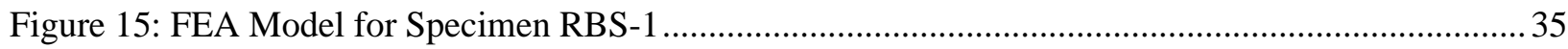

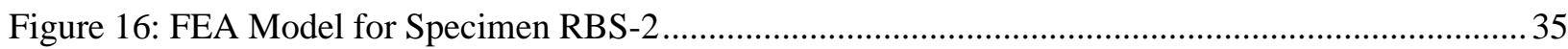

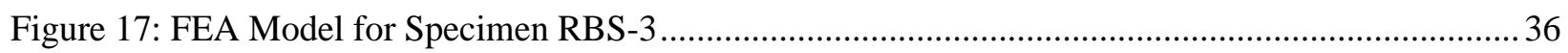

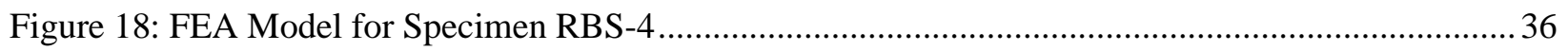

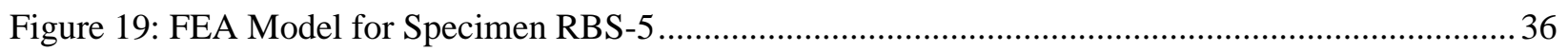

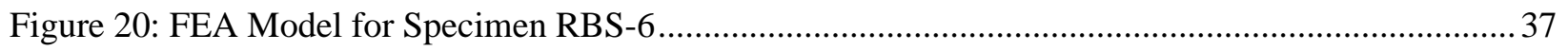

Figure 21: Schematic of Response Variables Considered in Sensitivity Study ......................................... 38

Figure 22: Strength Degradation Rate (Uang and Fan, 2001) .............................................................. 39

Figure 23: Experimental Moment vs Rotation Curve for RBS-1 ….................................................... 41

Figure 24: Experimental Moment vs Rotation Curve for RBS-2 ….....................................................4

Figure 25: Experimental Moment vs Rotation Curve for RBS-3 …..................................................... 41

Figure 26: Experimental Moment vs Rotation Curve for RBS-4 ........................................................ 41

Figure 27: Experimental Moment vs Rotation Curve for RBS-5 …................................................... 42

Figure 28: Experimental Moment vs Rotation Curve for RBS-6 ....................................................... 42

Figure 29: Experimental Moment vs Rotation Curve for RBS-7 ............................................................. 42

Figure 30: Experimental Moment vs Rotation Curve for RBS-8 …..................................................... 42

Figure 31: Experimental Moment vs Rotation Curve for RBS-9 ….......................................................42

Figure 32: Experimental Moment vs Rotation Curve for RBS-10 ...................................................... 42 
Figure 33: Half-Normal Probability Plot for Response R1 (Total Dissipated Energy) Phase-1................43

Figure 34: Half-Normal Probability Plot for Response R2 (Initial Stiffness) Phase-1 ...........................44

Figure 35: Half-Normal Probability Plot for Response R3 (Strength Degradation Rate) Phase 1 ............. 44

Figure 36: Half-Normal Probability Plot for Response R4 (Max. Moment Capacity) Phase-1 ................ 45

Figure 37: Half-Normal Probability Plot for Response R5 (Rupture Index) Phase-1 ............................. 45

Figure 38: Semi-foldover Augmented Design Dialogue Screen in Design Expert v.11 Software .............51

Figure 39: Experimental Moment vs Rotation Curve for RBS-33 …....................................................53

Figure 40: Experimental Moment vs Rotation Curve for RBS-34 ......................................................53

Figure 41: Experimental Moment vs Rotation Curve for RBS-35 ........................................................53

Figure 42: Experimental Moment vs Rotation Curve for RBS-36 .......................................................53

Figure 43: Experimental Moment vs Rotation Curve for RBS-37 ........................................................54

Figure 44: Experimental Moment vs Rotation Curve for RBS-38 …..................................................5

Figure 45: Experimental Moment vs Rotation Curve for RBS-39 ........................................................54

Figure 46: Experimental Moment vs Rotation Curve for RBS-40 .......................................................5

Figure 47: Experimental Moment vs Rotation Curve for RBS-41 ..........................................................5

Figure 48: Experimental Moment vs Rotation Curve for RBS-42 .......................................................5

Figure 49: Experimental Moment vs Rotation Curve for RBS-43 …...................................................5

Figure 50: Experimental Moment vs Rotation Curve for RBS-44 .....................................................5

Figure 51: Experimental Moment vs Rotation Curve for RBS-45 ….................................................5

Figure 52: Experimental Moment vs Rotation Curve for RBS-46 .......................................................55

Figure 53: Experimental Moment vs Rotation Curve for RBS-47 .......................................................5

Figure 54: Experimental Moment vs Rotation Curve for RBS-48 …..................................................5

Figure 55: Deflected Geometry of Specimen RBS-1 …..................................................................5

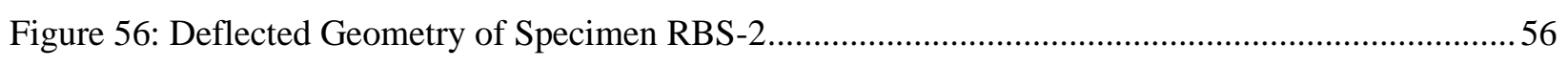

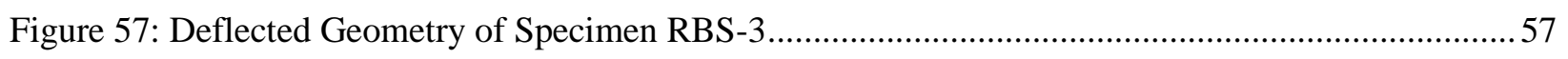

Figure 58: Deflected Geometry of Specimen RBS-4 …....................................................................5

Figure 59: Deflected Geometry of Specimen RBS-5 ......................................................................... 57

Figure 60: Half-Normal Probability Plot for Response R1 (Total Dissipated Energy) ...........................61

Figure 61: Pareto Chart for Response R1 (Total Dissipated Energy) ..................................................... 61

Figure 62: Percentage Contributions of Factors and Interactions on Response R1 .................................6 62

Figure 63: Plot of Marginal Means for Interaction AB in Selected Model for Response R1 .................... 64

Figure 64: 3D Response Surface and Contour Plots for 2FI AB in Selected Model for Response R1....... 64

Figure 65: Plot of Marginal Means for Interaction AC in Selected Model for Response R1 ....................65

Figure 66: 3D Response Surface and Contour Plots for 2FI AC in Selected Model for Response R1....... 65 
Figure 67: Plot of Marginal Means for Interaction AD in Selected Model for Response R1 ....................66

Figure 68: 3D Response Surface and Contour Plots for 2FI AD in Selected Model for Response R1 ......66

Figure 69: Plot of Marginal Means for Interaction AQ in Selected Model for Response R1 ...................67

Figure 70: 3D Response Surface and Contour Plots for 2FI AQ in Selected Model for Response R1 ......67

Figure 71: Plot of Marginal Means for Interaction AU in Selected Model for Response R1 .....................68

Figure 72: 3D Response Surface and Contour Plots for 2FI AU in Selected Model for Response R1 ......68

Figure 73: Plot of Marginal Means for Interaction BC in Selected Model for Response R1 ...................69

Figure 74: 3D Response Surface and Contour Plots for 2FI BC in Selected Model for Response R1 ....... 69

Figure 75: Plot of Marginal Means for Interaction BD in Selected Model for Response R1 .................... 70

Figure 76: 3D Response Surface and Contour Plots for 2FI BD in Selected Model for Response R1....... 70

Figure 77: Half-Normal Probability Plot for Response R2 (Initial Stiffness)............................................. 72

Figure 78: Pareto Chart for Response R2 (Initial Stiffness) ............................................................... 72

Figure 79: Percentage Contributions of Factors and Interactions on Response R2 .................................73

Figure 80: Plot of Marginal Means for Interaction BC in Selected Model for Response R2 ....................74

Figure 81: 3D Response Surface and Contour Plots for 2FI BC in Selected Model for Response R2 ....... 74

Figure 82: Plot of Marginal Means for Interaction BD in Selected Model for Response R2 ....................75

Figure 83: 3D Response Surface and Contour Plots for 2FI BD in Selected Model for Response R2....... 75

Figure 84: Half-Normal Probability Plot for Response R3 (Strength Degradation Rate) .........................77

Figure 85: Pareto Chart for Response R3 (Strength Degradation Rate) ..................................................78

Figure 86: Percentage Contributions of Factors and Interactions on Response R3 ..................................78

Figure 87: Plot of Marginal Means for Interaction AF in Selected Model for Response R3 ..................... 81

Figure 88: 3D Response Surface and Contour Plots for 2FI AF in Selected Model for Response R3 ........ 81

Figure 89: Plot of Marginal Means for Interaction AK in Selected Model for Response R3 .................... 82

Figure 90: 3D Response Surface and Contour Plots for 2FI AK in Selected Model for Response R3 ...... 82

Figure 91: Plot of Marginal Means for Interaction AL in Selected Model for Response R3 ..................... 83

Figure 92: 3D Response Surface and Contour Plots for 2FI AL in Selected Model for Response R3 ....... 83

Figure 93: Plot of Marginal Means for Interaction AR in Selected Model for Response R3 .................... 84

Figure 94: 3D Response Surface and Contour Plots for 2FI AR in Selected Model for Response R3....... 84

Figure 95: Plot of Marginal Means for Interaction BE in Selected Model for Response R3 .................... 85

Figure 96: 3D Response Surface and Contour Plots for 2FI BE in Selected Model for Response R3 ....... 85

Figure 97: Half-Normal Probability Plot for Response R4 (Maximum Moment Capacity)....................... 87

Figure 98: Pareto Chart for Response R4 (Maximum Moment Capacity) ............................................... 87

Figure 99: Percentage Contributions of Factors and Interactions on Response R4 ................................. 88

Figure 100: Plot of Marginal Means for Interaction BD in Selected Model for Response R4 ..................90 
Figure 101: 3D Response Surface and Contour Plots for 2FI BD in Selected Model for Response R4..... 90

Figure 102: Half-Normal Probability Plot for Response R5 (Rupture Index @ 7.5\% Total Storey Drift).92

Figure 103: Pareto Chart for Response R5 (Rupture Index @ 7.5\% Total Storey Drift) .........................92

Figure 104: Percentage Contributions of Factors and Interactions on Response R5 ............................... 93

Figure 105: Plot of Marginal Means for Interaction AD in Selected Model for Response R5 ..................95

Figure 106: 3D Response Surface and Contour Plots for 2FI AD in Selected Model for Response R5 ....95

Figure 107: Graphical Representation of Aggregate Percentile Contribution of Factors .........................97 



\section{CHAPTER - 1}

\section{INTRODUCTION}

\subsection{Background}

\subsubsection{Moment Resisting Frames}

A structural system consisting of beam column arrangement for moment resistance is generally termed as moment resisting frame. The concept of steel frames emerged with the construction of high-rise structures in Chicago and New York City in 1880 's when those steel frames were used as a system to carry gravity loads, and the lateral stiffness was provided by claddings and beams. The requirement of addressing lateral loads such as seismic and wind loads were established after 1906 San Francisco earthquake followed by the evolution of moment resisting frame system over the decades (Bruneau et al., 2011). The Moment Resisting Frames (MRFs) that are subjected to cyclic loading (e.g. lateral loads induced by seismic activities) are design and detailed specially to restrain the rotation of beam element at the connection and dissipate the energy resulted by the beam deflection due to applied loadings. A simple Moment Resisting Frame (MRF) is depicted in Figure 1.

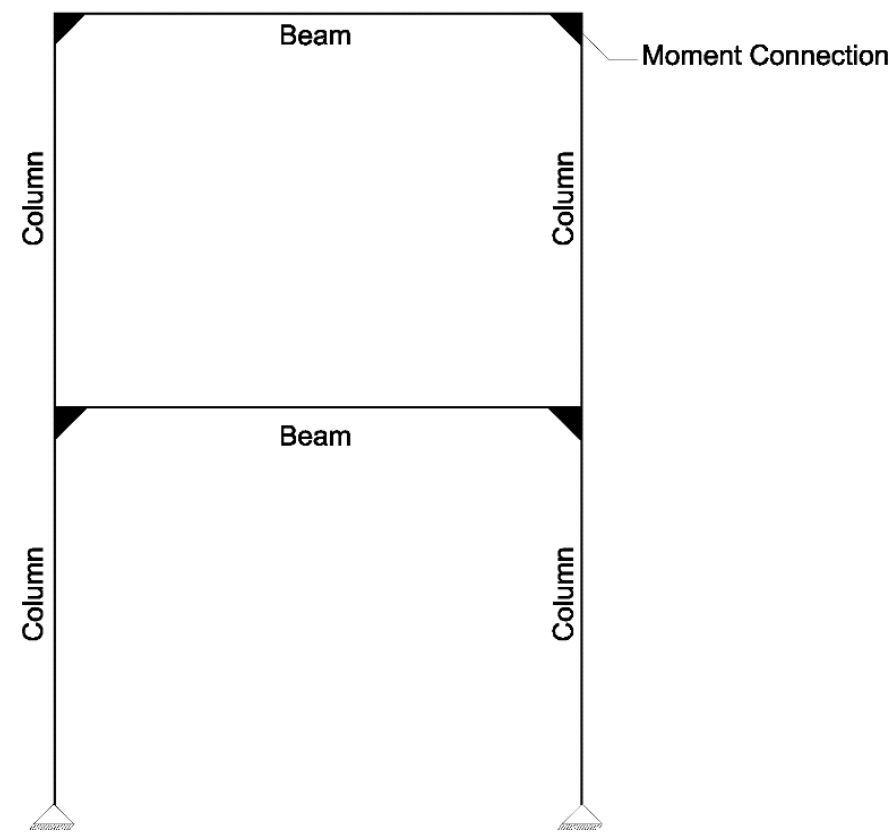

Figure 1: A Conceptual Sketch of a Moment Resisting Frame (MRF) 


\subsubsection{Need for Reduced Beam Sections (RBS)}

The unexpected brittle failure of beam to column welded moment connection reported across the greater Los Angeles area during 1994 Northridge, California earthquake triggered the researches to improve the behavior of the moment connections in MRFs. An approach of reducing the beam flexure capacity by reducing the beam section at certain point near the connection was adopted and named as reduced beam section or dog-bone connections (Paul Popov et al., 1998).

\subsection{Problem Statement}

The idea of developing such connections was introduced to deal with the cyclic loadings that may cause a brittle failure in the system due to stress concentrations at welded zones. Several efforts have been made to understand the effectiveness of RBS connections in comparison to a regular moment connection under cyclic loadings. However, to design the RBS connections efficiently, understanding the effects of different parameters on the performance of these connections under cyclic loadings is essential. These parameters will be discussed in detail in section 3.3 to 3.5 of this document. To achieve these objectives, a statistical design of experiment was required to analyze these effects and identifying individual and interactive effects of these parameters on the system and its sensitivity towards these parameters. The design of experiment will be discussed in section 3.6 of this document followed by the experimental procedure and its outcomes. 


\section{CHAPTER - 2}

\section{LITERATURE REVIEW}

In mid 90's, a study by (Chen and Chu, 1996) was carried out to observe the effectiveness of flange cut RBS connections in steel beams as a means of introducing plastic hinge in steel section ensuring the yielding to initiate from the steel section instead of weld to avoid stress concentrations in the welded zone. This was due to an uncertain behaviour of welded parts as observed in past. The experiment carried out for a $4 \%$ beam rotation suggested that by predefining an enlarged yielding zone by means of flange cuts, the energy dissipation was more predictable and reliable and resulted in an ultimate strength of the moment connection 1.29 times more than nominal values along with a drop in the stiffness by an acceptable difference of $3 \%$. The study recommended the determination of point of inflection by means of inelastic analysis under seismic and gravity loads.

Two years later, another experiment (Paul Popov et al., 1998) was completed that studied the fracture locations and failure modes of pre (traditional) vs post (RBS/ dog-bone) 1994 North ridge Earthquake connections. The elastic-plastic FEA of the beam-column welded junction explained the sudden brittle failure of weak beam flange at the welded section due to triaxial action. The study concluded that a connection of beam directly welded to the column fails with a brittle behaviour before attaining the plastic moment of the beam due to triaxial stresses and not because of the material properties and a RBS connection was found to be a viable solution to this problem of not being able to control the demand of ductility by material properties by introducing a plastic hinge in steel section. Some design recommendations were presented for these type of (radial cut) RBS connections in the compliance with SAC advisory 1 and AWS D1.1-98 codes of practises by (Engelhardt, 1999).

Another study (Uang et al., 2000) was conducted to evaluate the effectiveness of implementation of reduced beam sections for seismic rehabilitation of conventional moment connections that were used commonly before the Northridge earthquake. As the design of special moment resisting frames (SMRFs) is usually governed by story drift that is controlled by stiffnesses of lateral structural members rather than their strengths, the design might have larger sections than the required strength and hence can be reduced without posing any significant effect on overall stiffness of the frame resulting in the reduction in shear force in 
the panel zone, reduced force demand in column continuity plates and easier fulfilment of strong column - weak beam system requirement. Therefore, a RBS was introduced to the beam by reducing its bottom flange by $50 \%$ to induce the phenomenon of plastic hinge formation in the beam at specified location under the loading condition and the welds it was observed that providing RBS at bottom flange alone doesn't exhibit the ductile behavior of the connection unless welds developed with low toughness electrode (E70T-4) at top flange are replaced by welds made with a notch-tough electrode (E71T-8) (Uang et al., 2000).

At this point, the effectiveness of RBS over a conventional beam-column moment connection was proven and RBS were becoming more adaptable. That triggered need of new researches to study different aspects of RBS behaviour and ways to make it more efficient. Such an effort was made by (Uang and Fan, 2001) to assess if additional bracing is required near RBS region by analyzing the effects of slenderness ratio on plastic rotational capacity and strength degradation rate with the consideration of effects of slab on these responses statistically. The experiment was conducted on a database of 55 full scale RBS moment connection specimens tested under cyclic loading conditions by means of regression analysis. The study suggested that the slenderness ratio of web local buckling was most significant for the responses followed by the flange local buckling and lateral torsional buckling being the least significant for both linear and non-linear regression analysis for individual and combined effects. A regression model was developed using web and flange local buckling slenderness ratios as independent variables and plastic rotation capacity as response variable that recommended the limiting $h / t_{w}$ ratio for web local buckling to be $\frac{11,00}{\sqrt{F_{y}}}$ for seismic provisions. It was also concluded that concrete slab under positive bending contributed towards an increased plastic rotation capacity of RBS. These observations were later on verified as a result of experiment carried out by (Jones et al., 2002) on RBS connections with weak, balanced and very strong types of panel zones.

Another study (Chi and Uang, 2002) was conducted to assess the behaviour of RBS moment connection under cyclic loading with deep columns having wide-flange sections. Three specimens, namely DC-1, DC-2 and DC-3 with beam sections W36x150, W36x150, W27x194 and column sections W27x146, W27x194 and W27x194 respectively, were experimentally examined and it was observed that DC-1 and DC-2 were able to achieve $3 \%$ plastic rotation 
while specimen DC-3 had a brittle failure at $2.8 \%$ plastic rotation. Twisting in deep columns was also observed during the experiment and it was explained as a result of higher warping stresses in deep column sections due to their torsional properties and tendency of RBS connections to buckle laterally inducing torsion and out-of-plane bending effects in deep columns. A calculation procedure for the subject connection type considering the combined effects of in-plane, out-of-plane and warping stresses was also presented to verify the adequacy of the connection. Four years later, (Zhang et al., 2006) conducted more detailed experiment on RBS connections with deep columns that verified the findings of (Chi and Uang, 2002). In another similar study, (Zhang and Ricles, 2006) tested six full scale specimens to observe the effects of four parameters namely column size, beam size, floor slab and supplemental lateral brace at the end of RBS and presented more refined criteria to predict stress distribution in beam and column flanges.

The effects of introducing a RBS in a beam to column weak axis connection were studied by (Gilton and Uang, 2002) and it was observed that introduction of RBS to such connection type prevented a brittle failure in welded section due to stress concentration in groove weld at the edges of beam flange as observed in past. The RBS reduced the strain concentration at the edges of beam flange near the groove weld by three times. Also, the total plastic rotation of $3 \%$ was achieved without any yielding in column or panel zone as most of the plastic rotation occurred near RBS. It was also concluded that the far-side continuity plate was insignificant in reducing any stress concentrations in tested specimen. However, the near side continuity plate was suggested to be protruded at least $75 \mathrm{~mm}$ from the tips of the column flanges due to its tendency to reduce tensile force in beam flange. It was also suggested that if beam width is less than $70 \%$ of width of continuity plate, the plate should be trimmed at the edges to help reducing stress concentration near welds. This study also gave a design procedure for the connection type experimented. (Oh et al., 2015) also evaluated the weak axis column tree connection with RBS that yielded $5 \%$ of story drift with more stable deformation capacity curve for RBS as compared to conventional connections.

Efficiency of RBS in connections without continuity plates were investigated by (Pantelides et al., 2004) under ASIC 1997 and 2002 Seismic Provisions and it was found by testing four specimens that these specimen met the requirement of FEMA-350 for special moment frames. 
Also, the failure sequence showed a local buckling in beam web followed by buckling and failure in bottom flange of the beam. It was concluded that with strong panel zone and suitably thicker column flanges, effect of continuity plates on performance of RBS is insignificant.

The effect of panel zone on the performance of RBS were presented by (Lee et al., 2005) suggesting that a panel zone can develop $1 \%$ of plastic rotation without effecting the groove welds at beam flange resulting in a drop of lateral torsional buckling of the beam up to $50 \%$ of its value. The relation of panel zone to RBS was further explored by (Tabar and Deylami, 2005) that observed a reduction in flexural moment capacity of RBS with strong PZ due to lateral and local buckling. The hysteric response in slender beams is controlled by lateral torsional buckling as compared to web local buckling. The study recommended to implement a reduction factor of 0.85 to ultimate shear strength of PZ recommended by AISC seismic provision.

The idea of reduced section was tested on reduced flange plate type connection by (Chou and $\mathrm{Wu}, 2007$ ) when they evaluated 4 specimens that exhibited similar responses to past studies. Statistical analysis showed that the buckling force of reduced flange plate is highly sensitive to minimum width and slenderness ratio.

The formulation of non-prismatic beam element was presented by (Kim et al., 2007) to accommodate the effect of RBS while modeling a non-prismatic beam that can effectively predict elastic story drift of moment frames with RBS connections. An increase of 6 to $8 \%$ in story drift was observed for a $50 \%$ flange reduction while the increase in story drift for a $40 \%$ flange reduction was reported as 4.5 to 6\%. Another study (Lee and Kim, 2007) presented the design procedure for RBS steel moment connections with bolted web attachments having a much higher slip-critical bolt requirement as compared to conventional methods. The specimen exhibited a story drift of $5 \%$ without fracture.

The geometrical characteristics of RBS for European profiles were evaluated by (Pachoumis et al., 2009, 2010) with the help of 2 specimens. FEA was also performed for these specimens and results were compared to find out that geometrical characteristics of RBS are required to be readjusted to be applied on European profiles. This need of including RBS geometrical characteristics consideration to be included in European standards was also suggested by (Sophianopoulos, 2011). 
(Li et al., 2009) studied the local buckling of reduced beam section under cyclic loading by means of different specimen of RBS with 1,2, 3 and no set of stiffeners at RBS portion. The experiment presented an in-depth analysis of the behavior of laterally braced and unbraced RBS. A deterioration in the strength of the beam was observed even when there wasn't any significant lateral buckling observed in laterally unbraced length of 73.2ry. It was also noticed that with stiffened RBS, the last strength under cyclic loading was increased from under $80 \%$ of plastic moment which was observed with no stiffener case, to over $80 \%$ of plastic moment. It was also concluded that the thickness of stiffener effects least on the strength of RBS and a sufficient strength can be achieved by using a stiffener thickness equal to beam web thickness. Also, the maximum stress at RBS portion of stiffened RBS beam was noted to be more than a non-stiffened RBS beam while it didn't differ much at the fixed support location for both stiffened and un-stiffened conditions (Li et al., 2009).

Two specimen for end plate moment connection with RBS were analyzed by (Sofias et al., 2014) to observe the effect of RBS on end plate moment connection elements and it was concluded that due to development of a plastic hinge at predetermined location, the end plate, bolts, column flange, stiffeners and other connection elements did not experience any plasticizing and failures.

A low cycle fatigue damage model of RBS in beams with out-of-plane skew were evaluated by (Prinz and Richards, 2016) to see the effects of the angle of skew on the connection and the results from the experiment showed that the skew induced increased twisting in column and minor yielding at column flanges.

The behavior of RBS with floor slab system was studied by (Li et al., 2017) by designing, constructing and testing 6 specimen including 1 reference specimen. The reference specimen was developed without slab while the other specimens were designed and constructed with slabs. A composite hollow core steel column filled with concrete was used in all specimens while the beams had 3 types of cross-sections in different specimens. The study concluded that through-diaphragms were adequate to connect RBS beams to the composite columns considered in the study. Also, it was observed that the influence of RBS on flexural stiffness of connection was more significant under hogging moments as compared to sagging moment. 
Moreover, the flange cut depth didn't affect the seismic behavior of the connection, however, a deeper cut resulted in abrupt strength degradation of the beam flange. 


\section{CHAPTER - 3}

\section{METHODOLOGY}

\subsection{GENERAL}

In order to study the effects of different factors on any process, experiments are conducted with number of tests dealing with different combinations of these factors to observe the correlations and significance of these factors as well as the sensitivity and variability of the outcome of the experiments. However, an ill-designed experiment can result in a significant number of redundant tests, thus, to address this problem, an experiment can be designed to mitigate these efforts and conduct the experiment more efficiently to achieve desired objectives. In this study, a computer experiment was planned, designed and conducted to observe the behaviour through variation of different responses as the factors vary.

It is also important to select a reliable and adequate method to carry out the experiment so that the results would be error free and consistent. A finite element analysis approach was adopted using a renowned and reliable finite element analysis software package ANSYS Mechanical APDL 18.1 (Canonsburg, 2012). The design and the means to conduct the experiment are discussed in the following sections.

\subsection{FINITE ELEMENT MODEL}

As mentioned in section 3.1, a parametric finite element model was developed by using Solid 185 3D 8 nodes homogenous structural solid element type in ANSYS Mechanical APDL. Details of the model development process are explained in following sections while a sample parametric code for analytical model on ANSYS APDL is presented in Appendix A.

\subsubsection{Geometry}

The model consisted of a beam connected monolithically with the flange of a column. The beam had 2 radial cuts in its flange to form the dog-bone section type while the column had continuity plates and doubler web plates, however, the experiment had required such scenarios where either continuity plate or doubler 
plate or both were not provided. Therefore, the model can be divided into 4 generic types. These types can be identified as shown in Figures 2 through $\mathbf{5}$.
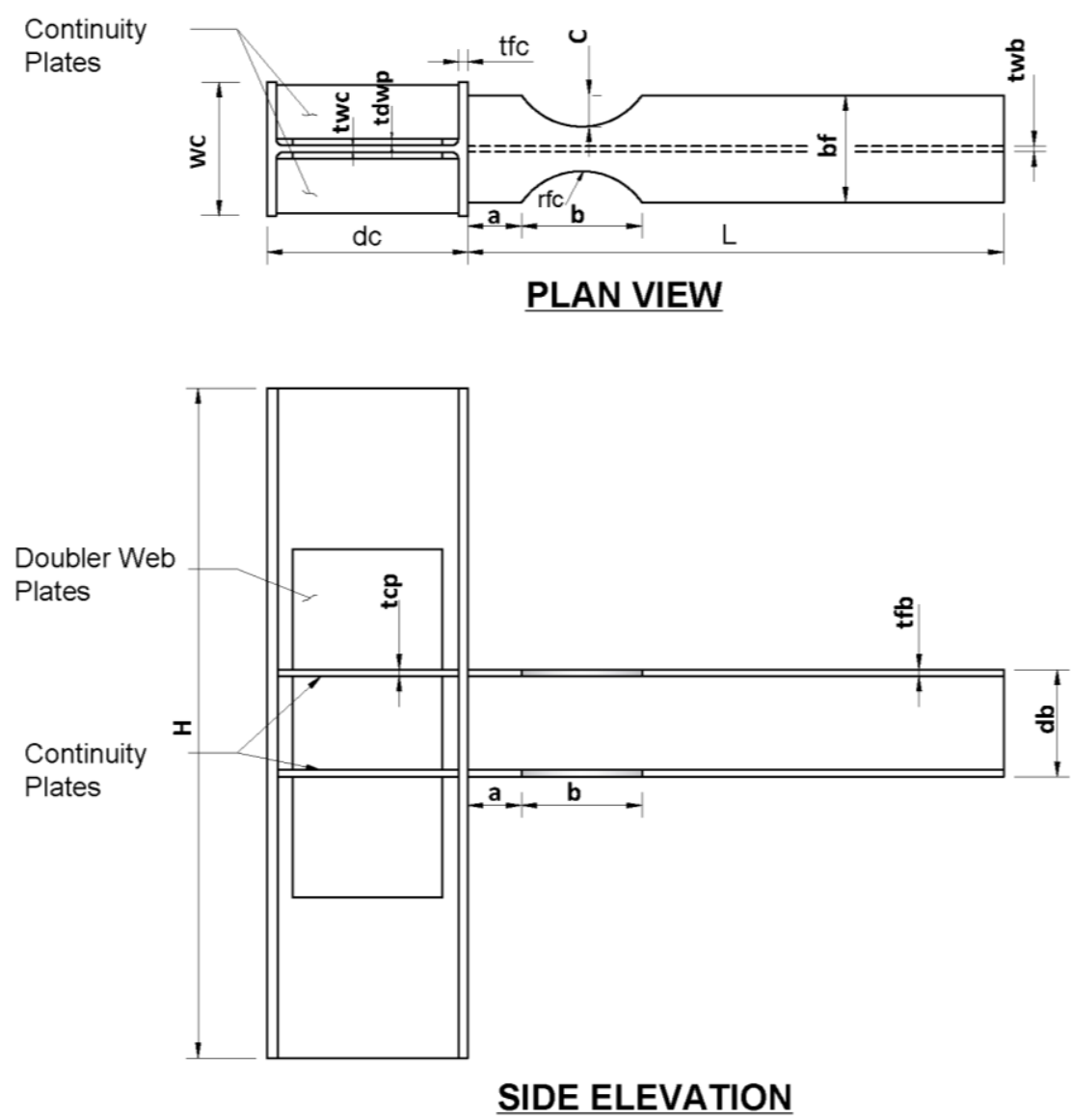

Figure 2: Type I - RBS with Continuity and Doubler Web Plates 

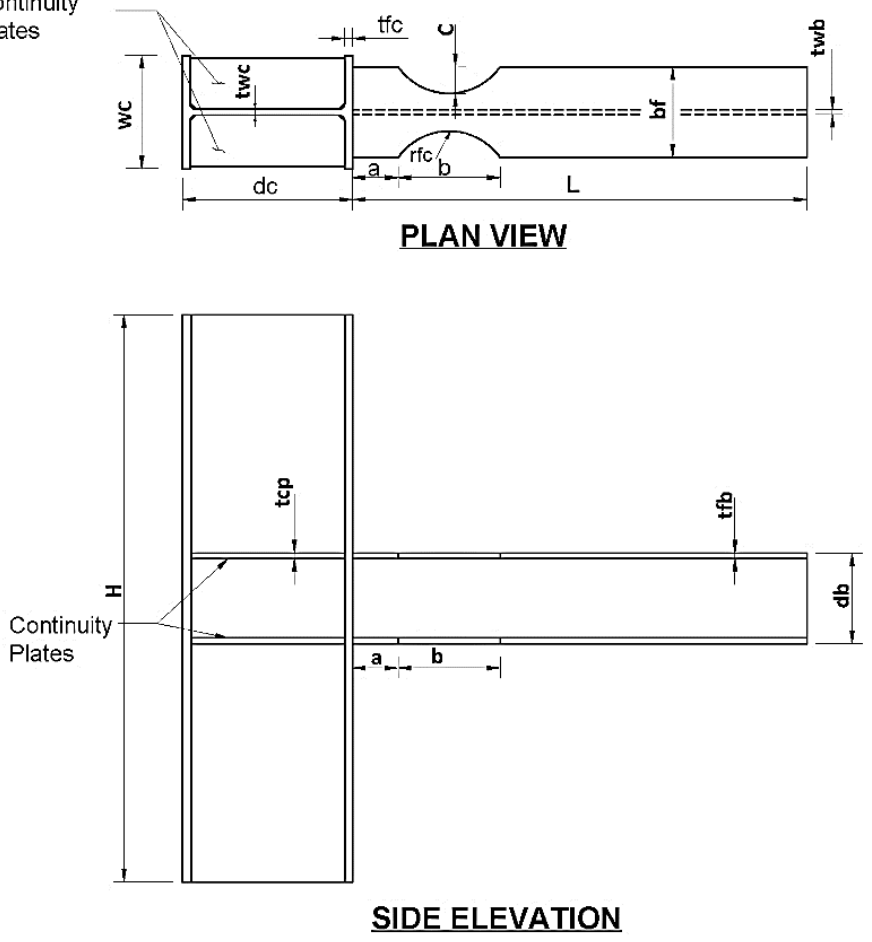

Figure 3: Type II - RBS with Continuity Plates
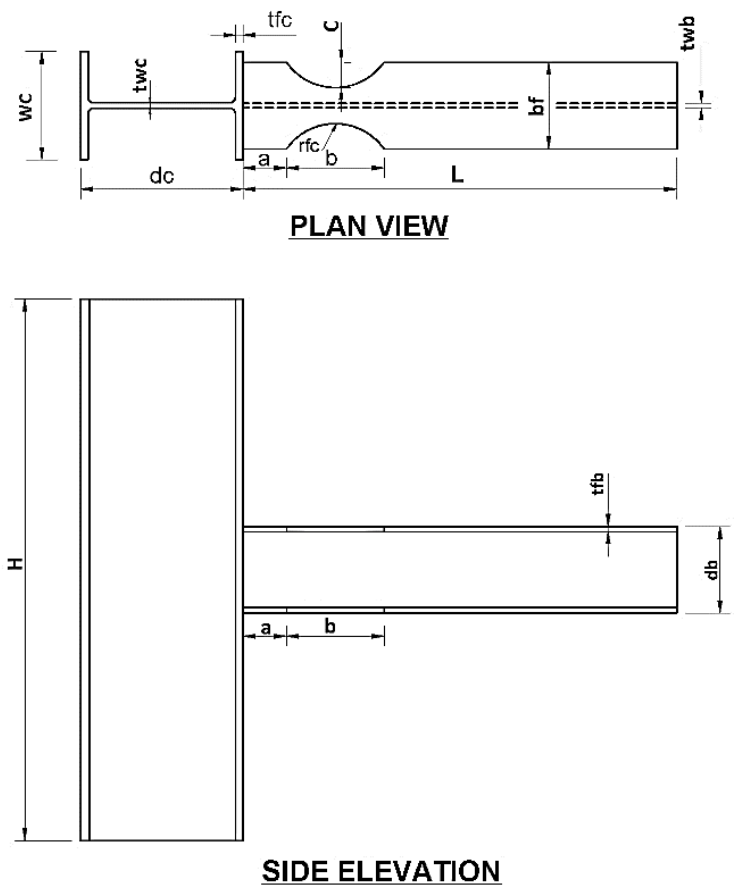

Figure 4: Type III - RBS with Doubler Web Plates 

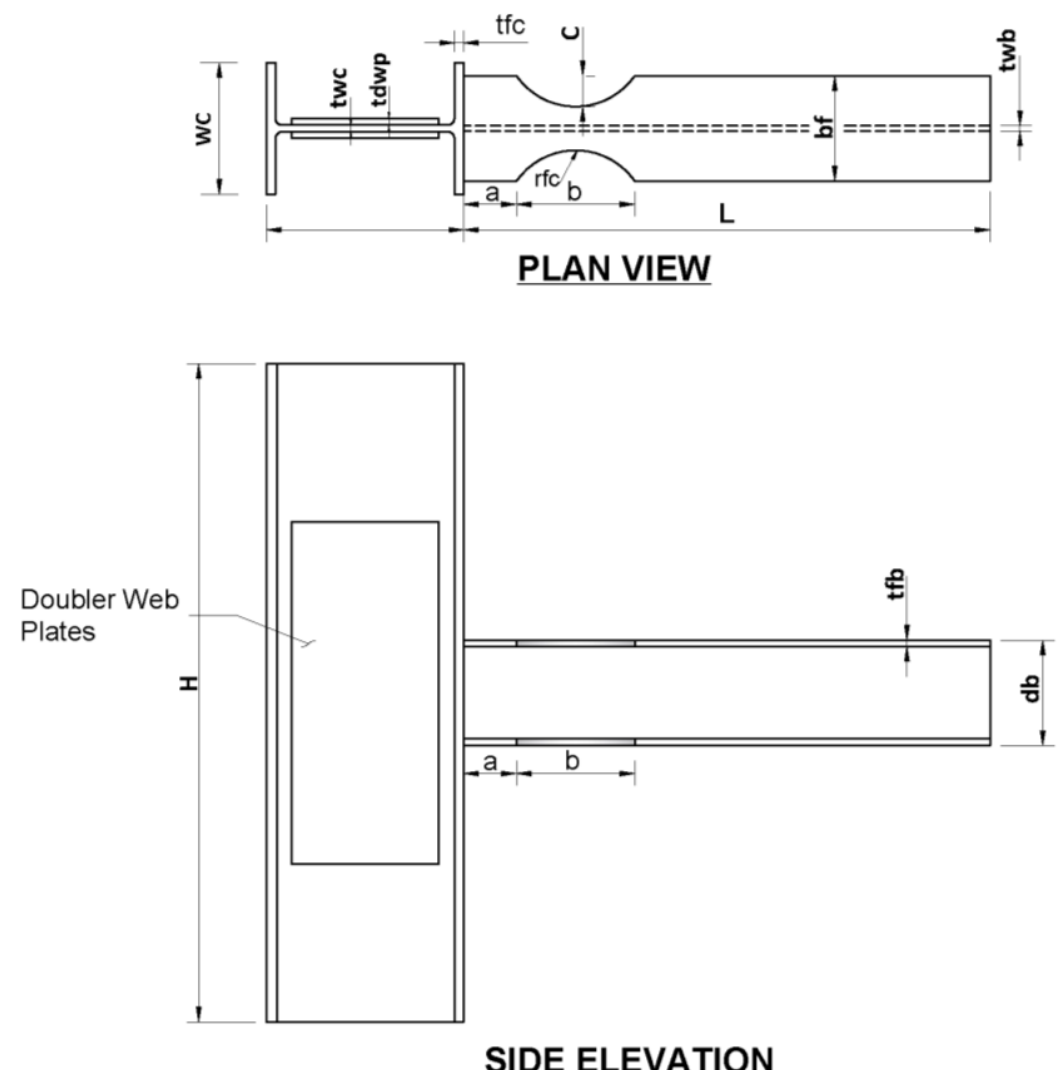

Figure 5: Type IV - RBS without Continuity and Doubler Web Plates

\subsubsection{Material}

The material for the specimen was selected as steel with a minimum and maximum values of modulus of elasticity that are shown in sections 3.3 to 3.5 and a Poisson's ratio of 0.3 was selected for the all cases. For non-linear analysis, bilinear stiffness was considered with a post-yielding modulus of elasticity as $1 \%$ of pre-yielding modulus elasticity $(1 \% \mathrm{E})$. The bilinear stiffness curve of the material is depicted in Figure 6. 


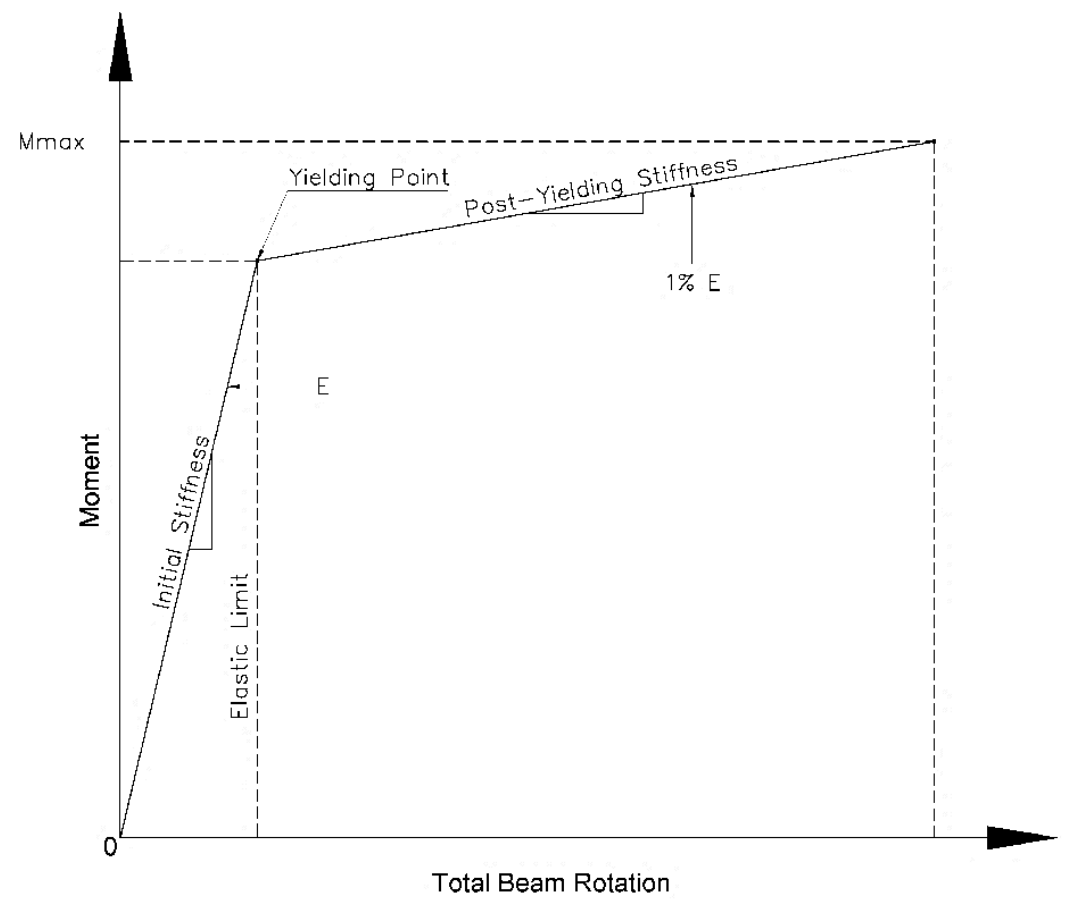

Figure 6: Bilinear Stiffness Curve of Material

\subsubsection{Meshing}

The model was meshed using mapped meshing to ensure better stress and deformation distribution amongst elements. Since, our area of interest was more specifically the area of beam from face of column to slightly farther the end of RBS flange cut and column panel zone, these portions were meshed using a finer mesh as compared to the tip of the beam and top and bottom portions of column as depicted in Figure 7. 


\subsubsection{Boundary Conditions}

The tip of the beam was restrained against out of plane displacement in lateral direction (parallel to weak axis of beam) while the column was fixed at bottom and restrained against lateral displacements in both directions (weak and strong axes of column) as shown in Figure 7.

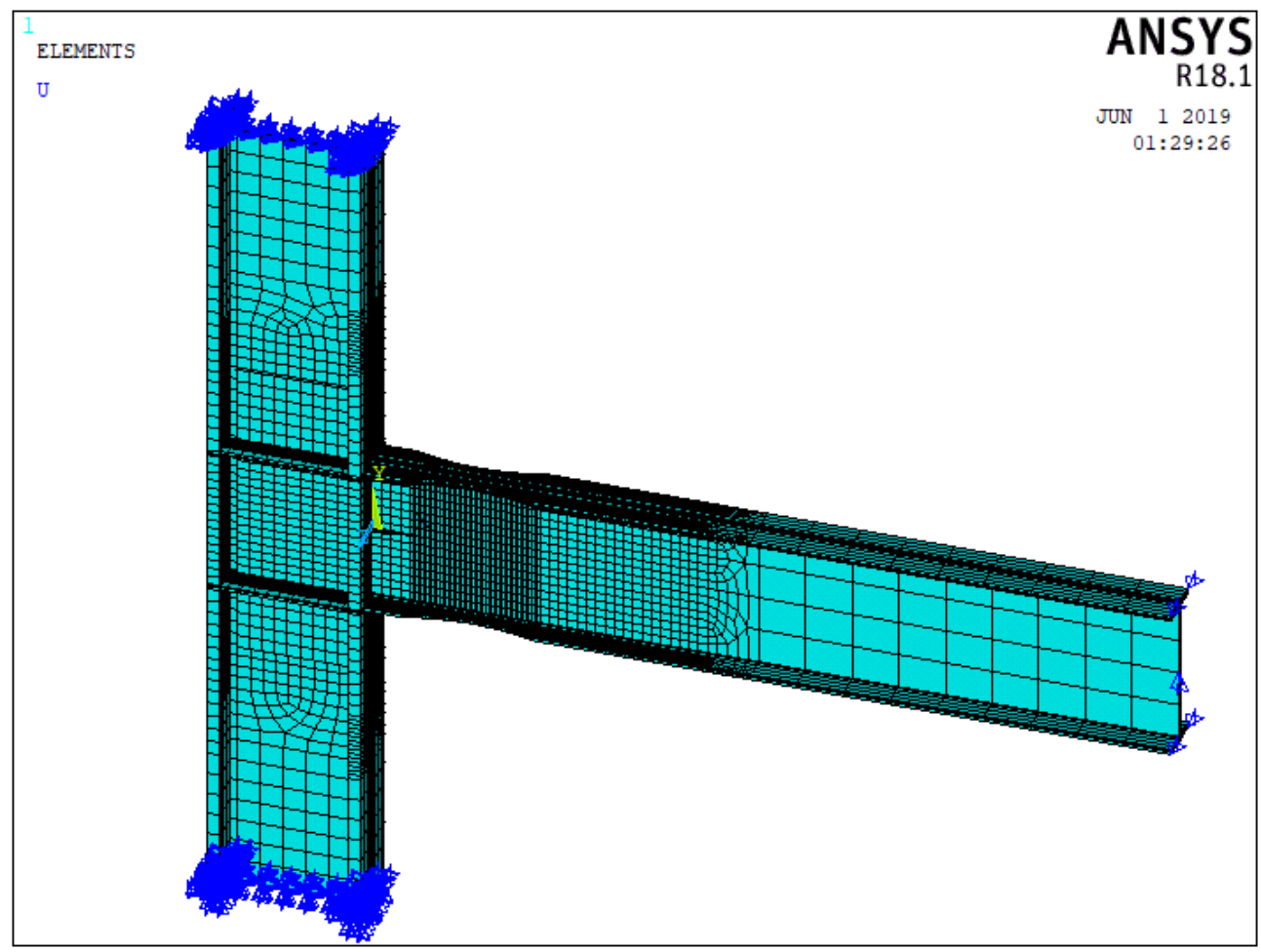

Figure 7: A Depiction of Model Meshing and Boundary Conditions

\subsubsection{Loading Conditions}

The beam was loaded at its tip with cyclic deflection as per SAC loading protocol as shown in Figure 8. Every run was performed with a consistent loading history of 11 cycles with a maximum of $7.5 \%$ deflection at the tip of the beam to record the responses for the static analysis with non linear geometric effects considerations. 


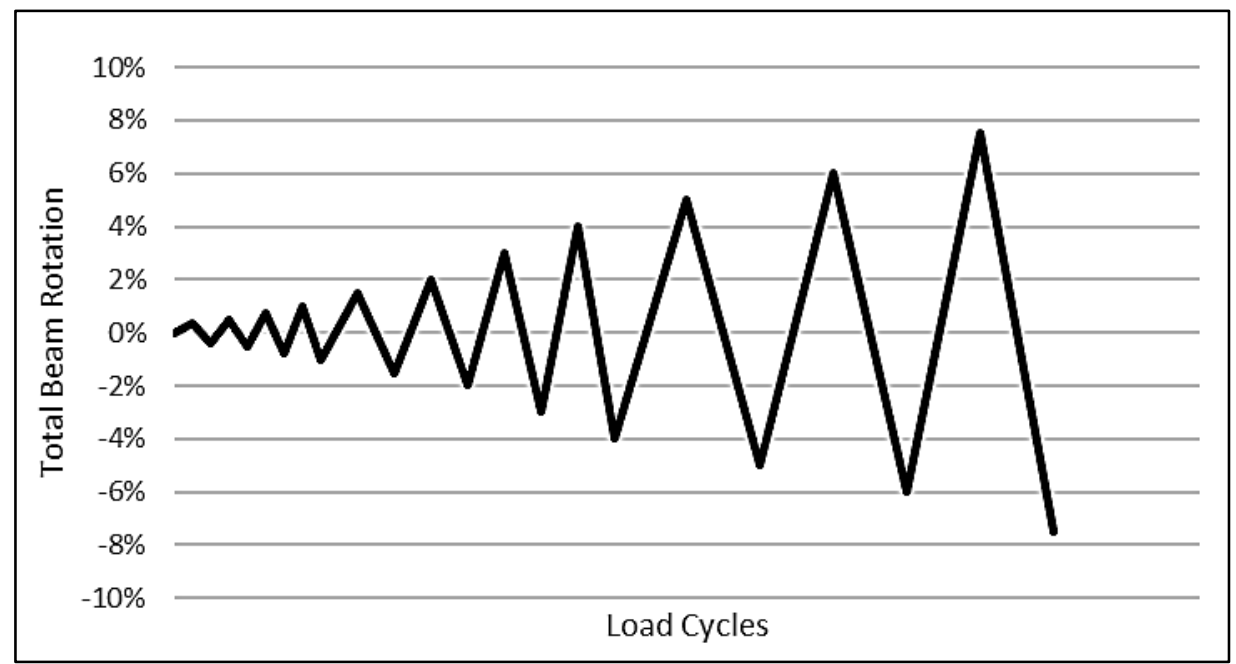

Figure 8: Loading History

\subsubsection{Validation of the Finite Element Model}

The process of validation is a vital part of the process to ensure that the experiment is error free and yields accurate results, in this regard, the analytical model was validated by analyzing 2 specimens referred as RBS1-S and RBS2-S in a study by Tabar and Deylami (2005) and comparing the results to the results of source study. These specimens were loaded as per SAC loading protocol as shown in Figure 8 up to rotations recorded by the reference study for both specimens. The parameters used in the analysis are presented in Tables $\mathbf{1}$ and $\mathbf{2}$. The comparison of responses for RBS1-S and RBS2-S are presented in Figures 9 and 10, respectively. 
Table 1: Parameters for Validation Specimen RBS1-S

\begin{tabular}{|c|c|c|c|c|c|c|c|}
\hline \multirow{13}{*}{ 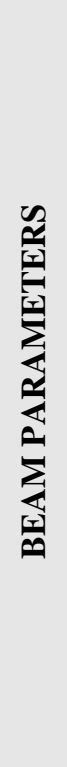 } & $\begin{array}{c}\text { S. } \\
\text { No. }\end{array}$ & PARAMETER & Value & \multirow{13}{*}{ 吾 } & $\begin{array}{c}\text { S. } \\
\text { No. }\end{array}$ & PARAMETER & Value \\
\hline & 1 & $\mathrm{bf}(\mathrm{mm})$ & 150.00 & & 13 & $\mathrm{wc}(\mathrm{mm})$ & 200.00 \\
\hline & 2 & $\mathrm{db}(\mathrm{mm})$ & 300.00 & & 14 & $\mathrm{dc}(\mathrm{mm})$ & 200.00 \\
\hline & 3 & $\mathrm{tfb}(\mathrm{mm})$ & 10.70 & & 15 & $\mathrm{tfc}(\mathrm{mm})$ & 15.00 \\
\hline & 4 & twb (mm) & 7.10 & & 16 & twc (mm) & 9.00 \\
\hline & 5 & $\mathrm{a}(\mathrm{mm})$ & 80.00 & & 17 & $\mathrm{H}(\mathrm{mm})$ & 3000 \\
\hline & 6 & $\mathrm{~b}(\mathrm{~mm})$ & 200.00 & & 18 & tdwp (mm) & 10.00 \\
\hline & 7 & $\mathrm{c}(\mathrm{mm})$ & 32.00 & & 19 & $\operatorname{tcp}(\mathrm{mm})$ & 11.00 \\
\hline & 8 & $\mathrm{~L}(\mathrm{~mm})$ & 2500 & & 20 & Escf (MPa) & $2.10 \mathrm{E}+05$ \\
\hline & 9 & Esbf (MPa) & $2.10 \mathrm{E}+05$ & & 21 & Fycf (MPa) & 250.00 \\
\hline & 10 & Fybf (MPa) & 250.00 & & 22 & Escw (MPa) & $2.10 \mathrm{E}+05$ \\
\hline & 11 & Esbw (MPa) & $2.10 \mathrm{E}+05$ & & 23 & Fycw (MPa) & 250.00 \\
\hline & 12 & Fybw (MPa) & 250.00 & & & & \\
\hline
\end{tabular}

Note: For acronyms, refer to section 3.3 or glossary of acronyms and symbols

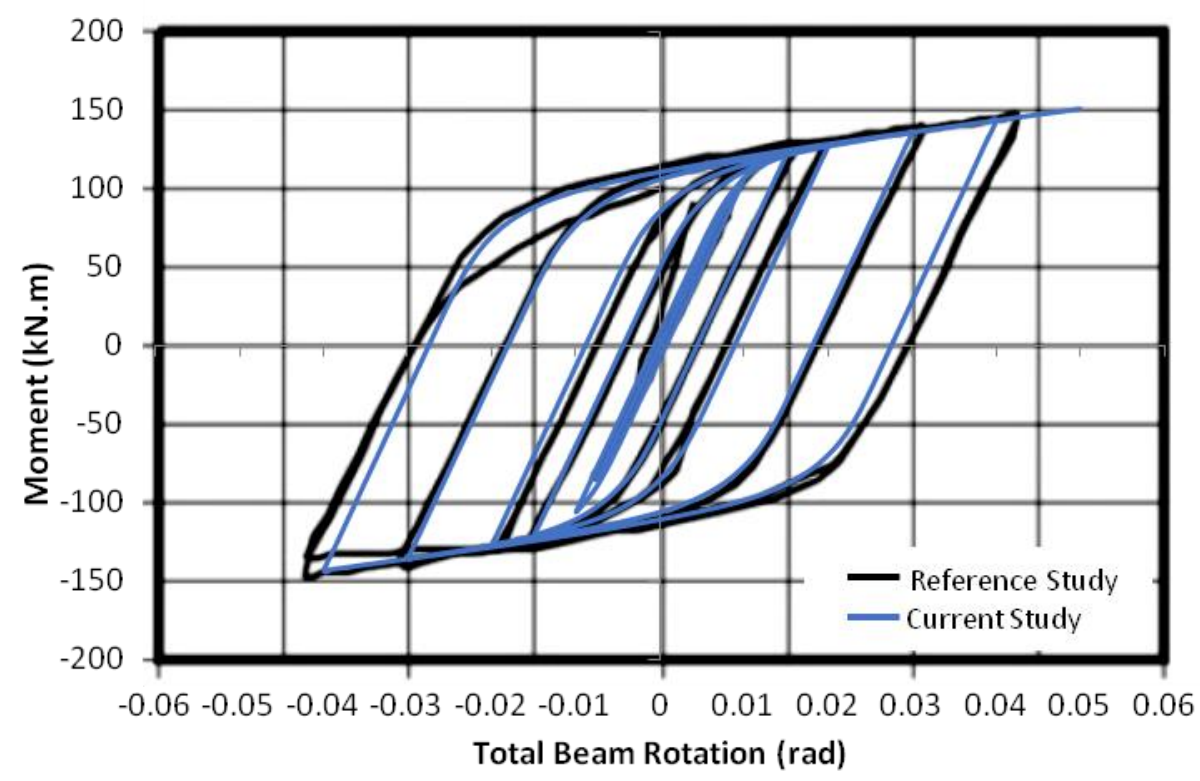

Figure 9: Response Comparison for RBS1-S (Tabar and Deylami 2005) 
Table 2: Parameters for Validation Specimen RBS2-S

\begin{tabular}{|c|c|c|c|c|c|c|c|}
\hline \multirow{13}{*}{ 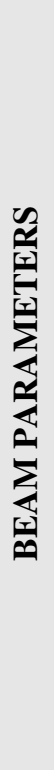 } & $\begin{array}{c}\text { S. } \\
\text { No. }\end{array}$ & PARAMETER & Value & \multirow{13}{*}{ 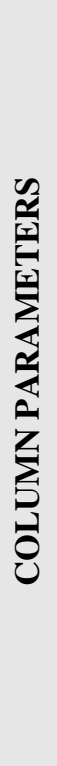 } & $\begin{array}{c}\text { S. } \\
\text { No. }\end{array}$ & PARAMETER & Value \\
\hline & 1 & bf (mm) & 190.00 & & 13 & $\mathrm{wc}(\mathrm{mm})$ & 300.00 \\
\hline & 2 & $\mathrm{db}(\mathrm{mm})$ & 450.00 & & 14 & $\mathrm{dc}(\mathrm{mm})$ & 300.00 \\
\hline & 3 & $\mathrm{tfb}(\mathrm{mm})$ & 14.60 & & 15 & $\mathrm{tfc}(\mathrm{mm})$ & 19.00 \\
\hline & 4 & $\mathrm{twb}(\mathrm{mm})$ & 19.40 & & 16 & twc (mm) & 11.00 \\
\hline & 5 & $\mathrm{a}(\mathrm{mm})$ & 120.00 & & 17 & $\mathrm{H}(\mathrm{mm})$ & 3000 \\
\hline & 6 & $\mathrm{~b}(\mathrm{~mm})$ & 350.00 & & 18 & $\operatorname{tdwp}(\mathrm{mm})$ & 10.00 \\
\hline & 7 & $\mathrm{c}(\mathrm{mm})$ & 45.00 & & 19 & tcp (mm) & 19.00 \\
\hline & 8 & $\mathrm{~L}(\mathrm{~mm})$ & 2500 & & 20 & Escf (MPa) & $2.10 \mathrm{E}+05$ \\
\hline & 9 & Esbf (MPa) & $2.10 \mathrm{E}+05$ & & 21 & Fycf (MPa) & 250.00 \\
\hline & 10 & Fybf (MPa) & 250.00 & & 22 & Escw (MPa) & $2.10 \mathrm{E}+05$ \\
\hline & 11 & Esbw (MPa) & $2.10 \mathrm{E}+05$ & & 23 & Fycw (MPa) & 250.00 \\
\hline & 12 & Fybw (MPa) & 250.00 & & & & \\
\hline
\end{tabular}

Note: For acronyms, refer to section 3.3 or glossary of acronyms and symbols

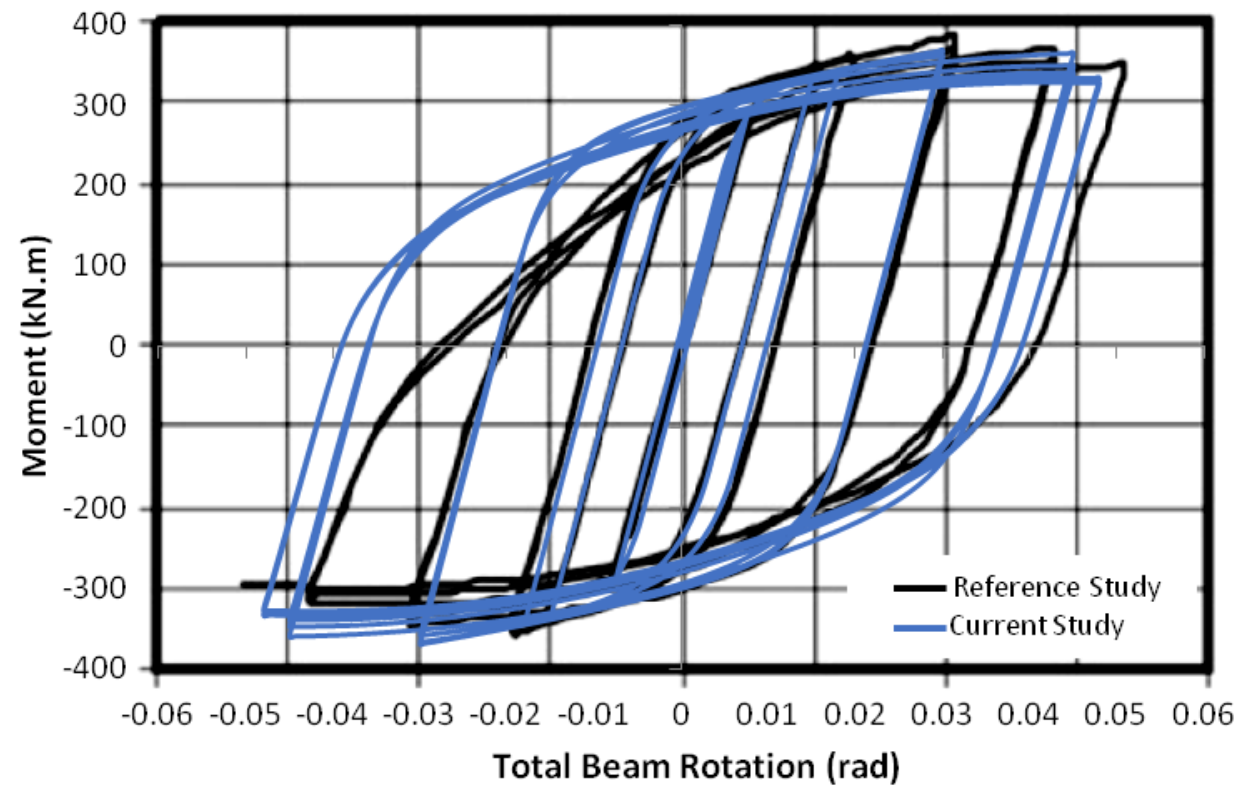

Figure 10: Response Comparison for RBS2-S (Tabar and Deylami 2005)

As a result of this validation process, it was evident that the FEA model developed for this study exhibits tendencies to perform analysis under cyclic loading conditions precisely and it was adequate and valid to be used for the experiment. 


\subsection{IDENTIFICATION OF FACTORS}

Past studies on the behaviour of RBS under cyclic loading have shown that there are several parameters that may potentially affect the performance of RBS under these loading conditions. Those parameters were collected from such studies to develop a range of levels as shown in Table 3. 


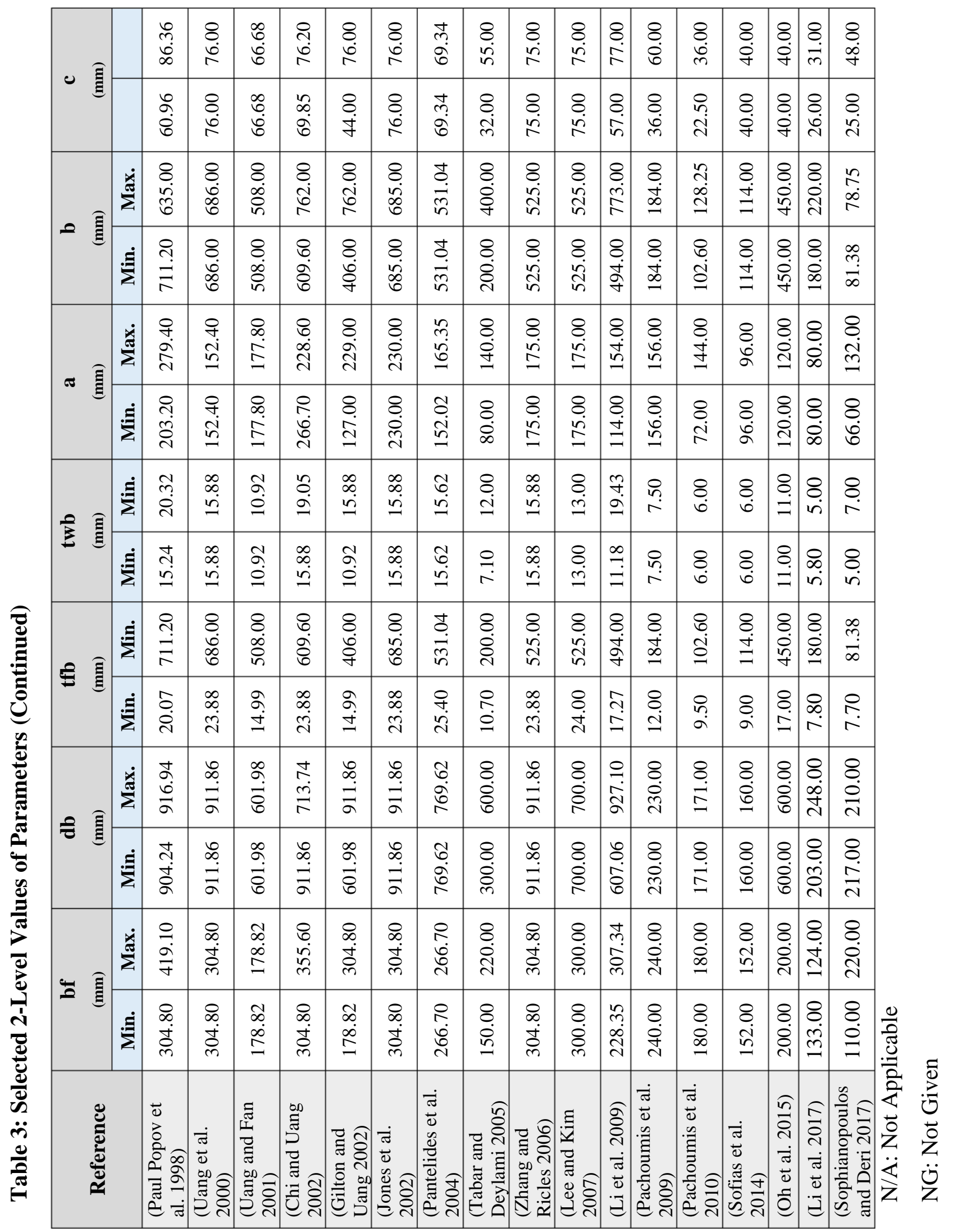




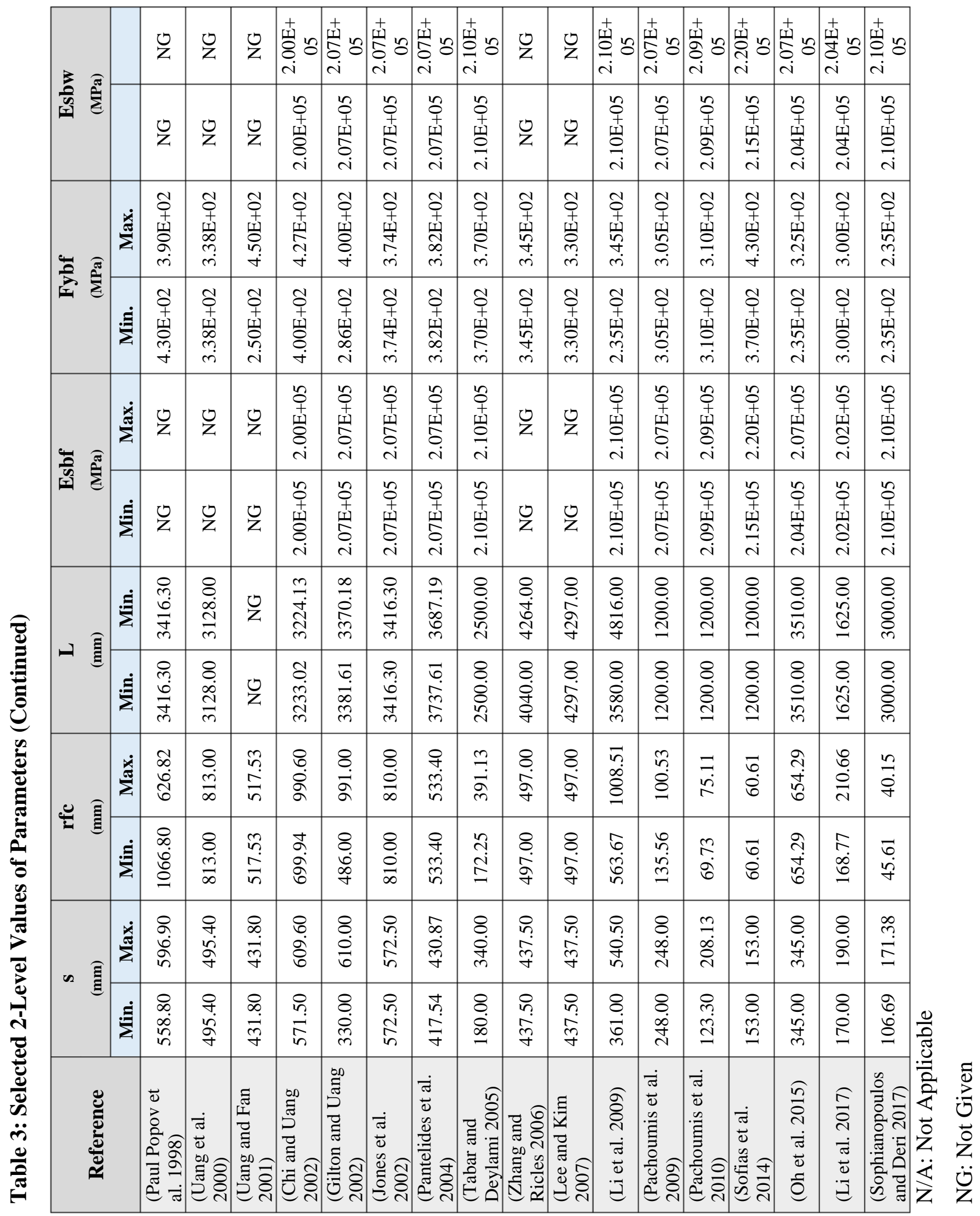




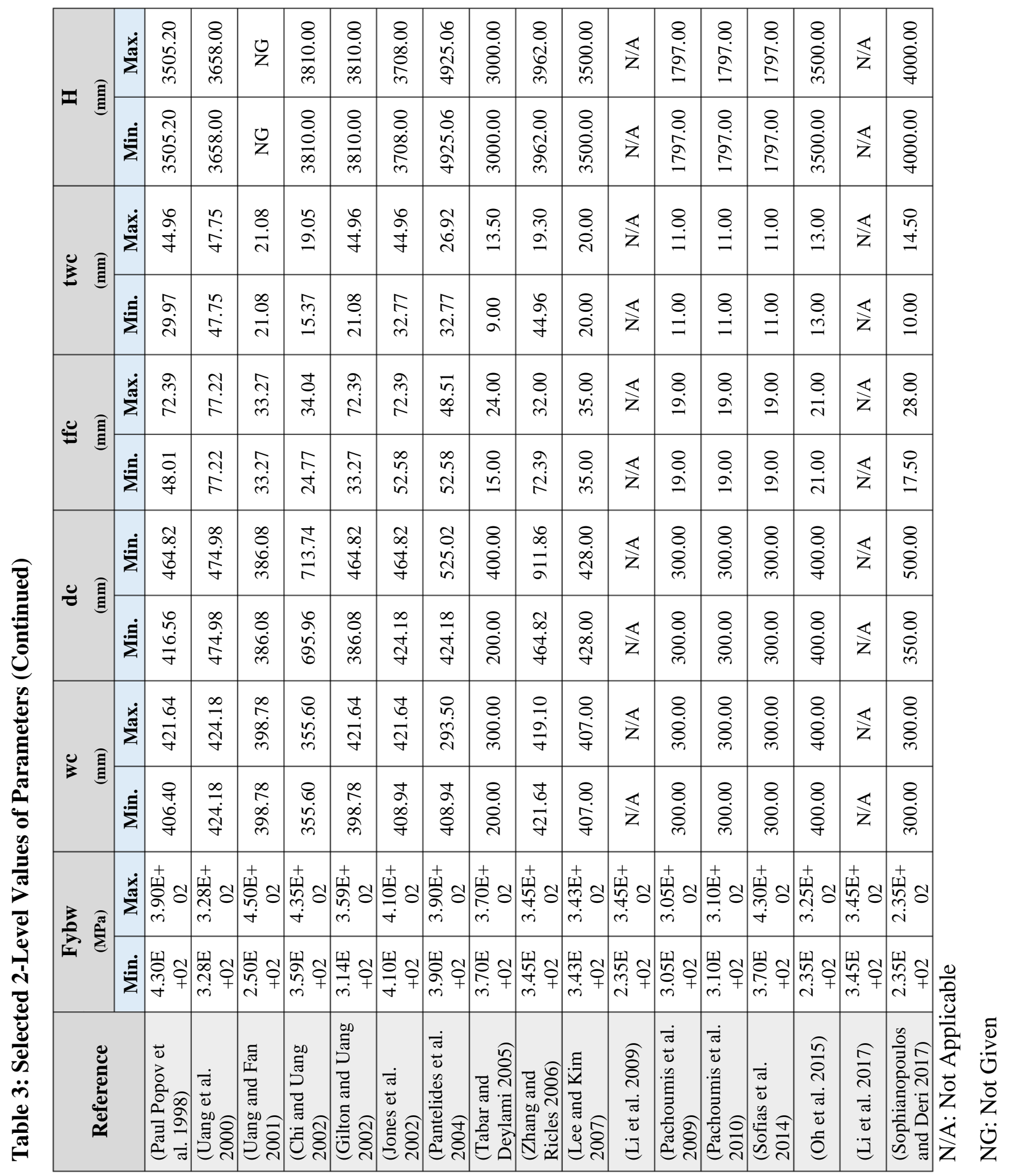




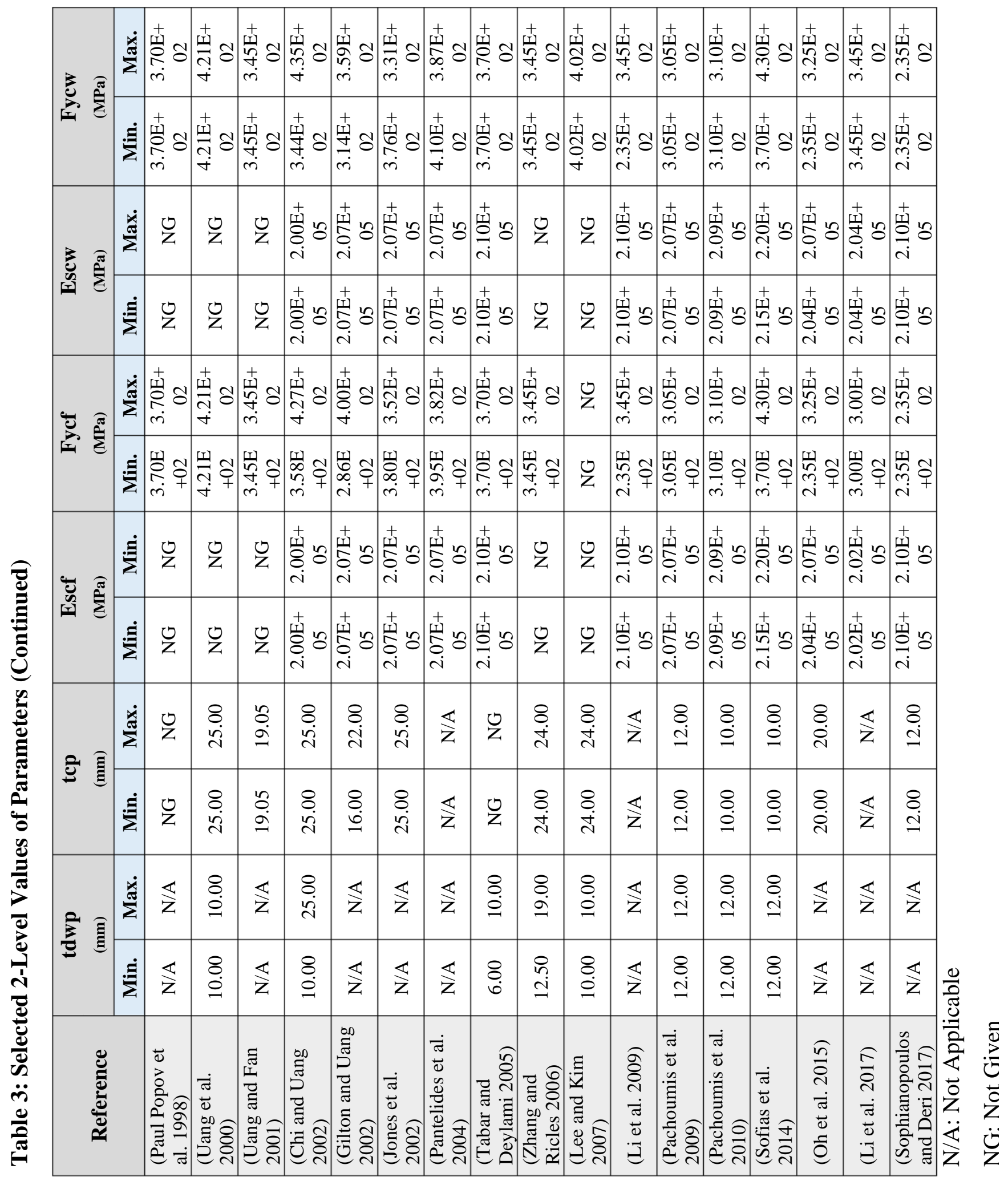




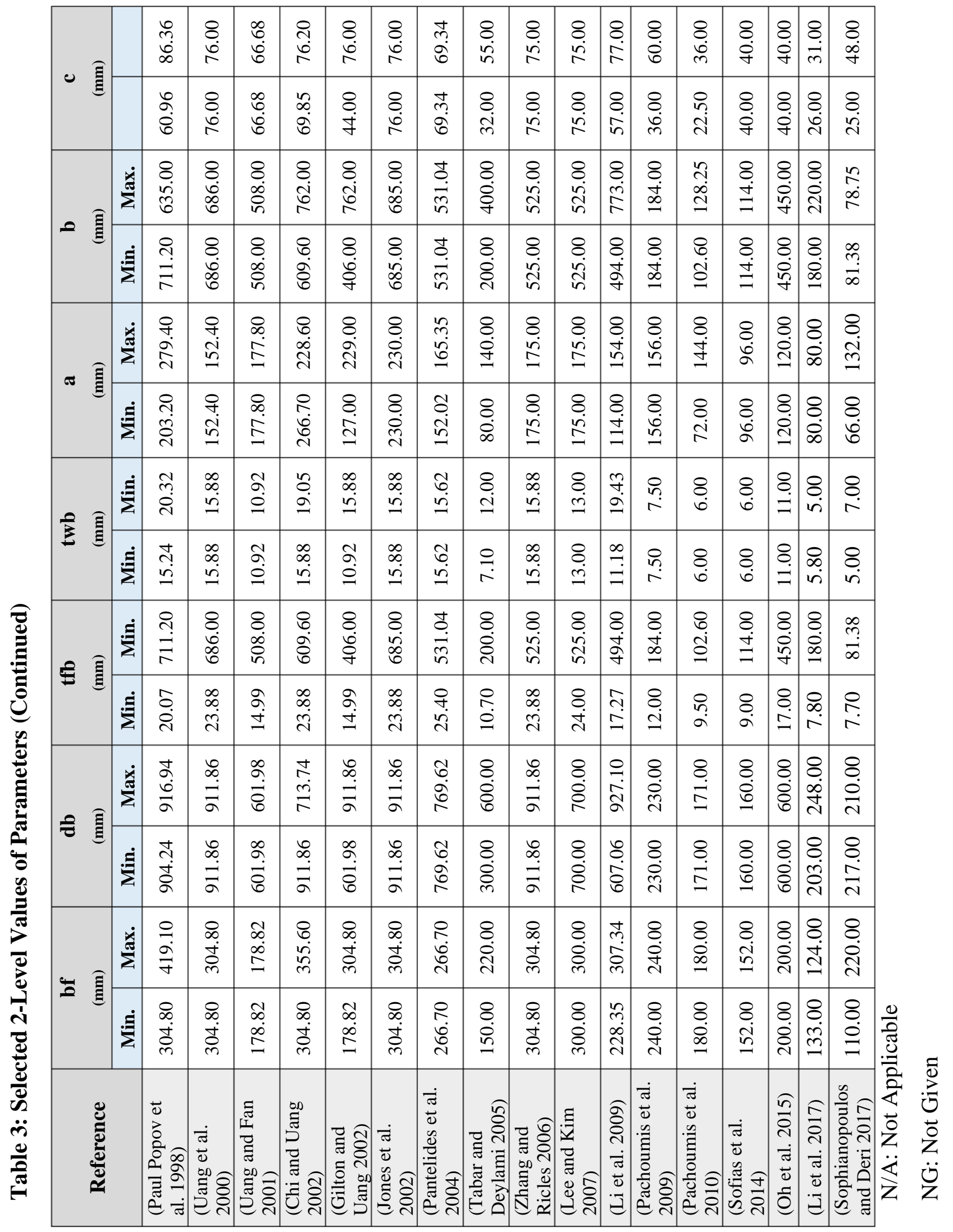




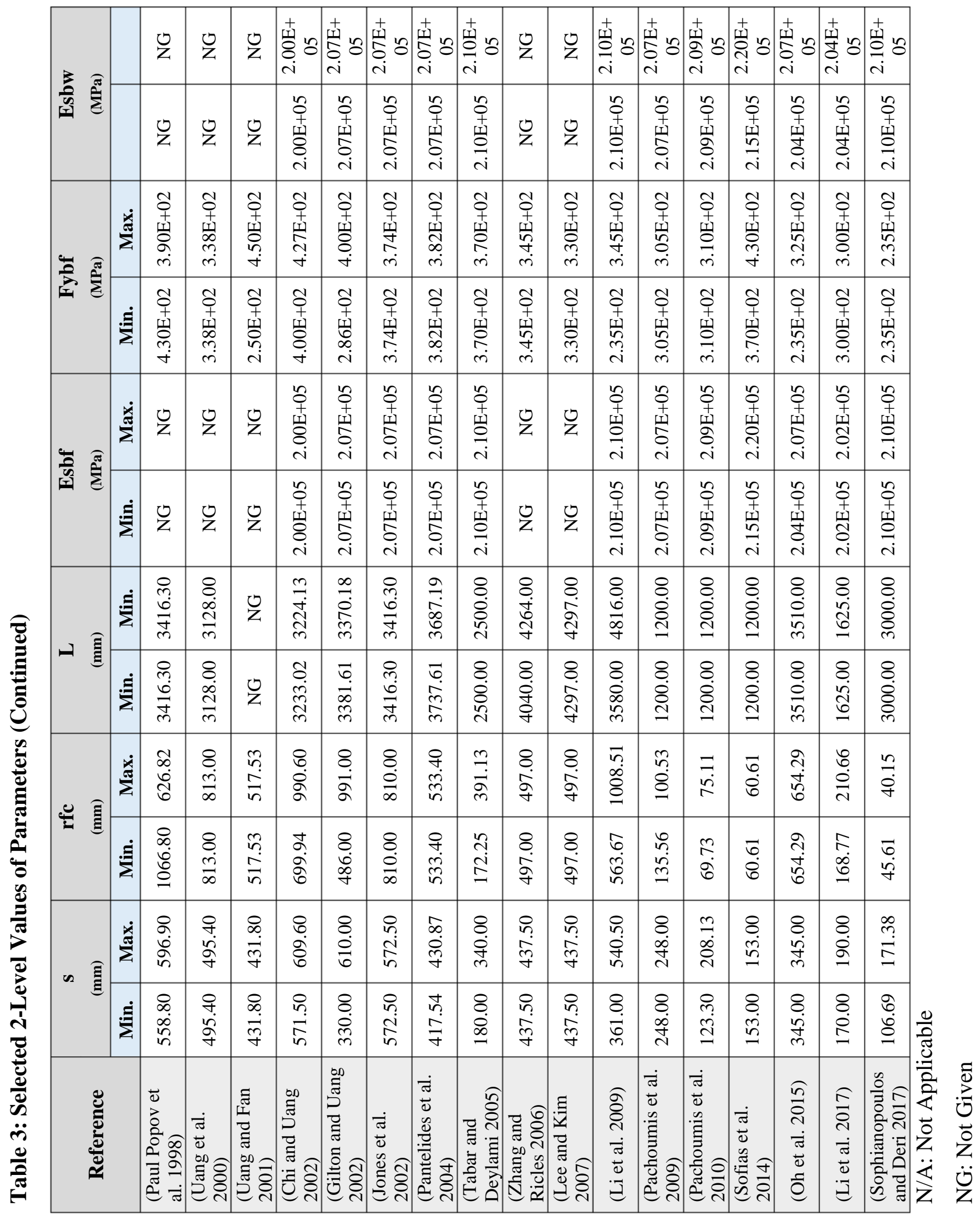




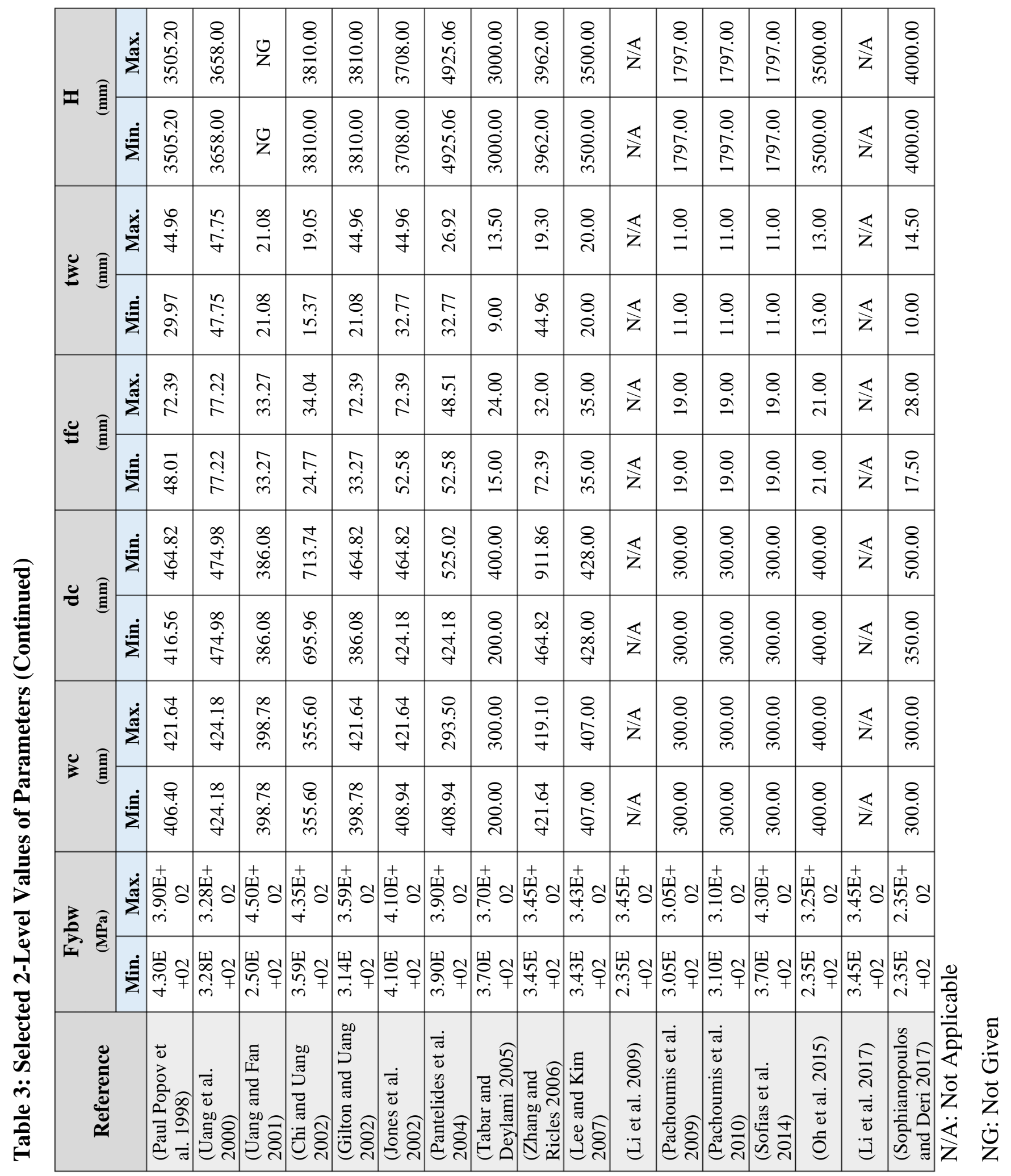




\begin{tabular}{|c|c|c|c|c|c|c|c|c|c|c|c|c|c|c|}
\hline \multicolumn{15}{|c|}{ s } \\
\hline \multicolumn{15}{|c|}{ 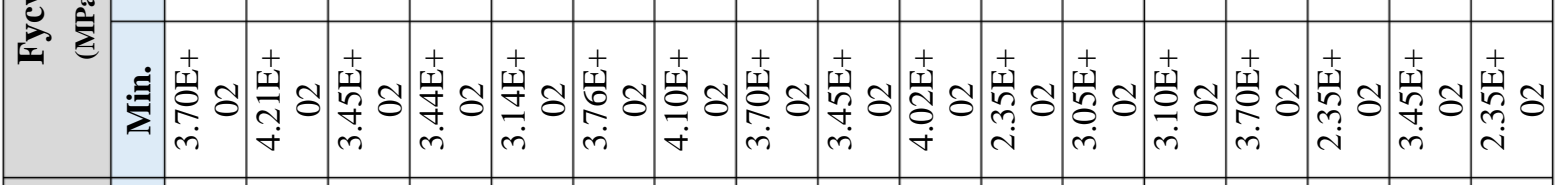 } \\
\hline 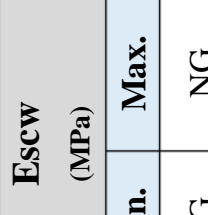 & \multicolumn{2}{|c|}{$\stackrel{0}{2}$} & \multicolumn{5}{|c|}{ 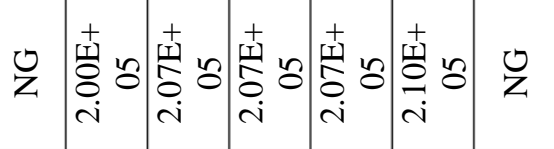 } & \multicolumn{7}{|c|}{ 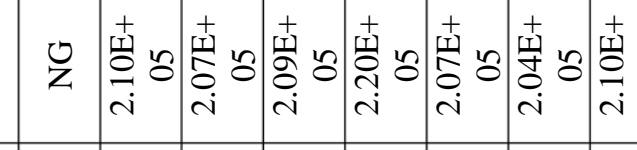 } \\
\hline 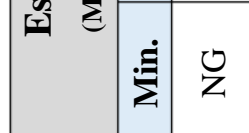 & \multicolumn{3}{|c|}{ 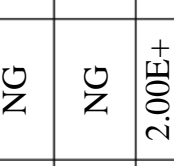 } & 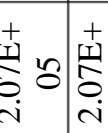 & 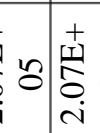 & 粴 & & \multicolumn{7}{|c|}{ 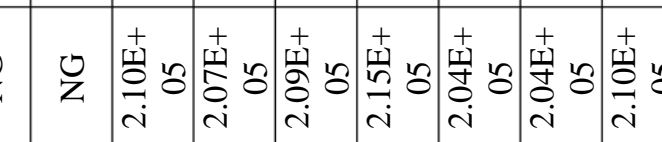 } \\
\hline \multicolumn{15}{|c|}{ 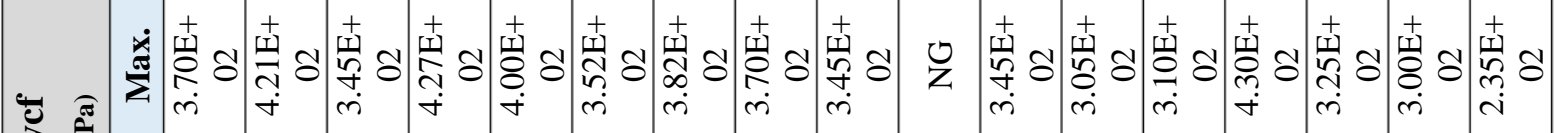 } \\
\hline \multicolumn{15}{|c|}{ 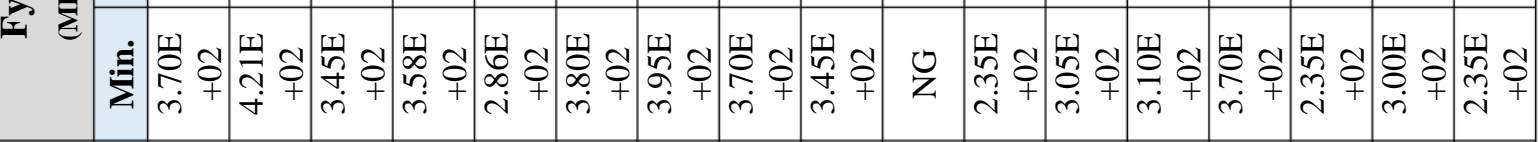 } \\
\hline \multirow[t]{2}{*}{$=\frac{2}{2}$} & & \multicolumn{5}{|c|}{ 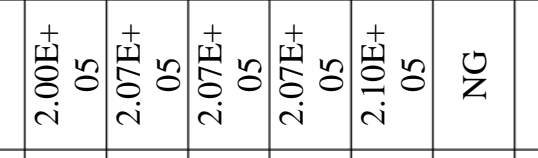 } & \multicolumn{7}{|c|}{ 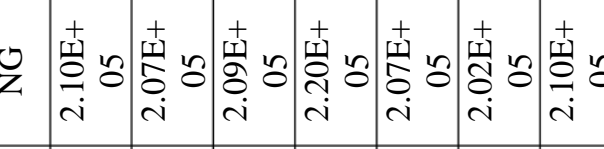 } \\
\hline & $\frac{5}{2}$ & \multicolumn{2}{|c|}{ 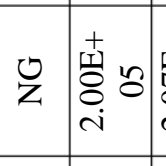 } & \multicolumn{4}{|c|}{ 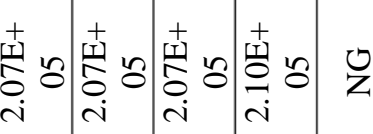 } & \multicolumn{7}{|c|}{ 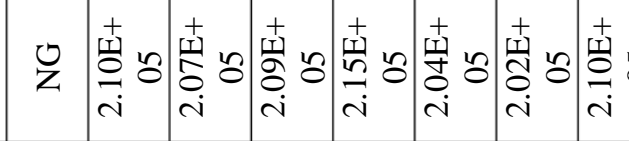 } \\
\hline 要 & 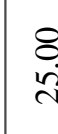 & $\stackrel{g}{\stackrel{g}{g}}$ & $\mid$ & & & $\breve{z}$ & $f$ & & & & $\stackrel{8}{\stackrel{\circ}{g}}$ & & & 童 \\
\hline 妾 & 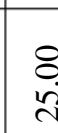 & 罗 & $\mid$ & 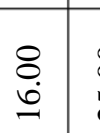 & 桨 & $\frac{0}{z}$ & & & & 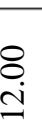 & $\stackrel{8}{\stackrel{8}{\Xi}}$ & \begin{tabular}{l}
8 \\
\hdashline \\
\hdashline
\end{tabular} & & \\
\hline 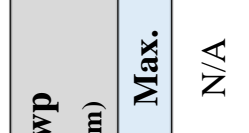 & & $\frac{\hat{s}}{\mathrm{z}}$ & $\mid$\begin{tabular}{|c}
8 \\
0 \\
0 \\
3
\end{tabular} & $\frac{\hat{s}}{\mathrm{z}}$ & & & & & & & & & & \\
\hline 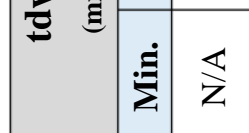 & g. & $\bar{z}$ & 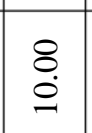 & $\frac{\underline{z}}{\bar{z}}$ & \begin{tabular}{|l|l}
$\mathbf{z}$ \\
$\bar{z}$
\end{tabular} & & 离 & & & & 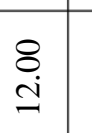 & 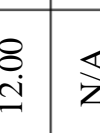 & & \\
\hline & & & & & & & & & & & & & & \\
\hline
\end{tabular}


The following symbols are used in Tables 1 to 3 .

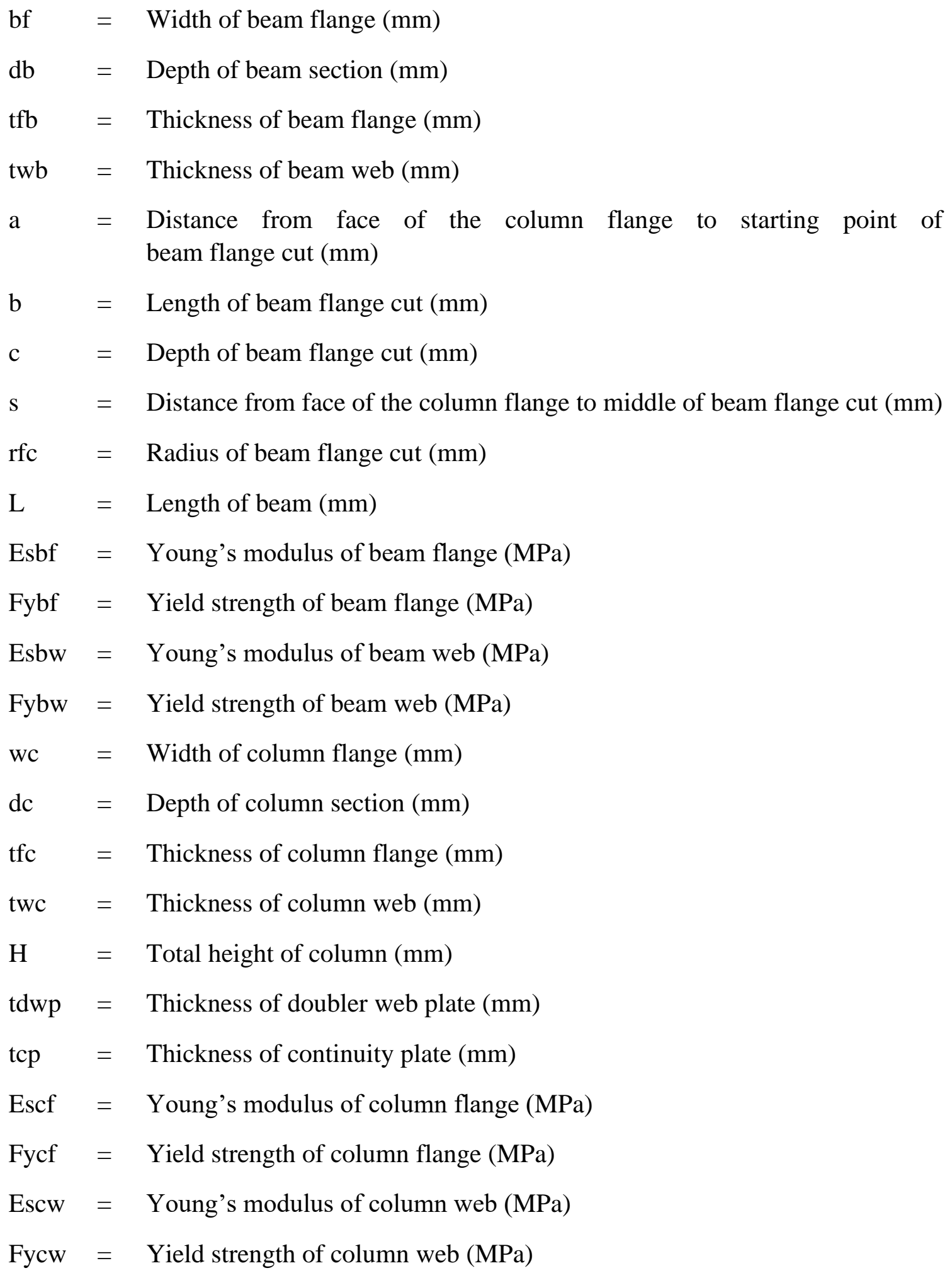


A total of 756 values for 25 factors/ parameters were noted from 17 different studies to define a practical range of values to be set for a two-level factorial design of experiment that will be discussed later in section 3.4 of this document.

\subsection{SELECTION OF FACTORS}

A prerequisite of carrying out a good experiment is that all the factors are independent and not correlated so that results can effectively portray a clear picture based on statistical analysis regarding the effects of individual factors on the response of the process. Therefore, those factors which are dependent on other factors were dropped. There were 2 such factors; namely:

- Factor s: Dependent of factors a and b

- Factor rfc: Dependent of factors b and c

Dropping these 2 factors resulted in 23 independent factors. In ideal scenario, minimum and maximum level values for these factors would be the highest and lowest values recorded from the past studies, however, that approach would have lead to incompatibility between the factors (for example a maximum value of depth of beam flange cut "c" was more than half of minimum value of beam flange width "bf" excluding thickness of beam web "twb"), therefore, the values were set to cover a maximum possible range with a balance of factors' compatibility as mentioned in Table 3. 
Table 3: Selected 2-Level Values of Parameters

\begin{tabular}{|c|c|c|c|c|c|c|c|c|c|}
\hline \multirow{13}{*}{ 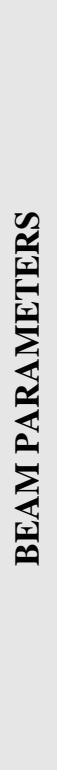 } & $\begin{array}{c}\text { S. } \\
\text { No. }\end{array}$ & PARAMETER & Min & $\operatorname{Max}$ & \multirow{13}{*}{ 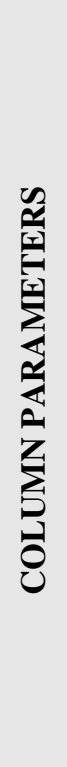 } & $\begin{array}{c}\text { S. } \\
\text { No. }\end{array}$ & PARAMETER & Min & $\operatorname{Max}$ \\
\hline & 1 & bf (mm) & 178.82 & 304.80 & & 13 & $\mathrm{wc}(\mathrm{mm})$ & 355.60 & 424.18 \\
\hline & 2 & $\mathrm{db}(\mathrm{mm})$ & 160.00 & 927.10 & & 14 & $\mathrm{dc}(\mathrm{mm})$ & 406.40 & 911.86 \\
\hline & 3 & $\mathrm{tfb}(\mathrm{mm})$ & 7.70 & 34.29 & & 15 & $\mathrm{tfc}(\mathrm{mm})$ & 24.77 & 72.39 \\
\hline & 4 & $\mathrm{twb}(\mathrm{mm})$ & 5.00 & 20.32 & & 16 & $\mathrm{twc}(\mathrm{mm})$ & 15.37 & 44.96 \\
\hline & 5 & $\mathrm{a}(\mathrm{mm})$ & 66.00 & 228.60 & & 17 & $\mathrm{H}(\mathrm{mm})$ & 3000 & 5000 \\
\hline & 6 & $\mathrm{~b}(\mathrm{~mm})$ & 78.75 & 773.00 & & 18 & tdwp (mm) & 6.00 & 25.00 \\
\hline & 7 & $\mathrm{c}(\mathrm{mm})$ & 22.50 & 60.00 & & 19 & $\mathrm{tcp}(\mathrm{mm})$ & 0.00 & 25.00 \\
\hline & 8 & $\mathrm{~L}(\mathrm{~mm})$ & 1200 & 4816.00 & & 20 & Escf (MPa) & $2.02 \mathrm{E}+05$ & $2.12 \mathrm{E}+05$ \\
\hline & 9 & Esbf (MPa) & $1.85 \mathrm{E}+05$ & $2.12 \mathrm{E}+05$ & & 21 & Fycf (MPa) & 235.00 & 430.00 \\
\hline & 10 & Fybf (MPa) & 235.00 & 450.00 & & 22 & Escw (MPa) & $2.04 \mathrm{E}+05$ & $2.12 \mathrm{E}+05$ \\
\hline & 11 & Esbw (MPa) & $1.85 \mathrm{E}+05$ & $2.12 \mathrm{E}+05$ & & 23 & Fycw (MPa) & 235.00 & 430.00 \\
\hline & 12 & Fybw (MPa) & 235.00 & 450.00 & & & & & \\
\hline
\end{tabular}




\subsection{FINALIZATION OF FACTORS}

As discussed in section 3.4 , there were 23 potentially significant factors that can affect the performance of RBS, however, a two-level factorial design of experiment can be carried out up to 21 factors using Design Expert v.11 software (Anderson et al., 2017); Therefore, 2 factors that are of least significance had to be dropped after an analytical investigation of their affect on the response of RBS under cyclic loading conditions. Incidentally, 8 models were analyzed for a total beam rotation of up to $2 \%$ under cyclic loads to study the significance of effect of Young's modulus of beam web, beam flange, column web and column flange separately with a high and low value for each of these variables. All other values were kept constant as mentioned in Table 4.

Table 4: Values of Parameters for Testing 2 Insignificant Factors

\begin{tabular}{|c|c|c|c|c|c|c|c|c|c|}
\hline \multirow{13}{*}{ 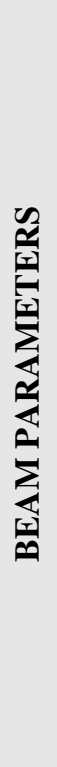 } & $\begin{array}{c}\text { S. } \\
\text { No. }\end{array}$ & PARAMETER & Min & $\operatorname{Max}$ & \multirow{13}{*}{ 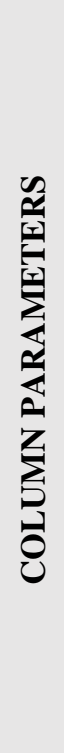 } & $\begin{array}{l}\text { S. } \\
\text { No. }\end{array}$ & PARAMETER & Min & Max \\
\hline & 1 & $\mathrm{bf}(\mathrm{mm})$ & 241.81 & 241.81 & & 13 & $\mathrm{wc}(\mathrm{mm})$ & 389.89 & 389.89 \\
\hline & 2 & $\mathrm{db}(\mathrm{mm})$ & 543.55 & 543.55 & & 14 & $\mathrm{dc}(\mathrm{mm})$ & 659.13 & 659.13 \\
\hline & 3 & $\mathrm{tfb}(\mathrm{mm})$ & 20.995 & 20.995 & & 15 & $\mathrm{tfc}(\mathrm{mm})$ & 48.58 & 48.58 \\
\hline & 4 & twb (mm) & 12.66 & 12.66 & & 16 & twc (mm) & 30.165 & 30.165 \\
\hline & 5 & $\mathrm{a}(\mathrm{mm})$ & 147.3 & 147.3 & & 17 & $\mathrm{H}(\mathrm{mm})$ & 4000 & 4000 \\
\hline & 6 & $\mathrm{~b}(\mathrm{~mm})$ & 425.875 & 425.875 & & 18 & tdwp (mm) & 15.5 & 15.5 \\
\hline & 7 & $\mathrm{c}(\mathrm{mm})$ & 41.25 & 41.25 & & 19 & $\operatorname{tcp}(\mathrm{mm})$ & 12.5 & 12.5 \\
\hline & 8 & $\mathrm{~L}(\mathrm{~mm})$ & 3008 & 3008 & & 20 & Escf (MPa) & $2.02 \mathrm{E}+05$ & $2.12 \mathrm{E}+05$ \\
\hline & 9 & Esbf (MPa) & $1.85 \mathrm{E}+05$ & $2.12 \mathrm{E}+05$ & & 21 & Fycf (MPa) & 332.5 & 332.5 \\
\hline & 10 & Fybf (MPa) & 342.5 & 342.5 & & 22 & Escw (MPa) & $2.04 \mathrm{E}+05$ & $2.12 \mathrm{E}+05$ \\
\hline & 11 & Esbw (MPa) & $1.85 \mathrm{E}+05$ & $2.12 \mathrm{E}+05$ & & 23 & Fycw (MPa) & 332.5 & 332.5 \\
\hline & 12 & Fybw (MPa) & 342.5 & 342.5 & & & & & \\
\hline
\end{tabular}

The values for the 4 subject variables for 8 tests were as follows, while the rest of the parameters were equal to the mean of the ranges defined in Table 3:

- $\quad$ Model 1: Value of Esbf = 1.85E+05 MPa

- $\quad$ Model 2: Value of Esbf = 2.12E+05 MPa

- Model 3: Value of Esbw = 1.85E+05 MPa

- $\quad$ Model 4: Value of Esbw = 2.12E+05 MPa

- Model 5: Value of Escf = 2.02E+05 MPa 
- Model 6: Value of Escf = 2.12E+05 MPa

- Model 7: Value of Escw = 2.04E+05 MPa

- Model 8: Value of Escw = 2.12E+05 MPa

The test responses were recorded and matched in pairs of Model $1 \& 2$, Model $3 \& 4$, Model $5 \& 6$ and Model $7 \& 8$ as shown in Figures 11 through 14 .

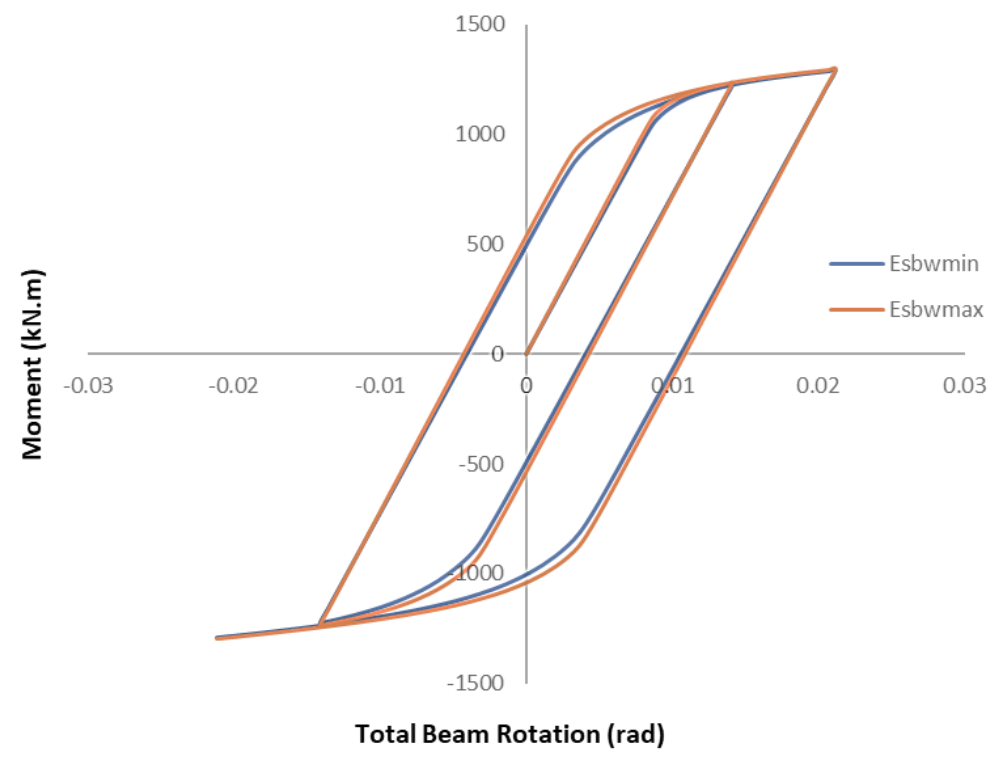

Figure 11: Comparison of Model $1 \&$ Model 2 Results

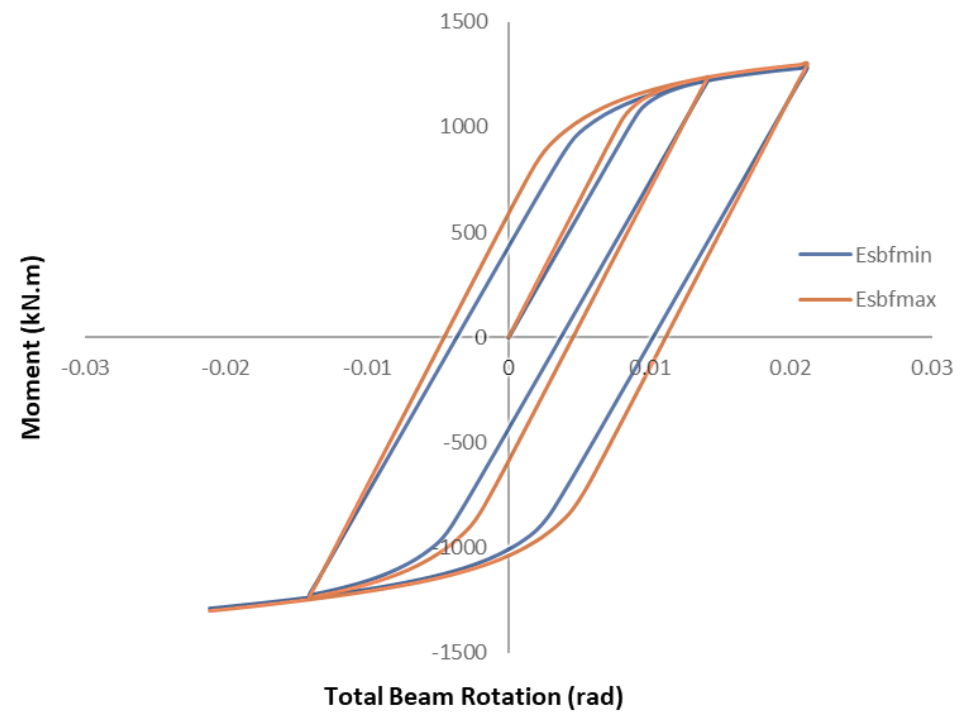

Figure 12: Comparison of Model 3 \& Model 4 Results 


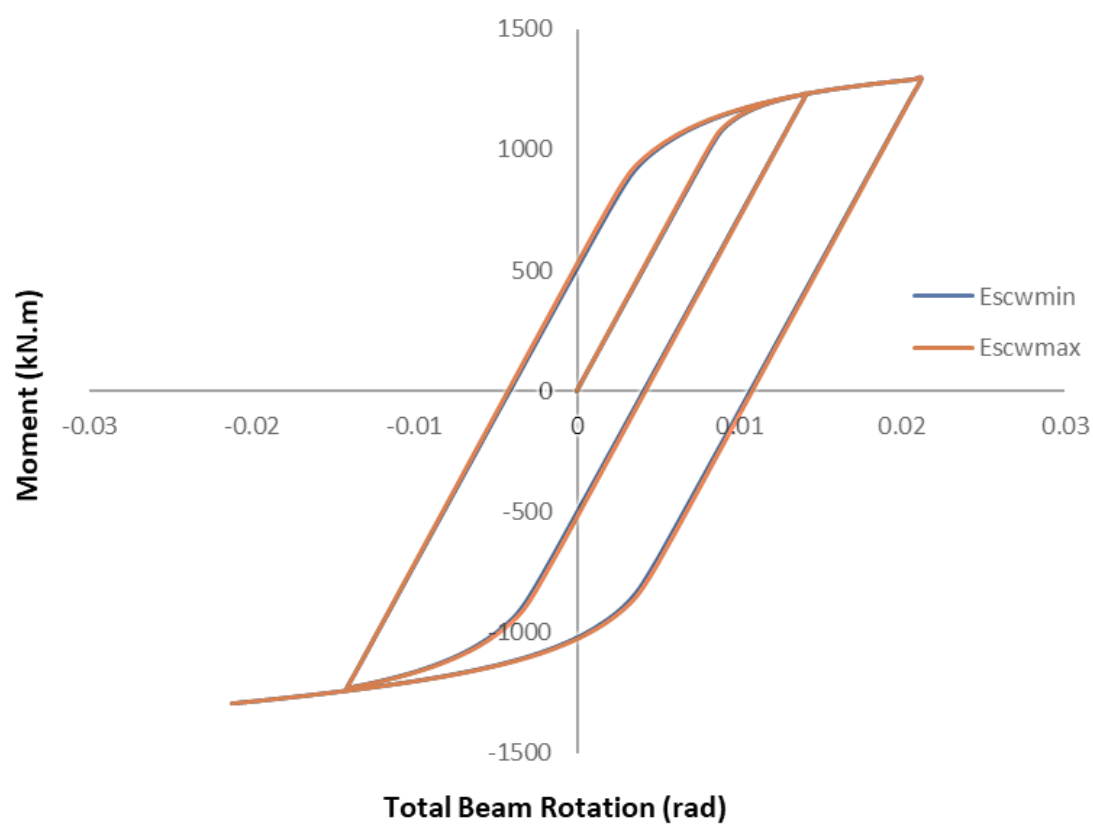

Figure 13: Comparison of Model 5 \& Model 6 Results

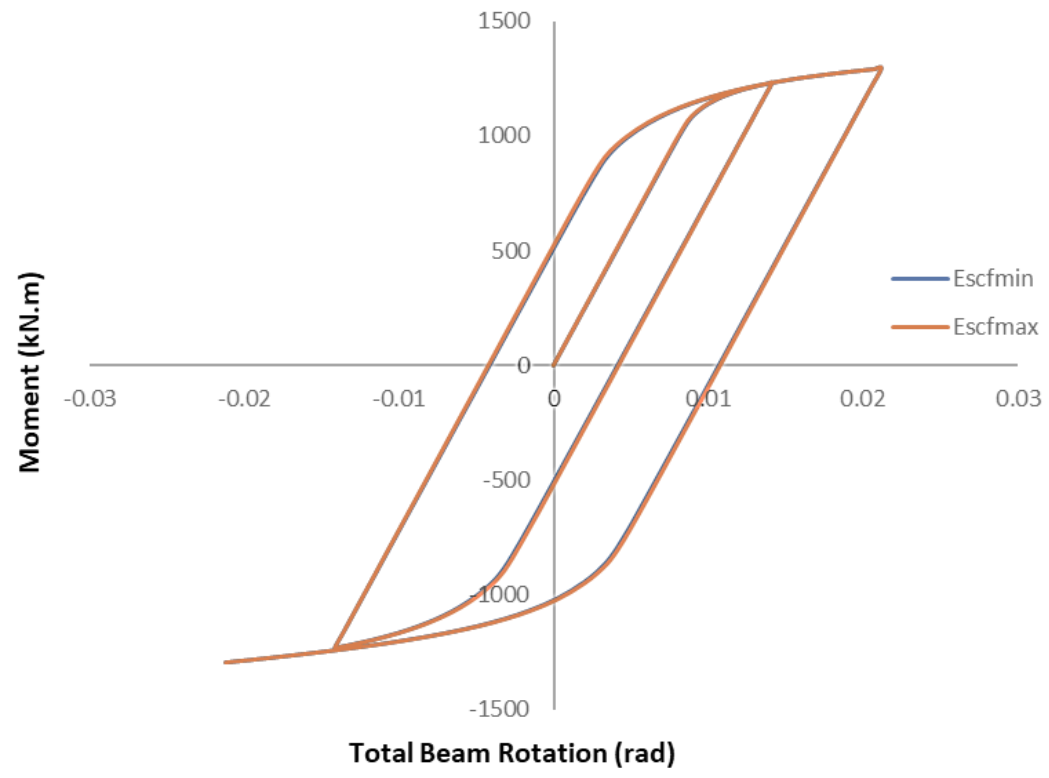

Figure 14: Comparison of Model 7 \& Model 8 Results

The tests yielded a difference of $0.413 \%, 1.3 \%, 0.073 \%$ and $0.005 \%$ between models $1 \&$ 2, models $3 \& 4$, models $5 \& 6$ and models $7 \& 8$, respectively. Therefore, it was safe to conclude that the value of young's modulus of column web and column flange had minimum effect on the response and there fore can be dropped from the factors. 
With the help of these tests, the final 21 factors to be considered for experiment were set to be as mentioned in Table 5.

Table 5: Finalized 2-Level Values of Parameters

\begin{tabular}{|c|c|c|c|c|c|c|c|c|c|c|c|}
\hline \multirow{13}{*}{ 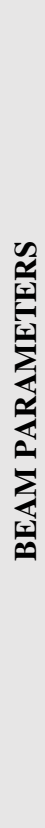 } & $\begin{array}{c}\text { S. } \\
\text { No. }\end{array}$ & PARAMETER & $\sum_{\substack{0 \\
0}}^{0}$ & Min & Max & \multirow{13}{*}{ 焉 } & $\begin{array}{c}\text { S. } \\
\text { No. }\end{array}$ & PARAMETER & $\begin{array}{l}\sum_{0}^{0} \\
\sum_{0}^{0}\end{array}$ & Min & $\operatorname{Max}$ \\
\hline & 1 & $\mathrm{bf}(\mathrm{mm})$ & A & 178.82 & 304.80 & & 13 & $\mathrm{wc}(\mathrm{mm})$ & $\mathrm{N}$ & 355.60 & 424.18 \\
\hline & 2 & $\mathrm{db}(\mathrm{mm})$ & B & 160.00 & 927.10 & & 14 & $\mathrm{dc}(\mathrm{mm})$ & $\mathrm{O}$ & 406.40 & 911.86 \\
\hline & 3 & $\mathrm{tfb}(\mathrm{mm})$ & $\mathrm{C}$ & 7.70 & 34.29 & & 15 & $\mathrm{tfc}(\mathrm{mm})$ & $\mathrm{P}$ & 24.77 & 72.39 \\
\hline & 4 & twb (mm) & $\mathrm{D}$ & 5.00 & 20.32 & & 16 & twc (mm) & Q & 15.37 & 44.96 \\
\hline & 5 & $\mathrm{a}(\mathrm{mm})$ & $\mathrm{E}$ & 66.00 & 228.60 & & 17 & $\mathrm{H}(\mathrm{mm})$ & $\mathrm{R}$ & 3000 & 5000 \\
\hline & 6 & $\mathrm{~b}(\mathrm{~mm})$ & $\mathrm{F}$ & 78.75 & 773.00 & & 18 & $\operatorname{tdwp}(\mathrm{mm})$ & $S$ & 6.00 & 25.00 \\
\hline & 7 & $\mathrm{c}(\mathrm{mm})$ & G & 22.50 & 60.00 & & 19 & $\mathrm{tcp}(\mathrm{mm})$ & $\mathrm{T}$ & 0.00 & 25.00 \\
\hline & 8 & $\mathrm{~L}(\mathrm{~mm})$ & $\mathrm{H}$ & 1200 & 4816.00 & & 20 & Fycf (MPa) & $\mathrm{U}$ & 235.00 & 430.00 \\
\hline & 9 & Esbf (MPa) & $\mathrm{J}$ & $1.85 \mathrm{E}+05$ & $2.12 \mathrm{E}+05$ & & 21 & Fycw (MPa) & V & 235.00 & 430.00 \\
\hline & 10 & Fybf (MPa) & $\mathrm{K}$ & 235.00 & 450.00 & & & & & & \\
\hline & 11 & Esbw (MPa) & $\mathrm{L}$ & $1.85 \mathrm{E}+05$ & $2.12 \mathrm{E}+05$ & & & & & & \\
\hline & 12 & Fybw (MPa) & M & 235.00 & 450.00 & & & & & & \\
\hline
\end{tabular}

\subsection{DESIGN OF EXPERIMENT}

In order to study the cause and effect relationships between the parameters/ factors and response of the connection more efficiently in a systematic way, a computer experiment for 21 factors was designed with Two-Level $2^{\mathrm{K}}$ Factorial design approach to optimize the experiment efficiency by reducing number of required runs from $2^{21}=2097152$ runs to just 32 runs. This design of the experiment and analysis of the results were performed with the aid of renowned statistical computer software package Stat-Ease ${ }^{\circledR}$ Design-Expert ${ }^{\circledR}$. To verify the effects of the main factors on responses and unravel the combined effects of multi-factor interactions, a semi-fold over augmented design was added to the existing design with 16 more combinations. In the first phase of experiment, 32 combinations of factors were generated for 32 randomized model runs as shown in Table 6, each test was named as RBS-N, where "N" stands for the number of model. 
Table 6: Coded Factor Combinations for Experiment Phase 1

\begin{tabular}{|c|c|c|c|c|c|c|c|c|c|c|c|c|c|c|c|c|c|c|c|c|c|}
\hline है & $\begin{array}{c}\text { bf } \\
\mathrm{mm}\end{array}$ & $\begin{array}{l}\text { db } \\
\text { mm }\end{array}$ & $\begin{array}{l}\mathbf{t f b} \\
\mathrm{mm}\end{array}$ & $\begin{array}{l}\text { twb } \\
\mathrm{mm}\end{array}$ & $\begin{array}{r}\mathbf{a} \\
\mathbf{m m}\end{array}$ & $\begin{array}{c}\text { b } \\
\mathbf{m m}\end{array}$ & $\begin{array}{c}\mathbf{c} \\
\mathrm{mm}\end{array}$ & $\begin{array}{c}\mathbf{L} \\
\mathbf{m m}\end{array}$ & $\begin{array}{c}\text { Esbf } \\
\text { MPa }\end{array}$ & $\begin{array}{c}\text { Fybf } \\
\text { MPa }\end{array}$ & $\begin{array}{c}\text { Esbw } \\
\text { MPa }\end{array}$ & $\begin{array}{c}\text { Fybw } \\
\text { MPa }\end{array}$ & $\begin{array}{l}\text { wc } \\
\text { mm }\end{array}$ & $\begin{array}{l}\text { dc } \\
\mathrm{mm}\end{array}$ & $\begin{array}{l}\text { tfc } \\
\text { mm }\end{array}$ & $\begin{array}{l}\text { twc } \\
\mathrm{mm}\end{array}$ & $\begin{array}{c}\mathbf{H} \\
\mathbf{m m}\end{array}$ & $\begin{array}{c}\text { tdwp } \\
\text { mm }\end{array}$ & $\begin{array}{l}\text { tcp } \\
\text { mm }\end{array}$ & $\begin{array}{c}\text { Fycf } \\
\text { MPa }\end{array}$ & $\begin{array}{c}\text { Fycw } \\
\text { MPa }\end{array}$ \\
\hline 1 & -1 & -1 & -1 & -1 & -1 & -1 & -1 & -1 & -1 & 1 & -1 & -1 & -1 & 1 & -1 & -1 & 1 & -1 & 1 & 1 & -1 \\
\hline 3 & -1 & 1 & -1 & -1 & -1 & 1 & 1 & -1 & 1 & -1 & 1 & -1 & 1 & -1 & -1 & 1 & -1 & -1 & 1 & -1 & 1 \\
\hline 4 & 1 & 1 & -1 & -1 & -1 & -1 & -1 & 1 & 1 & 1 & -1 & 1 & 1 & 1 & 1 & 1 & 1 & -1 & -1 & -1 & -1 \\
\hline 6 & 1 & -1 & 1 & -1 & -1 & -1 & 1 & -1 & 1 & 1 & 1 & -1 & 1 & 1 & 1 & -1 & -1 & 1 & 1 & -1 & -1 \\
\hline 7 & -1 & 1 & 1 & -1 & -1 & -1 & 1 & 1 & -1 & 1 & 1 & 1 & -1 & 1 & -1 & 1 & -1 & 1 & -1 & 1 & -1 \\
\hline 8 & 1 & 1 & 1 & -1 & -1 & 1 & -1 & -1 & -1 & -1 & -1 & -1 & -1 & -1 & 1 & 1 & 1 & 1 & 1 & 1 & 1 \\
\hline 9 & -1 & -1 & -1 & 1 & -1 & -1 & 1 & 1 & 1 & -1 & -1 & -1 & -1 & 1 & 1 & 1 & -1 & 1 & -1 & -1 & 1 \\
\hline 13 & -1 & -1 & 1 & 1 & -1 & 1 & 1 & -1 & -1 & 1 & -1 & 1 & 1 & -1 & 1 & 1 & -1 & -1 & 1 & 1 & -1 \\
\hline 14 & 1 & -1 & 1 & 1 & -1 & -1 & -1 & 1 & -1 & -1 & 1 & -1 & 1 & 1 & -1 & 1 & 1 & -1 & -1 & 1 & 1 \\
\hline 15 & -1 & 1 & 1 & 1 & -1 & -1 & -1 & -1 & 1 & -1 & 1 & 1 & -1 & 1 & 1 & -1 & 1 & -1 & 1 & -1 & 1 \\
\hline 16 & 1 & 1 & 1 & 1 & -1 & 1 & 1 & 1 & 1 & 1 & -1 & -1 & -1 & -1 & -1 & -1 & -1 & -1 & -1 & -1 & -1 \\
\hline 17 & -1 & -1 & -1 & -1 & 1 & -1 & -1 & -1 & -1 & 1 & 1 & 1 & 1 & -1 & 1 & 1 & -1 & 1 & -1 & -1 & 1 \\
\hline 18 & 1 & -1 & -1 & -1 & 1 & 1 & 1 & 1 & -1 & -1 & -1 & -1 & 1 & 1 & -1 & 1 & 1 & 1 & 1 & -1 & -1 \\
\hline 19 & -1 & 1 & -1 & -1 & 1 & 1 & 1 & -1 & 1 & -1 & -1 & 1 & -1 & 1 & 1 & -1 & 1 & 1 & -1 & 1 & -1 \\
\hline 20 & 1 & 1 & -1 & -1 & 1 & -1 & -1 & 1 & 1 & 1 & 1 & -1 & -1 & -1 & -1 & -1 & -1 & 1 & 1 & 1 & 1 \\
\hline 26 & 1 & -1 & -1 & 1 & 1 & 1 & -1 & -1 & 1 & 1 & -1 & -1 & 1 & 1 & 1 & -1 & -1 & -1 & -1 & 1 & 1 \\
\hline 27 & -1 & 1 & -1 & 1 & 1 & 1 & -1 & 1 & -1 & 1 & -1 & 1 & -1 & 1 & -1 & 1 & -1 & -1 & 1 & -1 & 1 \\
\hline 28 & 1 & 1 & -1 & 1 & 1 & -1 & 1 & -1 & -1 & -1 & 1 & -1 & -1 & -1 & 1 & 1 & 1 & -1 & -1 & -1 & -1 \\
\hline 29 & -1 & -1 & 1 & 1 & 1 & 1 & 1 & -1 & -1 & 1 & 1 & -1 & -1 & 1 & -1 & -1 & 1 & 1 & -1 & -1 & 1 \\
\hline 30 & 1 & -1 & 1 & 1 & 1 & -1 & -1 & 1 & -1 & -1 & -1 & 1 & -1 & -1 & 1 & -1 & -1 & 1 & 1 & -1 & -1 \\
\hline 31 & -1 & 1 & 1 & 1 & 1 & -1 & -1 & -1 & 1 & -1 & -1 & -1 & 1 & -1 & -1 & 1 & -1 & 1 & -1 & 1 & -1 \\
\hline 32 & 1 & 1 & 1 & 1 & 1 & 1 & 1 & 1 & 1 & 1 & 1 & 1 & 1 & 1 & 1 & 1 & 1 & 1 & 1 & 1 & 1 \\
\hline
\end{tabular}

Note: -1 and 1 indicate the minimum and maximum values respectively as mentioned in Table $\mathbf{5}$. 


\subsection{ANALYTICAL SPECIMEN GEOMETRIES}

For all 48 test runs (i.e. from RBS-1 to RBS 48), the FEA models were created. The geometries of specimens RBS-1 to RBS-6 are shown in Figures 15 through 20. Graphical representation of rest of the FEA models are presented in Appendix A of this document.
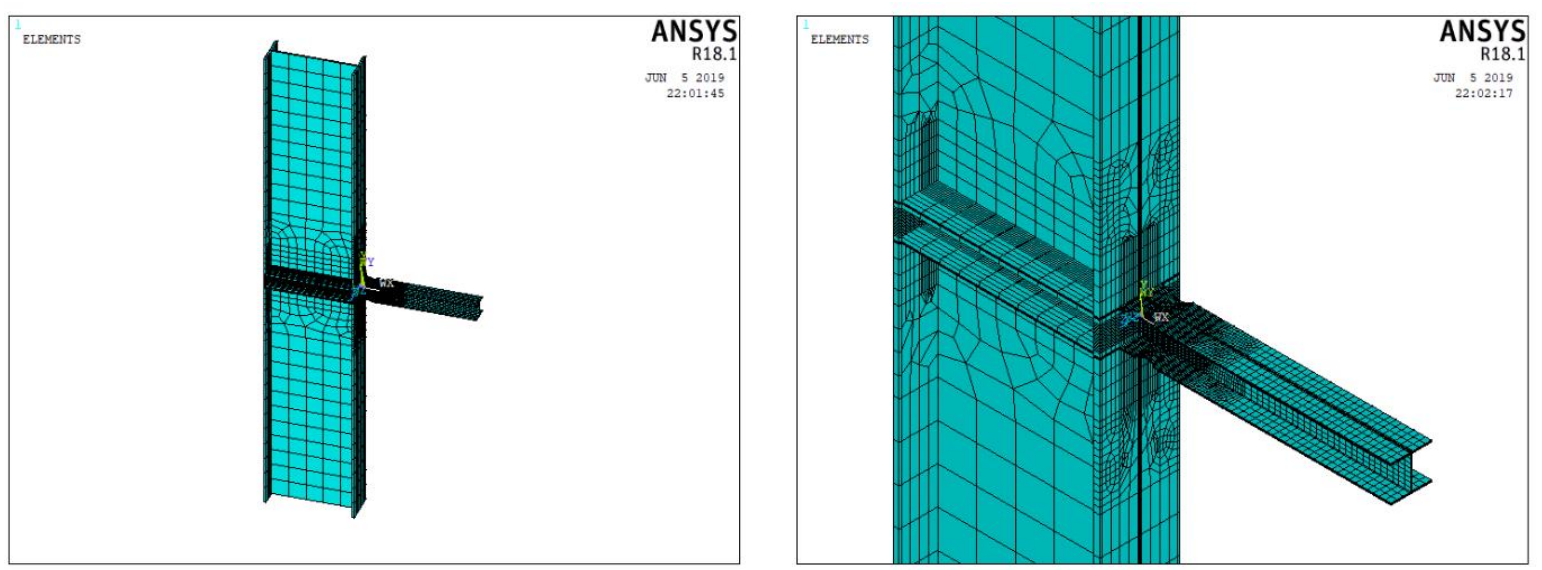

Figure 15: FEA Model for Specimen RBS-1
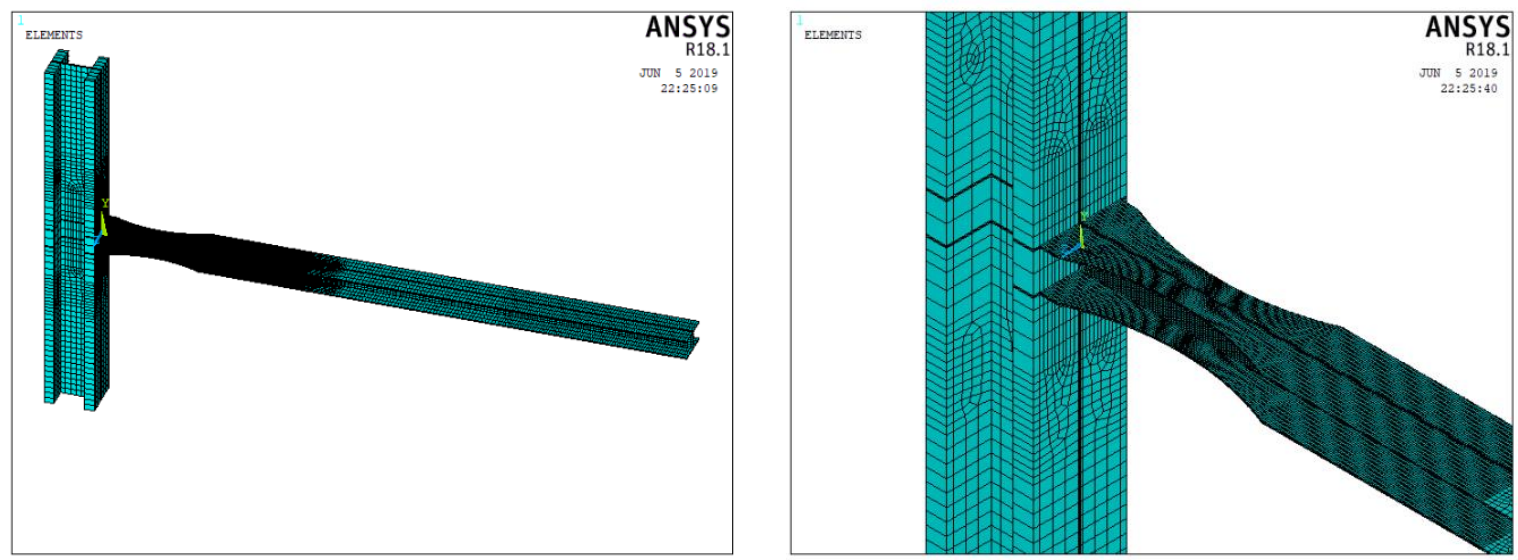

Figure 16: FEA Model for Specimen RBS-2 

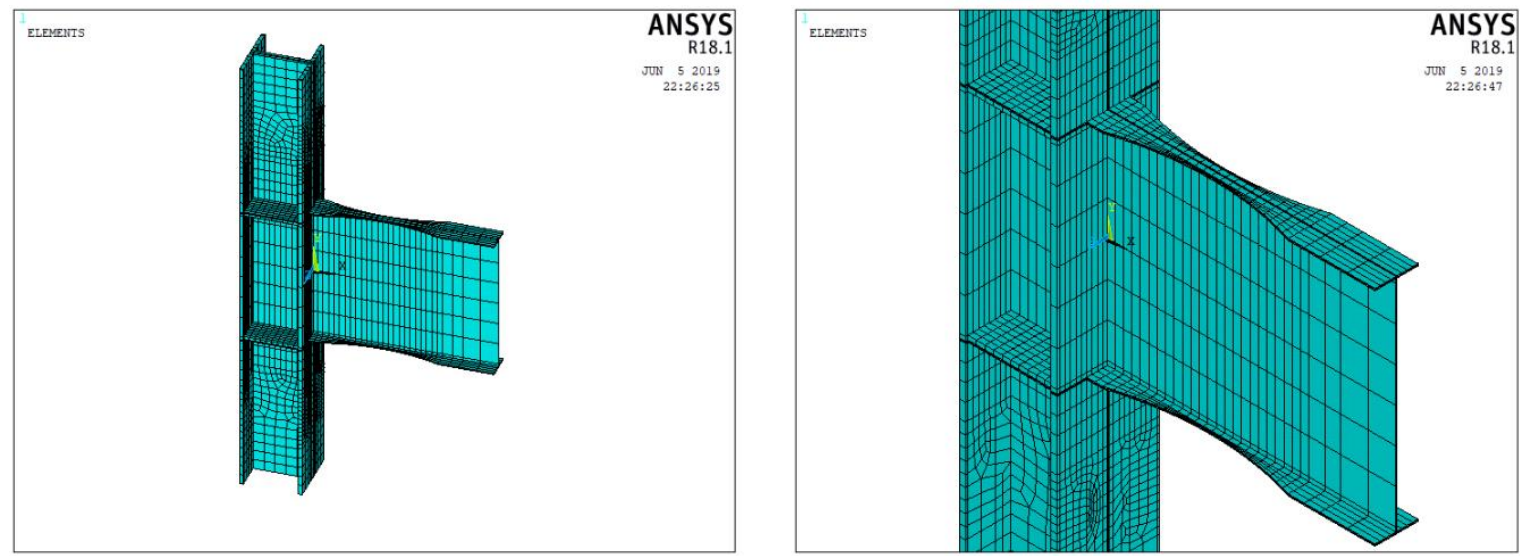

Figure 17: FEA Model for Specimen RBS-3
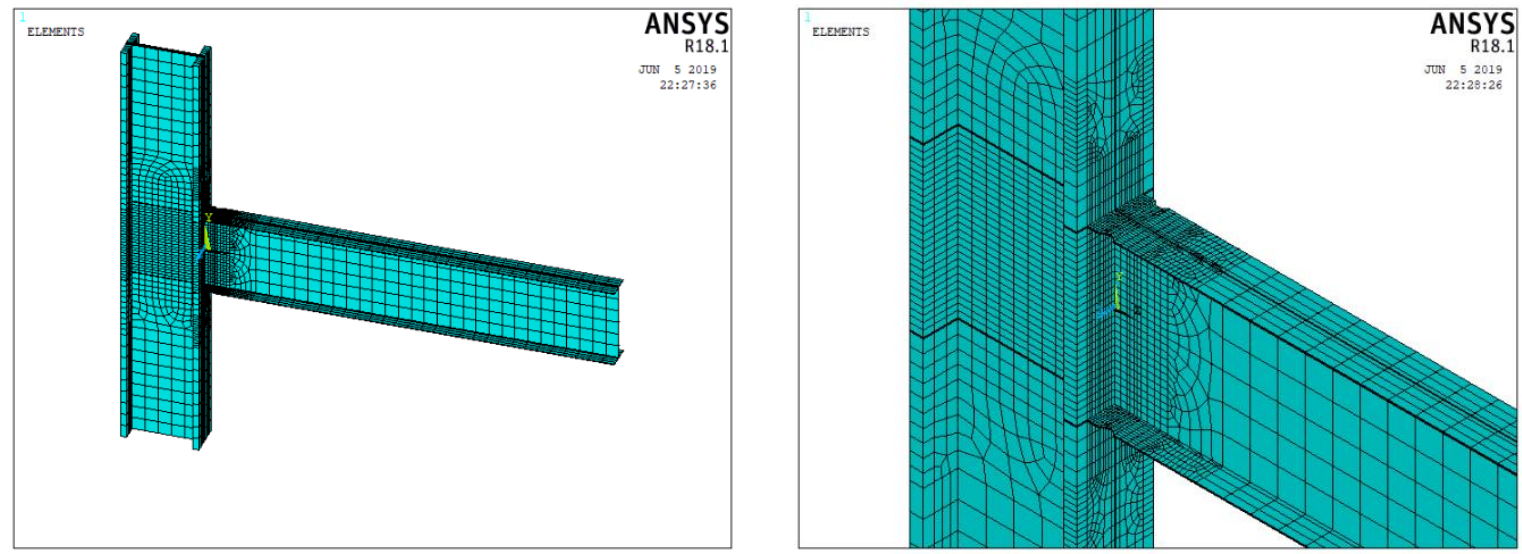

Figure 18: FEA Model for Specimen RBS-4
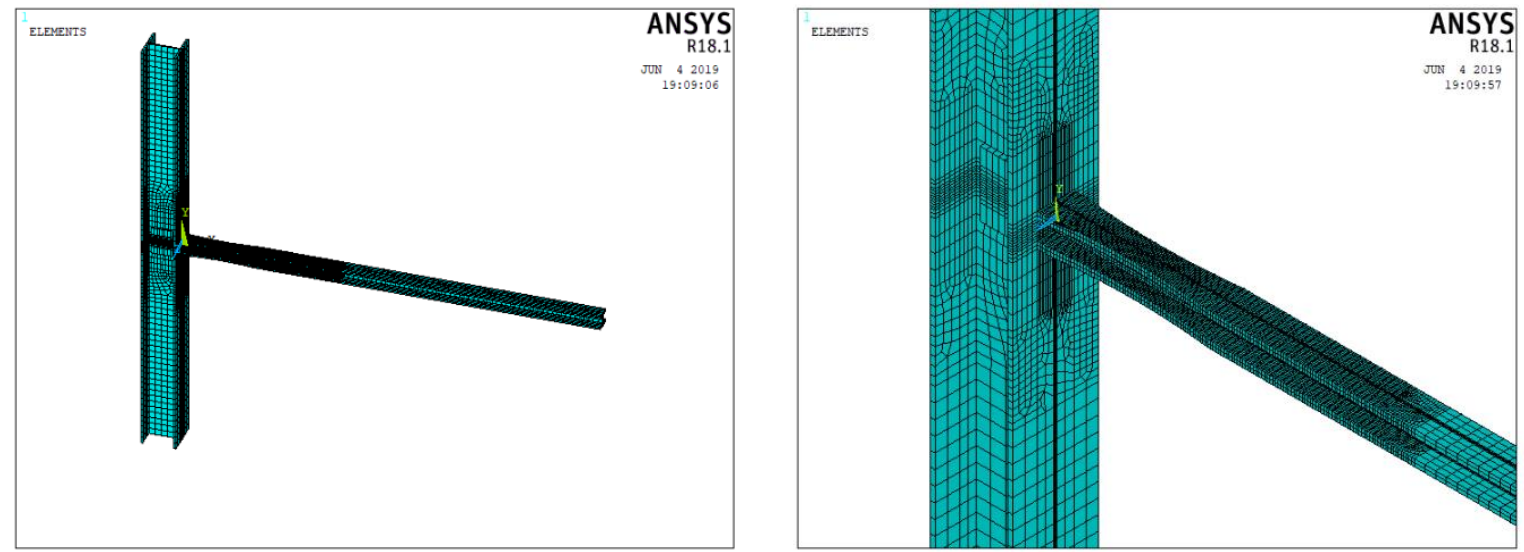

Figure 19: FEA Model for Specimen RBS-5 

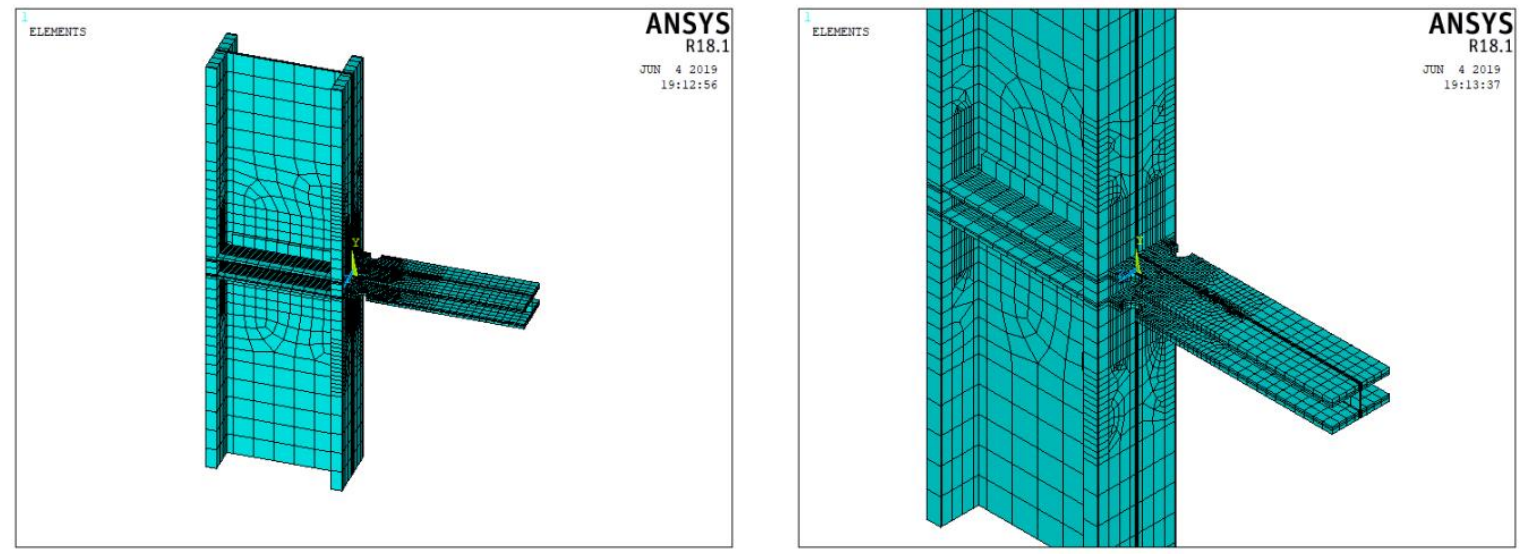

Figure 20: FEA Model for Specimen RBS-6 


\subsection{RESPONSE VARIABLES}

The tests were carried out to record five response variables to assess the sensitivity of RBS connections towards the parameters under considerations. These response variables are depicted in Figure 21 and discussed in following sections.

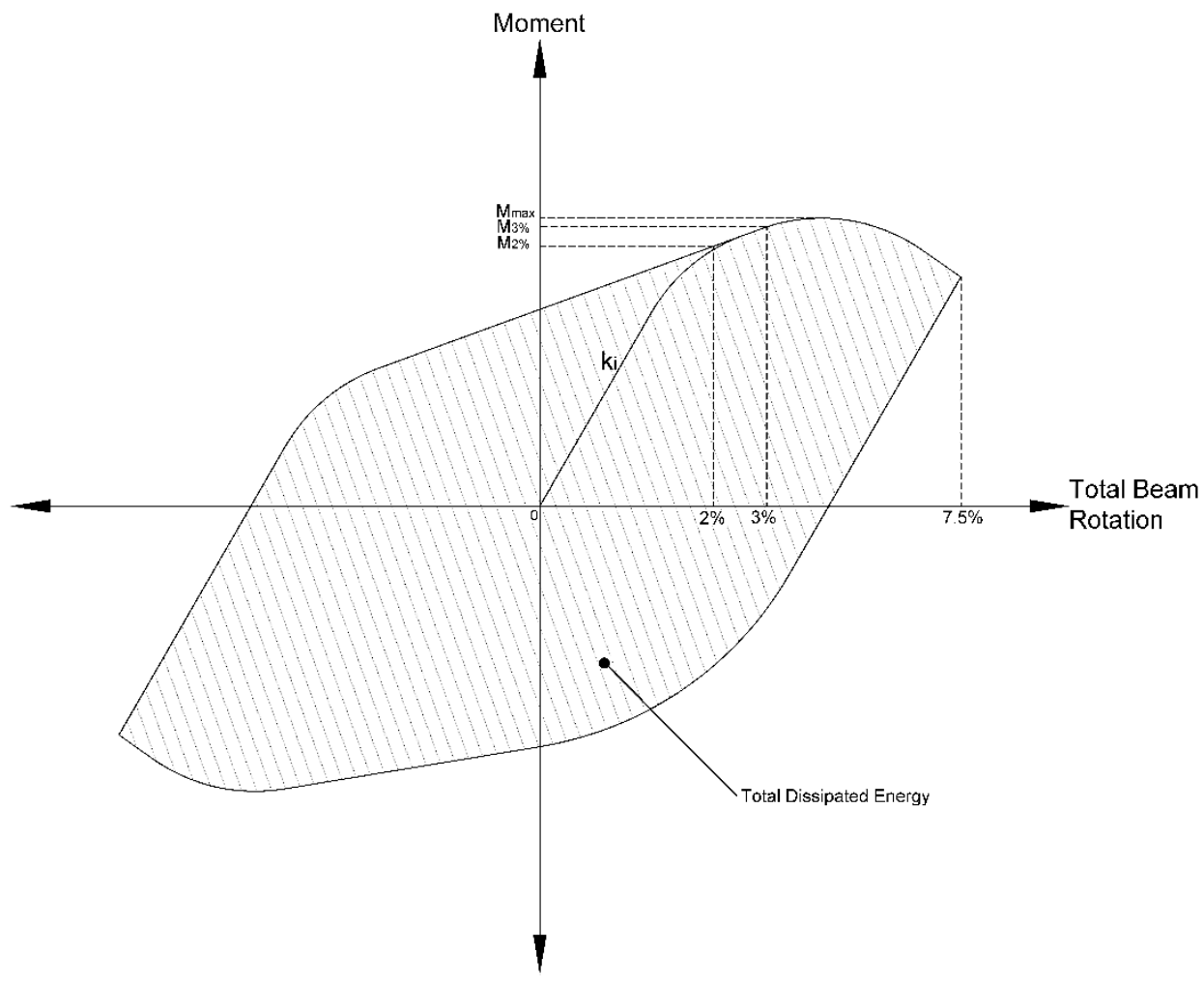

Figure 21: Schematic of Response Variables Considered in Sensitivity Study

\subsubsection{R1: Total Dissipated Energy}

The dissipation of energy in the subject system under cyclic loading is caused by yielding and wearing of steel (Dastfan et al., 2018), hence it was calculated as the area enclosed by the hysteric curve of each test by the trapezoidal method. 


\subsubsection{R2: Initial Stiffness $\left(\mathbf{k}_{\mathbf{i}}\right)$}

The resistance of the beam to deformation before yielding is called initial stiffness and was set as another measure to the subject system's performance under the applied conditions.

\subsubsection{R3: Strength Degradation Rate}

Degradation in the strength caused by buckling was calculated by Strength Degradation Rate (SDR) as a ratio of maximum moment resistance of RBS at $2 \%$ rotation to maximum moment resistance of RBS at 3\% rotation as depicted in Figure 22 (Uang and Fan, 2001).

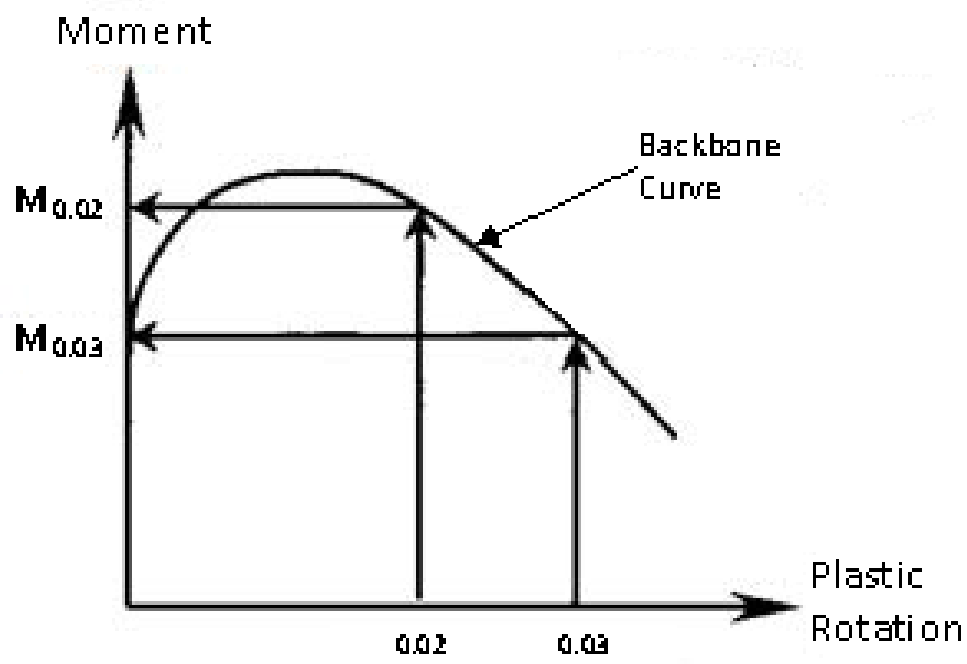

Figure 22: Strength Degradation Rate (Uang and Fan, 2001)

\subsubsection{R4: Maximum Moment Resistance}

Maximum resistance in each complete hysteric response was set as another measure of the performance of RBS in the terms of peak moment for each test as depicted in Figure 21. 


\subsubsection{R5: Rupture Index @ 7.5\% Total Storey Drift}

Vulnerability of a section to rupture is calculated by Rupture Index (RI) as the ratio of the equivalent plastic strain index to the ductile fracture strain (Rahnavard et al. 2015; Moradi and Alam, 2017). RI can be written as:

$$
R I=\frac{P E E Q / \varepsilon_{f}}{\exp \left(1.5 \frac{p}{q}\right)}
$$

Where;

$\begin{array}{lll}\mathrm{RI} & = & \text { Rupture Index } \\ \mathrm{PEEQ} & = & \text { Equivalent Plastic Strain Index } \\ \varepsilon_{f} & = & \text { Ductile Fracture Strain } \\ \mathrm{p} & = & \text { Hydrostatic Pressure } \\ \mathrm{q} & = & \text { Von Mises Stress }\end{array}$




\section{CHAPTER - 4}

\section{THE EXPERIMENT}

\subsection{PHASE - 1 RESPONSE PLOTS}

In Phase -1 of the experiment, 32 specimens were analyzed as explained in section 3 and the hysteric responses for first 10 runs are shown in Figures 23 through 32 while rest of the response plots for Phase -1 of this experiment are presented in Appendix B of this document.

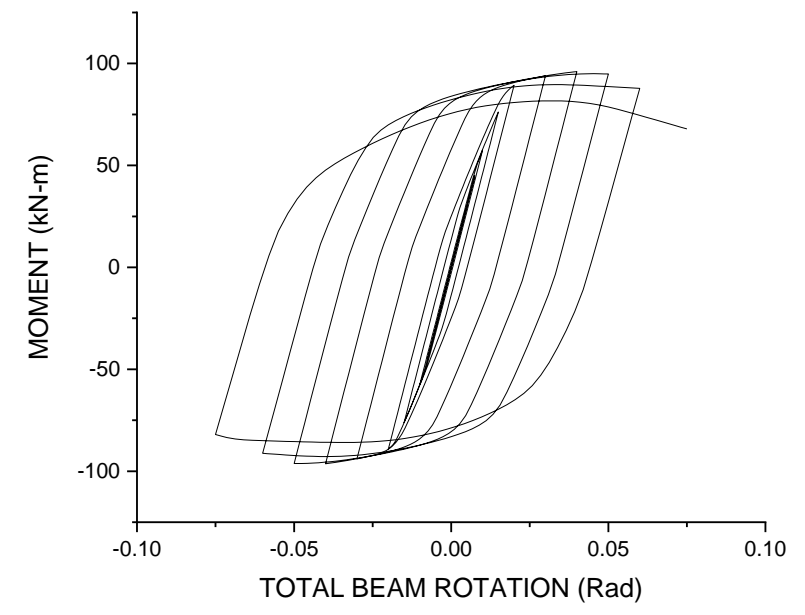

Figure 23: Experimental Moment vs Rotation Curve for RBS-1

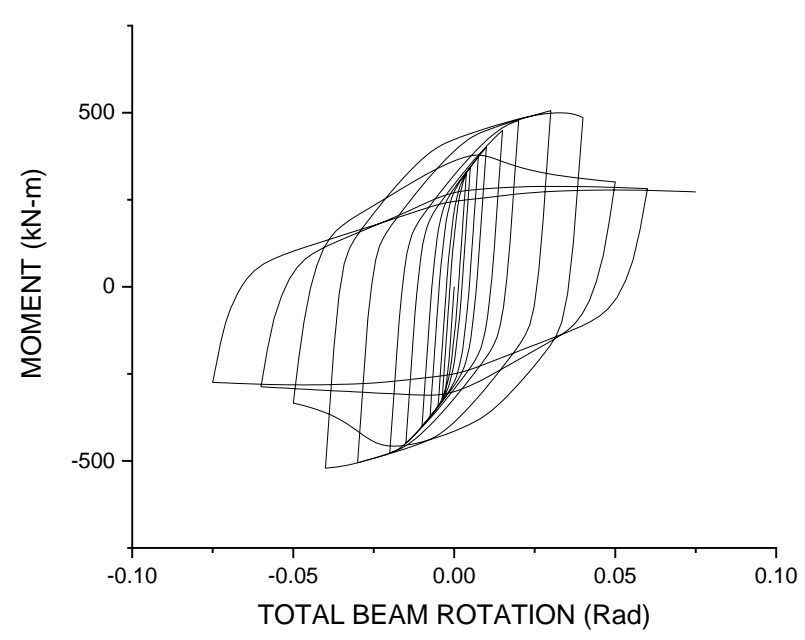

Figure 25: Experimental Moment vs Rotation Curve for RBS-3

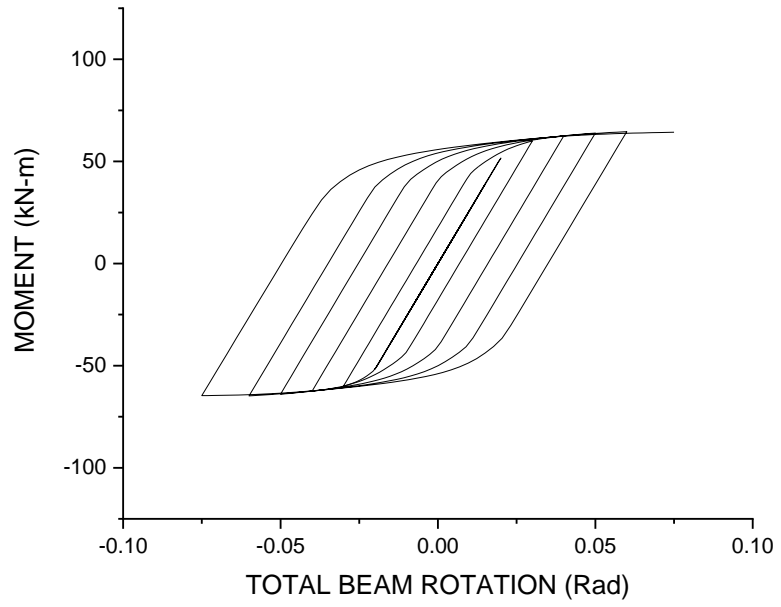

Figure 24: Experimental Moment vs Rotation Curve for RBS-2

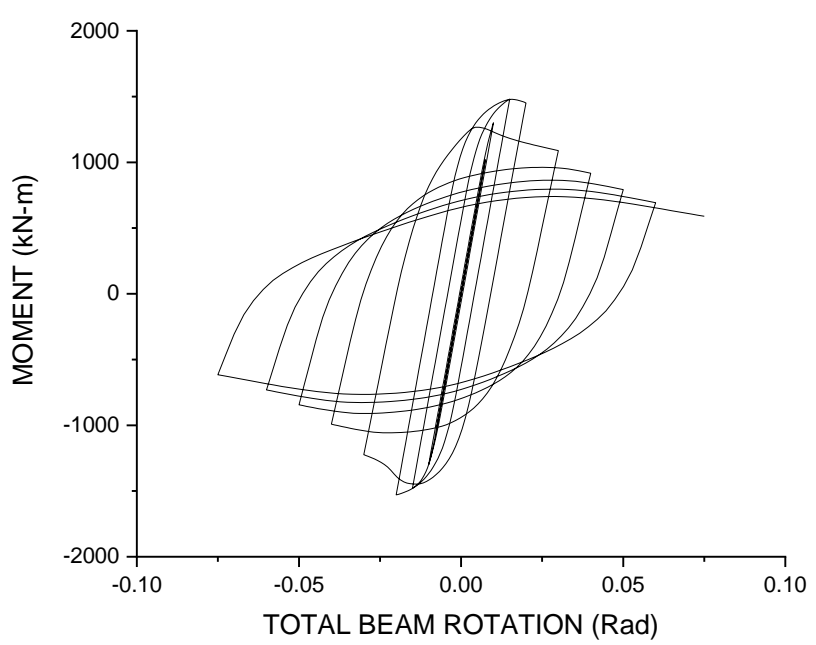

Figure 26: Experimental Moment vs Rotation Curve for RBS-4 


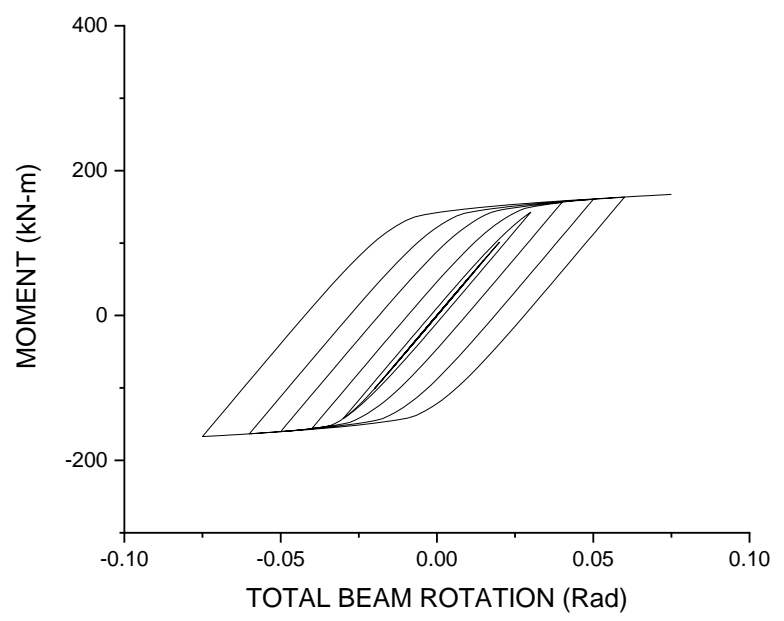

Figure 27: Experimental Moment vs Rotation Curve for RBS-5

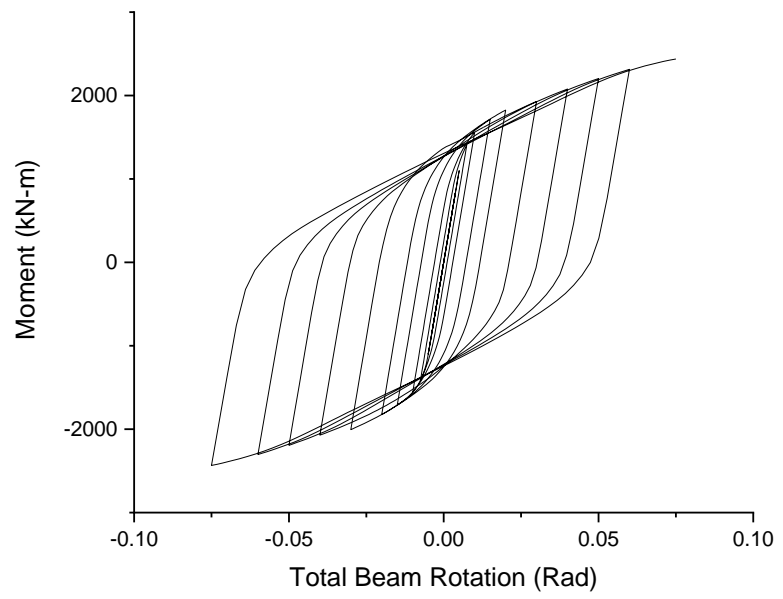

Figure 29: Experimental Moment vs Rotation Curve for RBS-7

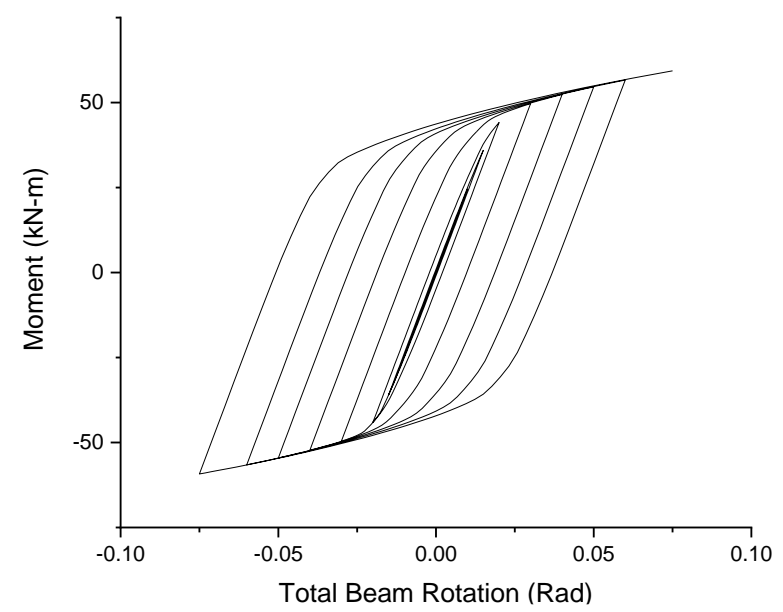

Figure 31: Experimental Moment vs Rotation Curve for RBS-9

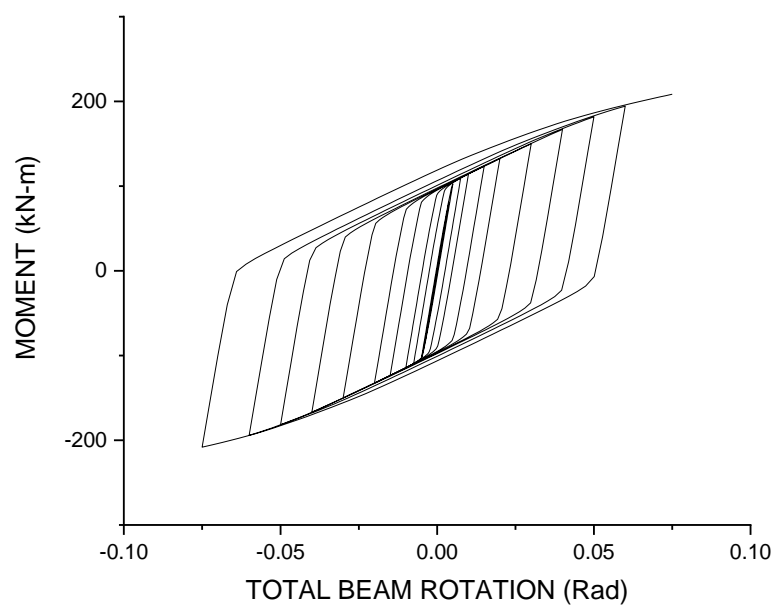

Figure 28: Experimental Moment vs Rotation Curve for RBS-6

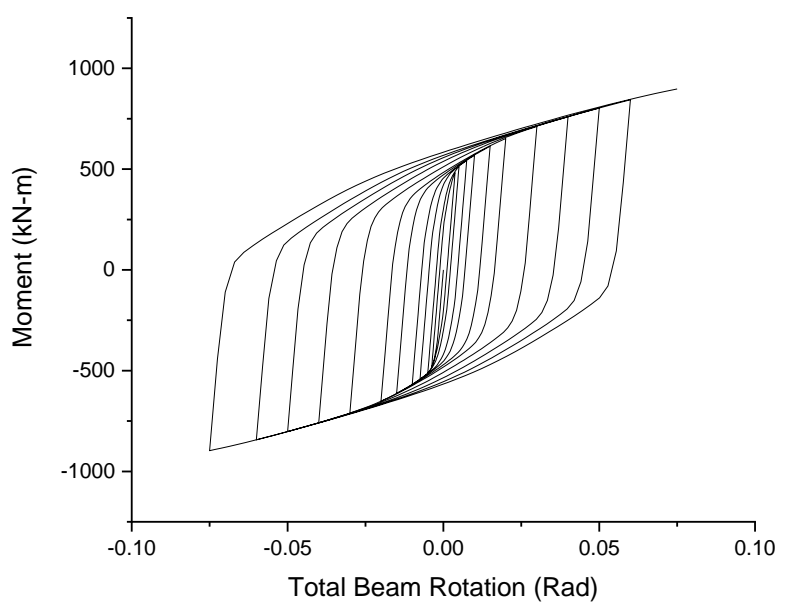

Figure 30: Experimental Moment vs Rotation Curve for RBS-8

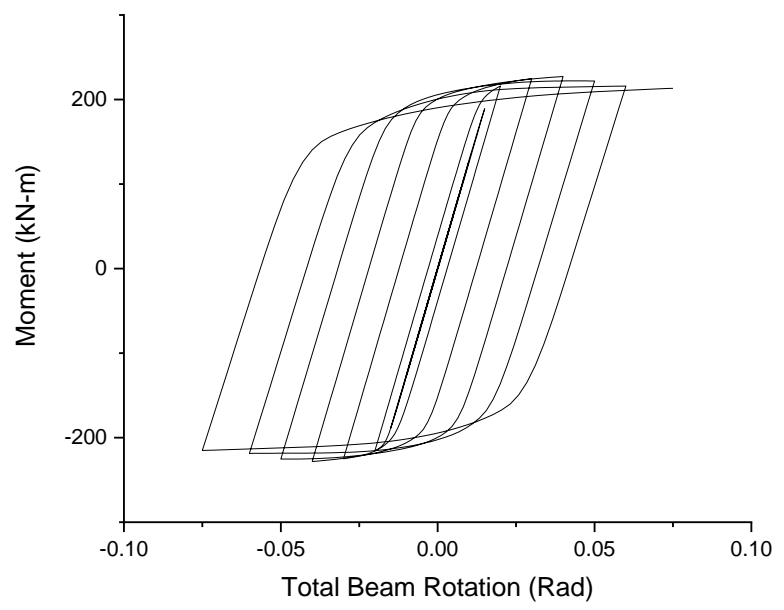

Figure 32: Experimental Moment vs Rotation Curve for RBS-10 


\subsection{INITIAL SENSITIVITY ANALYSIS}

The response variables from phase-I were analyzed to observe the sensitivity of the behaviour of RBS connection. Each response represents a regression model that determines the sensitivity of the response towards certain significant factors considered in the model. To identify the significant independent variables of each regression model, half-normal distribution plots were created for all 5 regression analyses. According to Central Limit Theorem, the distribution of averages is likely to exhibit a normal distribution, therefore, in a half-normal plot of absolute values of the estimated effects versus their respective cumulative normal probabilities, insignificant factors accumulate over a straight line pattern (Montgomery, 2013) leaving the significant ones to be identified with ease as they fall distant from the linear trend. The half normal plots of the 5 responses are presented in Figures $\mathbf{3 3}$ through $\mathbf{3 7}$.

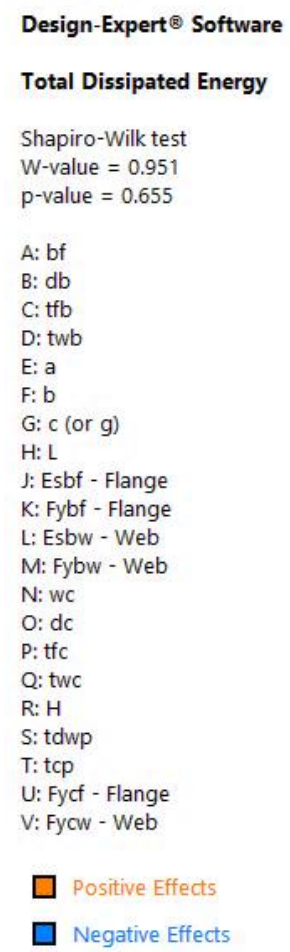

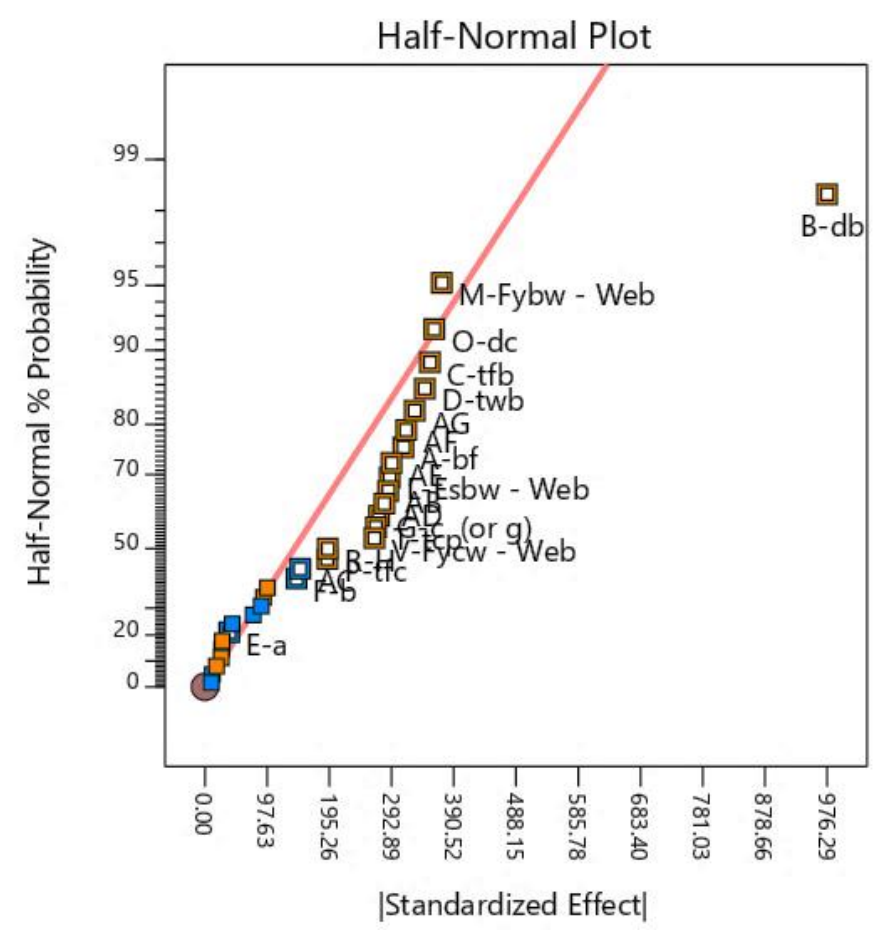

Figure 33: Half-Normal Probability Plot for Response R1 (Total Dissipated Energy) Phase-1 

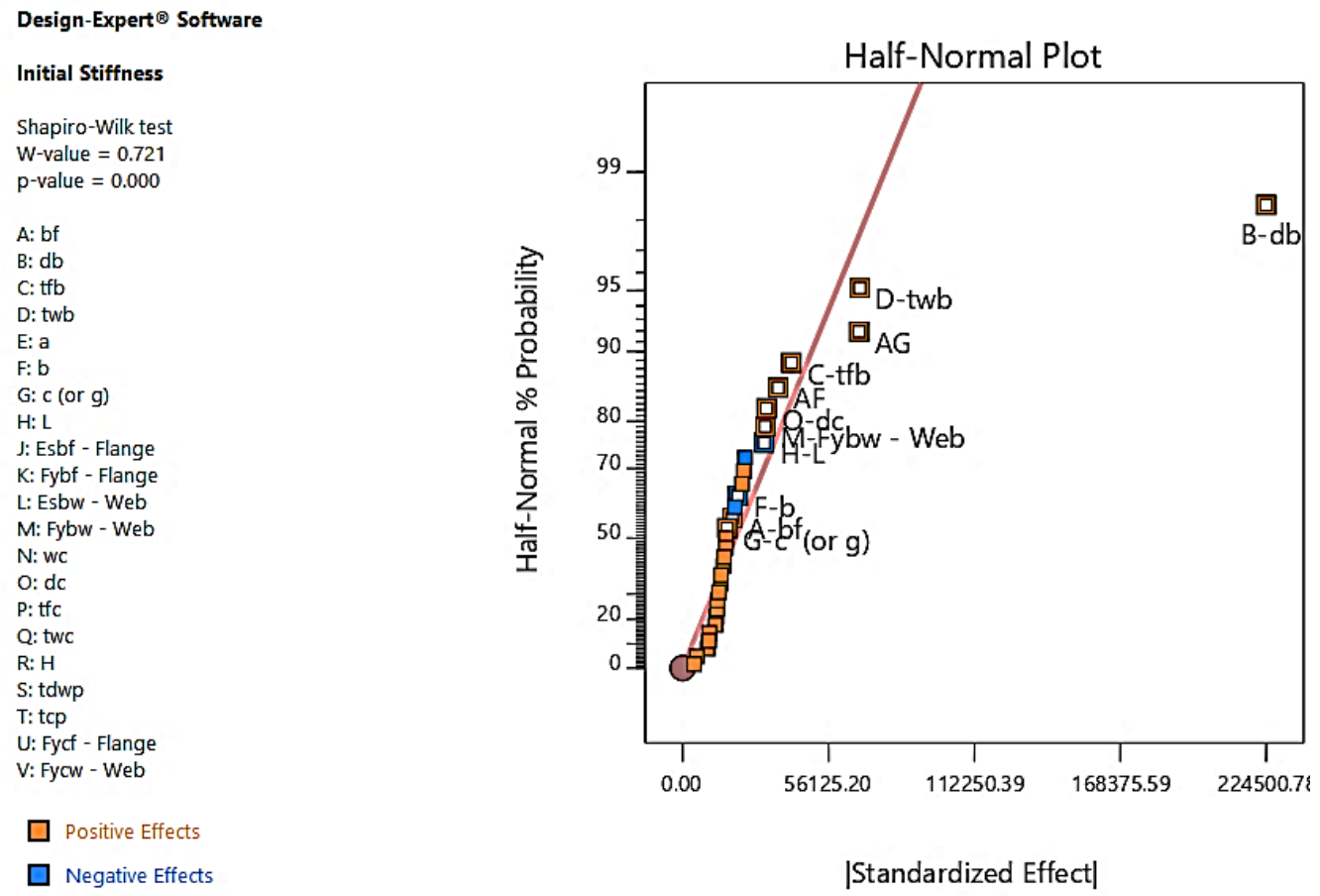

Figure 34: Half-Normal Probability Plot for Response R2 (Initial Stiffness) Phase-1
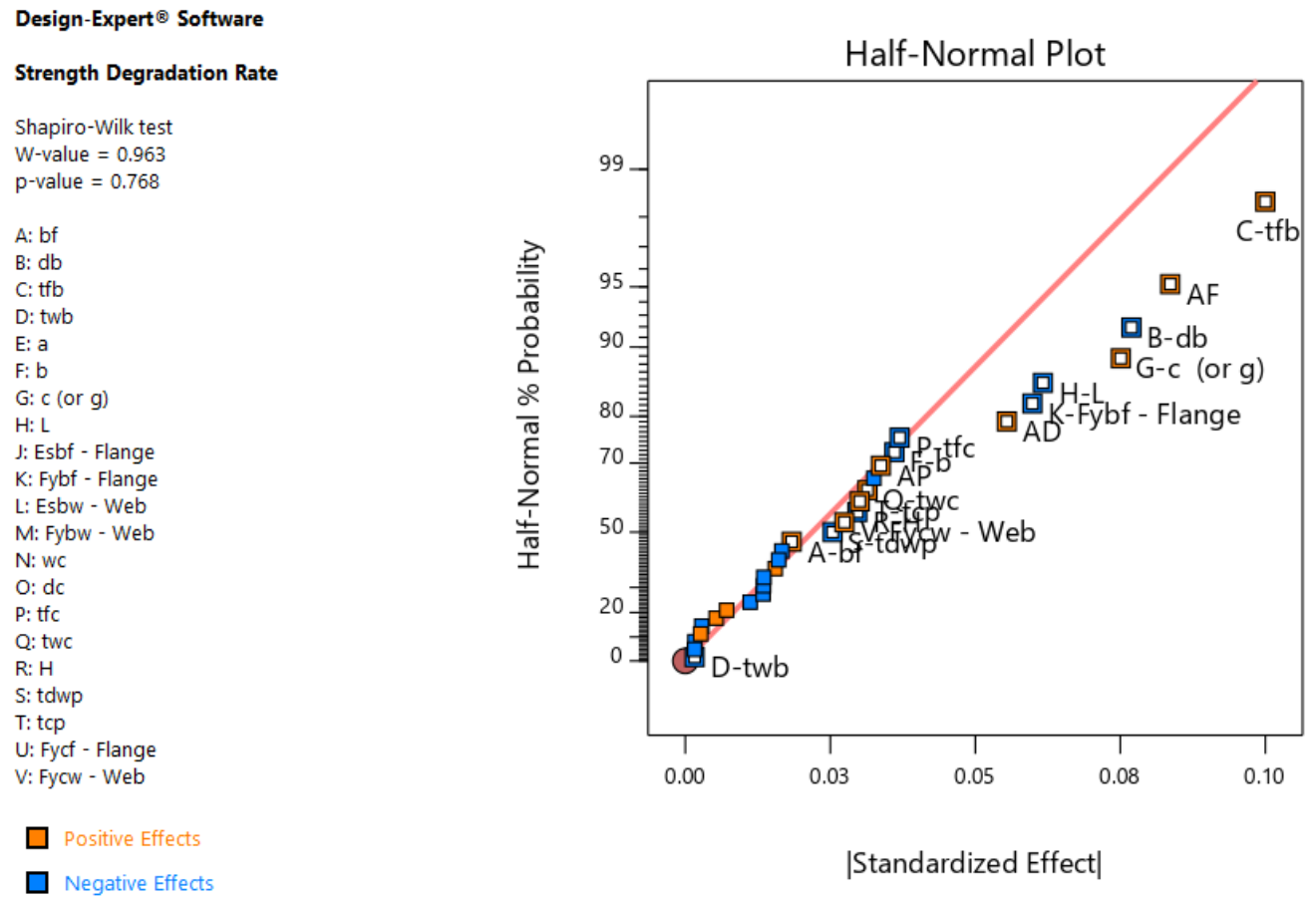

Figure 35: Half-Normal Probability Plot for Response R3 (Strength Degradation Rate) Phase 1 
Design-Expert ${ }^{\circledR}$ Software

Max Moment Capacity

Shapiro-Wilk test

W-value $=0.953$

p-value $=0.469$

A: bf

C: tfb

D: twb

E: a

G: c (or g)

H: L

J: Esbf - Flange

$\mathrm{K}$ : Fybf - Flange

L: Esbw - Web

M: Fybw - Web

$\mathrm{N}$ : wc

O: dc

P: tfc

Q: twc

R: $\mathrm{H}$

S: tdwp

T: tcp

U: Fycf - Flange

V: Fycw - Web

$\square$ Positive Effects

$\square$ Negative Effects

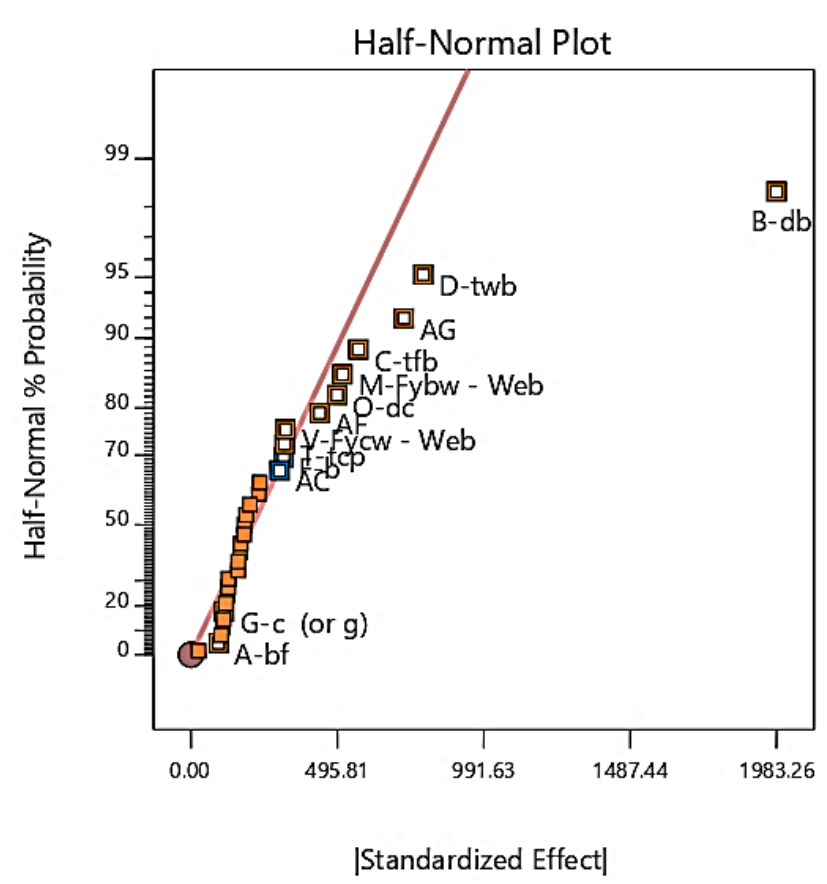

Figure 36: Half-Normal Probability Plot for Response R4

(Max. Moment Capacity) Phase-1

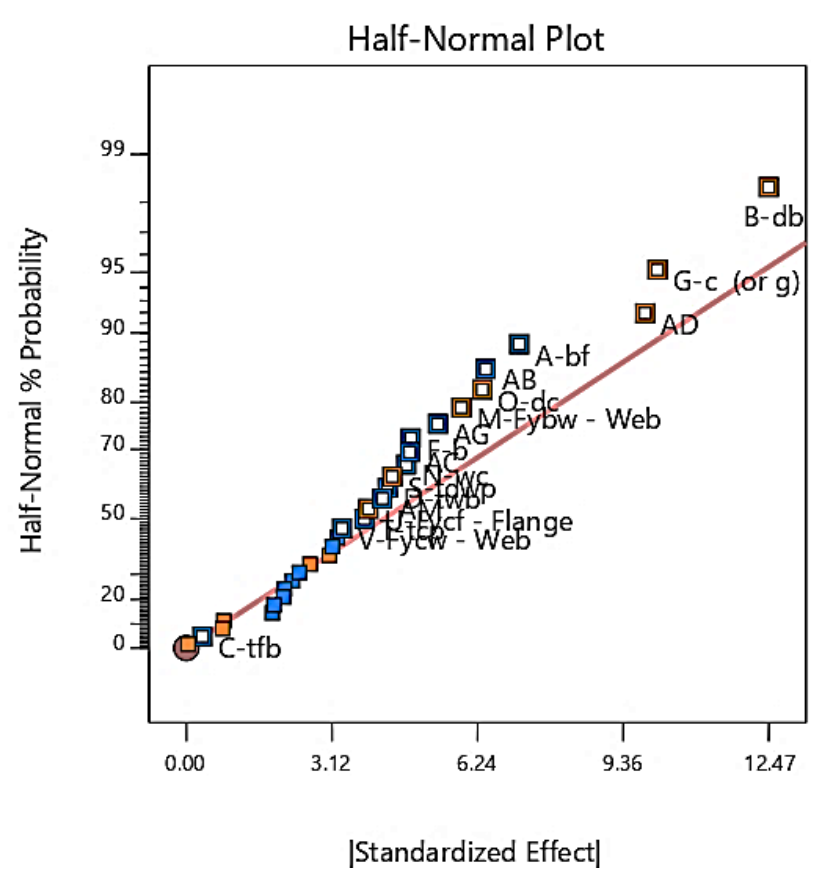

Figure 37: Half-Normal Probability Plot for Response R5

(Rupture Index) Phase-1 
These results can be evaluated rationally by Analysis of Variance (ANOVA) tables (from

Tables 7 to 11) for each response as follows.

Table 7: ANOVA of Selected Model for Response R1, Phase-1

\begin{tabular}{|l|r|r|r|r|r|l|}
\hline SOURCE & \multicolumn{1}{l}{$\begin{array}{l}\text { SUM OF } \\
\text { SQUARES }\end{array}$} & df & $\begin{array}{l}\text { MEAN } \\
\text { SQUARE }\end{array}$ & F-VALUE & P-VALUE & \\
\hline Model & 19506075.88 & 20 & 975303.7942 & 37.07362 & $2.31 E-07$ & Significant \\
\hline A-bf & 777664.2951 & 1 & 777664.2951 & 29.56088 & 0.000205 & \\
\hline B-db & 7625170.638 & 1 & 7625170.638 & 289.8509 & $2.98 E-09$ & \\
\hline C-tfb & 998088.8188 & 1 & 998088.8188 & 37.93974 & $7.11 E-05$ & \\
\hline D-twb & 952622.6759 & 1 & 952622.6759 & 36.21146 & $8.7 E-05$ & \\
\hline E-a & 11839.31024 & 1 & 11839.31024 & 0.45004 & 0.516154 & \\
\hline F-b & 165483.8401 & 1 & 165483.8401 & 6.290436 & 0.029086 & \\
\hline G-c (or g) & 596436.4771 & 1 & 596436.4771 & 22.67197 & 0.000589 & \\
\hline L-Esbw - Web & 672414.5054 & 1 & 672414.5054 & 25.56008 & 0.000369 & \\
\hline M-Fybw - Web & 1106380.707 & 1 & 1106380.707 & 42.05617 & $4.52 E-05$ & \\
\hline O-dc & 1035646.848 & 1 & 1035646.848 & 39.36741 & $6.05 E-05$ & \\
\hline P-tfc & 295542.4004 & 1 & 295542.4004 & 11.23427 & 0.006457 & \\
\hline R-H & 297434.0326 & 1 & 297434.0326 & 11.30618 & 0.006336 & \\
\hline T-tcp & 576540.1943 & 1 & 576540.1943 & 21.91567 & 0.00067 & \\
\hline V-Fycw - Web & 566483.4793 & 1 & 566483.4793 & 21.53339 & 0.000716 & \\
\hline AB & 662925.503 & 1 & 662925.503 & 25.19938 & 0.00039 & \\
\hline AC & 178878.9383 & 1 & 178878.9383 & 6.799615 & 0.024361 & \\
\hline AD & 634053.417 & 1 & 634053.417 & 24.10188 & 0.000465 & \\
\hline AE & 686996.6958 & 1 & 686996.6958 & 26.11438 & 0.000339 & \\
\hline AF & 798077.6802 & 1 & 798077.6802 & 30.33684 & 0.000184 & \\
\hline AG & 2867395.4281 & 1 & 867395.4281 & 32.97177 & 0.00013 & \\
\hline Residual & 19795455.24 & 31 & & & & \\
\hline Cor Total & & & & & & \\
\hline
\end{tabular}


Table 8: ANOVA of Selected Model for Response R2, Phase-1

\begin{tabular}{|l|r|r|r|r|l|l|}
\hline SOURCE & $\begin{array}{l}\text { SUM OF } \\
\text { SQUARES }\end{array}$ & df & $\begin{array}{l}\text { MEAN } \\
\text { SQUARE }\end{array}$ & \multicolumn{1}{l}{$\begin{array}{l}\text { VALUE } \\
\text { V-VALUE }\end{array}$} & \\
\hline Model & $5.35235 E+11$ & 11 & 48657741995 & 25.51525 & $2.2587 E-09$ & Significant \\
\hline A-bf & 2931570374 & 1 & 2931570374 & 1.53726 & 0.22937662 & \\
\hline B-db & $4.03205 E+11$ & 1 & $4.03205 E+11$ & 211.43341 & $4.2639 E-12$ & \\
\hline C-tfb & 13948371264 & 1 & 13948371264 & 7.31427 & 0.01364318 & \\
\hline D-twb & 37196295746 & 1 & 37196295746 & 19.50507 & 0.00026581 & \\
\hline F-b & 3614657880 & 1 & 3614657880 & 1.89546 & 0.1838046 & \\
\hline G-c (or g) & 2349195942 & 1 & 2349195942 & 1.23187 & 0.2802095 & \\
\hline H-L & 7868373219 & 1 & 7868373219 & 4.12603 & 0.0557313 & \\
\hline M-Fybw - Web & 8078685468 & 1 & 8078685468 & 4.23631 & 0.0528358 & \\
\hline O-dc & 8355611604 & 1 & 8355611604 & 4.38153 & 0.0492818 & \\
\hline AF & 10812230837 & 1 & 10812230837 & 5.66974 & 0.0273115 & \\
\hline AG & 36875363899 & 1 & 36875363899 & 19.33678 & 0.0002779 & \\
\hline Residual & 38140121715 & 20 & 1907006086 & & & \\
\hline Cor Total & $5.73375 E+11$ & 31 & & & & \\
\hline
\end{tabular}


Table 9: ANOVA of Selected Model for Response R3, Phase-1

\begin{tabular}{|l|r|r|r|r|r|l|}
\hline SOURCE & \multicolumn{1}{l|}{$\begin{array}{l}\text { SUM OF } \\
\text { SQUARES }\end{array}$} & df & \multicolumn{1}{l}{$\begin{array}{l}\text { MEAN } \\
\text { SQUARE }\end{array}$} & F-VALUE & P-VALUE & \\
\hline Model & 0.396062246 & 17 & 0.023297779 & 14.96589 & 0.00000 & Significant \\
\hline A-bf & 0.002814055 & 1 & 0.002814055 & 1.80768 & 0.20017 & \\
\hline B-db & 0.049525085 & 1 & 0.049525085 & 31.81364 & 0.00006 & \\
\hline C-tfb & 0.083703973 & 1 & 0.083703973 & 53.76927 & 0.00000 & \\
\hline D-twb & $2.16136 E-05$ & 1 & $2.16136 E-05$ & 0.01388 & 0.90788 & \\
\hline F-b & 0.010888384 & 1 & 0.010888384 & 6.99442 & 0.01923 & \\
\hline G-c (or g) & 0.047188566 & 1 & 0.047188566 & 30.31272 & 0.00008 & \\
\hline H-L & 0.031815242 & 1 & 0.031815242 & 20.43729 & 0.00048 & \\
\hline K-Fybf - Flange & 0.029973575 & 1 & 0.029973575 & 19.25425 & 0.00062 & \\
\hline P-tfc & 0.01143883 & 1 & 0.01143883 & 7.34801 & 0.01690 & \\
\hline Q-twc & 0.008262938 & 1 & 0.008262938 & 5.30790 & 0.03708 & \\
\hline R-H & 0.007370626 & 1 & 0.007370626 & 4.73470 & 0.04718 & \\
\hline S-tdwp & 0.005405669 & 1 & 0.005405669 & 3.47246 & 0.08351 & \\
\hline T-tcp & 0.007578574 & 1 & 0.007578574 & 4.86828 & 0.04456 & \\
\hline V-Fycw - Web & 0.006303686 & 1 & 0.006303686 & 4.04932 & 0.06384 & \\
\hline AD & 0.025735019 & 1 & 0.025735019 & 16.53151 & 0.00116 & \\
\hline AF & 0.058516283 & 1 & 0.058516283 & 37.58935 & 0.00003 & \\
\hline AP & 0.009520129 & 1 & 0.009520129 & 6.11549 & 0.02683 & \\
\hline Residual & 0.021794152 & 14 & 0.001556725 & & & \\
\hline Cor Total & 0.417856398 & 31 & & & & \\
\hline & & & & & & \\
\hline
\end{tabular}


Table 10: ANOVA of Selected Model for Response R4, Phase-1

\begin{tabular}{|l|r|r|r|r|r|l|}
\hline SOURCE & $\begin{array}{l}\text { SUM OF } \\
\text { SQUARES }\end{array}$ & df & $\begin{array}{l}\text { MEAN } \\
\text { SQUARE }\end{array}$ & F-VALUE & P-VALUE & \\
\hline Model & 52031482.27 & 13 & 4002421.713 & 19.9861 & 0.0000 & Significant \\
\hline A-bf & 70133.42716 & 1 & 70133.42716 & 0.3502 & 0.5614 & \\
\hline B-db & 31466547.48 & 1 & 31466547.48 & 157.1285 & 0.0000 & \\
\hline C-tfb & 2569583.146 & 1 & 2569583.146 & 12.8312 & 0.0021 & \\
\hline D-twb & 4952480.826 & 1 & 4952480.826 & 24.7303 & 0.0001 & \\
\hline F-b & 787818.7096 & 1 & 787818.7096 & 3.9340 & 0.0628 & \\
\hline G-c (or g) & 100318.6572 & 1 & 100318.6572 & 0.5009 & 0.4882 & \\
\hline M-Fybw - Web & 2104680.754 & 1 & 2104680.754 & 10.5097 & 0.0045 & \\
\hline O-dc & 1959800.789 & 1 & 1959800.789 & 9.7863 & 0.0058 & \\
\hline T-tcp & 805571.8361 & 1 & 805571.8361 & 4.0226 & 0.0602 & \\
\hline V-Fycw - Web & 818783.8993 & 1 & 818783.8993 & 4.0886 & 0.0583 & \\
\hline AC & 719474.3712 & 1 & 719474.3712 & 3.5927 & 0.0742 & \\
\hline AF & 1520238.512 & 1 & 1520238.512 & 7.5913 & 0.0130 & \\
\hline AG & 4156049.864 & 1 & 4156049.864 & 20.7533 & 0.0002 & \\
\hline Residual & 3604678.175 & 18 & 200259.8986 & & & \\
\hline Cor Total & 55636160.45 & 31 & & & & \\
\hline
\end{tabular}


Table 11: ANOVA of Selected Model for Response R5, Phase-1

\begin{tabular}{|l|r|r|r|r|r|l|}
\hline SOURCE & \multicolumn{1}{l|l}{$\begin{array}{l}\text { SUM OF } \\
\text { SQUARES }\end{array}$} & df & $\begin{array}{l}\text { MEAN } \\
\text { SQUARE }\end{array}$ & \multicolumn{1}{l|}{ F-VALUE } & P-VALUE & \\
\hline Model & 5630.02956 & 17 & 331.1782094 & 7.660786 & 0.000198 & Significant \\
\hline A-bf & 406.5377033 & 1 & 406.5377033 & 9.403995 & 0.008370 & \\
\hline B-db & 1244.792276 & 1 & 1244.792276 & 28.794427 & 0.000100 & \\
\hline C-tfb & 0.951366877 & 1 & 0.951366877 & 0.022007 & 0.884184 & \\
\hline D-twb & 148.7905317 & 1 & 148.7905317 & 3.441810 & 0.084743 & \\
\hline F-b & 184.753254 & 1 & 184.753254 & 4.273696 & 0.057714 & \\
\hline G-c (or g) & 814.9194129 & 1 & 814.9194129 & 18.850645 & 0.000677 & \\
\hline M-Fybw - Web & 277.7565243 & 1 & 277.7565243 & 6.425040 & 0.023810 & \\
\hline N-wc & 177.359864 & 1 & 177.359864 & 4.102673 & 0.062316 & \\
\hline O-dc & 321.5553786 & 1 & 321.5553786 & 7.438191 & 0.016358 & \\
\hline S-tdwp & 155.823094 & 1 & 155.823094 & 3.604486 & 0.078432 & \\
\hline T-tcp & 116.4424939 & 1 & 116.4424939 & 2.693538 & 0.123021 & \\
\hline U-Fycf - & 121.6192038 & 1 & 121.6192038 & 2.813285 & 0.115662 & \\
Flange & & & & & & \\
\hline AB & 328.9774037 & 1 & 328.9774037 & 7.609877 & 0.015383 & \\
\hline AC & 183.4130916 & 1 & 183.4130916 & 4.242696 & 0.058518 & \\
\hline AD & 772.8599927 & 1 & 772.8599927 & 17.877730 & 0.000843 & \\
\hline AG & 232.5222893 & 1 & 232.5222893 & 5.378685 & 0.036014 & \\
\hline AM & 140.9556788 & 1 & 140.9556788 & 3.260575 & 0.092506 & \\
\hline Residual & 605.2244767 & 14 & 43.23031976 & & & \\
\hline Cor Total & 6235.254036 & 31 & & & & \\
\hline
\end{tabular}

At this point, it was observed that where the half-normal distributions of all responses exhibited remarkable significance of factor B (depth of beam $-d b$ ), they also showed no (in models for R1, R2, R3 and R4) or minimum (in model of R4) significance of factor U (Yield Strength of Column Flange - Fycf - Flange) and considerably high significance of combined effects of certain factors which was an ambiguous situation i.e. it is hard to tell if the effect is significant because of either one of factors in the interaction or both. On observing these combined effects, it was evident that all of the combined effects included factor A (width of beam flange - bf) that gives a logical hint that it might be factor A controlling these effects but the F-Values for factor A in models 2, 3 and 4 were found to be significantly lower than other significant factors. 
In order to clarify the significance of factor $\mathrm{A}$ in models 2, 3 and 4; and confirm other results on the basis of concrete evidence, a semi-foldover augmented design of experiment was carried out as a Phase- 2 of experiment and are discussed in following sections. This design was folded on factor $A$ that was needed to be clarified and since factor $U$ was found to be of minimum significance, it was set to its higher level as depicted in Figure 38. The semi-foldover design and its responses are discussed in detail in the following sections.

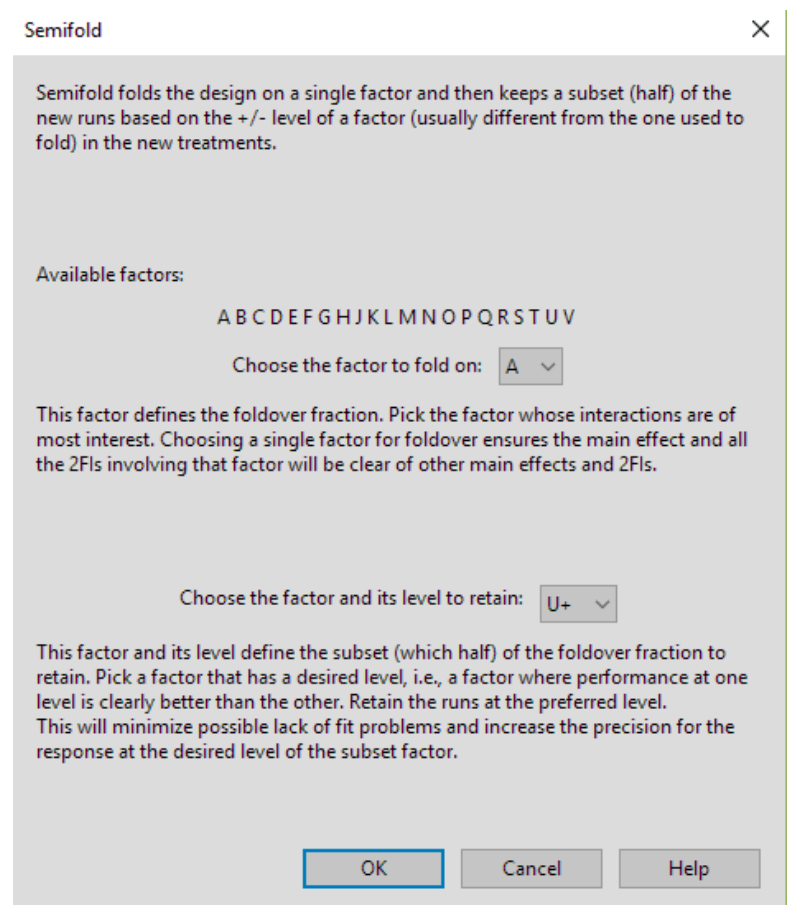

\section{Figure 38: Semi-foldover Augmented Design Dialogue Screen in Design Expert v.11 Software}

\subsection{SEMI-FOLD OVER AUGMENTED DESIGN (PHASE-2)}

As discussed in section 4.2, the results from phase-1 have shown some significant 2 factors interactions (2FIs) that had factor A (bf) in common. Therefore, by carrying out semifoldover augmented design, 16 more test combinations were generated using Design Expert software as presented in Table 12. 
Table 12: Coded Factor Combinations for Experiment Phase 2 (Semi-Fold over)

\begin{tabular}{|c|c|c|c|c|c|c|c|c|c|c|c|c|c|c|c|c|c|c|c|c|c|}
\hline$\stackrel{\mathscr{A}}{\simeq}$ & $\begin{array}{c}\text { bf } \\
\mathrm{mm}\end{array}$ & $\begin{array}{l}\text { db } \\
\text { mm }\end{array}$ & $\begin{array}{l}\mathbf{t f b} \\
\mathbf{m m}\end{array}$ & $\begin{array}{l}\text { twb } \\
\text { mm }\end{array}$ & $\begin{array}{c}\mathbf{a} \\
\mathbf{m m}\end{array}$ & $\begin{array}{c}\text { b } \\
\mathbf{m m}\end{array}$ & $\begin{array}{c}\mathbf{c} \\
\mathrm{mm}\end{array}$ & $\begin{array}{c}\mathbf{L} \\
\mathbf{m m}\end{array}$ & $\begin{array}{c}\text { Esbf } \\
\text { MPa }\end{array}$ & $\begin{array}{c}\text { Fybf } \\
\text { MPa }\end{array}$ & $\begin{array}{c}\text { Esbw } \\
\text { MPa }\end{array}$ & $\begin{array}{c}\text { Fybw } \\
\text { MPa }\end{array}$ & $\begin{array}{l}\text { wc } \\
\text { mm }\end{array}$ & $\begin{array}{l}\text { dc } \\
\mathrm{mm}\end{array}$ & $\begin{array}{l}\text { tfc } \\
\text { mm }\end{array}$ & $\begin{array}{l}\text { twc } \\
\mathrm{mm}\end{array}$ & $\begin{array}{c}\mathbf{H} \\
\mathrm{mm}\end{array}$ & $\begin{array}{c}\text { tdwp } \\
\text { mm }\end{array}$ & $\begin{array}{l}\text { tcp } \\
\text { mm }\end{array}$ & $\begin{array}{c}\text { Fycf } \\
\text { MPa }\end{array}$ & $\begin{array}{c}\text { Fycw } \\
\text { MPa }\end{array}$ \\
\hline 34 & 1 & -1 & -1 & -1 & -1 & -1 & -1 & -1 & -1 & 1 & -1 & -1 & -1 & 1 & -1 & -1 & 1 & -1 & 1 & 1 & -1 \\
\hline 36 & 1 & 1 & 1 & -1 & -1 & -1 & 1 & 1 & -1 & 1 & 1 & 1 & -1 & 1 & -1 & 1 & -1 & 1 & -1 & 1 & -1 \\
\hline 37 & -1 & 1 & 1 & -1 & -1 & 1 & -1 & -1 & -1 & -1 & -1 & -1 & -1 & -1 & 1 & 1 & 1 & 1 & 1 & 1 & 1 \\
\hline 39 & -1 & 1 & -1 & 1 & -1 & -1 & 1 & -1 & -1 & -1 & -1 & 1 & 1 & 1 & -1 & -1 & -1 & 1 & 1 & 1 & 1 \\
\hline 40 & 1 & -1 & 1 & 1 & -1 & 1 & 1 & -1 & -1 & 1 & -1 & 1 & 1 & -1 & 1 & 1 & -1 & -1 & 1 & 1 & -1 \\
\hline 41 & -1 & -1 & 1 & 1 & -1 & -1 & -1 & 1 & -1 & -1 & 1 & -1 & 1 & 1 & -1 & 1 & 1 & -1 & -1 & 1 & 1 \\
\hline 42 & 1 & 1 & -1 & -1 & 1 & 1 & 1 & -1 & 1 & -1 & -1 & 1 & -1 & 1 & 1 & -1 & 1 & 1 & -1 & 1 & -1 \\
\hline 46 & 1 & -1 & -1 & 1 & 1 & -1 & 1 & 1 & 1 & -1 & 1 & 1 & 1 & -1 & -1 & -1 & 1 & -1 & 1 & 1 & -1 \\
\hline 47 & -1 & -1 & -1 & 1 & 1 & 1 & -1 & -1 & 1 & 1 & -1 & -1 & 1 & 1 & 1 & -1 & -1 & -1 & -1 & 1 & 1 \\
\hline 48 & 1 & 1 & 1 & 1 & 1 & -1 & -1 & -1 & 1 & -1 & -1 & -1 & 1 & -1 & -1 & 1 & -1 & 1 & -1 & 1 & -1 \\
\hline
\end{tabular}

Note: -1 and 1 indicate the minimum and maximum values respectively as mentioned in Table 5 . 


\subsection{PHASE - 2 RESPONSE PLOTS}

In Phase -2 of the experiment, 16 new test runs were conducted to verify the observations of Phase - 1 and clarify the significance of factor A (bf). The response plots for these test runs are presented in Figures 39 through 54.

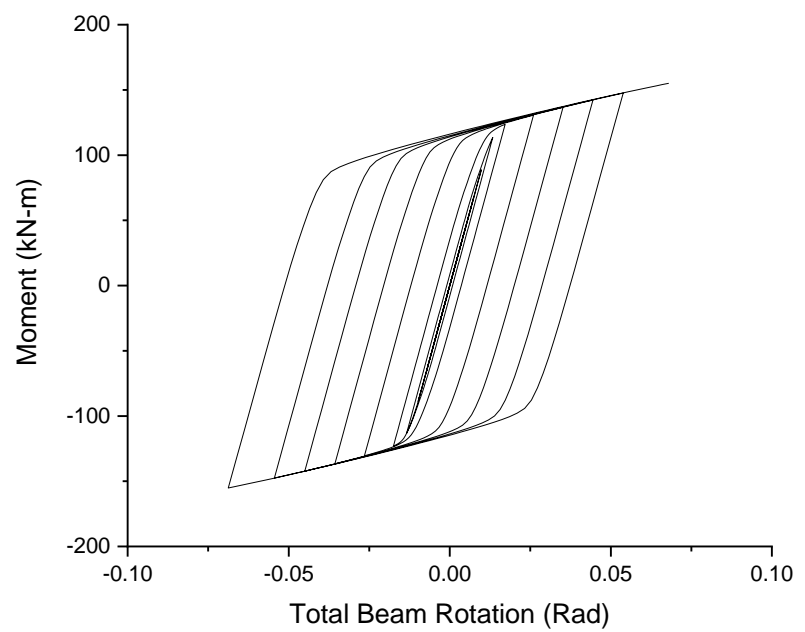

Figure 39: Experimental Moment vs Rotation Curve for RBS-33

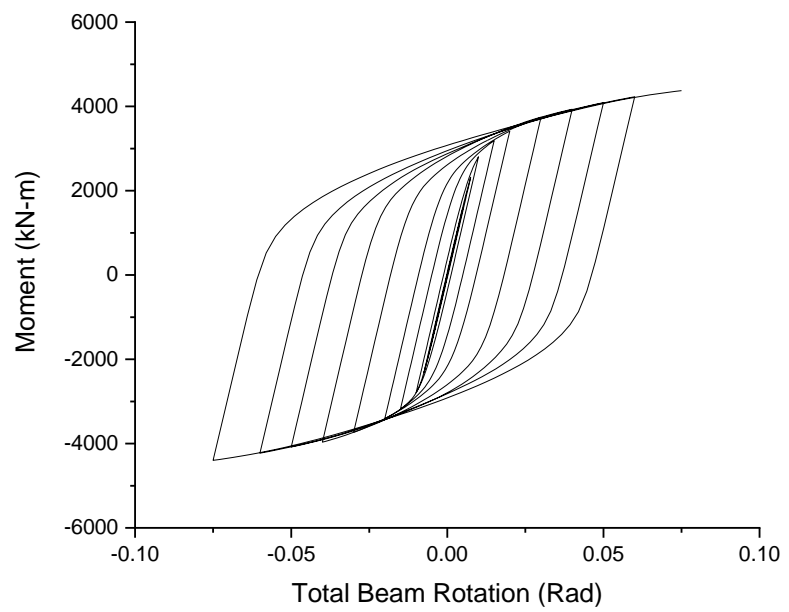

Figure 41: Experimental Moment vs Rotation Curve for RBS-35

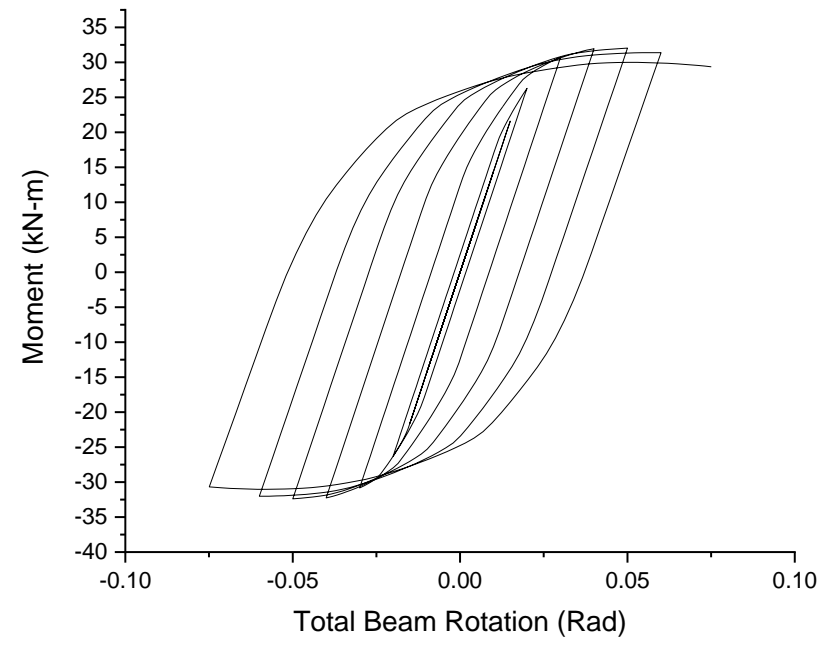

Figure 40: Experimental Moment vs Rotation Curve for RBS-34

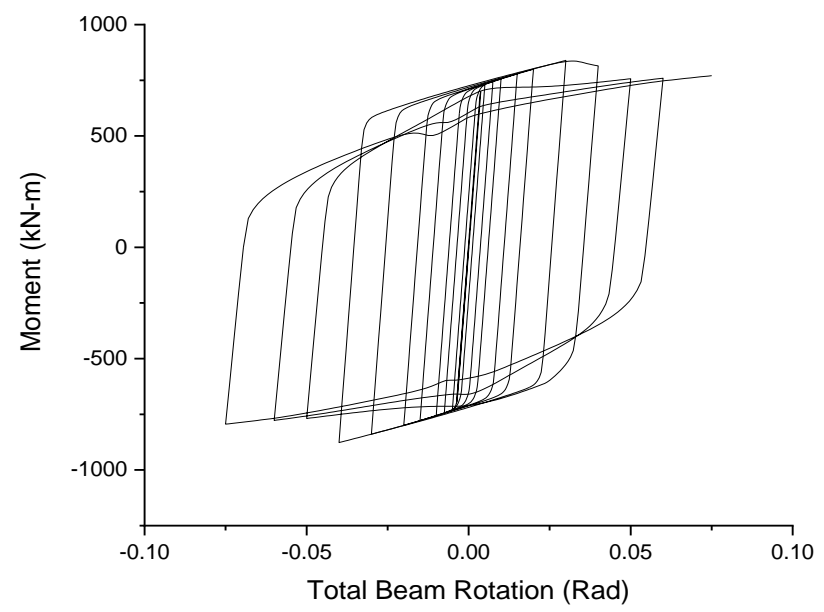

Figure 42: Experimental Moment vs Rotation Curve for RBS-36 


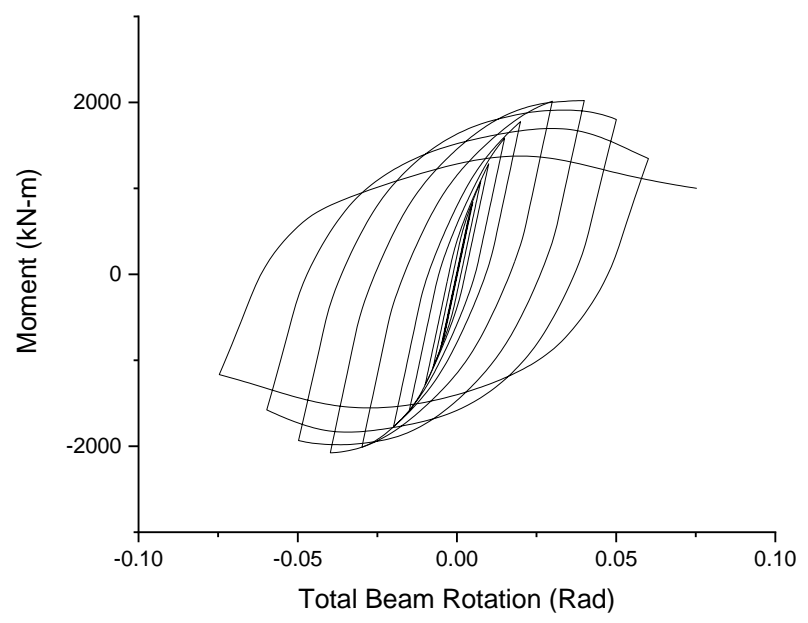

Figure 43: Experimental Moment vs Rotation Curve for RBS-37

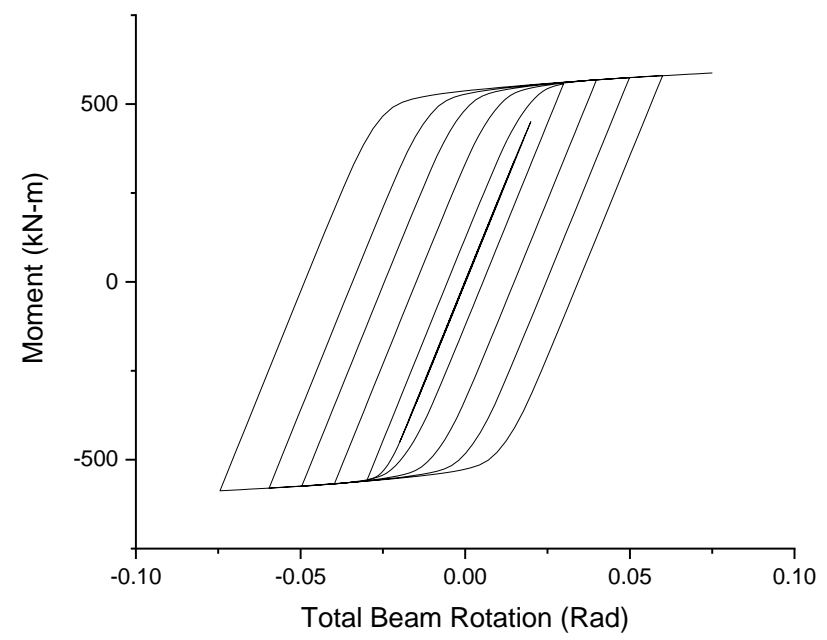

Figure 45: Experimental Moment vs Rotation Curve for RBS-39

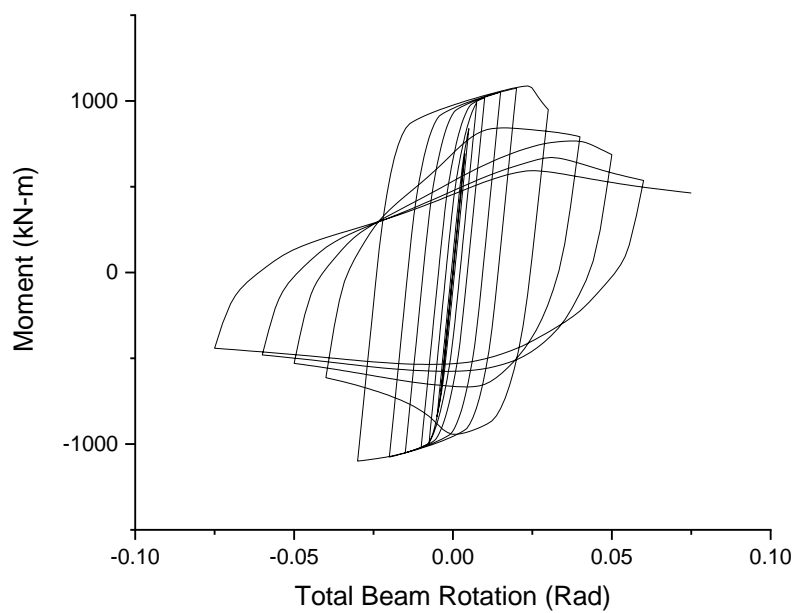

Figure 47: Experimental Moment vs Rotation Curve for RBS-41

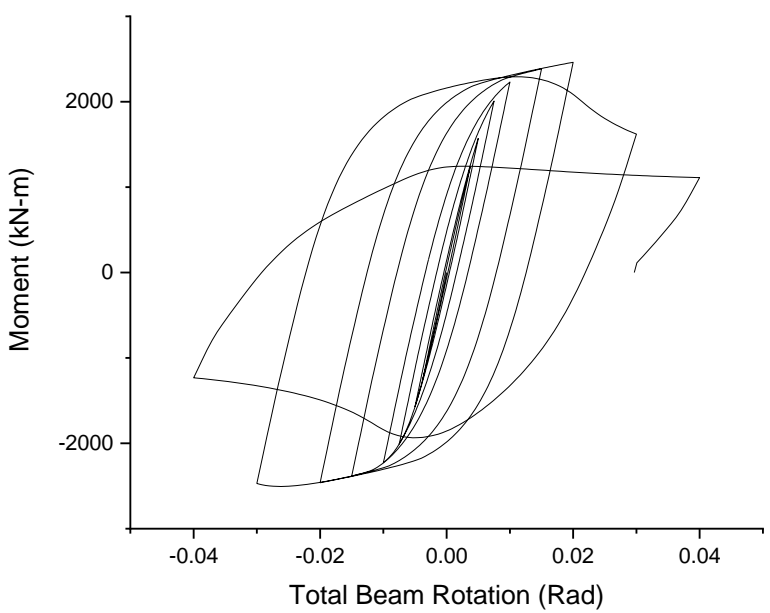

Figure 44: Experimental Moment vs Rotation Curve for RBS-38

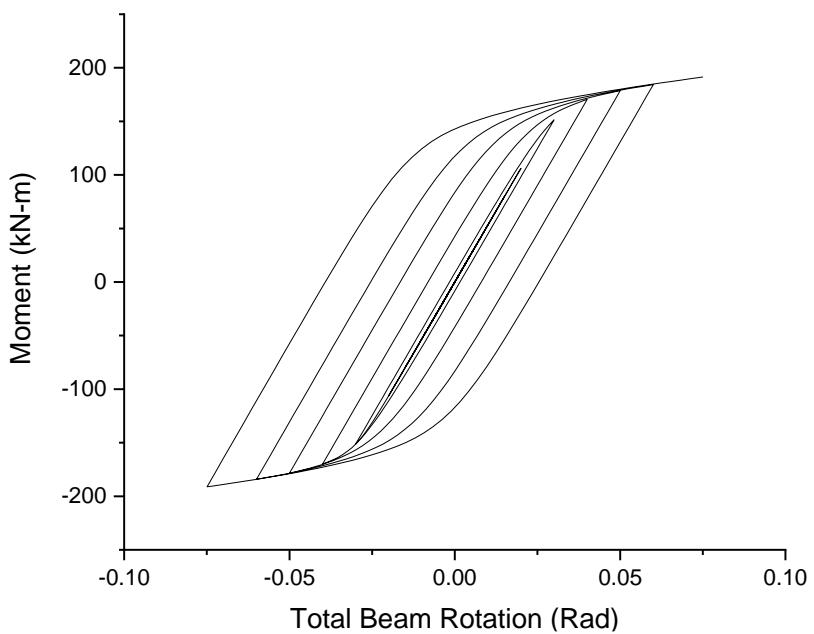

Figure 46: Experimental Moment vs Rotation Curve for RBS-40

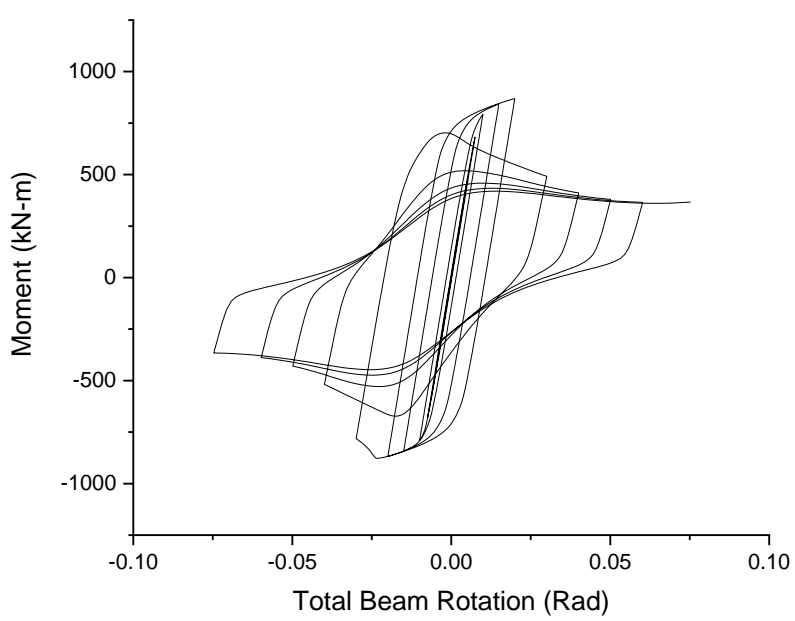

Figure 48: Experimental Moment vs Rotation Curve for RBS-42 


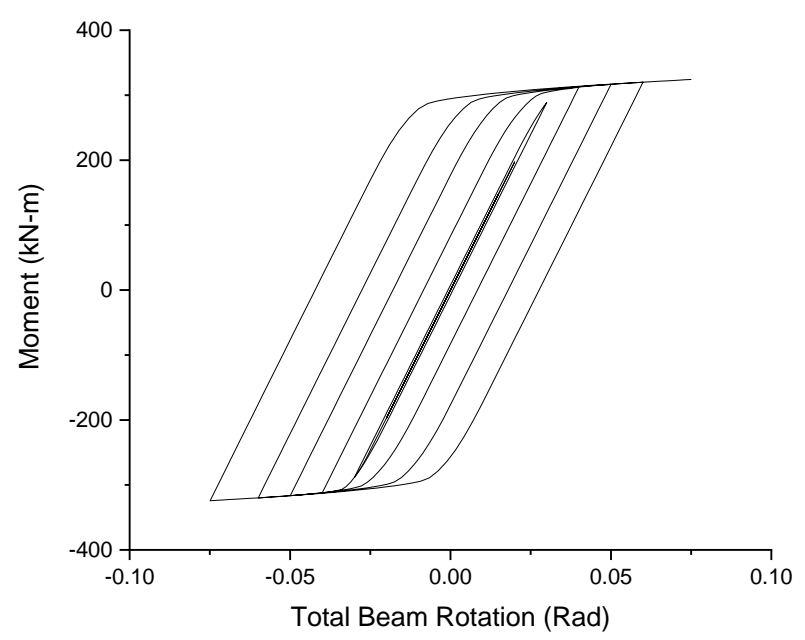

Figure 49: Experimental Moment vs Rotation Curve for RBS-43

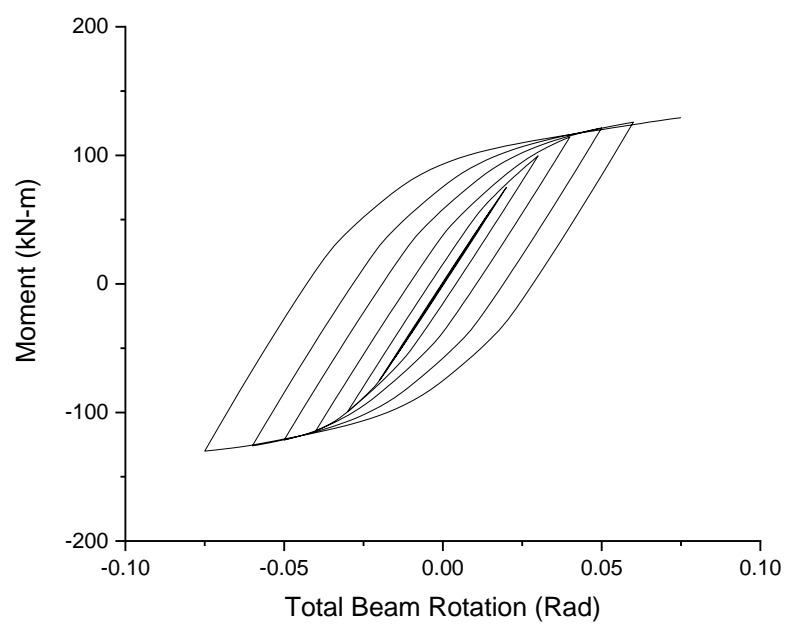

Figure 51: Experimental Moment vs Rotation Curve for RBS-45

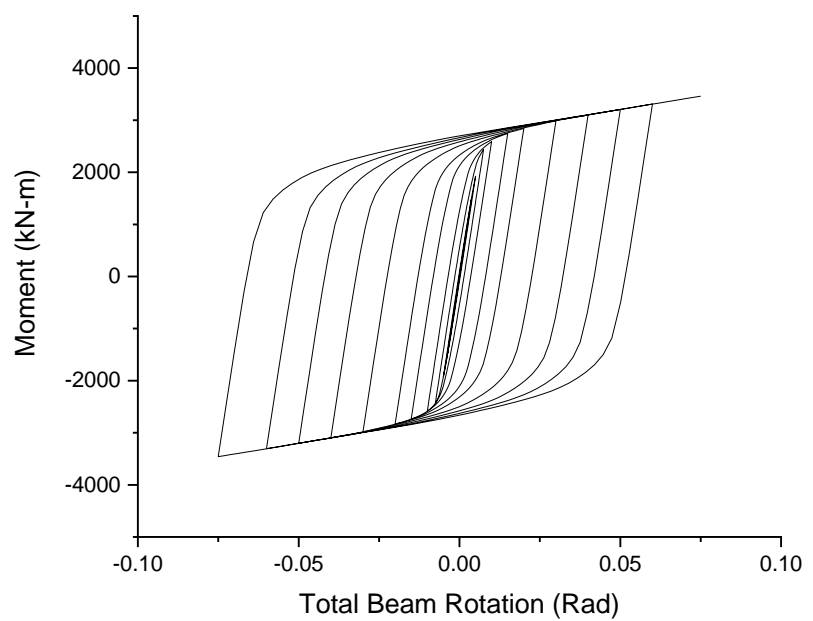

Figure 53: Experimental Moment vs Rotation Curve for RBS-47

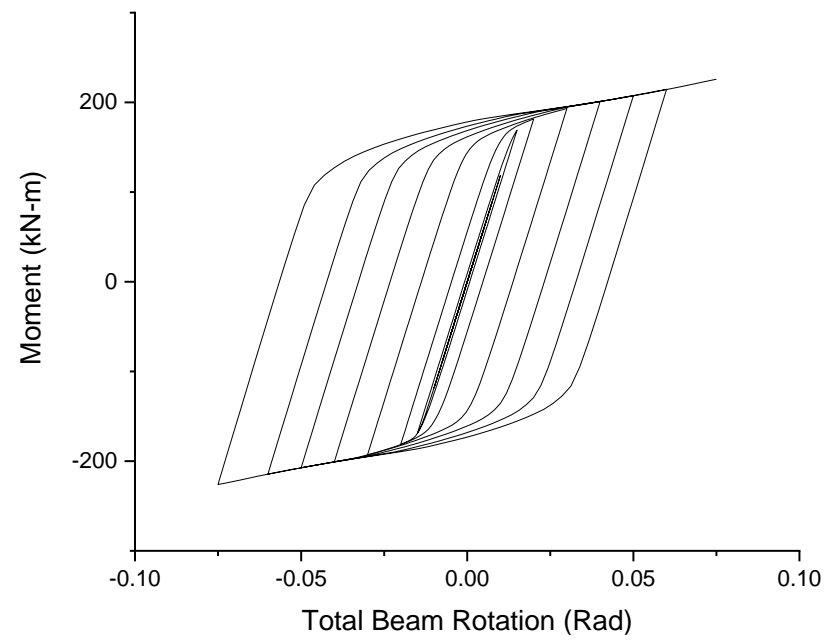

Figure 50: Experimental Moment vs Rotation Curve for RBS-44

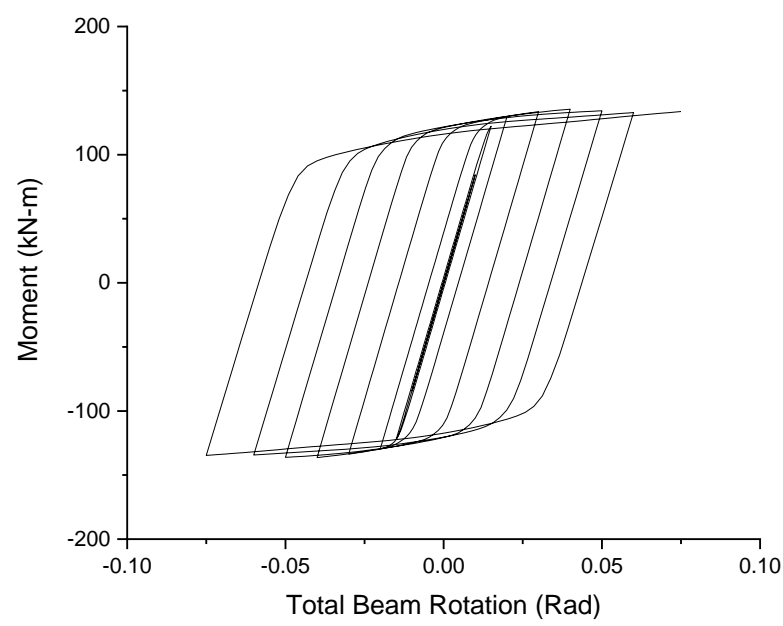

Figure 52: Experimental Moment vs Rotation Curve for RBS-46

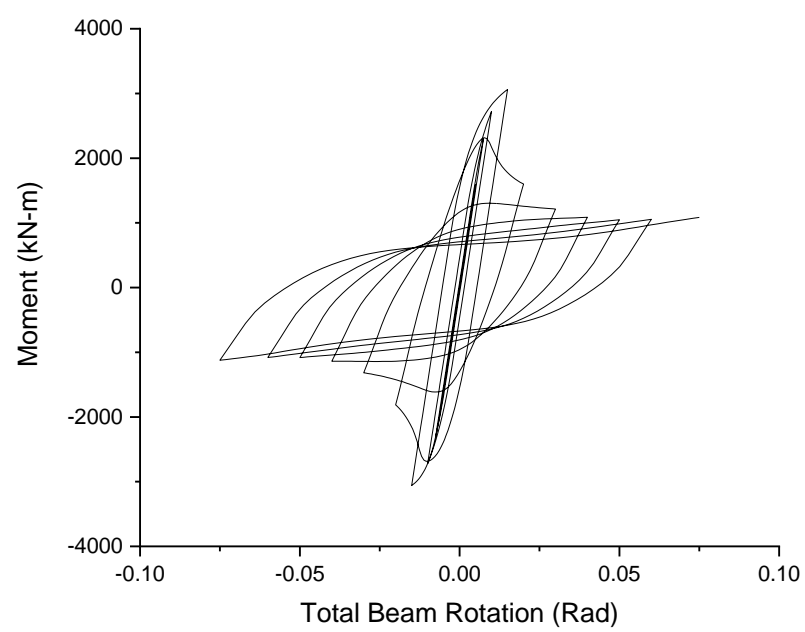

Figure 54: Experimental Moment vs Rotation Curve for RBS-48 


\section{CHAPTER - 5}

\section{RESULTS AND DISCUSSIONS}

\subsection{DEFLECTED GEOMETRIES OF FEA MODELS}

The post processing maximum deflection modes under the cyclic loading are presented in this section for specimen RBS-1 to RBS-5 whereas rest of the deflected geometries are presented in Appendix C.
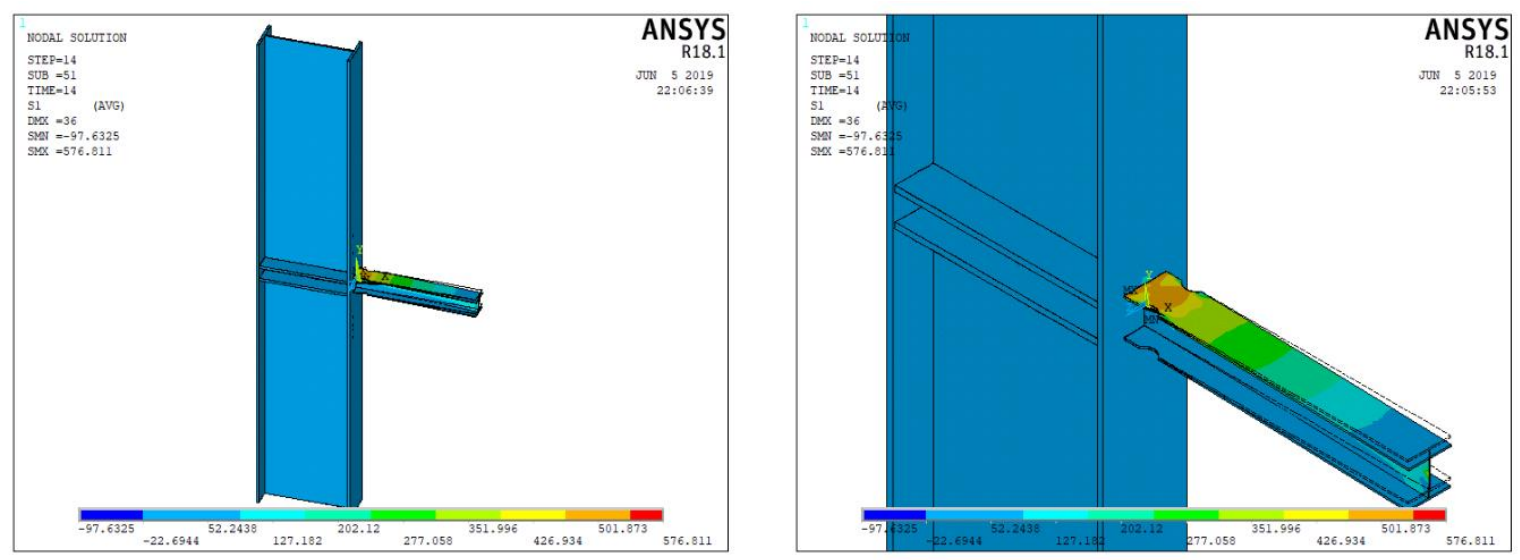

Figure 55: Deflected Geometry of Specimen RBS-1
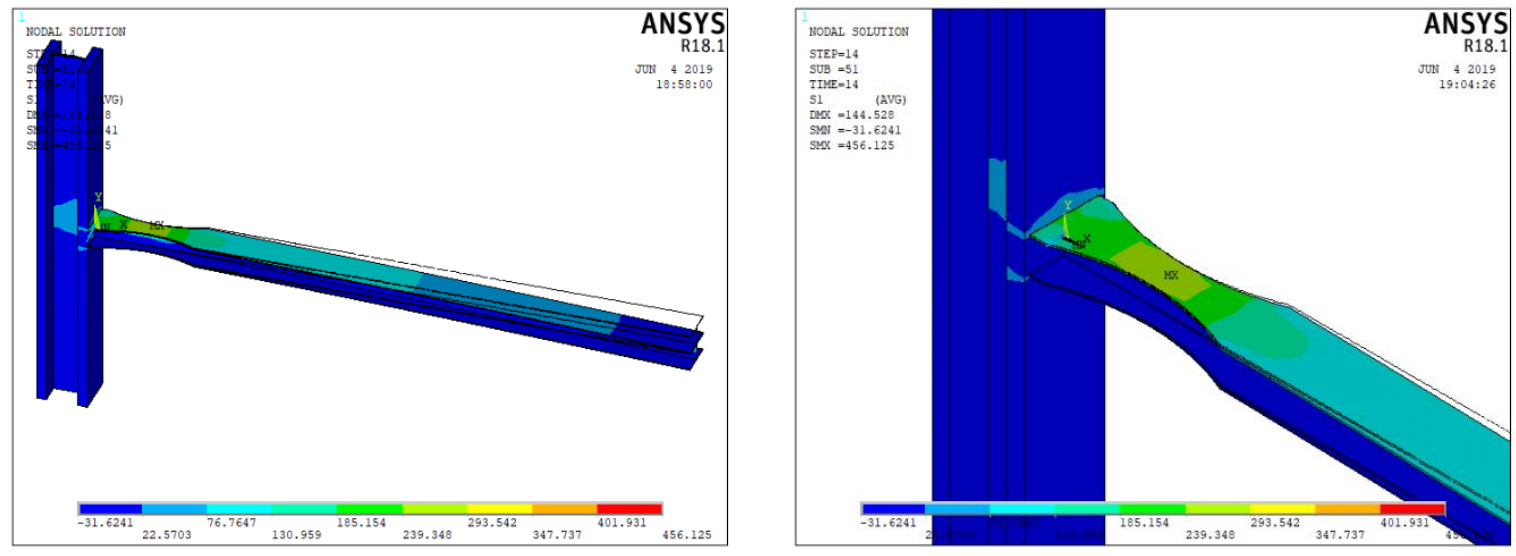

Figure 56: Deflected Geometry of Specimen RBS-2 

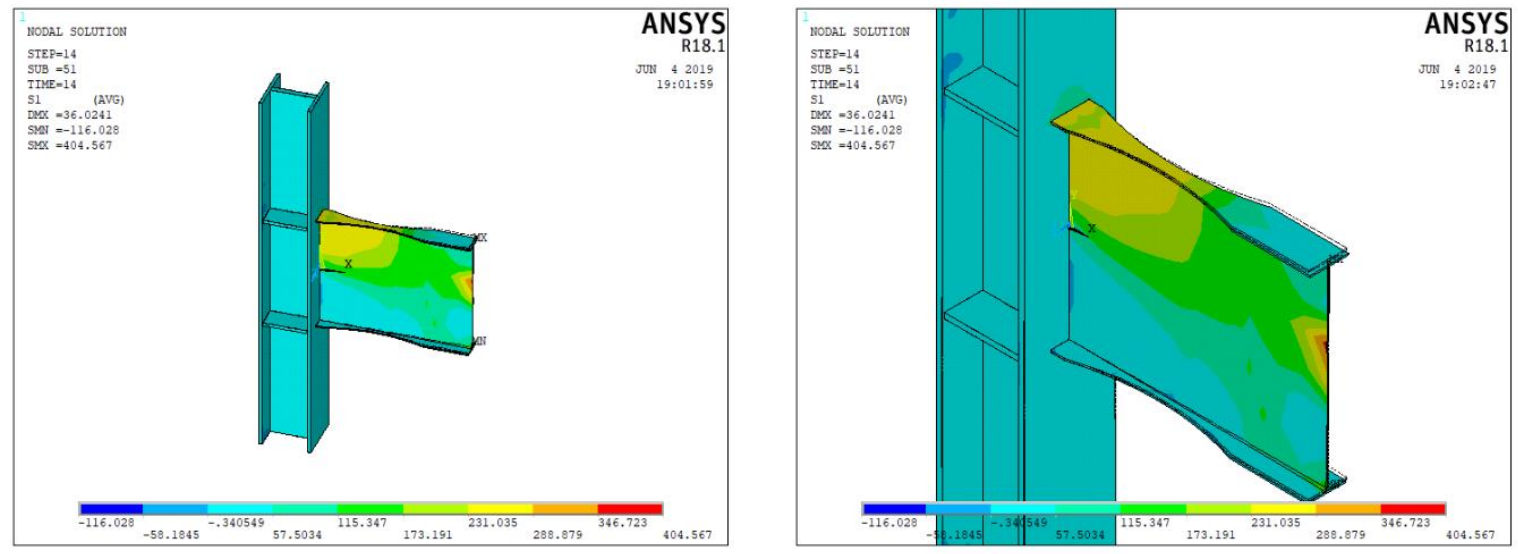

Figure 57: Deflected Geometry of Specimen RBS-3
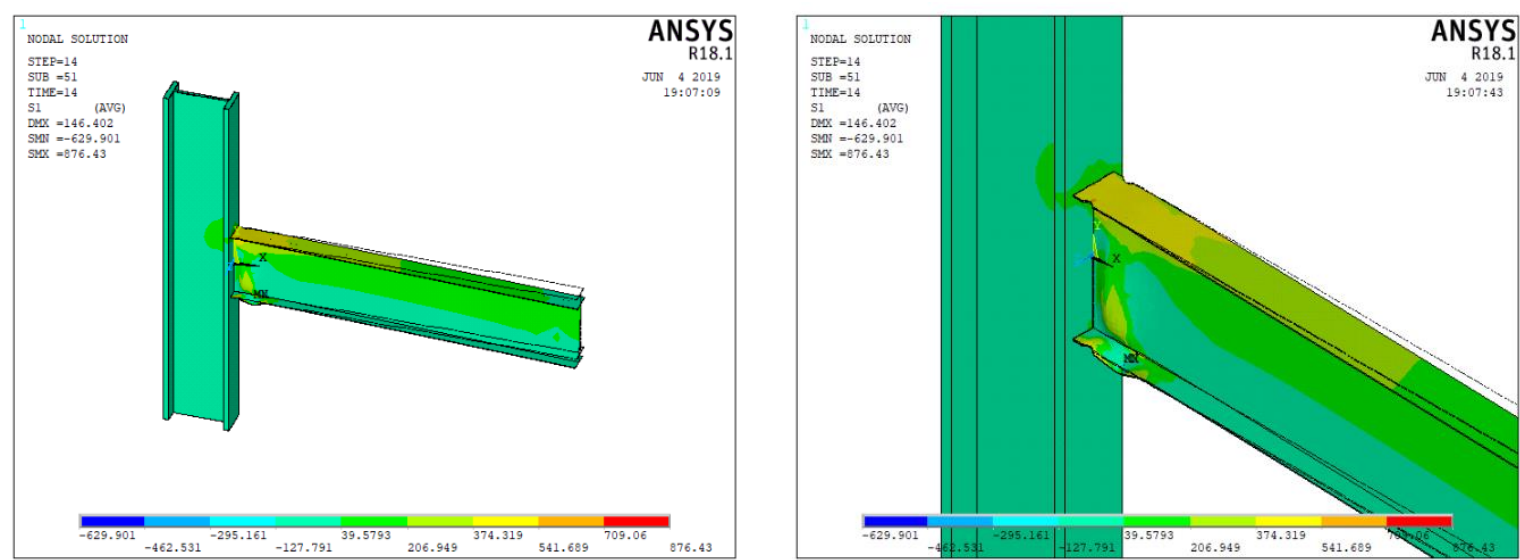

Figure 58: Deflected Geometry of Specimen RBS-4
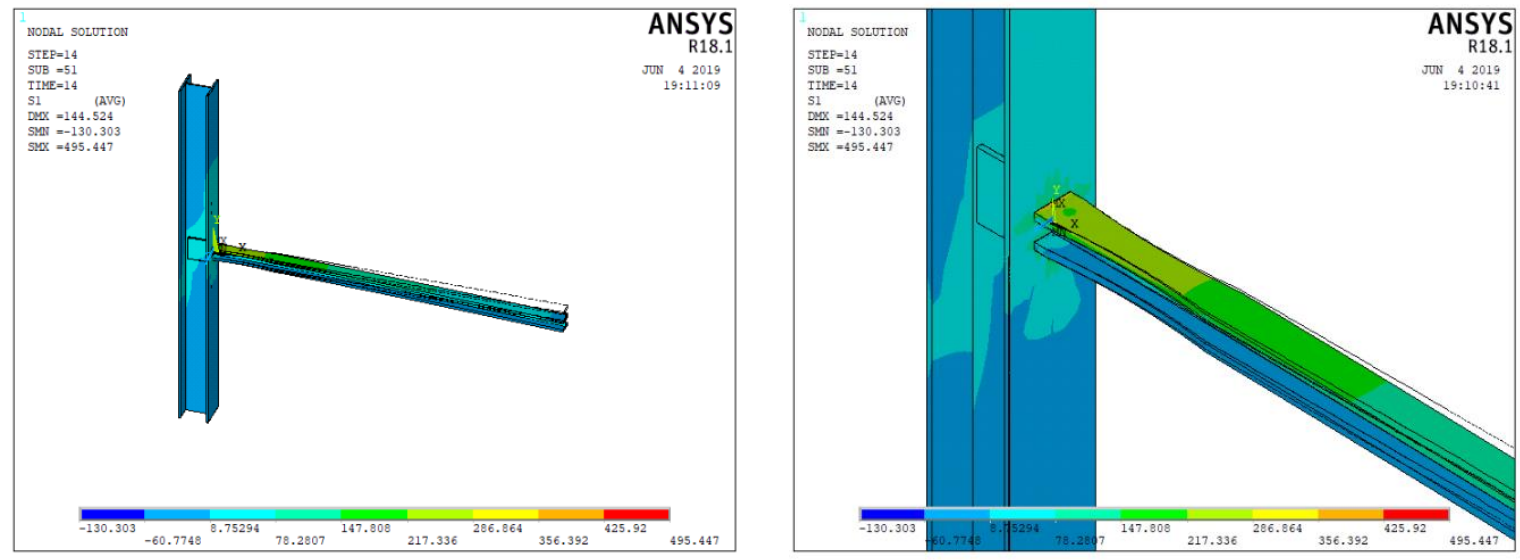

Figure 59: Deflected Geometry of Specimen RBS-5 


\subsection{OVERALL SENSITIVITY ANALYSIS OF EFFECTS}

The second phase of experiment using semi-foldover augmented design yielded the results that helped in understanding the effects of the significant factors independently. However, solution for model no. 38 was not able to converge beyond $4 \%$ total beam rotation because of excessive deformation as depicted in deflected geometry shown for RBS-38 presented in Appendix $\mathrm{C}$ of this document and therefore the results from this model were not included in the sensitivity analysis which was conducted for results yielded at $7.5 \%$ total beam rotation. These results are presented in Table $\mathbf{1 3}$ and the analysis of these results is discussed in the following sub-sections.

Table 13: Results from Both Phases of the Experiment

\begin{tabular}{|c|c|c|c|c|c|c|}
\hline Phase & Run & $\begin{array}{c}\text { Response } 1 \\
\text { R1 } \\
(\mathbf{k J} / \mathbf{m})\end{array}$ & $\begin{array}{c}\text { Response } 2 \\
\text { R2 } \\
(\mathrm{kN}-\mathrm{m})\end{array}$ & $\begin{array}{c}\text { Response } 3 \\
\text { R3 } \\
-\end{array}$ & $\begin{array}{c}\text { Response } 4 \\
\text { R4 } \\
(\mathrm{kN}-\mathrm{m})\end{array}$ & $\begin{array}{c}\text { Response } 5 \\
\text { R5 } \\
-\end{array}$ \\
\hline \multirow{23}{*}{ 站 } & 1 & 53.744 & 6032.00 & 1.029 & 96.331 & 1.480 \\
\hline & 2 & 28.733 & 2634.21 & 1.023 & 64.819 & 0.537 \\
\hline & 3 & 299.911 & 132416.00 & 1.027 & 520.700 & 3.312 \\
\hline & 4 & 636.742 & 136271.94 & 0.750 & 1529.446 & 4.925 \\
\hline & 5 & 55.679 & 5139.91 & 1.020 & 167.178 & 0.458 \\
\hline & 6 & 104.087 & 21856.00 & 1.078 & 208.470 & 0.351 \\
\hline & 7 & 1201.633 & 221208.99 & 1.085 & 2438.456 & 49.063 \\
\hline & 8 & 559.076 & 185504.00 & 1.061 & 897.390 & 0.947 \\
\hline & 9 & 25.400 & 2441.46 & 1.040 & 59.319 & 2.637 \\
\hline & 10 & 127.577 & 12720.00 & 1.018 & 228.254 & 1.896 \\
\hline & 11 & 366.872 & 154582.87 & 0.542 & 1572.385 & 1.084 \\
\hline & 12 & 2113.492 & 377648.00 & 1.036 & 3121.184 & 25.041 \\
\hline & 13 & 122.093 & 11360.00 & 1.021 & 232.639 & 0.944 \\
\hline & 14 & 79.684 & 8288.11 & 1.045 & 312.578 & 1.227 \\
\hline & 15 & 2472.888 & 368528.00 & 1.035 & 4130.528 & 16.181 \\
\hline & 16 & 1098.735 & 209322.94 & 1.048 & 1742.862 & 2.562 \\
\hline & 17 & 68.890 & 6576.00 & 1.015 & 116.932 & 1.359 \\
\hline & 18 & 31.896 & 2826.95 & 1.022 & 73.839 & 0.498 \\
\hline & 19 & 170.566 & 156176.00 & 0.831 & 773.075 & 58.061 \\
\hline & 20 & 509.016 & 124578.63 & 0.768 & 1268.414 & 0.486 \\
\hline & 21 & 66.276 & 5846.65 & 1.018 & 173.983 & 0.266 \\
\hline & 22 & 141.630 & 16080.00 & 1.050 & 285.936 & 0.369 \\
\hline & 23 & 1101.264 & 149892.70 & 1.056 & 2215.962 & 30.610 \\
\hline
\end{tabular}




\begin{tabular}{|c|c|c|c|c|c|c|}
\hline & 24 & 1248.835 & 213808.00 & 1.025 & 1643.977 & 0.837 \\
\hline & 25 & 25.042 & 2505.71 & 1.036 & 84.237 & 1.571 \\
\hline & 26 & 103.373 & 12464.00 & 0.987 & 204.624 & 1.182 \\
\hline & 27 & 250.751 & 181427.50 & 0.852 & 2320.633 & 0.767 \\
\hline & 28 & 1400.861 & 287000.47 & 1.050 & 2201.200 & 16.983 \\
\hline & 29 & 101.331 & 10576.00 & 1.047 & 250.613 & 3.782 \\
\hline & 30 & 92.819 & 8994.85 & 1.026 & 343.511 & 0.709 \\
\hline & 31 & 161.994 & 364496.00 & 1.040 & 2867.322 & 0.644 \\
\hline & 32 & 3256.290 & 465492.29 & 1.008 & 5391.878 & 3.480 \\
\hline \multirow{16}{*}{$\begin{array}{l}\text { N } \\
\text { 焉 } \\
\frac{1}{2} \\
2\end{array}$} & 33 & 70.604 & 9125.393 & 1.044 & 155.137 & 0.201 \\
\hline & 34 & 14.541 & 1477.725 & 1.057 & 32.388 & 0.595 \\
\hline & 35 & 2366.737 & 318160.595 & 1.068 & 4398.024 & 12.987 \\
\hline & 36 & 215.763 & 202092.632 & 1.034 & 850.961 & 0.572 \\
\hline & 37 & 1089.375 & 173825.065 & 1.024 & 2076.996 & 0.070 \\
\hline & 38 & $\mathrm{~N} / \mathrm{C}$ & $\mathrm{N} / \mathrm{C}$ & $\mathrm{N} / \mathrm{C}$ & $\mathrm{N} / \mathrm{C}$ & $\mathrm{N} / \mathrm{C}$ \\
\hline & 39 & 260.534 & 22704.000 & 1.013 & 587.581 & 0.425 \\
\hline & 40 & 55.198 & 5332.659 & 1.035 & 191.388 & 1.093 \\
\hline & 41 & 552.845 & 187136.000 & 0.963 & 1099.554 & 5.738 \\
\hline & 42 & 327.202 & 93612.980 & 0.597 & 877.413 & 0.719 \\
\hline & 43 & 110.662 & 9894.332 & 1.012 & 324.281 & 0.164 \\
\hline & 44 & 117.412 & 11872.000 & 1.031 & 225.931 & 3.176 \\
\hline & 45 & 39.624 & 3790.686 & 1.037 & 130.061 & 1.491 \\
\hline & 46 & 82.014 & 8432.000 & 1.019 & 136.350 & 1.858 \\
\hline & 47 & 2365.757 & 403488.000 & 1.037 & 3460.198 & 3.543 \\
\hline & 48 & 727.069 & 318353.342 & 0.401 & 3061.107 & 3.110 \\
\hline
\end{tabular}

N/C: Solution not Converged 


\subsubsection{For Response Variable R1 (Total Dissipated Energy)}

The final predictive model for response variable R1 having a coefficient of determination $\left(\mathrm{R}^{2}\right)$ of 0.9552 can be written as a coded equation as follows:

$$
\begin{aligned}
R 1=\beta_{0}+\beta_{1} A & +\beta_{2} B+\beta_{3} C+\beta_{4} D+\beta_{5} E+\beta_{6} F+\beta_{7} J+\beta_{8} K+\beta_{9} L+\beta_{10} M \\
& +\beta_{11} O+\beta_{12} Q+\beta_{13} S+\beta_{14} U+\beta_{15} A B+\beta_{16} A C+\beta_{17} A D \\
& +\beta_{18} A E+\beta_{19} A J+\beta_{20} A Q+\beta_{21} A S+\beta_{22} A U+\beta_{23} B C+\beta_{24} B D \\
& +\beta_{25} A B D
\end{aligned}
$$

Where values of all $\beta$ are given in Table 14.

Table 14: Coefficients of Model for Response R1

\begin{tabular}{|l|r|l|r|}
\hline Coefficient & Value & Coefficient & Value \\
\hline$\beta_{0}$ & 561.98717 & $\beta_{13}$ & -11.273586 \\
\hline$\beta_{1}$ & 159.37976 & $\beta_{14}$ & -4.9423484 \\
\hline$\beta_{2}$ & 482.62068 & $\beta_{15}$ & 143.48346 \\
\hline$\beta_{3}$ & 197.77191 & $\beta_{16}$ & -31.268507 \\
\hline$\beta_{4}$ & 142.40859 & $\beta_{17}$ & 150.46106 \\
\hline$\beta_{5}$ & -21.259977 & $\beta_{18}$ & 146.52183 \\
\hline$\beta_{6}$ & -105.44805 & $\beta_{19}$ & -104.8402 \\
\hline$\beta_{7}$ & 11.51335 & $\beta_{20}$ & 139.90719 \\
\hline$\beta_{8}$ & 117.68004 & $\beta_{21}$ & 133.77843 \\
\hline$\beta_{9}$ & 109.03266 & $\beta_{22}$ & 136.5399 \\
\hline$\beta_{10}$ & 177.22434 & $\beta_{23}$ & 165.66373 \\
\hline$\beta_{11}$ & 170.20163 & $\beta_{24}$ & 131.96968 \\
\hline$\beta_{12}$ & -16.828696 & $\beta_{25}$ & 145.24099 \\
\hline
\end{tabular}

The half-normal plot (Figure 60) and Pareto chart (Figure 61) show the marginal significance of factor B over all other factors with a contribution of $35.47 \%$. A graphical representation of the percentage contribution of factors in the energy dissipation is also presented in Figure 62. 

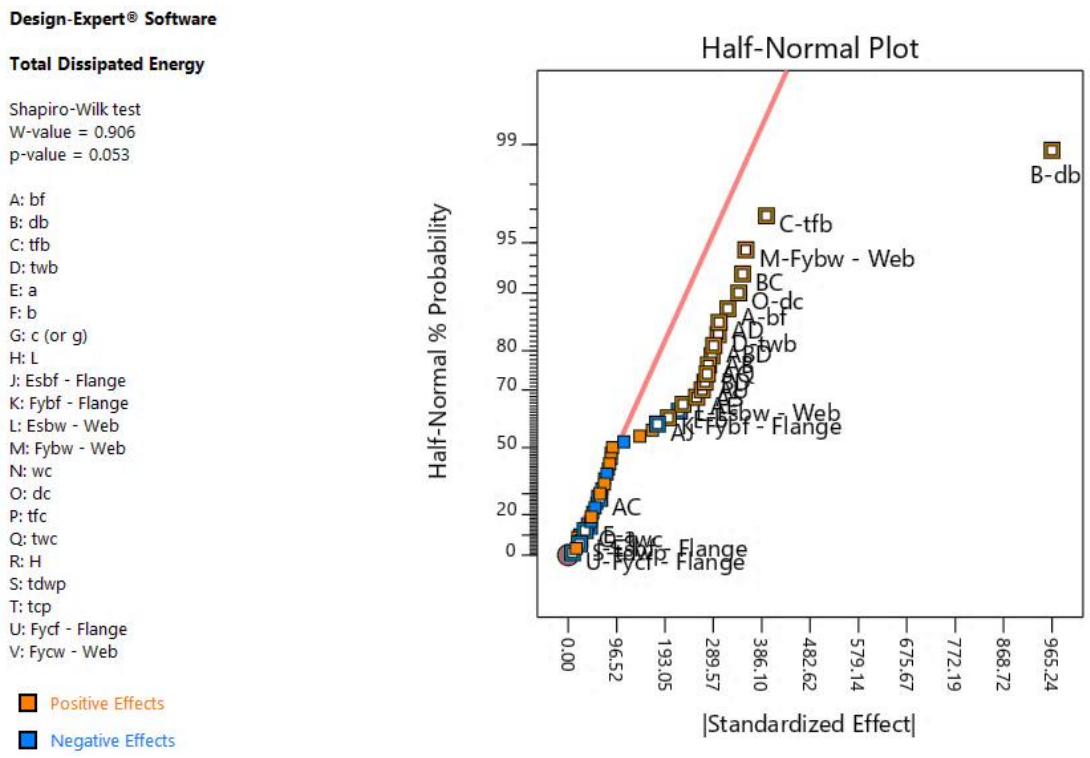

Figure 60: Half-Normal Probability Plot for Response R1 (Total Dissipated Energy)

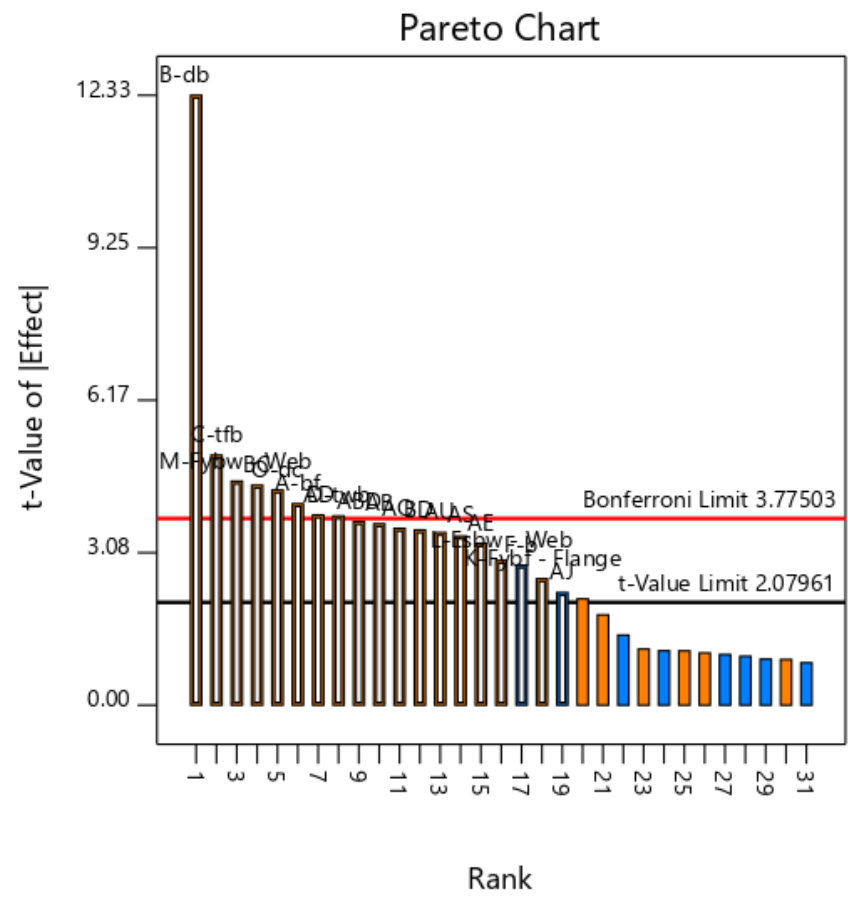

Figure 61: Pareto Chart for Response R1 (Total Dissipated Energy) 


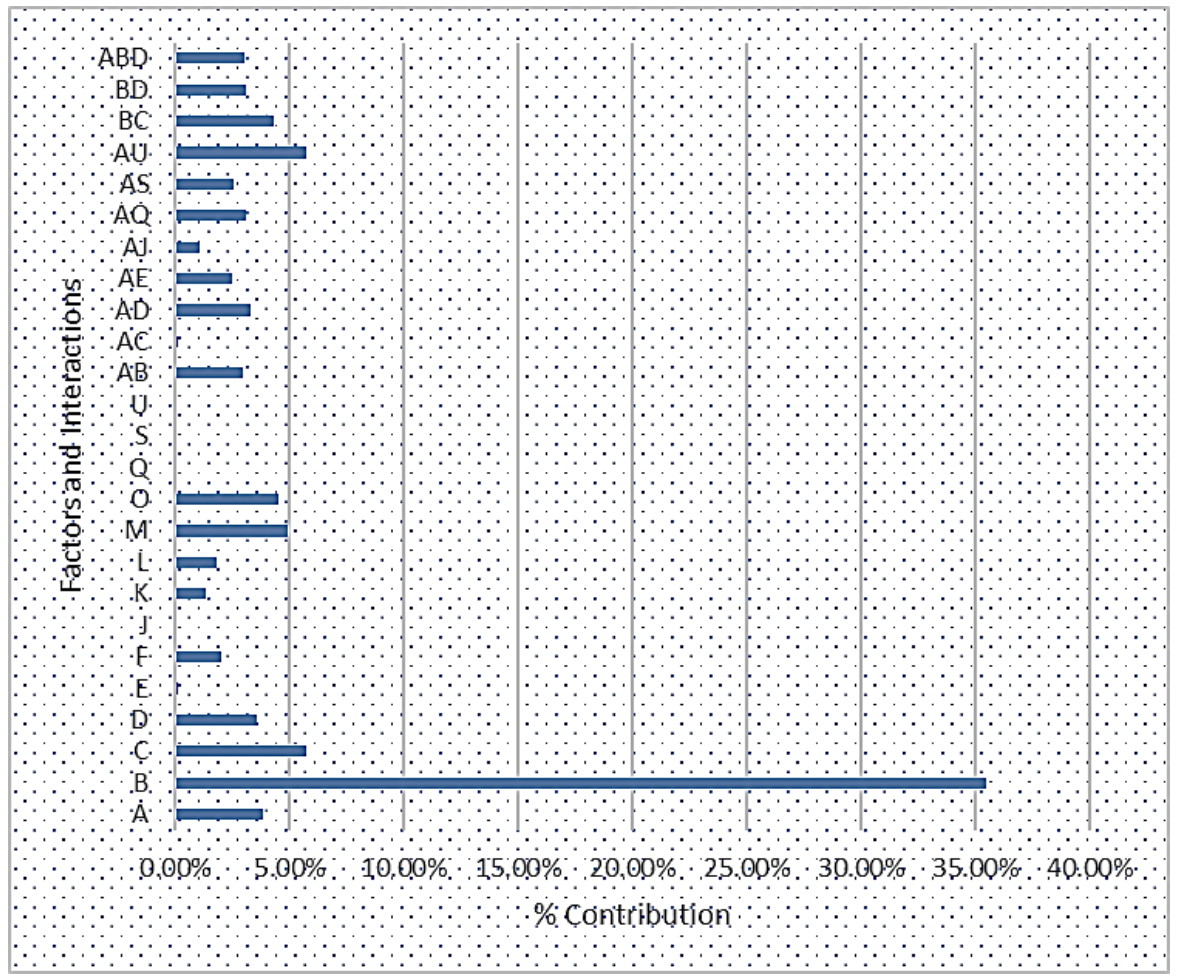

Figure 62: Percentage Contributions of Factors and Interactions on Response R1

The Analysis of Variance for the selected model confirmed the acute sensitivity of the response $\mathrm{R} 1$ to the factor $\mathrm{B}$ with the highest F-value of 152.09. It is also to be noted that factors with considerably lower F-values like factors E, J, Q, S and U were included in the model just to maintain hierarchy i.e. it can be seen by the ANOVA presented in Table 15 that factor Q has an F-Value as small as 0.1849 was included in the model because the 2FI AQ had a higher F-Value of 12.78. 
Table 15: ANOVA of Selected Model for Response R1

\begin{tabular}{|c|c|c|c|c|c|c|}
\hline SOURCE & $\begin{array}{l}\text { SUM OF } \\
\text { SQUARES }\end{array}$ & $\mathrm{df}$ & $\begin{array}{l}\text { MEAN } \\
\text { SQUARE }\end{array}$ & F-VALUE & P-VALUE & \\
\hline Block & 278.5705278 & 1 & 278.5705278 & & & \\
\hline Model & 27298838.08 & 25 & 1091953.523 & 17.04637 & 0.00000 & Significant \\
\hline A-bf & 1062563.529 & 1 & 1062563.529 & 16.58756 & 0.00059 & \\
\hline B-db & 9743172.77 & 1 & 9743172.77 & 152.09959 & 0.00000 & \\
\hline C-tfb & 1636129.879 & 1 & 1636129.879 & 25.54144 & 0.00006 & \\
\hline D-twb & 936009.5962 & 1 & 936009.5962 & 14.61194 & 0.00106 & \\
\hline E-a & 18906.63028 & 1 & 18906.63028 & 0.29515 & 0.59294 & \\
\hline F-b & 513198.0269 & 1 & 513198.0269 & 8.01148 & 0.01034 & \\
\hline J-Esbf - Flange & 5544.877806 & 1 & 5544.877806 & 0.08656 & 0.77163 & \\
\hline K-Fybf - Flange & 418070.7193 & 1 & 418070.7193 & 6.52646 & 0.01889 & \\
\hline L-Esbw - Web & 548682.526 & 1 & 548682.526 & 8.56542 & 0.00834 & \\
\hline M-Fybw - Web & 1313818.158 & 1 & 1313818.158 & 20.50987 & 0.00020 & \\
\hline $\mathrm{O}-\mathrm{dc}$ & 1211758.159 & 1 & 1211758.159 & 18.91662 & 0.00031 & \\
\hline Q-twc & 11846.48428 & 1 & 11846.48428 & 0.18493 & 0.67176 & \\
\hline S-tdwp & 5316.339209 & 1 & 5316.339209 & 0.08299 & 0.77625 & \\
\hline U-Fycf - Flange & 781.6578462 & 1 & 781.6578462 & 0.01220 & 0.91314 & \\
\hline $\mathrm{AB}$ & 861176.6211 & 1 & 861176.6211 & 13.44373 & 0.00153 & \\
\hline$\overline{A C}$ & 40898.07153 & 1 & 40898.07153 & 0.63846 & 0.43366 & \\
\hline$\overline{\mathrm{AD}}$ & 946971.1925 & 1 & 946971.1925 & 14.78306 & 0.00101 & \\
\hline$\overline{\mathrm{AE}}$ & 686996.6958 & 1 & 686996.6958 & 10.72463 & 0.00379 & \\
\hline AJ & 331817.8826 & 1 & 331817.8826 & 5.17997 & 0.03400 & \\
\hline AQ & 818782.5769 & 1 & 818782.5769 & 12.78192 & 0.00189 & \\
\hline AS & 748618.8323 & 1 & 748618.8323 & 11.68661 & 0.00272 & \\
\hline $\mathrm{AU}$ & 779843.9247 & 1 & 779843.9247 & 12.17406 & 0.00231 & \\
\hline $\mathrm{BC}$ & 1266667.955 & 1 & 1266667.955 & 19.77381269 & 0.000247666 & \\
\hline $\mathrm{BD}$ & 803815.1853 & 1 & 803815.1853 & 12.54826953 & 0.002044335 & \\
\hline ABD & 882402.8955 & 1 & 882402.8955 & 13.77509354 & 0.001379823 & \\
\hline Residual & 1281157.028 & 20 & 64057.85142 & & & \\
\hline Cor Total & 28580273.68 & 46 & & & & \\
\hline
\end{tabular}

The effect of interaction between factor A and B on the total dissipated energy as shown in Figures 63 and 64 demonstrated that the total dissipated energy was increased by $81.7 \%$ as values of factor A (bf) was increased from low-level to highlevel at low-level value of factor B (db). For high-level value of factor B, the rise in total dissipated energy was dropped from $81.7 \%$ to $50.1 \%$ with increase in the 
value of factor A from low to high-level. That indicates sensitivity of effect of factor A on energy dissipation towards the value of factor B.

Design-Expert ${ }^{\circledR}$ Software
Factor Coding: Actual
Total Dissipated Energy $(\mathbf{k J} / \mathbf{m})$
X1 $=$ A: bf
X2 $=$ B: db
Actual Factors
C: tfb $=20.995$
D: twb $=12.66$
E: $a=147.3$
F: $b=425.875$
G: $c$ (or g) $=41.25$
H: $L=3008$
J: Esbf - Flange $=198500$
K: Fybf - Flange $=342.5$
L: Esbw - Web $=198500$
M: Fybw - Web $=342.5$
N: wC $=389.89$
O: dc $=659.13$
P: tfc $=48.58$
Q: twc $=30.165$
R: $H=4000$
S: tdwp $=12.5$
T: tcp $=12.5$
U: Fycf - Flange $=332.5$
V: Fycw - Web $=332.5$

$\square$ B- 160
$\Delta \quad$ B +927.1

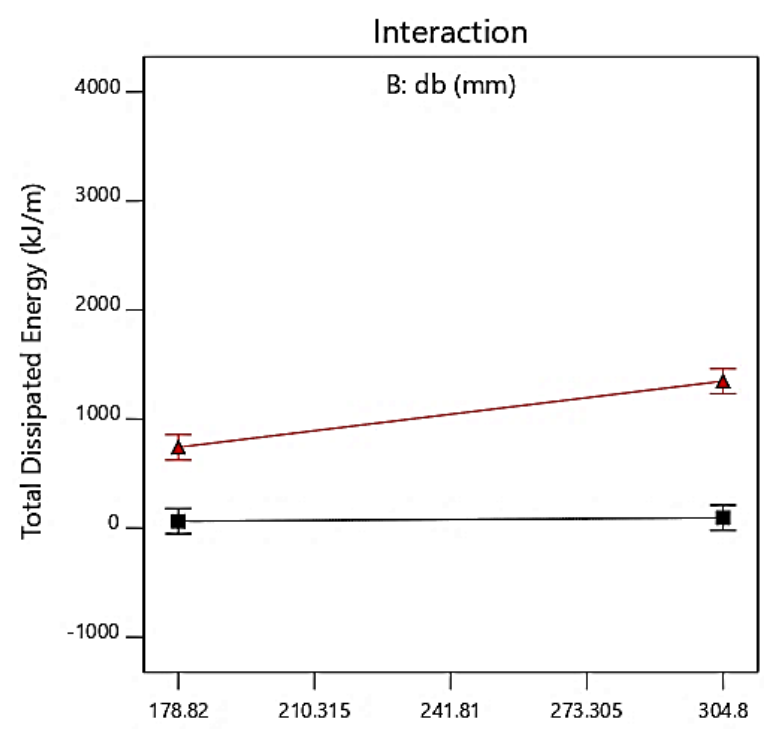

Figure 63: Plot of Marginal Means for Interaction AB in Selected Model for Response R1
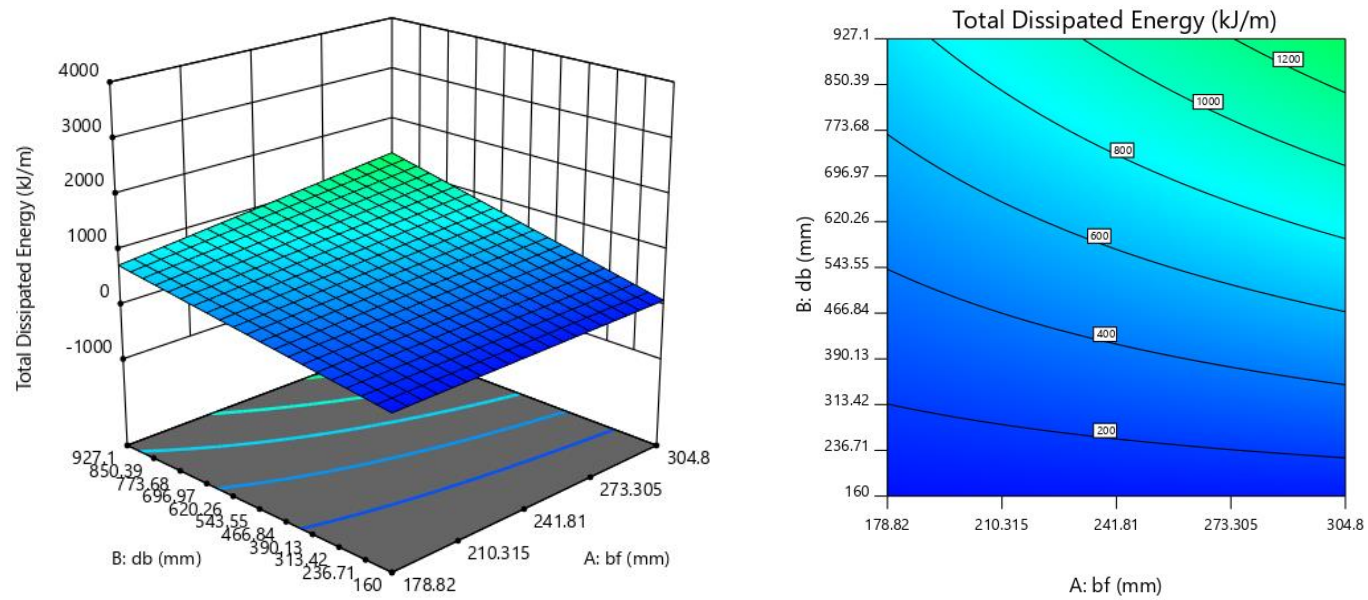

Figure 64: 3D Response Surface and Contour Plots for 2FI AB in Selected Model for Response R1 
On the other hand, the $2 \mathrm{FI}$ interaction between factor $\mathrm{A}$ and $\mathrm{C}$ provides evidence that the total energy dissipation was increased at a lower rate (by 40.56\%) with the increase in value of factor A (bf) at low-level value of factor $\mathrm{C}(\mathrm{tfb})$ as compared to the rate, it rise with the increase in value of factor $A$ at high-level value of factor C (219.68\%) as presented in Figures 65 and 66. In other words, factor C has an inverse relation with effect of factor A on total energy dissipation.
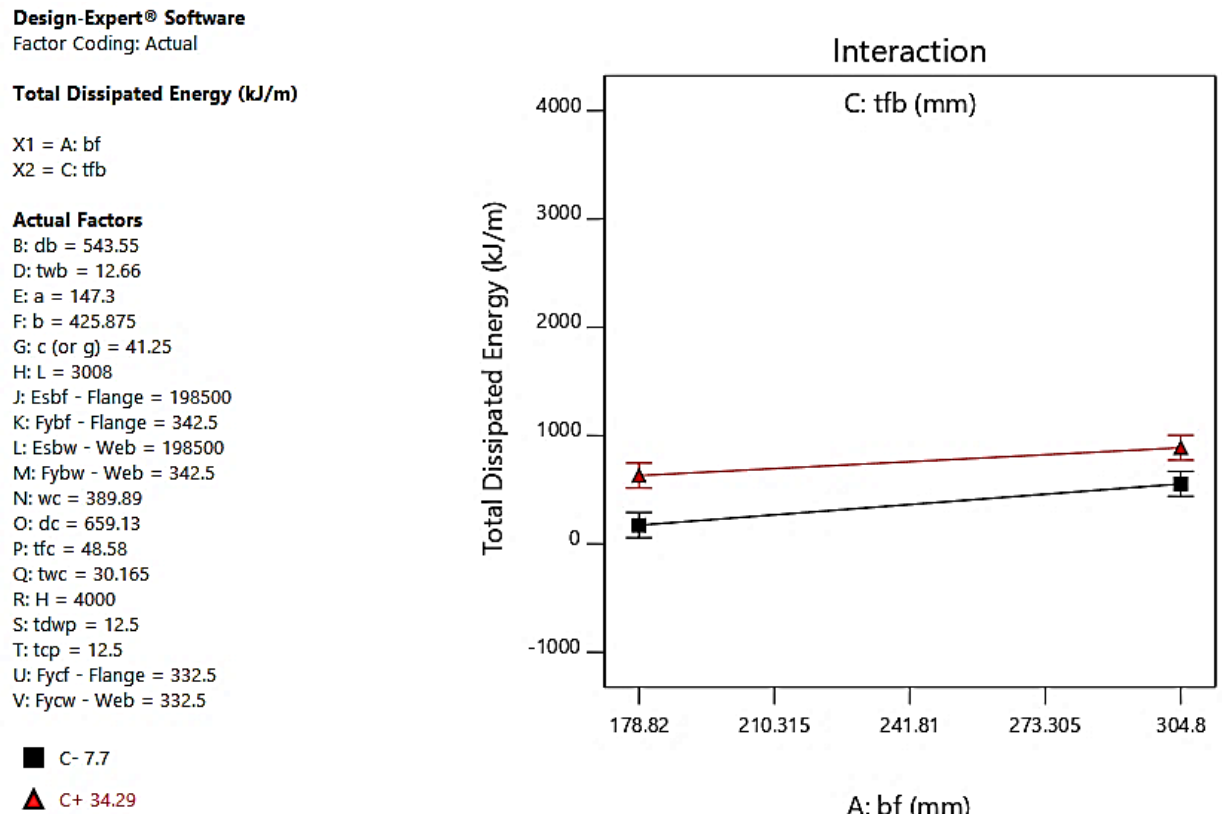

$\Delta \mathrm{C}+34.29$

A: bf $(\mathrm{mm})$

Figure 65: Plot of Marginal Means for Interaction AC in Selected Model for Response R1
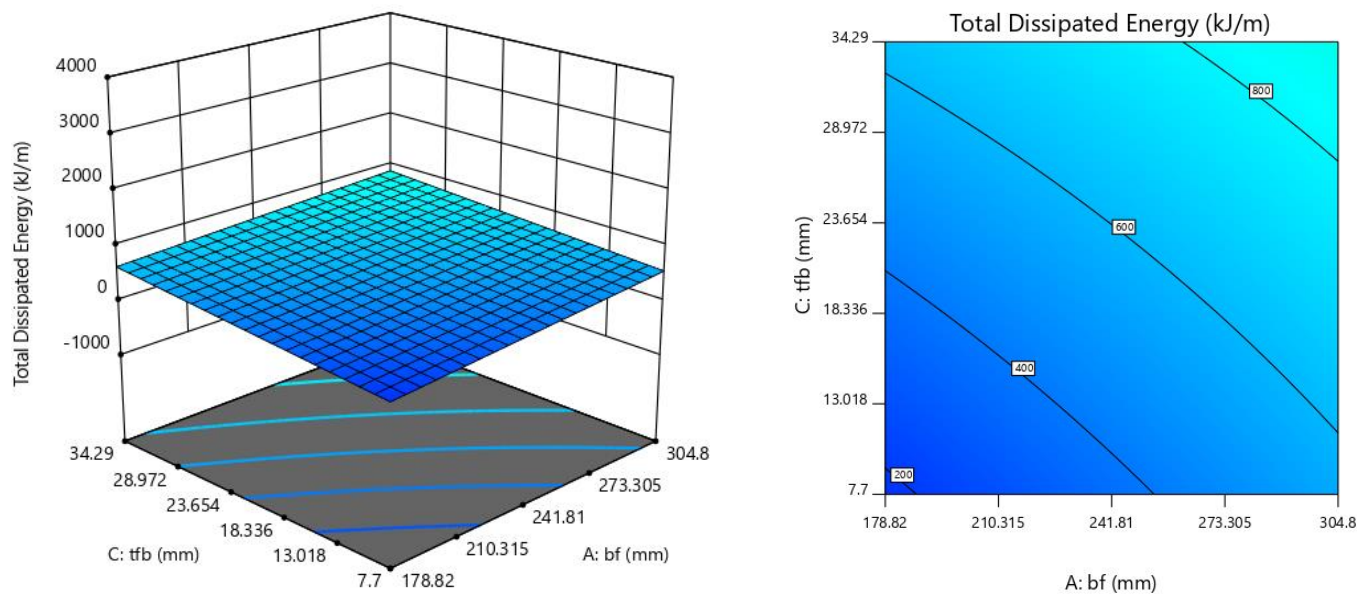

Figure 66: 3D Response Surface and Contour Plots for 2FI AC in Selected Model for Response R1 
Interaction between factors $\mathrm{A}$ and $\mathrm{D}$ was found to be similar to but more sensitive than that of factors $\mathrm{A}$ and $\mathrm{B}$, i.e. increase in value of factor A resulted in an increase in the total dissipated energy by $150 \%$ at a high-level value of factor $\mathrm{D}$ while this rate was decreased to $4.34 \%$ for a rise in total dissipated energy with a rise in the value of factor A from low-level to high-level as shown in Figures 67 and 68.
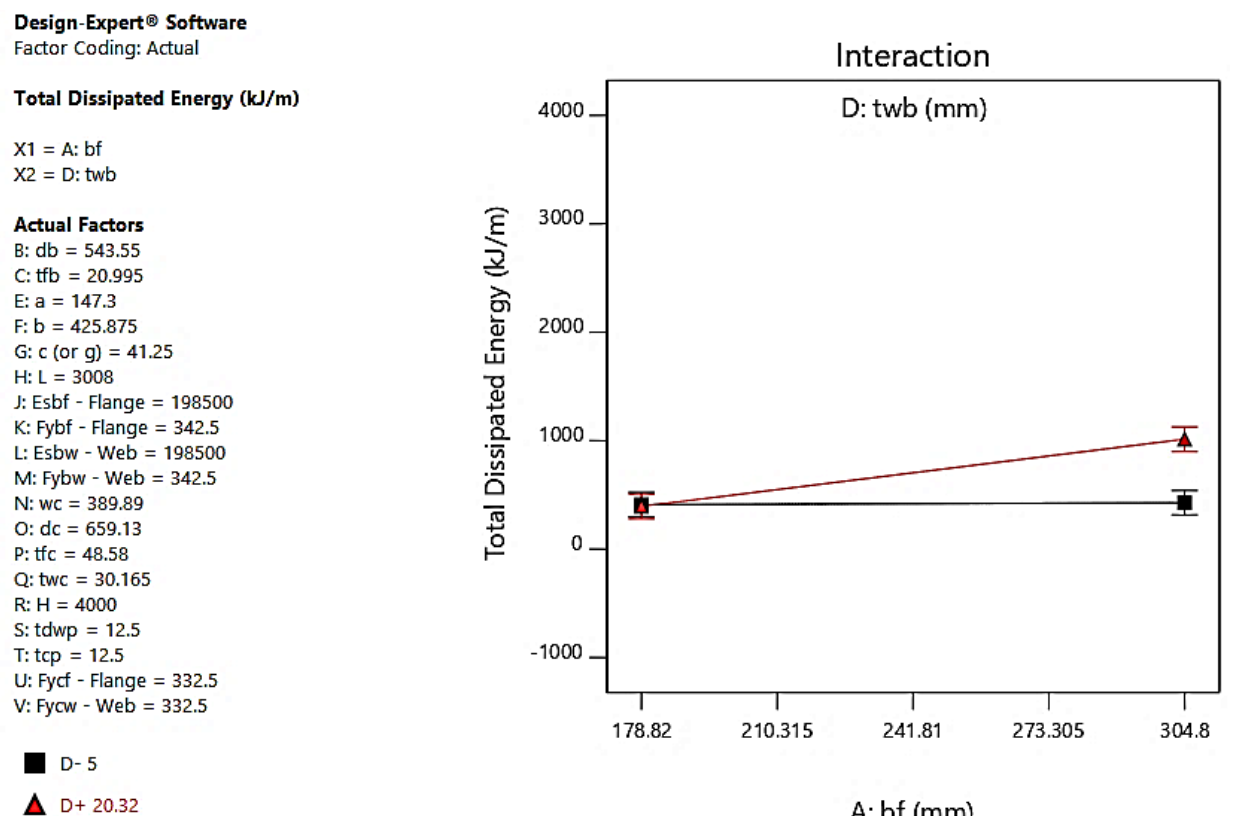

Figure 67: Plot of Marginal Means for Interaction AD in Selected Model for Response R1
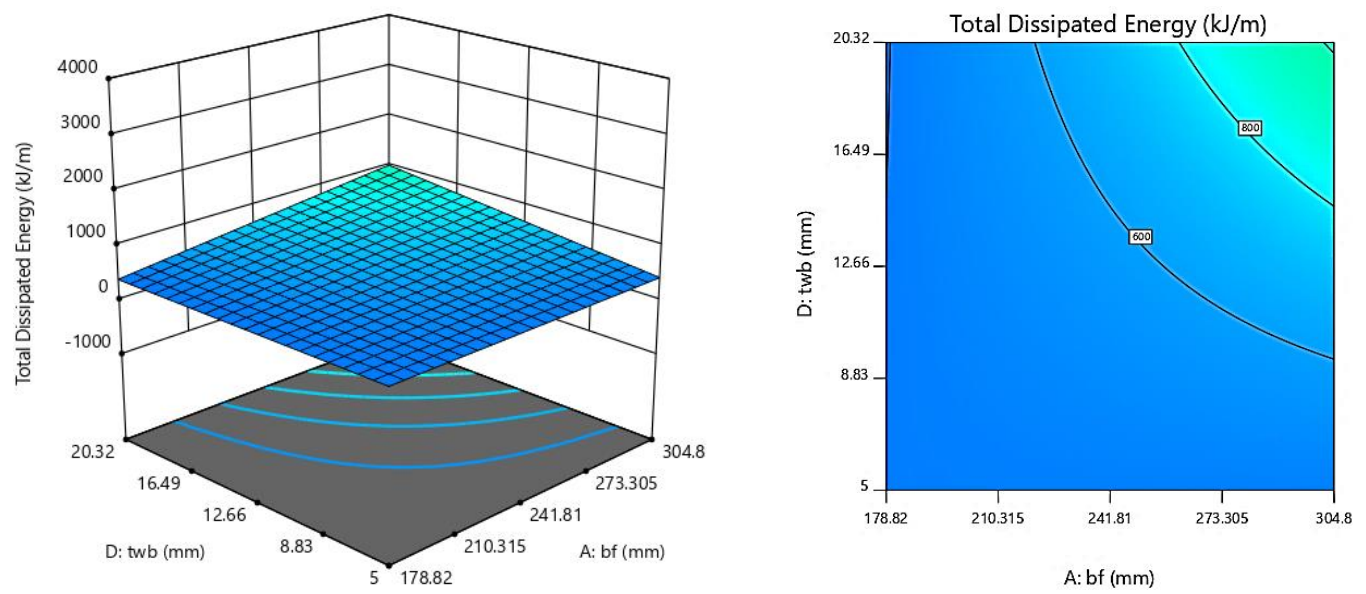

Figure 68: 3D Response Surface and Contour Plots for 2FI AD in Selected

Model for Response R1 
The interaction AQ in Figures 69 and 70 had shown a direct relation of value of factor Q (twc) on the effect of value of factor A on total dissipated energy as increasing the value of factor A from low-level to high-level increases total dissipated energy by $6.96 \%$ at low-level value of factor Q and by $243.45 \%$ at highlevel value of factor $\mathrm{Q}$.
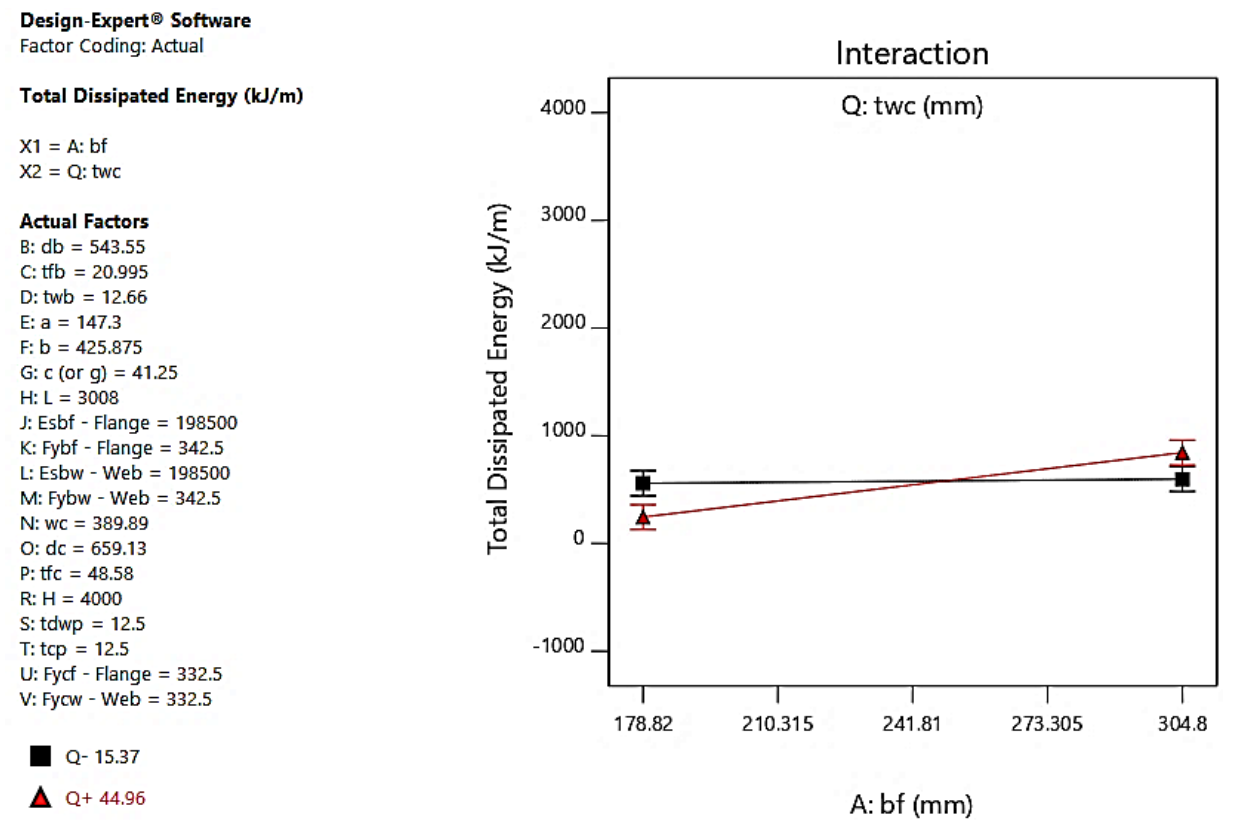

Figure 69: Plot of Marginal Means for Interaction AQ in Selected Model for Response R1
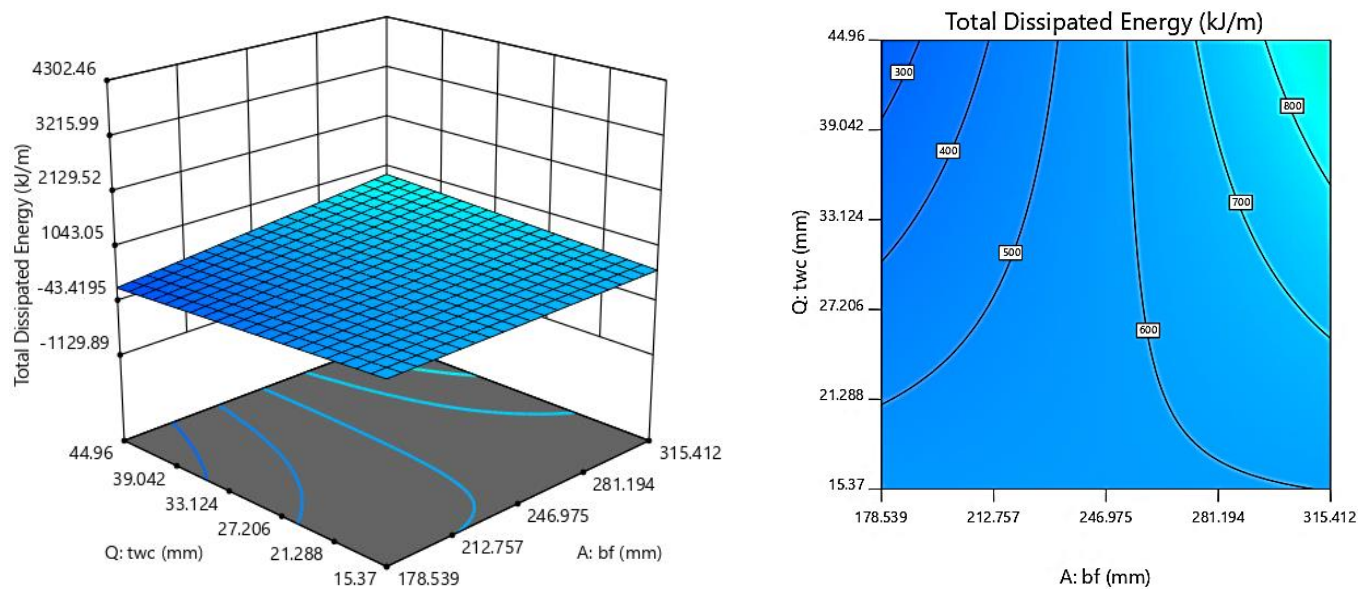

Figure 70: 3D Response Surface and Contour Plots for 2FI AQ in Selected Model for Response R1 
The 2FI of factor $\mathrm{A}$ and $\mathrm{U}$ as illustrated in Figures 71 and 72 shows a direct relation of factor $U$ (Fycf) to the effect of value of factor A on total dissipated energy. Increase in the value of factor A has increased total dissipated energy by $8.40 \%$ at low-level value of factor $\mathrm{E}$ and this value was increased to $226.65 \%$ at high-level value of factor $\mathrm{E}$.

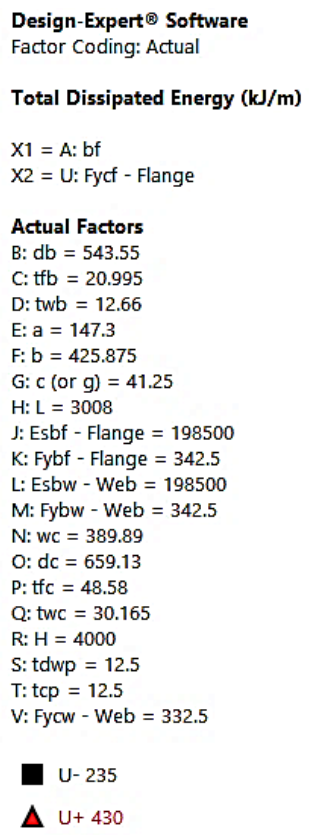

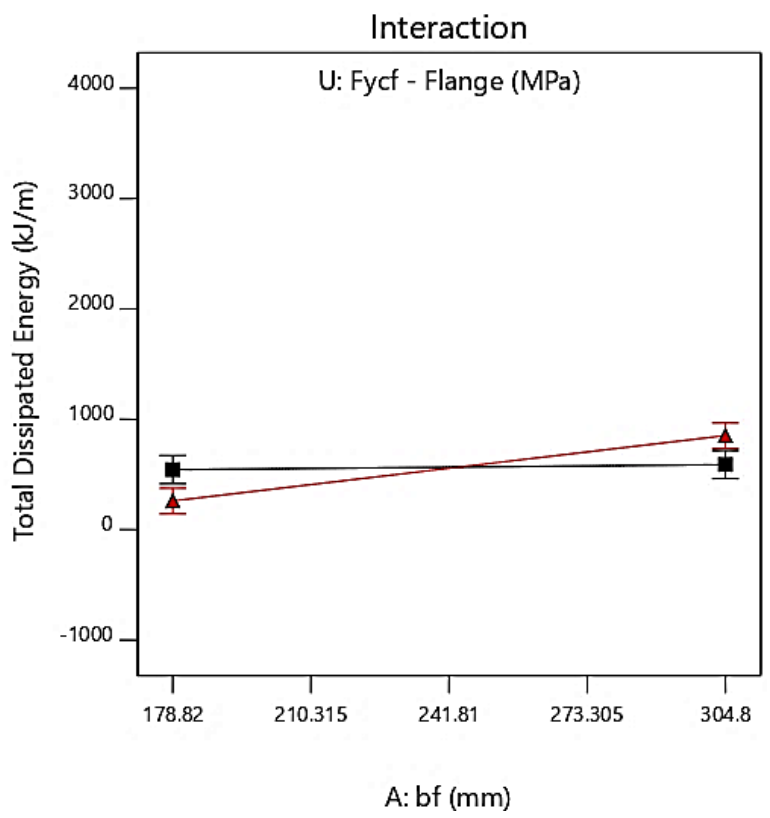

Figure 71: Plot of Marginal Means for Interaction AU in Selected Model for Response R1
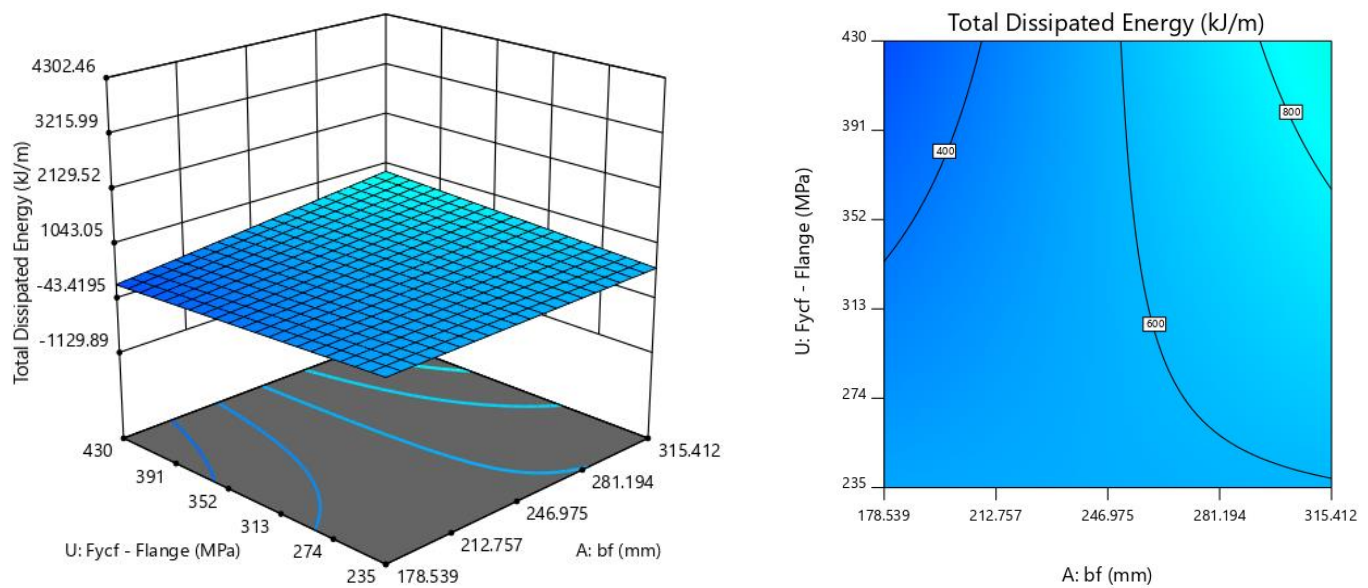

Figure 72: 3D Response Surface and Contour Plots for 2FI AU in Selected Model for Response R1 
Also, the interactions BC and BD suggested that direct relation of total dissipated energy to value of factor A is influenced positively by values of $\mathrm{C}$ and $\mathrm{D}$ as shown in Figures 73 and 76. The increase in total dissipated energy with increase in value of factor B (db) was observed to be $1341.38 \%$ and $2879.46 \%$ for low- and highlevel values of factor $\mathrm{C}$ and $1017.45 \%$ and $1813.59 \%$ for low- and high-level values of factor $\mathrm{D}$ respectively.
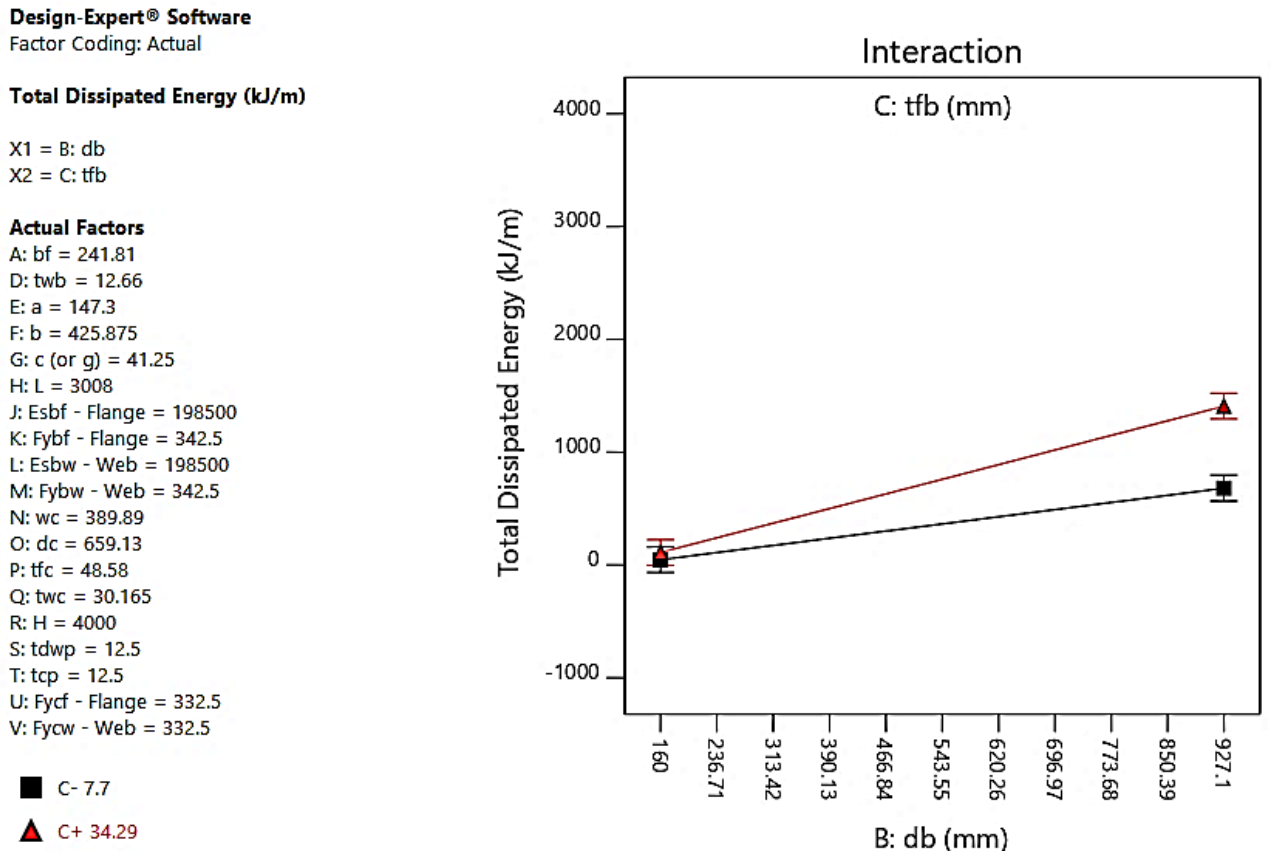

Figure 73: Plot of Marginal Means for Interaction BC in Selected Model for Response R1
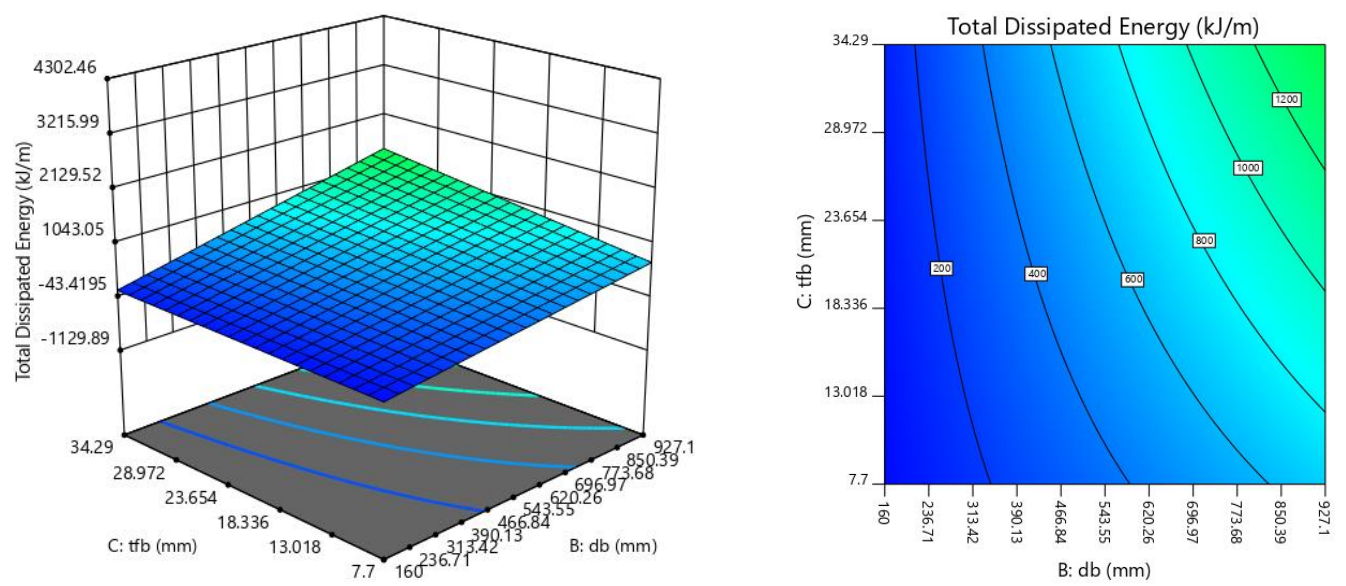

Figure 74: 3D Response Surface and Contour Plots for 2FI BC in Selected Model for Response R1 
Design-Expert ${ }^{\circledR}$ Software

Factor Coding: Actual

Total Dissipated Energy (kJ/m)

$\mathrm{X} 1=\mathrm{B}: \mathrm{db}$

$\mathrm{X} 2$ = D: twb

Actual Factors

A: bf $=241.81$

C: $t \mathrm{tb}=20.995$

$\mathrm{E}: \mathrm{a}=147.3$

$F: b=425.875$

G: $\mathrm{c}$ (or $\mathrm{g}$ ) $=41.25$

$\mathrm{H}: \mathrm{L}=3008$

$\mathrm{J}:$ Esbf - Flange $=198500$

$\mathrm{K}:$ Fybf - Flange $=342.5$

L: Esbw - Web $=198500$

$\mathrm{M}:$ Fybw - Web $=342.5$

$\mathrm{N}: \mathrm{wc}=389.89$

$\mathrm{O}: \mathrm{dc}=659.13$

P: $\mathrm{tfc}=48.58$

$\mathrm{Q}:$ twc $=30.165$

R: $\mathrm{H}=4000$

S: tdwp $=12.5$

$\mathrm{T}: \mathrm{tcp}=12.5$

$\mathrm{U}$ : Fycf - Flange $=332.5$

V: Fycw - Web $=332.5$

D- 5

$\Delta \mathrm{D}+20.32$

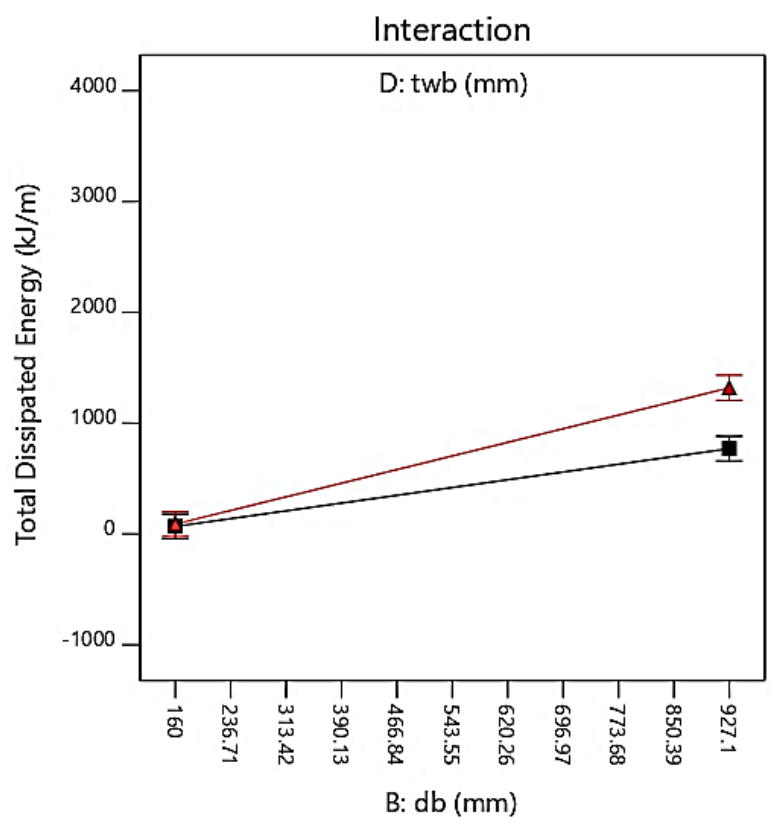

Figure 75: Plot of Marginal Means for Interaction BD in Selected Model for Response R1
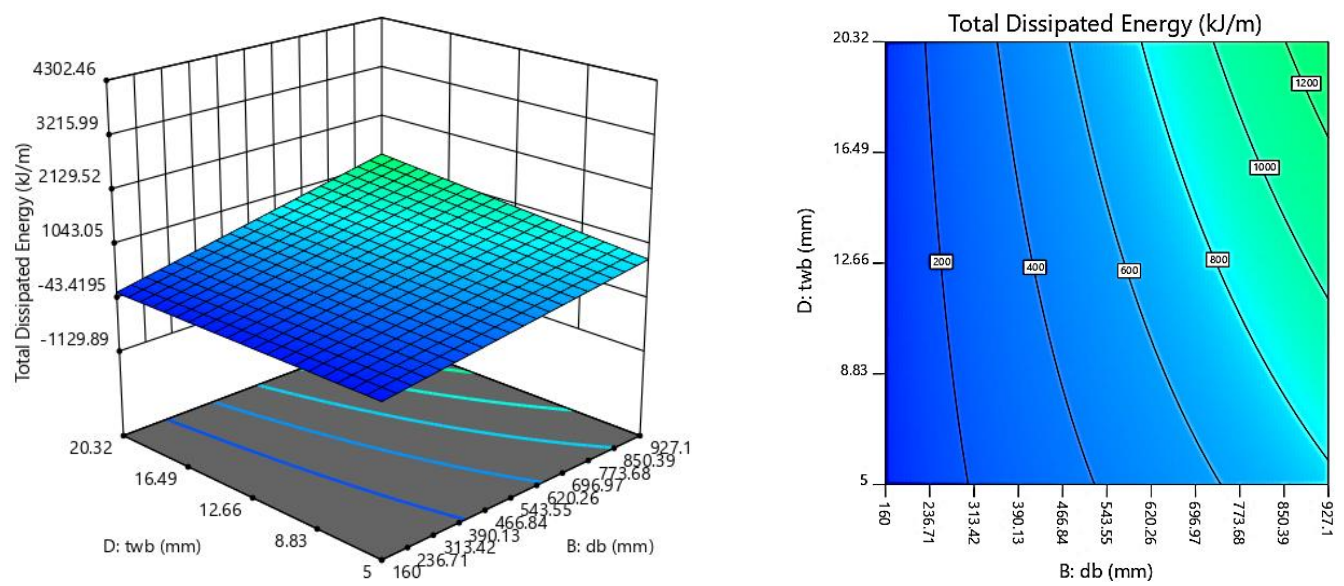

Figure 76: 3D Response Surface and Contour Plots for 2FI BD in Selected Model for Response R1 


\subsubsection{For Response Variable $R 2$ (Initial Stiffness)}

The selected model for response variable $\mathrm{R} 2$ had an $\mathrm{R}^{2}$ value of 0.91 and can be written as:

$$
R 2=\beta_{0}+\beta_{1} B+\beta_{2} C+\beta_{3} D+\beta_{4} H+\beta_{5} M+\beta_{6} B C+\beta_{7} B D
$$

Where values of all $\beta$ are given in Table 16.

Table 16: Coefficients of Model for Response R2

\begin{tabular}{|l|l|l|r|}
\hline Coefficient & Value & Coefficient & Value \\
\hline$\beta_{0}$ & 124679.3312 & $\beta_{4}$ & -14797.51035 \\
\hline$\beta_{1}$ & 114669.6962 & $\beta_{5}$ & 15713.14532 \\
\hline$\beta_{2}$ & 24885.36107 & $\beta_{6}$ & 22097.09506 \\
\hline$\beta_{3}$ & 30867.65431 & $\beta_{7}$ & 30440.64194 \\
\hline
\end{tabular}

It is evident from the half-normal probability plot and Pareto chart as presented in Figures $\mathbf{7 7}$ and 78, that similar to model 1, B is the most significant factor for regression model 2 as well with a total contribution of $71.53 \%$. A graphical representation of the percentage contribution of factors in the initial stiffness is presented in Figure 79. 

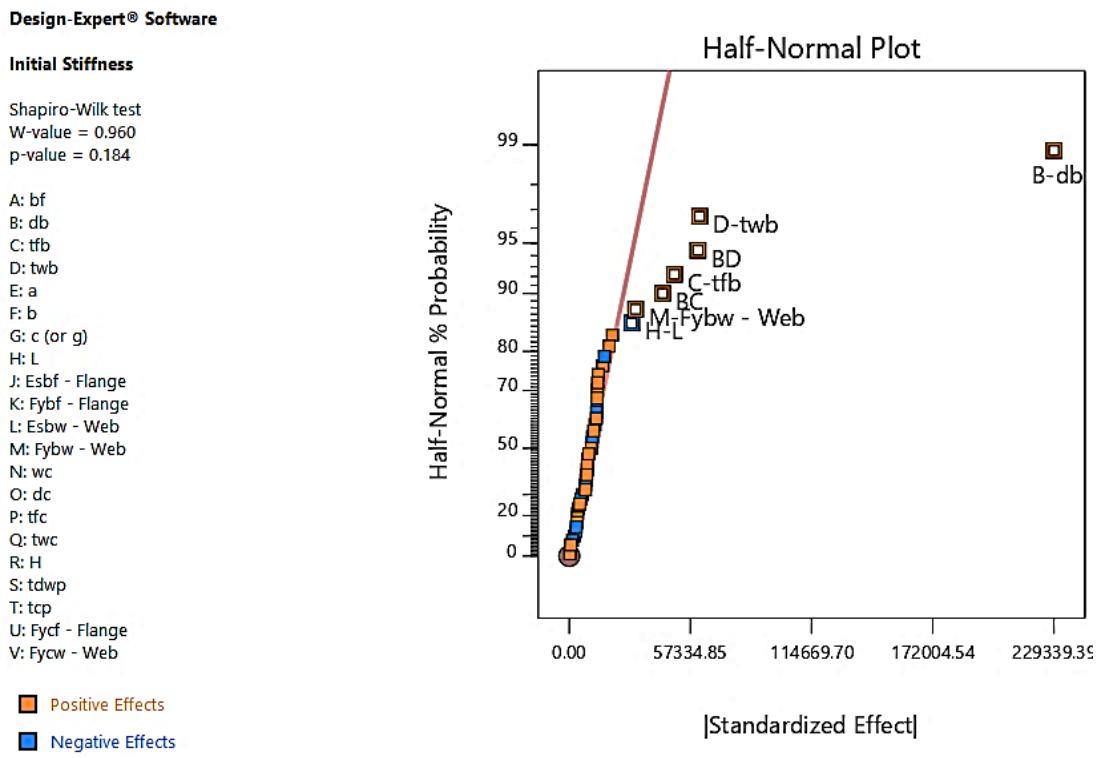

Figure 77: Half-Normal Probability Plot for Response R2 (Initial Stiffness)

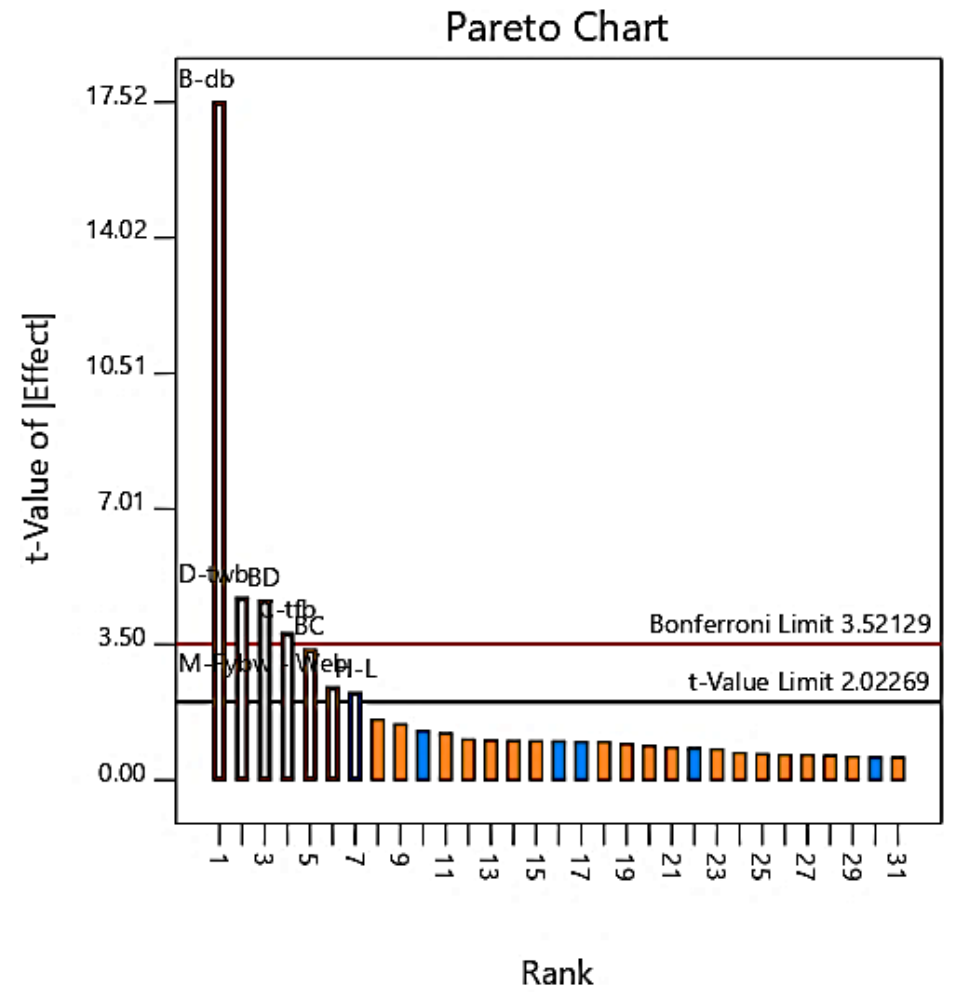

Figure 78: Pareto Chart for Response R2 (Initial Stiffness) 


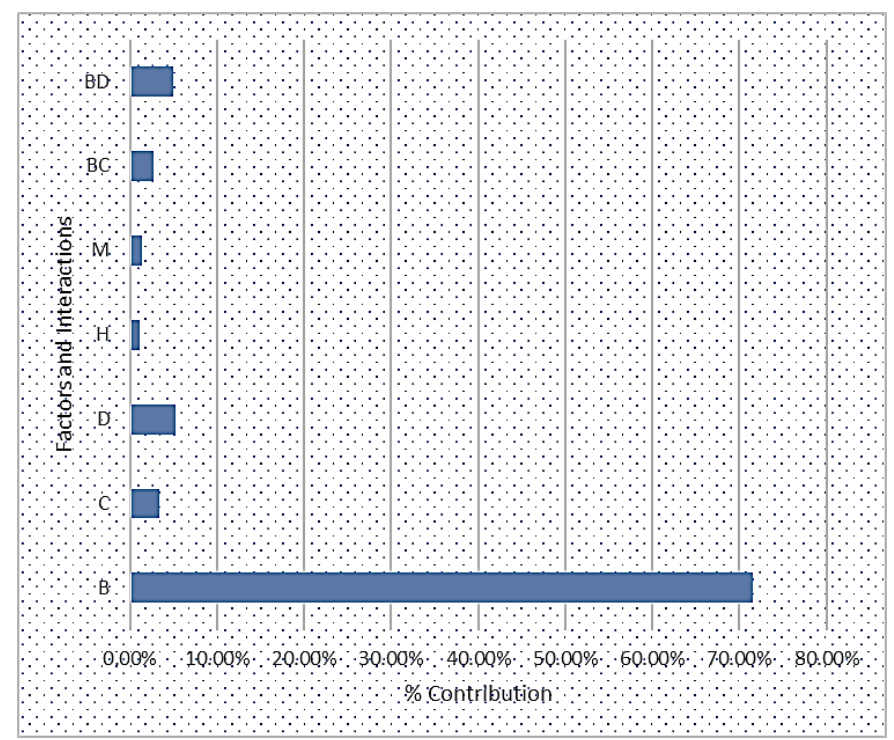

\section{Figure 79: Percentage Contributions of Factors and Interactions on Response R2}

ANOVA for model 2 (R2) as shown in Table 17 verified factor B as the most significant one with an F-value of 307.109.

Table 17: ANOVA of Selected Model for Response R2

\begin{tabular}{|l|r|r|r|r|r|r|}
\hline SOURCE & $\begin{array}{l}\text { SUM OF } \\
\text { SQUARES }\end{array}$ & df & $\begin{array}{l}\text { MEAN } \\
\text { SQUARE }\end{array}$ & F-VALUE & P-VALUE & \\
\hline Block & 81135099.13 & 1 & 81135099.13 & & & \\
\hline Model & $7.69758 \mathrm{E}+11$ & 7 & $1.09965 \mathrm{E}+11$ & 54.91498 & 0.00000 & Significant \\
\hline B-db & $6.14975 \mathrm{E}+11$ & 1 & $6.14975 \mathrm{E}+11$ & 307.10861 & 0.00000 & \\
\hline C-tfb & 28963305137 & 1 & 28963305137 & 14.46380 & 0.00050 & \\
\hline D-twb & 44562288160 & 1 & 44562288160 & 22.25368 & 0.00003 & \\
\hline H-L & 10240886003 & 1 & 10240886003 & 5.11413 & 0.02954 & \\
\hline M-Fybw - Web & 11547460384 & 1 & 11547460384 & 5.76661 & 0.02133 & \\
\hline BC & 22836555300 & 1 & 22836555300 & 11.40421 & 0.00170 & \\
\hline BD & 43337897739 & 1 & 43337897739 & 21.64224 & 0.00004 & \\
\hline Residual & 76093780146 & 38 & 2002467899 & & & \\
\hline Cor Total & $8.45933 \mathrm{E}+11$ & 46 & & & & \\
\hline
\end{tabular}

Similar to response $\mathrm{R} 1$, interactions between main factors $\mathrm{BC}$ and $\mathrm{BD}$ show that effect of factor B (db) on initial stiffness is directly affected by factors C and D as the initial stiffness increases with rise of value of factor B from low- to high-level 
by $2563.86 \%$ and $3865.05 \%$ for low- and high-level values of factor C and by $1757.96 \%$ and $3037.52 \%$ for low- and high-level values of factor D respectively as depicted in Figures 80 through 83.
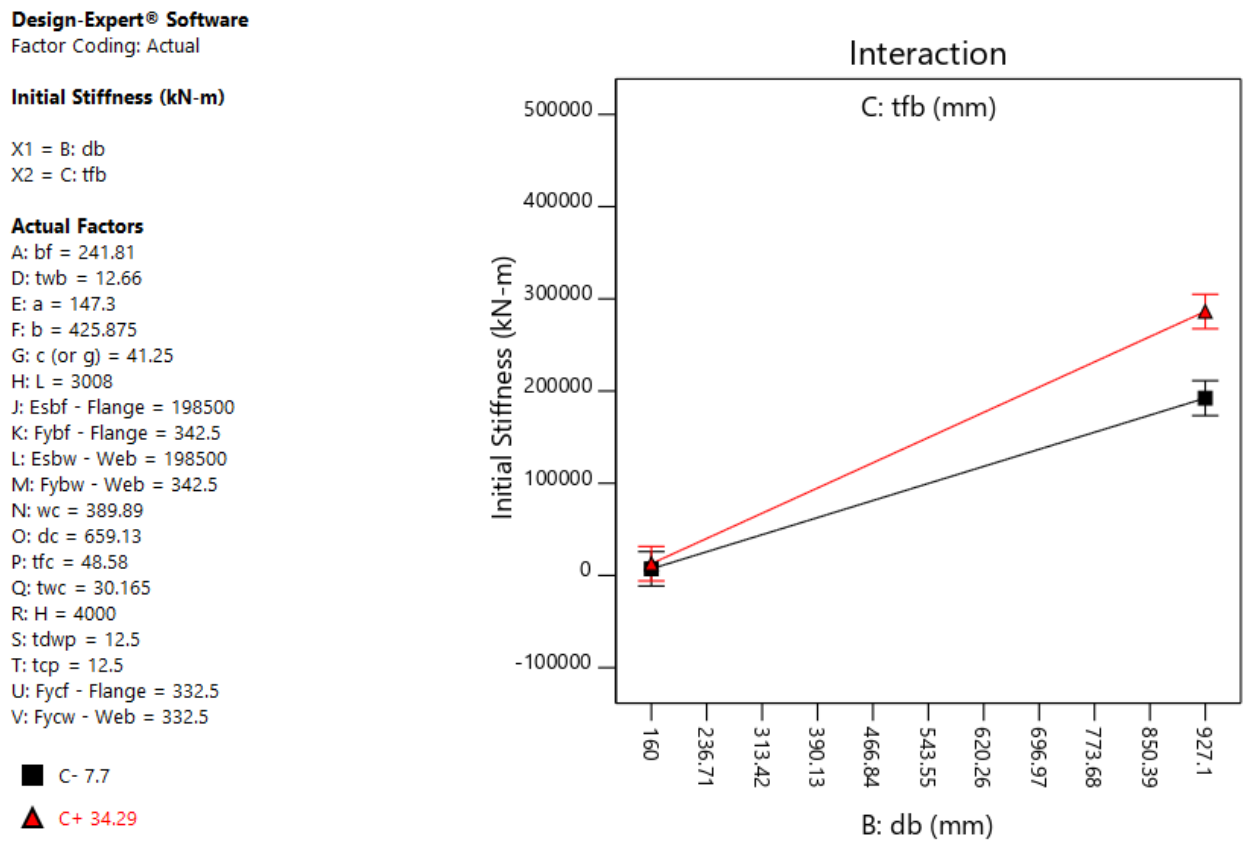

Figure 80: Plot of Marginal Means for Interaction BC in Selected Model for Response R2
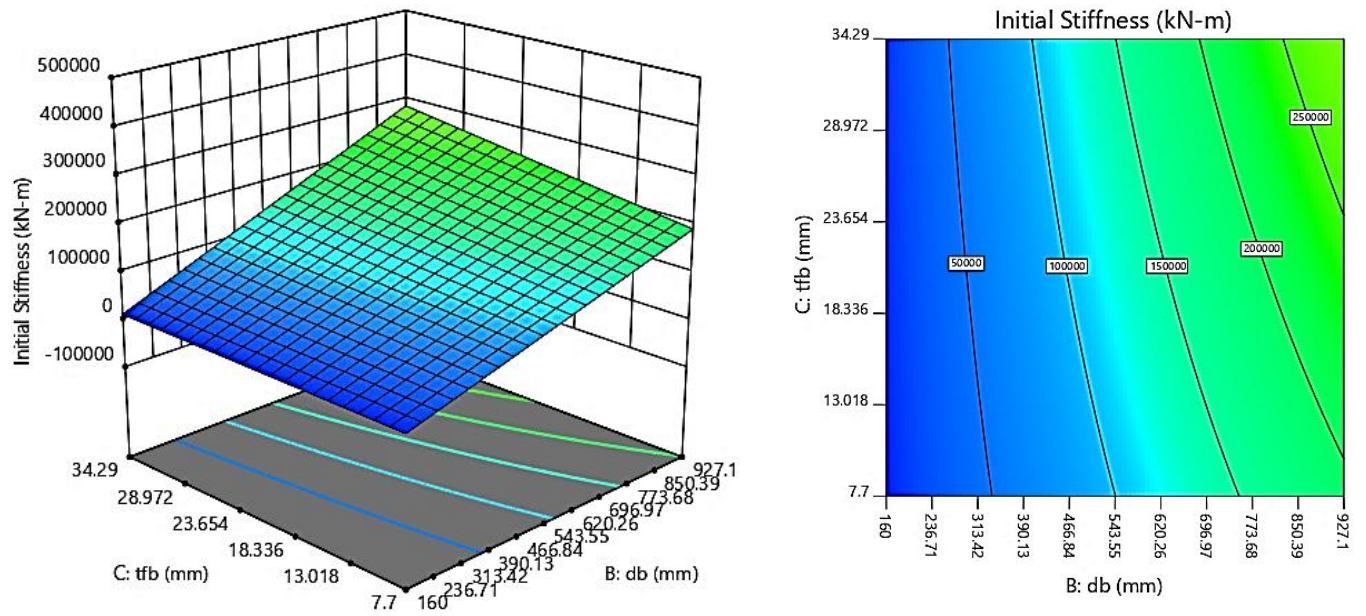

Figure 81: 3D Response Surface and Contour Plots for 2FI BC in Selected Model for Response $\mathbf{R} 2$ 
Design-Expert ${ }^{\circledR}$ Software

Factor Coding: Actual

Initial Stiffness (kN-m)

$\mathrm{X} 1=\mathrm{B}: \mathrm{db}$

$\mathrm{X} 2=\mathrm{D}: \mathrm{twb}$

Actual Factors

A: $b f=241.81$

C: $t$ tb $=20.995$

$E: a=147.3$

$\mathrm{F}: \mathrm{b}=425.875$

G: $c$ (or g) $=41.25$

$\mathrm{H}: \mathrm{L}=3008$

$\mathrm{J}:$ Esbf - Flange $=198500$

$\mathrm{K}:$ Fybf - Flange $=342.5$

L: Esbw - Web = 198500

M: Fybw - Web = 342.5

$\mathrm{N}: \mathrm{wC}=389.89$

$\mathrm{O}: \mathrm{dc}=659.13$

$\mathrm{P}: \mathrm{tfc}=48.58$

$\mathrm{Q}:$ twc $=30.165$

R: $\mathrm{H}=4000$

S: tdwp $=12.5$

$\mathrm{T}: \mathrm{tcp}=12.5$

U: Fycf - Flange $=332.5$

V: Fycw - Web $=332.5$

D- 5

$\Delta \mathrm{D}+20.32$

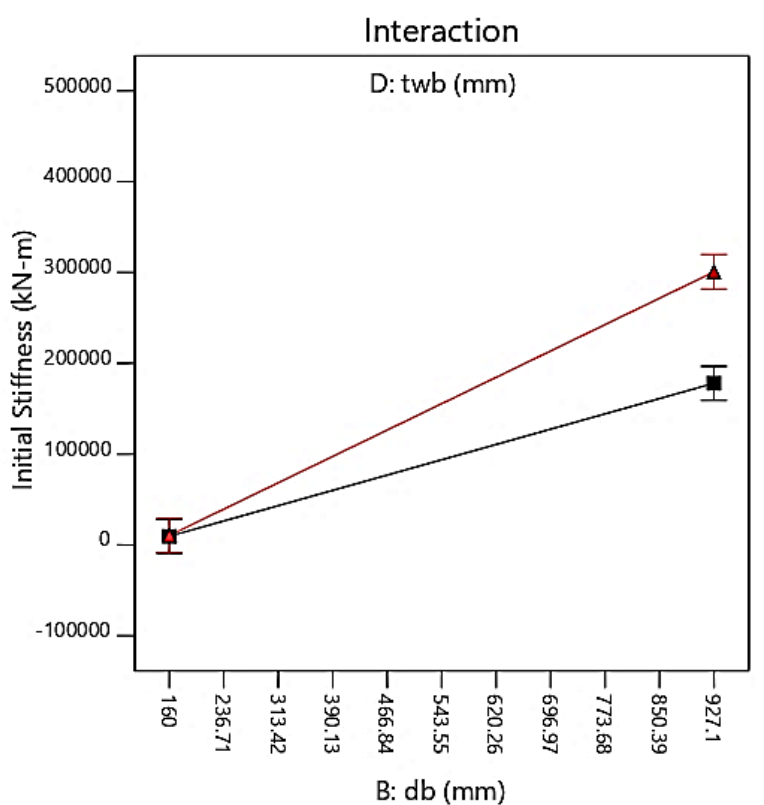

Figure 82: Plot of Marginal Means for Interaction BD in Selected Model for Response R2
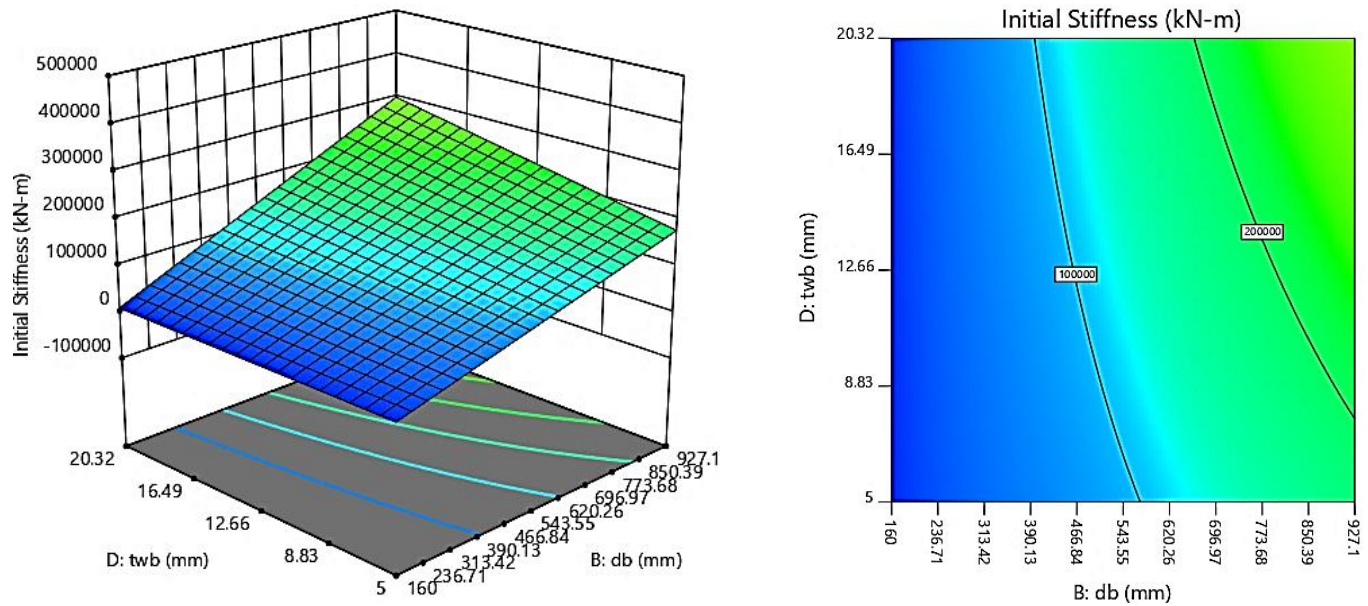

Figure 83: 3D Response Surface and Contour Plots for 2FI BD in Selected Model for Response $\mathbf{R} 2$ 


\subsubsection{For Response Variable R3 (Strength Degradation Rate)}

The coded model selected for response variable $\mathrm{R} 3$ with an $\mathrm{R}^{2}$ value of 0.9163 can be written as:

$$
\begin{aligned}
R 3=\beta_{0}+\beta_{1} A & +\beta_{2} B+\beta_{3} C+\beta_{4} D+\beta_{5} E+\beta_{6} F+\beta_{7} G+\beta_{8} H+\beta_{9} J+\beta_{10} K \\
& +\beta_{11} L+\beta_{12} N+\beta_{13} O+\beta_{14} P+\beta_{15} Q+\beta_{16} R+\beta_{17} A B \\
& +\beta_{18} A D+\beta_{19} A E+\beta_{20} A F+\beta_{21} A J+\beta_{22} A K+\beta_{23} A L+\beta_{24} A N \\
& +\beta_{25} A Q+\beta_{26} A R+\beta_{27} B E+\beta_{28} A B E
\end{aligned}
$$

Where values of all $\beta$ are given in Table 18 .

\section{Table 18: Coefficients of Model for Response R3}

\begin{tabular}{|l|r|l|r|}
\hline Coefficient & \multicolumn{1}{|l|}{ Value } & Coefficient & \multicolumn{1}{l|}{ Value } \\
\hline$\beta_{0}$ & 0.993 & $\beta_{15}$ & -0.0381 \\
\hline$\beta_{1}$ & 0.016 & $\beta_{16}$ & -0.0321 \\
\hline$\beta_{2}$ & -0.038 & $\beta_{17}$ & 0.0166 \\
\hline$\beta_{3}$ & 0.051 & $\beta_{18}$ & 0.0284 \\
\hline$\beta_{4}$ & 0.006 & $\beta_{19}$ & -0.0069 \\
\hline$\beta_{5}$ & -0.001 & $\beta_{20}$ & 0.0395 \\
\hline$\beta_{6}$ & -0.023 & $\beta_{21}$ & 0.0358 \\
\hline$\beta_{7}$ & 0.032 & $\beta_{22}$ & 0.0507 \\
\hline$\beta_{8}$ & -0.032 & $\beta_{23}$ & 0.0527 \\
\hline$\beta_{9}$ & -0.056 & $\beta_{24}$ & -0.0210 \\
\hline$\beta_{10}$ & -0.066 & $\beta_{25}$ & 0.0169 \\
\hline$\beta_{11}$ & -0.031 & $\beta_{26}$ & 0.0542 \\
\hline$\beta_{12}$ & -0.001 & $\beta_{27}$ & -0.0490 \\
\hline$\beta_{13}$ & 0.024 & $\beta_{28}$ & 0.0292 \\
\hline$\beta_{14}$ & -0.023 & & \\
\hline
\end{tabular}

The analysis of this model suggested that strength degradation rate of the connection does not exhibit a behaviour that can be attributed as sensitive towards just a single factor, however, the most significant factor in this scenario was found to be yield strength of beam flange material i.e. factor $\mathrm{K}$ as can be observed through half-normal plot (Figure 84) and Pareto chart (Figure 85) with a total contribution of $10.18 \%$ and an F-value of 28.18 , but we can see here that $2 \mathrm{FI}$ of factors A \& L (AL), Single Factor J, 2FIs of factors B \& E (BE) and A \& R (AR) and Single 
Factor $\mathrm{C}$ are not that far behind with a contribution of $8.30 \%, 7.34 \%, 7.19 \%, 6.78 \%$, $6.6 \%$ as shown in Figure 86 and F-values of 22.96, 20.31, 19.89, 18.76 and 18.27 respectively in Table 19 and the percentage contributions of factors in the response variable R3 (Strength Degradation Rate) is depicted in Figure 86.
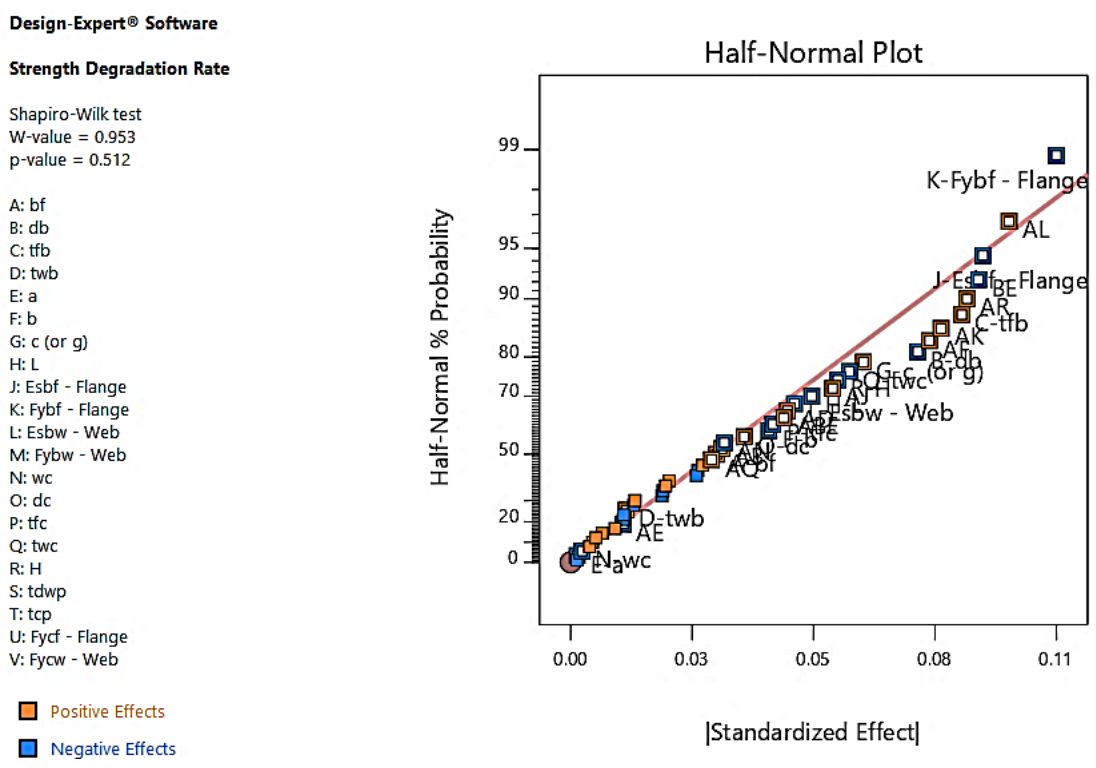

Figure 84: Half-Normal Probability Plot for Response R3 (Strength Degradation Rate) 


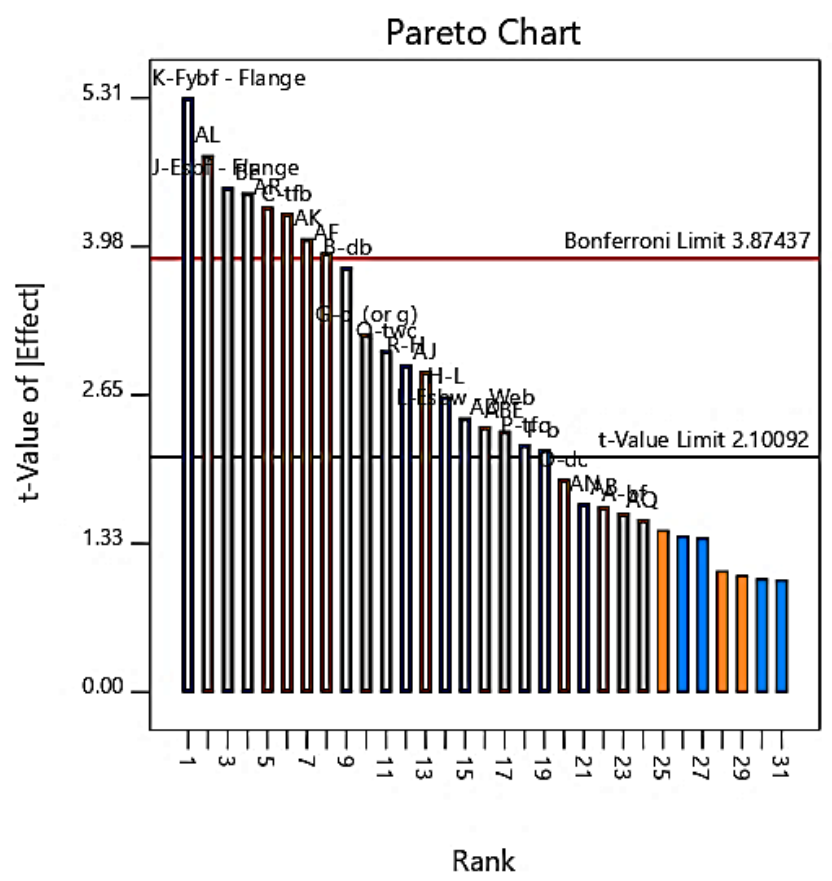

Figure 85: Pareto Chart for Response R3 (Strength Degradation Rate)

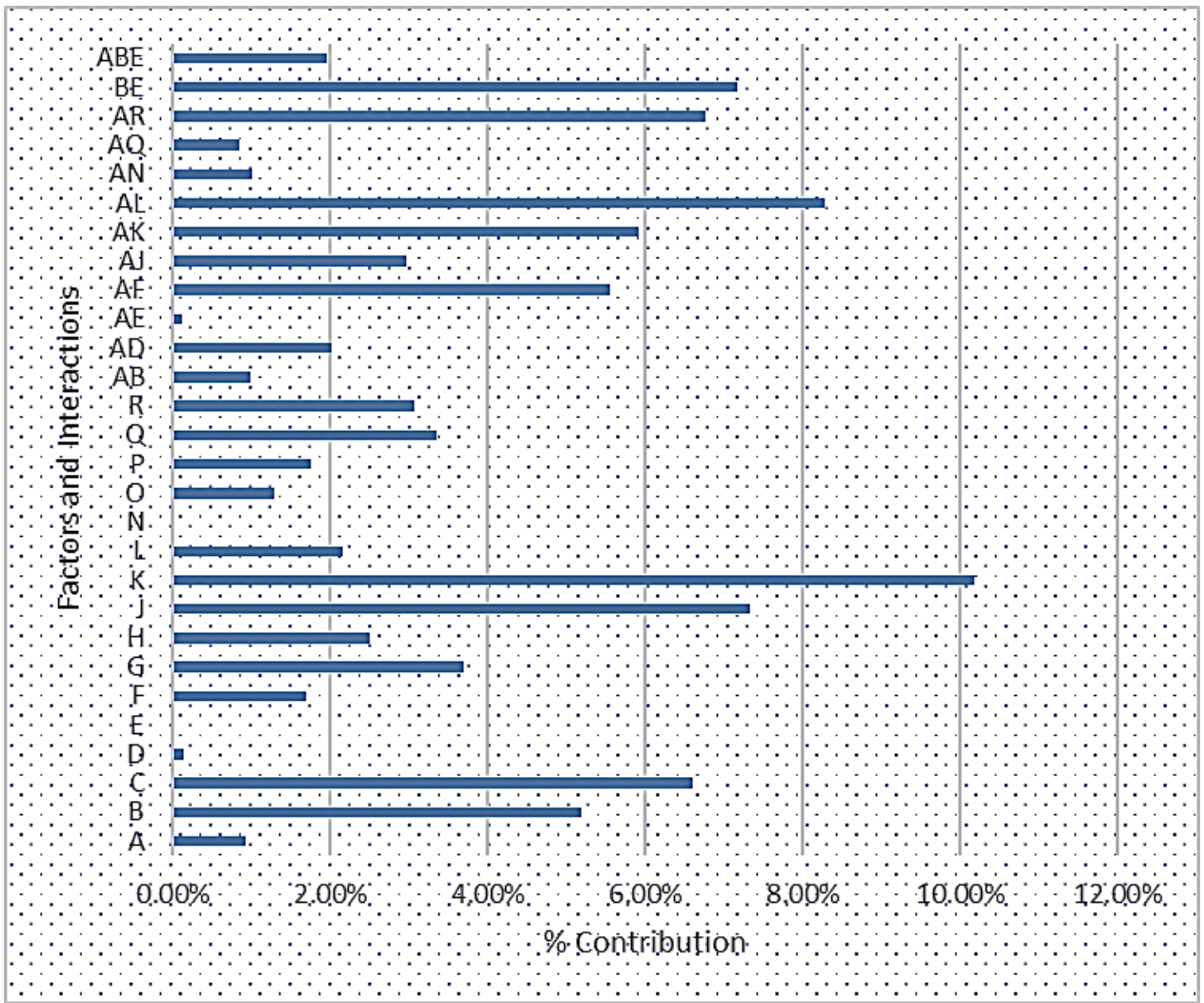

Figure 86: Percentage Contributions of Factors and Interactions on Response R3 
It can be observed here that factors that contributed more than $5 \%$ i.e. B, C, J, K and 2FIs AF, AK, AL, AR and BE were considerably more influential than other factors as the difference between percentage contribution of the least significant factor amongst these (B: 5.2\%) and the next most significant factor (G: 3.7\%). The ANOVA shown in Table 19 verifies this observation with a sudden drop in F-value from factor B (F-value: 14.39) to next most significant factor G (F-value: 10.23) 
Table 19: ANOVA of Selected Model for Response R3

\begin{tabular}{|l|r|r|r|r|r|r|}
\hline SOURCE & \multicolumn{1}{l}{$\begin{array}{l}\text { SUM OF } \\
\text { SQUARES }\end{array}$} & \multicolumn{1}{l}{ df } & \multicolumn{1}{l}{$\begin{array}{l}\text { MEAN } \\
\text { SQUARE }\end{array}$} & F-VALUE & P-VALUE & \\
\hline Block & 0.01055 & 1 & 0.01055 & & & \\
\hline Model & 0.85257 & 28 & 0.03045 & 6.64625 & 0.00008 & Significant \\
\hline A-bf & 0.01168 & 1 & 0.01168 & 2.54956 & 0.12875 & \\
\hline B-db & 0.06592 & 1 & 0.06592 & 14.38948 & 0.00145 & \\
\hline C-tfb & 0.08370 & 1 & 0.08370 & 18.27045 & 0.00051 & \\
\hline D-twb & 0.00168 & 1 & 0.00168 & 0.36742 & 0.55242 & \\
\hline E-a & 0.00002 & 1 & 0.00002 & 0.00509 & 0.94395 & \\
\hline F-b & 0.02150 & 1 & 0.02150 & 4.69346 & 0.04478 & \\
\hline G-c (or g) & 0.04690 & 1 & 0.04690 & 10.23651 & 0.00525 & \\
\hline H-L & 0.03182 & 1 & 0.03182 & 6.94446 & 0.01737 & \\
\hline J-Esbf - Flange & 0.09303 & 1 & 0.09303 & 20.30536 & 0.00031 & \\
\hline K-Fybf - & 0.12912 & 1 & 0.12912 & 28.18285 & 0.00006 & \\
Flange & & & & & & \\
\hline L-Esbw - Web & 0.02744 & 1 & 0.02744 & 5.98997 & 0.02555 & \\
\hline N-wc & 0.00007 & 1 & 0.00007 & 0.01548 & 0.90244 & \\
\hline O-dc & 0.01650 & 1 & 0.01650 & 3.60055 & 0.07488 & \\
\hline P-tfc & 0.02238 & 1 & 0.02238 & 4.88499 & 0.04109 & \\
\hline Q-twc & 0.04255 & 1 & 0.04255 & 9.28808 & 0.00728 & \\
\hline R-H & 0.03907 & 1 & 0.03907 & 8.52721 & 0.00955 & \\
\hline AB & 0.01251 & 1 & 0.01251 & 2.72976 & 0.11684 & \\
\hline AD & 0.02574 & 1 & 0.02574 & 5.61730 & 0.02988 & \\
\hline AE & 0.00151 & 1 & 0.00151 & 0.32944 & 0.57351 & \\
\hline AF & 0.07049 & 1 & 0.07049 & 15.38613 & 0.00110 & \\
\hline AJ & 0.03755 & 1 & 0.03755 & 8.19679 & 0.01077 & \\
\hline AK & 0.07510 & 1 & 0.07510 & 16.39256 & 0.00083 & \\
\hline AL & 0.10520 & 1 & 0.10520 & 22.96297 & 0.00017 & \\
\hline AN & 0.01292 & 1 & 0.01292 & 2.82045 & 0.11135 & \\
\hline AQ & 0.01086 & 1 & 0.01086 & 2.36940 & 0.14214 & \\
\hline AR & 0.08597 & 1 & 0.08597 & 18.76421 & 0.00045 & \\
\hline BE & 0.09111 & 1 & 0.09111 & 19.88623 & 0.00034 & \\
\hline ABE & 0.02489 & 1 & 0.02489 & 5.43360 & 0.03232 & \\
\hline Residual & 0.07788 & 17 & 0.00458 & & & \\
\hline Cor Total & 0.94100 & 46 & & & & \\
\hline & & & & & & \\
\hline
\end{tabular}

The interaction of factors A and $\mathrm{F}$ shows that for low-level value of factor $\mathrm{F}(\mathrm{b})$, strength degradation rate was decreased by $4.51 \%$ as factor $\mathrm{A}$ was increased from low-level value to high-level value but the effect of high-level value of factor F is 
opposite on the relation of factor A to SDR i.e. response R3 as it was increased with the rise in value of factor A from low- to high-level value by $12.16 \%$ as shown in Figures 87 and $\mathbf{8 8}$. It can be observed here that the effect of factor $\mathrm{A}$ on the response is more sensitive to higher value of factor $\mathrm{F}$.
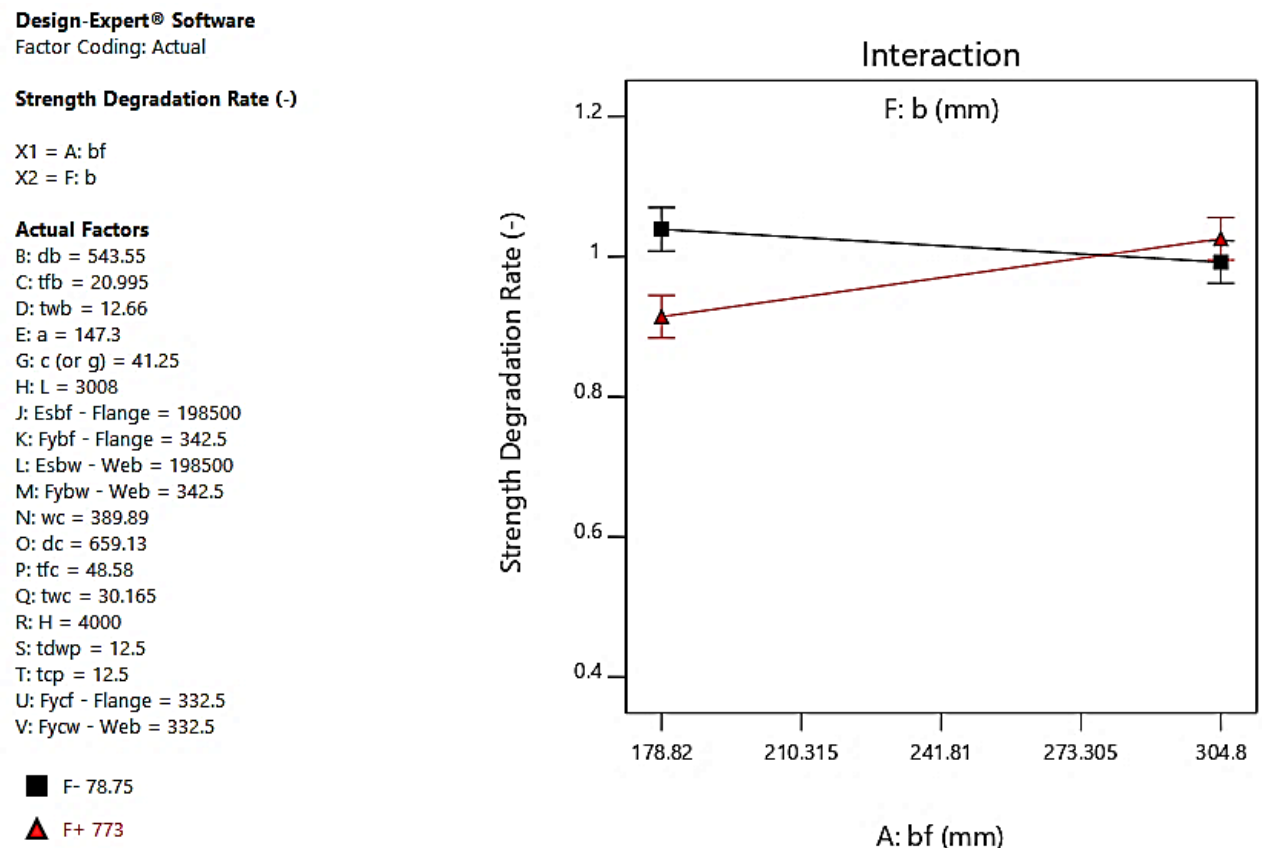

Figure 87: Plot of Marginal Means for Interaction AF in Selected Model for Response R3
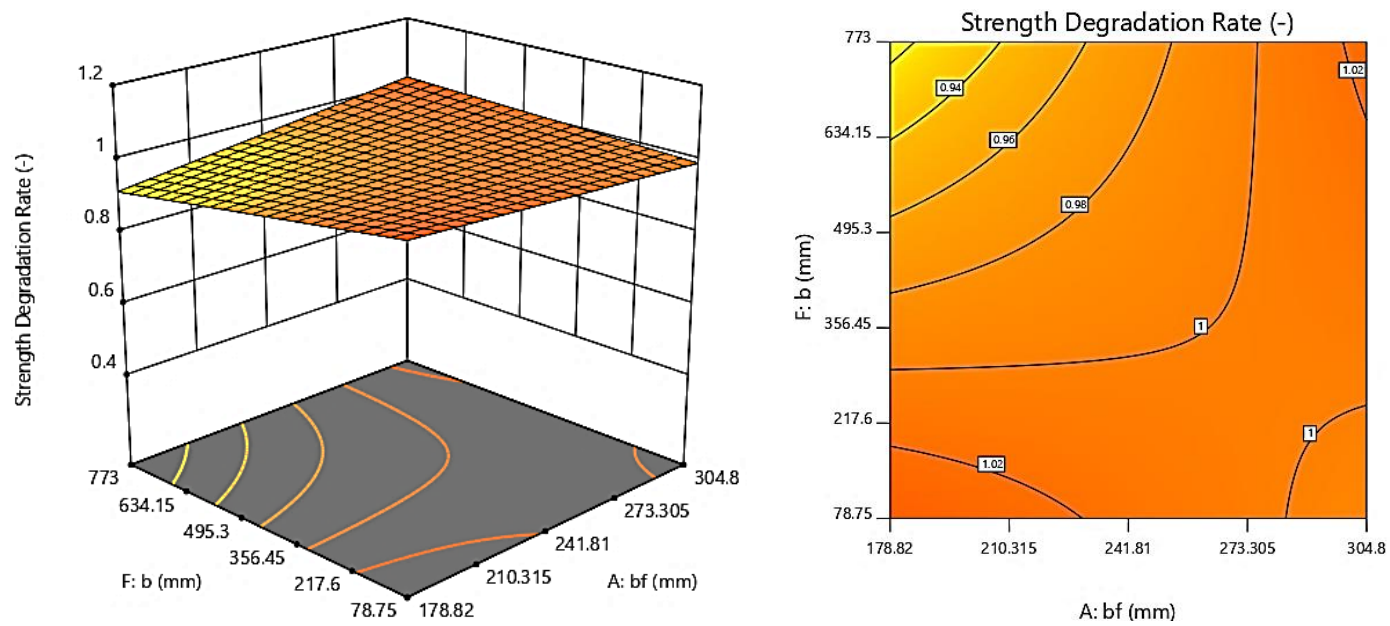

Figure 88: 3D Response Surface and Contour Plots for 2FI AF in Selected Model for Response R3 
Effect of factor K (Fybf) on strength degradation rate in interaction with factor A represented in Figures 89 and 90 suggested that at low-level value of factor K, increase in values of factor A decreased the SDR by $6.32 \%$ while for high-level value of $\mathrm{K}$ factor, the scenario was reversed as the SDR increased by $15.53 \%$ with the increase in value of factor A from low- to high-level.

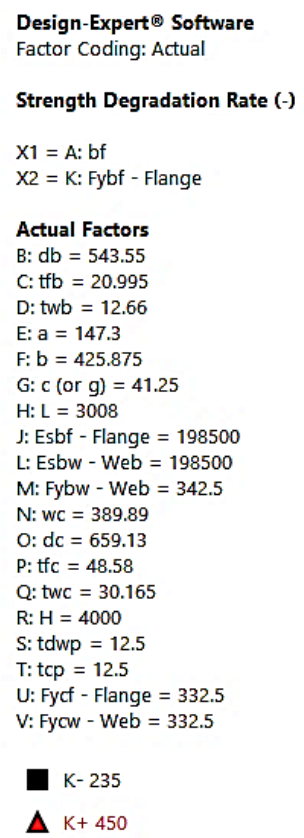

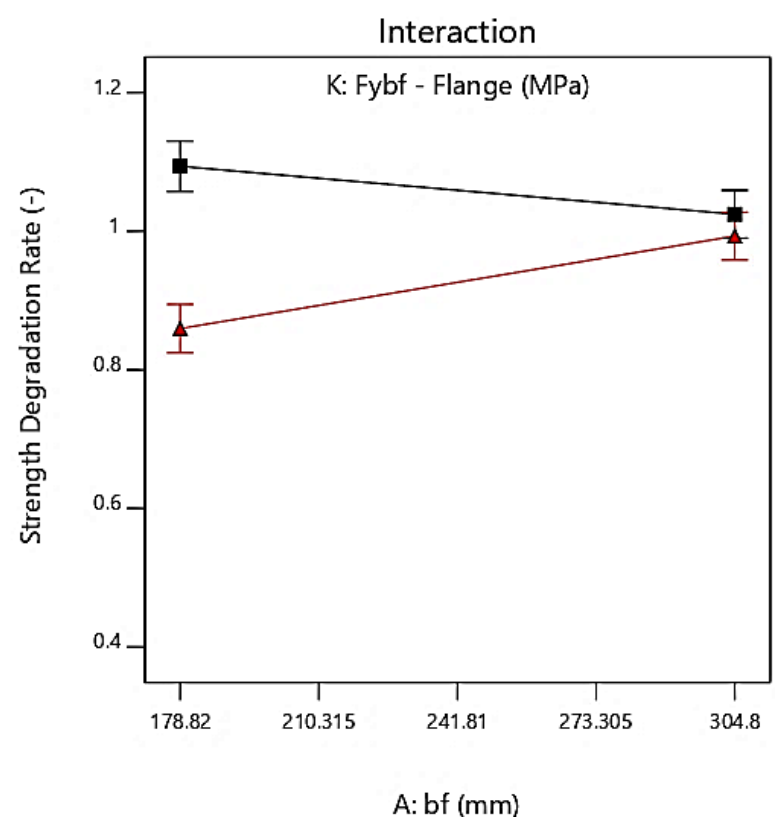

Figure 89: Plot of Marginal Means for Interaction AK in Selected Model for Response R3
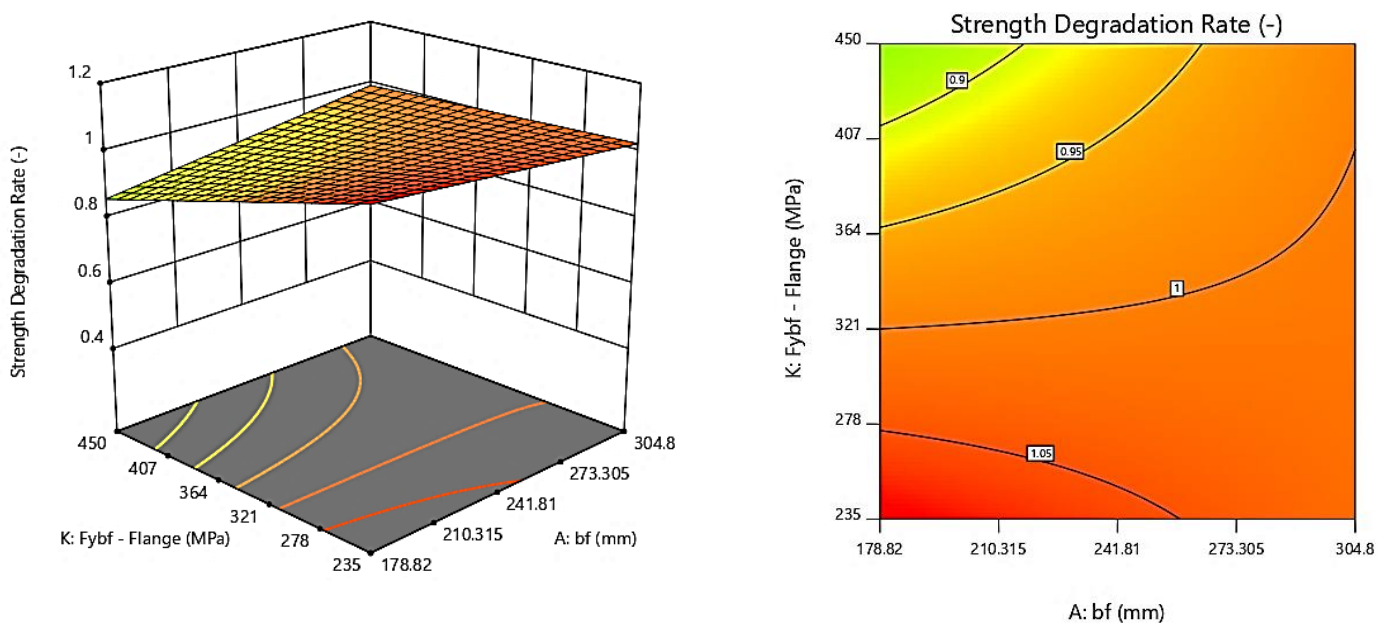

Figure 90: 3D Response Surface and Contour Plots for 2FI AK in Selected Model for Response R3 
The 2FIs of AL and AR exhibited similar behaviour as for low-level values of $\mathrm{L}$ and $\mathrm{R}$, the SDR dropped with the rise in the value of A from low-level to high-level by $6.9 \%$ and $7.17 \%$ respectively, while for the high-level values of $L$ and $R$, the response became directly proportional to value of factor A and increased by $15.39 \%$ and $15.79 \%$ respectively as shown in Figures 91 through 94.

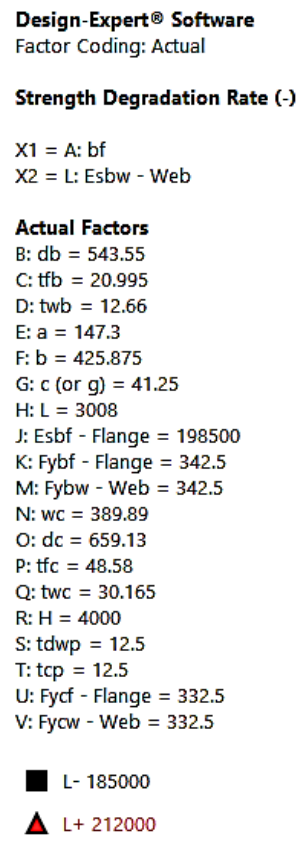

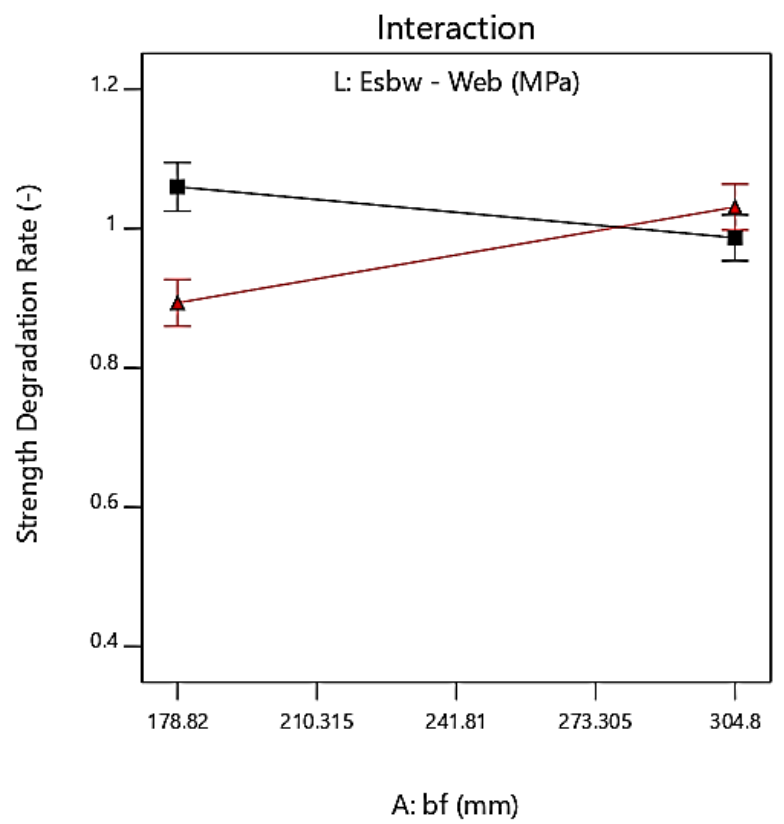

Figure 91: Plot of Marginal Means for Interaction AL in Selected Model for Response R3
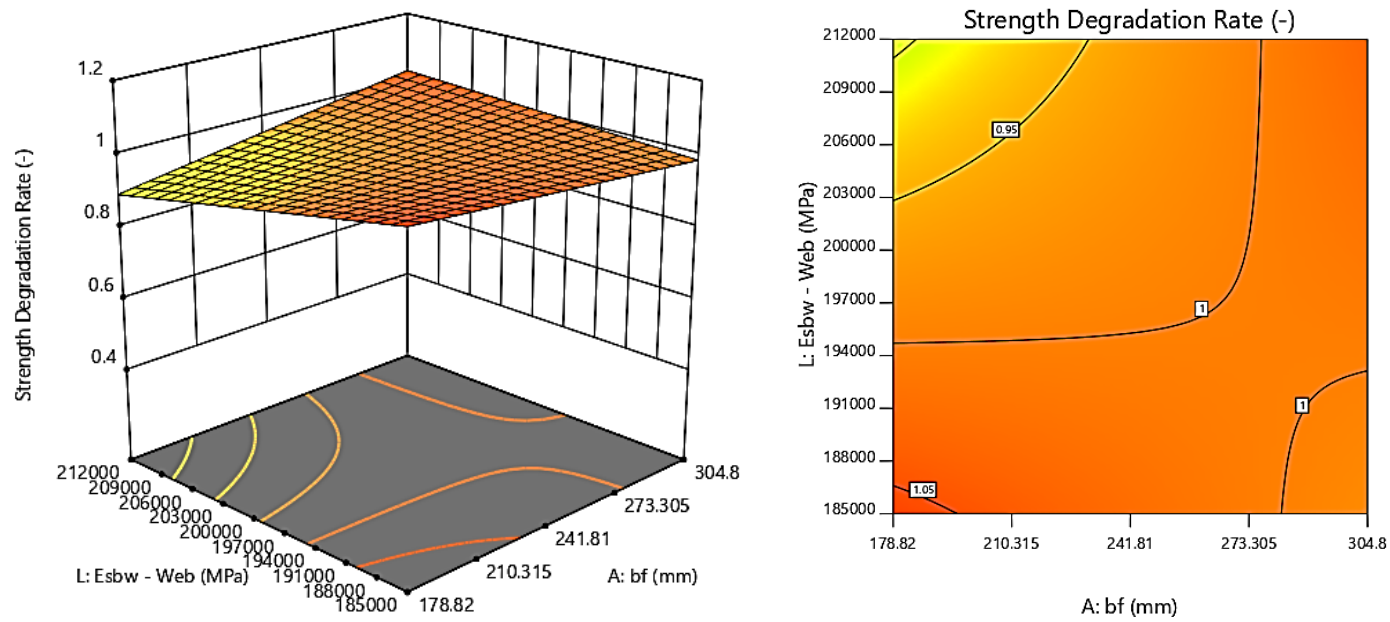

Figure 92: 3D Response Surface and Contour Plots for 2FI AL in Selected Model for Response R3 
Design-Expert ${ }^{\circledR}$ Software

Factor Coding: Actual

Strength Degradation Rate (-)

$\mathrm{X} 1=\mathrm{A}: \mathrm{bf}$

$\mathrm{X} 2=\mathrm{R}: \mathrm{H}$

Actual Factors

$\mathrm{B}: \mathrm{db}=543.55$

C: $t \mathrm{tb}=20.995$

$\mathrm{D}: \mathrm{twb}=12.66$

$\mathrm{E}: \mathrm{a}=147.3$

$\mathrm{F}: \mathrm{b}=425.875$

G: $\mathrm{c}$ (or g) $=41.25$

$\mathrm{H}: \mathrm{L}=3008$

$\mathrm{J}$ : Esbf - Flange $=198500$

K: Fybf - Flange $=342.5$

L: Esbw - Web $=198500$

$\mathrm{M}:$ Fybw - Web $=342.5$

$\mathrm{N}: \mathrm{wC}=389.89$

$\mathrm{O}: \mathrm{dc}=659.13$

$\mathrm{P}: \mathrm{tfc}=48.58$

$\mathrm{Q}: \mathrm{twc}=30.165$

S: tdwp $=12.5$

$\mathrm{T}: \mathrm{tcp}=12.5$

$\mathrm{U}:$ Fycf - Flange $=332.5$

V: Fycw - Web $=332.5$

$R-3000$

$\Delta \mathrm{R}+5000$

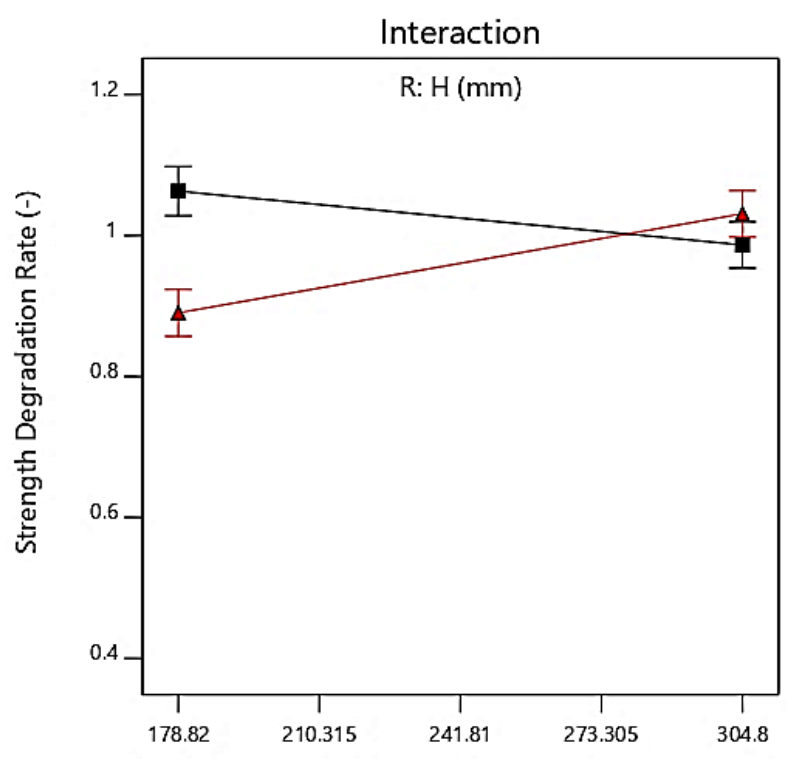

A: bf (mm)

Figure 93: Plot of Marginal Means for Interaction AR in Selected Model for Response R3
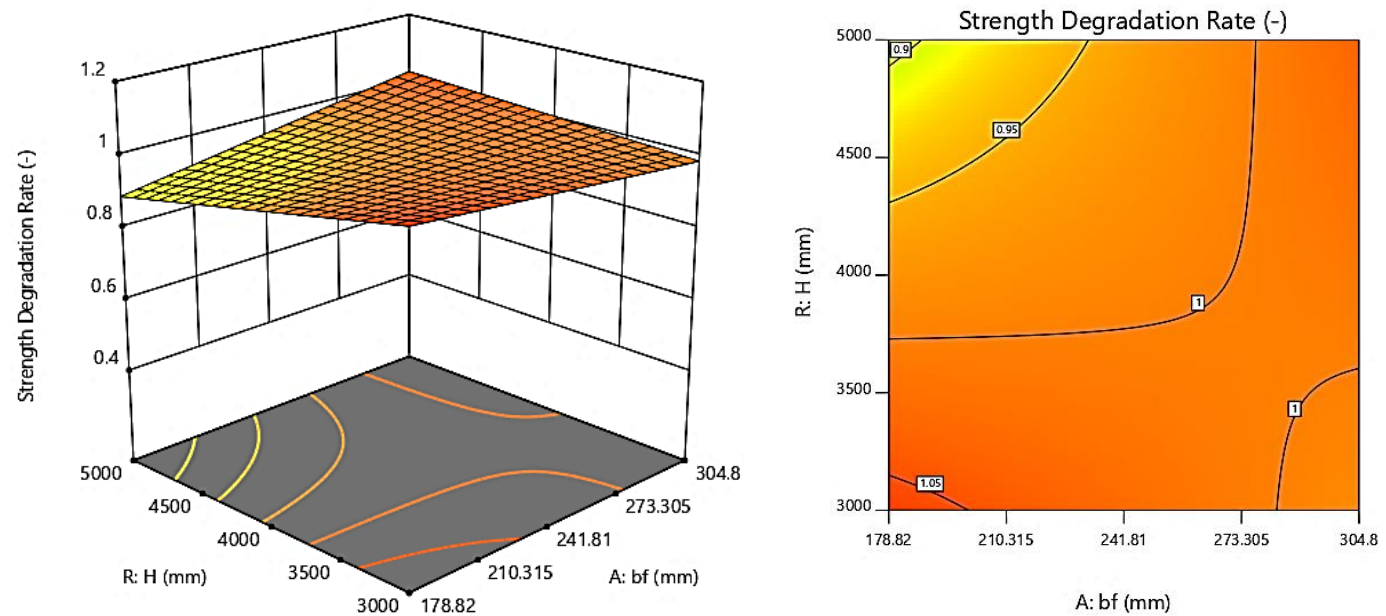

Figure 94: 3D Response Surface and Contour Plots for 2FI AR in Selected Model for Response R3 
It was observed from the interaction of factors $B$ and $E$ that low-level value of $E$ has lesser but direct effect on the relation of SDR to factor B as increasing the value of factor B from low- to high-level resulted in an increase in SDR by $2.20 \%$ while at high-level value of factor B poses reverse and more vigorous effect as SDR drops by $16.16 \%$ with an increase in value of factor B from low- to high-level as shown in Figures 95 and 96 below.

Design-Expert ${ }^{\circledR}$ Software
Factor Coding: Actual
Strength Degradation Rate (-)
X1 = B: db
X2 = E: a
Actual Factors
A: bf $=241.81$
C: tfb $=20.995$
D: twb $=12.66$
F: $b=425.875$
G: $c$ (or g) $=41.25$
H: $L=3008$
J: Esbf - Flange $=198500$
K: Fybf - Flange $=342.5$
L: Esbw - Web $=198500$
M: Fybw - Web $=342.5$
N: wc $=389.89$
O: $d c=659.13$
P: tfc $=48.58$
Q: twc $=30.165$
R: $H=4000$
S: tdwp $=12.5$
T: tcp $=12.5$
U: Fycf - Flange $=332.5$
V: Fycw - Web $=332.5$

$\square E-66$

$\Delta \mathrm{E}+228.6$

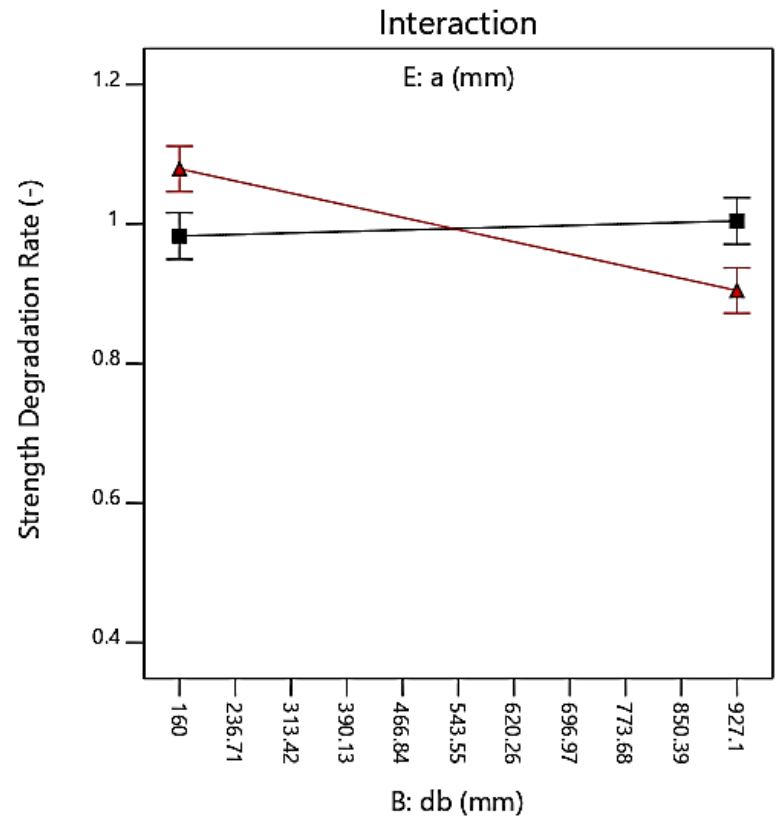

Figure 95: Plot of Marginal Means for Interaction BE in Selected Model for Response R3
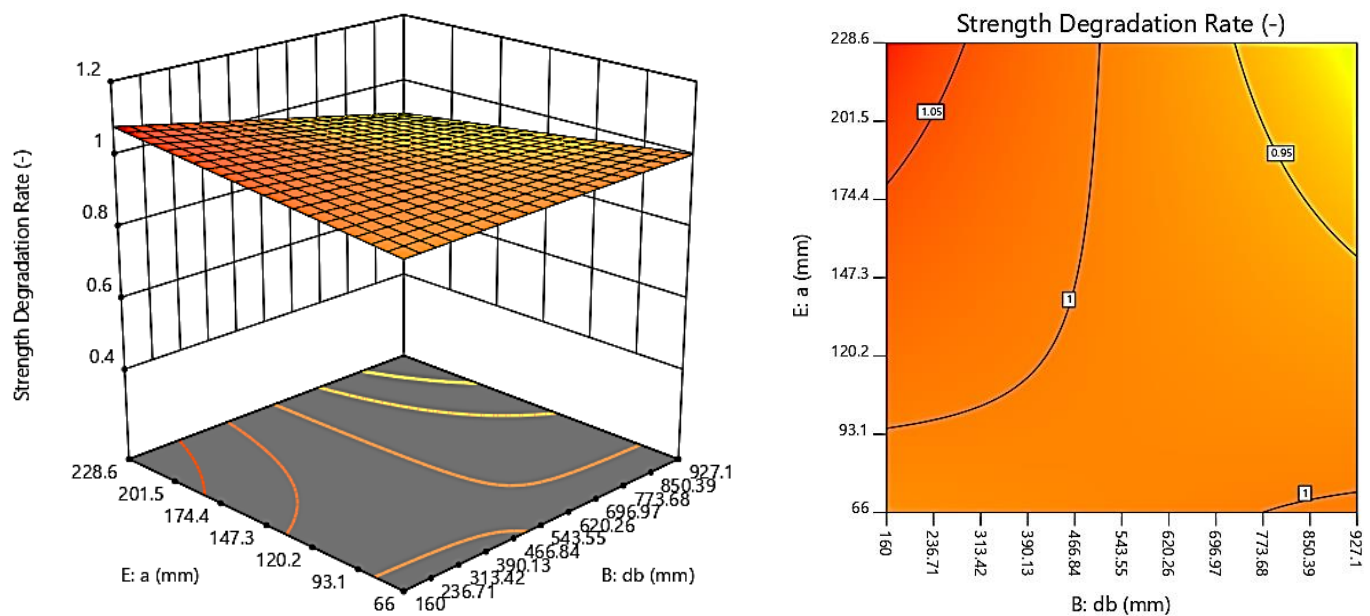

Figure 96: 3D Response Surface and Contour Plots for 2FI BE in Selected Model for Response R3 


\subsubsection{For Response Variable R4 (Maximum Moment Capacity)}

The selected model for response variable $\mathrm{R} 4$ with an $\mathrm{R}^{2}$ value of 0.915 can be written as a coded equation as follows:

$$
\begin{gathered}
R 4=\beta_{0}+\beta_{1} A+\beta_{2} B+\beta_{3} C+\beta_{4} D+\beta_{5} F+\beta_{6} M+\beta_{7} O+\beta_{8} Q+\beta_{9} S \\
+\beta_{10} A Q+\beta_{11} A S+\beta_{12} B C+\beta_{13} B D
\end{gathered}
$$

$\beta$ values are provided in Table 20.

Table 20: Coefficients of Model for Response R4

\begin{tabular}{|l|r|l|r|}
\hline Coefficient & \multicolumn{1}{|l|}{ Value } & Coefficient & \multicolumn{1}{l|}{ Value } \\
\hline$\beta_{0}$ & 1233.44 & $\beta_{7}$ & 252.85 \\
\hline$\beta_{1}$ & 109.60 & $\beta_{8}$ & 56.37 \\
\hline$\beta_{2}$ & 995.68 & $\beta_{9}$ & 67.11 \\
\hline$\beta_{3}$ & 284.67 & $\beta_{10}$ & 166.70 \\
\hline$\beta_{4}$ & 361.71 & $\beta_{11}$ & 158.71 \\
\hline$\beta_{5}$ & -195.48 & $\beta_{12}$ & 223.39 \\
\hline$\beta_{6}$ & 265.87 & $\beta_{13}$ & 326.88 \\
\hline
\end{tabular}

The half-normal probability distribution plot for response R4 shows an acute sensitivity for maximum moment capacity towards factor B i.e. depth of beam as shown in Figures 97 and 98 with a largest contribution of 54.68\% towards the response as presented in Figure 99. 

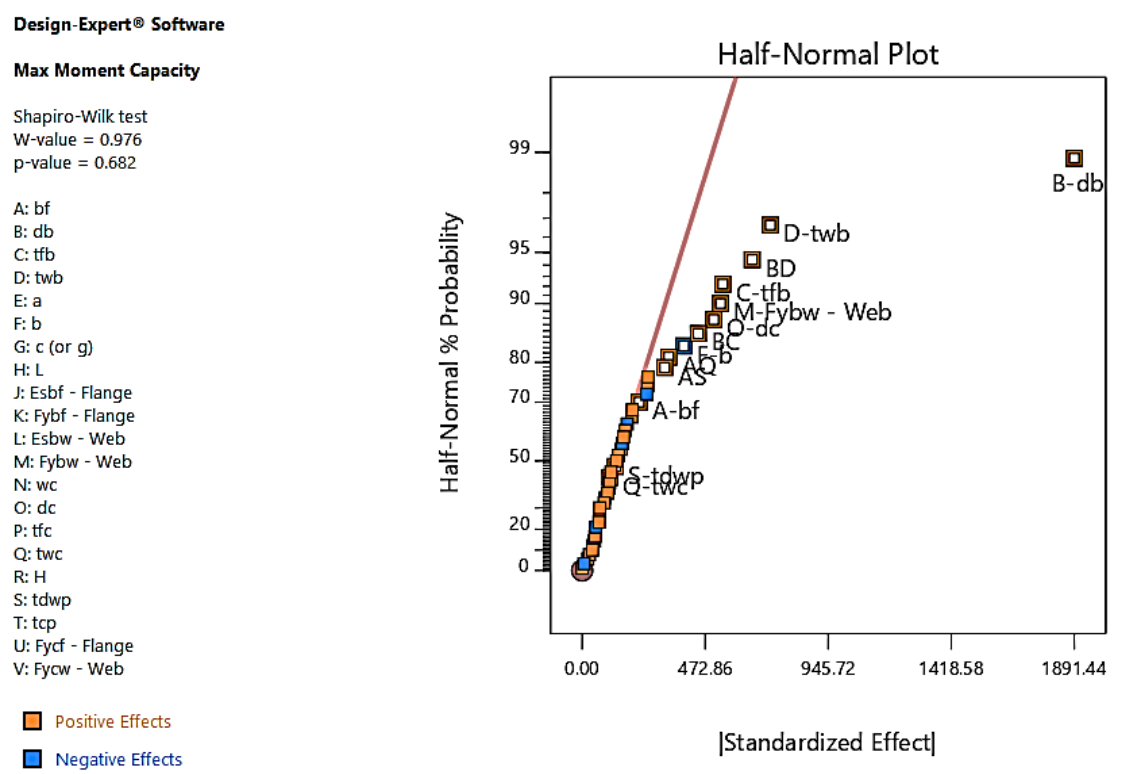

Figure 97: Half-Normal Probability Plot for Response R4 (Maximum Moment Capacity)

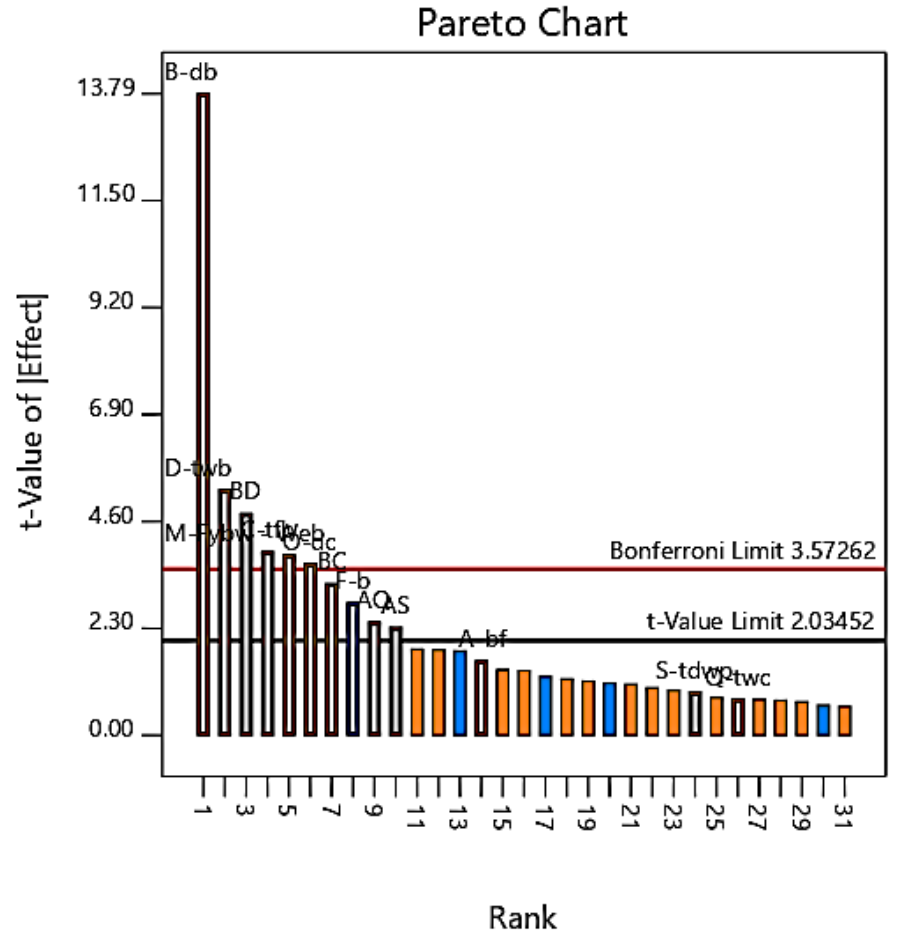

Figure 98: Pareto Chart for Response R4 (Maximum Moment Capacity) 


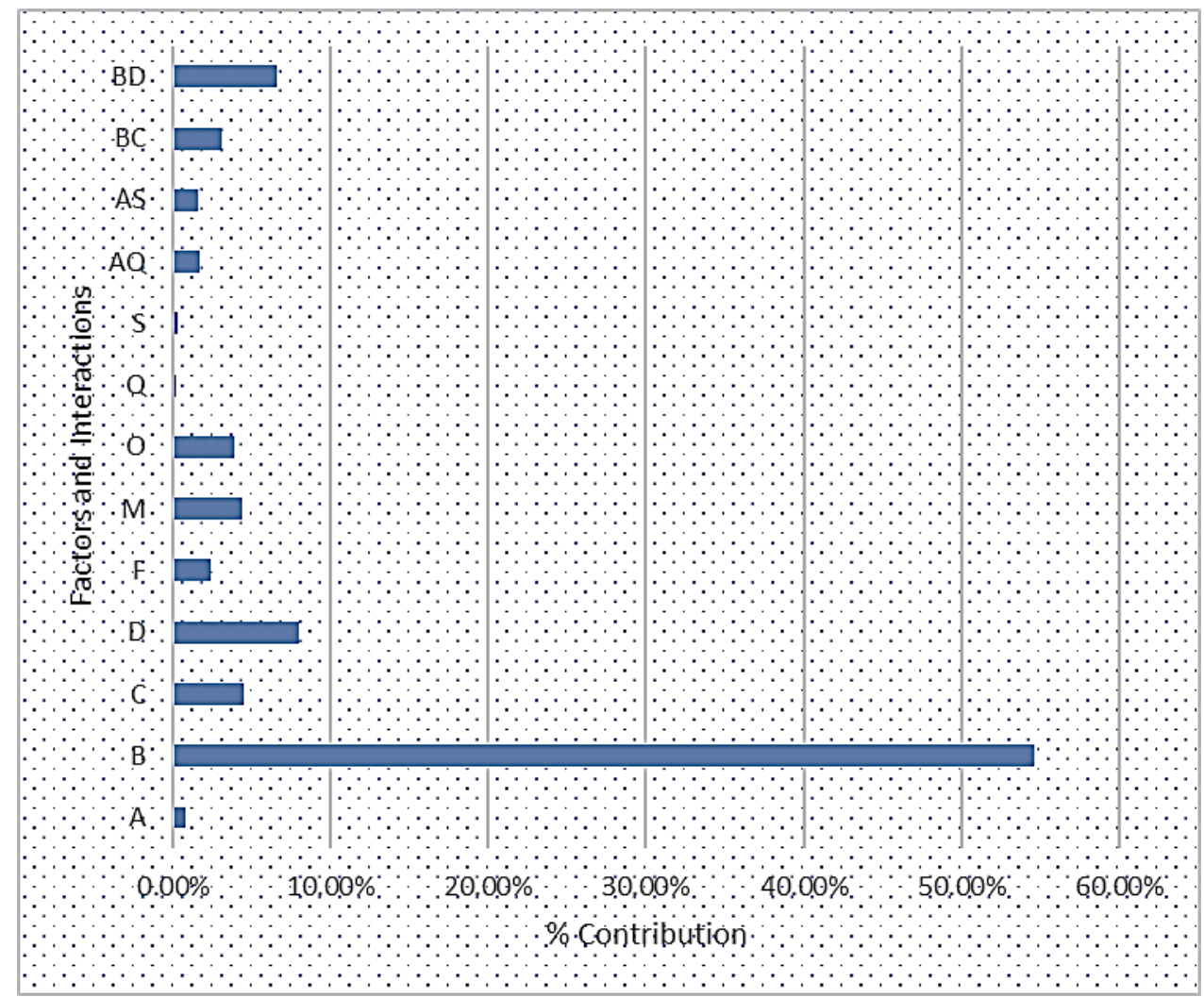

Figure 99: Percentage Contributions of Factors and Interactions on Response R4

It can be clearly observed here that B is the controlling factor in response R4 i.e. maximum moment capacity. An F-value of 190.287 for factor B in comparison to second highest F-value of 27.836 for factor D as shown in ANOVA Table 21 verifies the distinctive influence of factor B on the response R4. 
Table 21: ANOVA of Selected Model for Response R4

\begin{tabular}{|l|r|r|r|r|r|l|}
\hline SOURCE & \multicolumn{1}{l|l|}{$\begin{array}{l}\text { SUM OF } \\
\text { SQUARES }\end{array}$} & df & $\begin{array}{l}\text { MEAN } \\
\text { SQUARE }\end{array}$ & F-VALUE & P-VALUE & \\
\hline Block & 5.608 & 1 & 5.608 & & & \\
\hline Model & 76262618.559 & 13 & 5866355.274 & 26.790 & 0.000 & significant \\
\hline A-bf & 559675.858 & 1 & 559675.858 & 2.556 & 0.120 & \\
\hline B-db & 41667900.877 & 1 & 41667900.877 & 190.287 & 0.000 & \\
\hline C-tfb & 3405979.708 & 1 & 3405979.708 & 15.554 & 0.000 & \\
\hline D-twb & 6095414.145 & 1 & 6095414.145 & 27.836 & 0.000 & \\
\hline F-b & 1780331.376 & 1 & 1780331.376 & 8.130 & 0.008 & \\
\hline M-Fybw - & 3293279.511 & 1 & 3293279.511 & 15.040 & 0.000 & \\
Web & & & & & & \\
\hline O-dc & 2978556.945 & 1 & 2978556.945 & 13.602 & 0.001 & \\
\hline Q-twc & 133560.632 & 1 & 133560.632 & 0.610 & 0.441 & \\
\hline S-tdwp & 189293.224 & 1 & 189293.224 & 0.864 & 0.359 & \\
\hline AQ & 1294579.785 & 1 & 1294579.785 & 5.912 & 0.021 & \\
\hline AS & 1173534.231 & 1 & 1173534.231 & 5.359 & 0.027 & \\
\hline BC & 2324811.014 & 1 & 2324811.014 & 10.617 & 0.003 & \\
\hline BD & 4978039.390 & 1 & 4978039.390 & 22.733 & 0.000 & \\
\hline Residual & 7007167.986 & 32 & 218974.000 & & & \\
\hline Cor Total & 83269792.152 & 46 & & & & \\
\hline
\end{tabular}

The $2 \mathrm{FI}$ of factors $\mathrm{B}$ and $\mathrm{D}$ show that at factor $\mathrm{D}$ has a direct effect on the sensitivity of relation between maximum moment capacity and value of factor B. As it can be observed in Figures 100 and 101, at low-level value of factor D, the maximum moment capacity was increased by $659.17 \%$ as value of factor B was increased from low- to high-level value while this percentage was increased to $1337.84 \%$ for high-level value of factor D. 
Design-Expert ${ }^{\circledR 3}$ Software

Factor Coding: Actual

Max Moment Capacity (kN-m)

$\mathrm{X} 1=\mathrm{B}: \mathrm{db}$

X2 = D: twb

Actual Factors

A: $b f=241.81$

C: $t$ tb $=20.995$

$\mathrm{E}: \mathrm{a}=147.3$

$\mathrm{F}: \mathrm{b}=425.875$

$\mathrm{G}: \mathrm{c}($ or $\mathrm{g})=41.25$

$\mathrm{H}: \mathrm{L}=3008$

$\mathrm{J}$ : Esbf - Flange $=198500$

$\mathrm{K}$ : Fybf - Flange $=342.5$

L: Esbw - Web $=198500$

M: Fybw - Web $=342.5$

$\mathrm{N}: \mathrm{wc}=389.89$

$\mathrm{O}: \mathrm{dc}=659.13$

$\mathrm{P}: \mathrm{tfc}=48.58$

$\mathrm{Q}:$ twc $=30.165$

$\mathrm{R}: \mathrm{H}=4000$

$\mathrm{S}:$ tdwp $=12.5$

$\mathrm{T}: \mathrm{tcp}=12.5$

$\mathrm{U}:$ Fycf - Flange $=332.5$

$\mathrm{V}$ : Fycw - Web $=332.5$

D- 5

$\Delta \mathrm{D}+20.32$

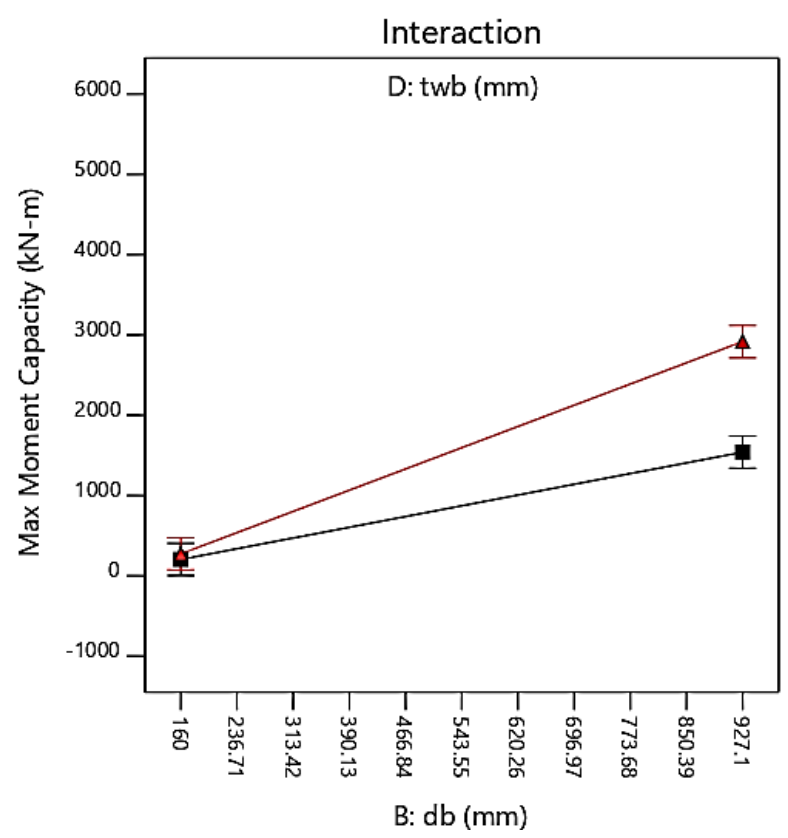

Figure 100: Plot of Marginal Means for Interaction BD in Selected Model for Response R4
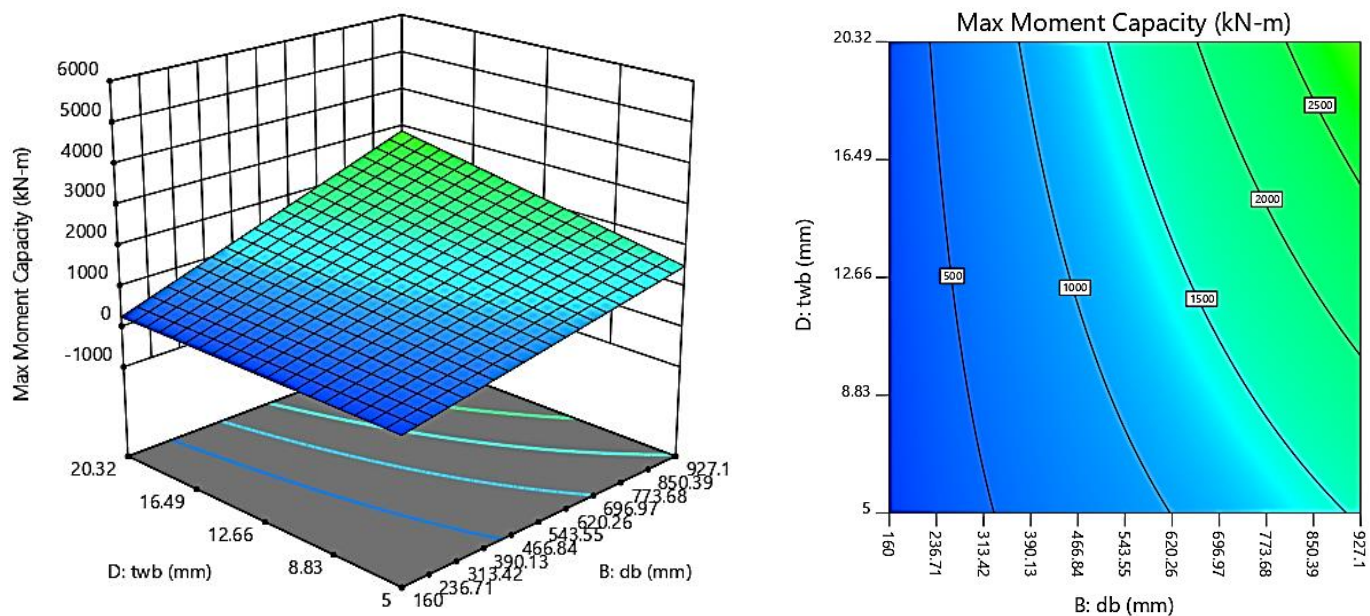

Figure 101: 3D Response Surface and Contour Plots for 2FI BD in Selected Model for Response R4 


\subsubsection{For Response Variable R5 (Rupture Index @ 7.5\% Total Storey Drift)}

The coded equation of selected model for response variable $\mathrm{R} 5$ with an $\mathrm{R}^{2}$ value of 0.9069 is:

$$
\begin{aligned}
R 5=\beta_{0}+\beta_{1} A & +\beta_{2} B+\beta_{3} C+\beta_{4} D+\beta_{5} F+\beta_{6} G+\beta_{7} M+\beta_{8} N+\beta_{9} O+\beta_{10} P \\
& +\beta_{11} Q+\beta_{12} T+\beta_{13} U+\beta_{14} A B+\beta_{15} A C+\beta_{16} A D+\beta_{17} A M+\beta_{18} A N \\
& +\beta_{19} A O+\beta_{20} A P+\beta_{21} A Q+\beta_{22} A T+\beta_{23} B D+\beta_{24} A B D
\end{aligned}
$$

Coefficient $\beta$ values are presented in Table 22.

Table 22: Coefficients of Model for Response R5

\begin{tabular}{|l|r|l|r|}
\hline Coefficient & \multicolumn{1}{l|}{ Value } & Coefficient & \multicolumn{1}{l|}{ Value } \\
\hline$\beta_{0}$ & 4.29 & $\beta_{13}$ & 1.83 \\
\hline$\beta_{1}$ & -2.30 & $\beta_{14}$ & -2.62 \\
\hline$\beta_{2}$ & 5.60 & $\beta_{15}$ & -1.83 \\
\hline$\beta_{3}$ & 0.23 & $\beta_{16}$ & 5.04 \\
\hline$\beta_{4}$ & -2.28 & $\beta_{17}$ & -2.36 \\
\hline$\beta_{5}$ & -2.45 & $\beta_{18}$ & -1.75 \\
\hline$\beta_{6}$ & 2.08 & $\beta_{19}$ & -2.41 \\
\hline$\beta_{7}$ & 3.067084 & $\beta_{20}$ & -1.10736 \\
\hline$\beta_{8}$ & -0.0638 & $\beta_{21}$ & 2.09657 \\
\hline$\beta_{9}$ & 5.045768 & $\beta_{22}$ & 2.602347 \\
\hline$\beta_{10}$ & 1.274103 & $\beta_{23}$ & -2.67257 \\
\hline$\beta_{11}$ & -1.21898 & $\beta_{24}$ & 3.086337 \\
\hline$\beta_{12}$ & -2.24715 & & \\
\hline
\end{tabular}

The half-normal probability distribution plot for response R5 suggest the significance of factors $\mathrm{B}$ and $\mathrm{O}$ and $2 \mathrm{FI}$ of factors $\mathrm{A}$ and $\mathrm{D}(\mathrm{AD})$ as can be observed from Figures 102 and 103. 
Design-Expert ${ }^{\circledR}$ Software

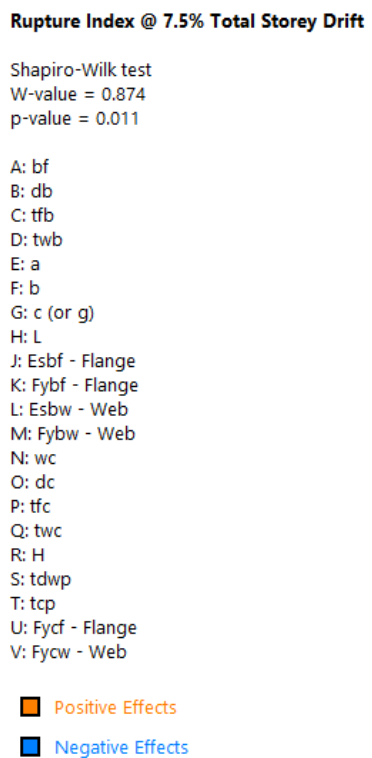

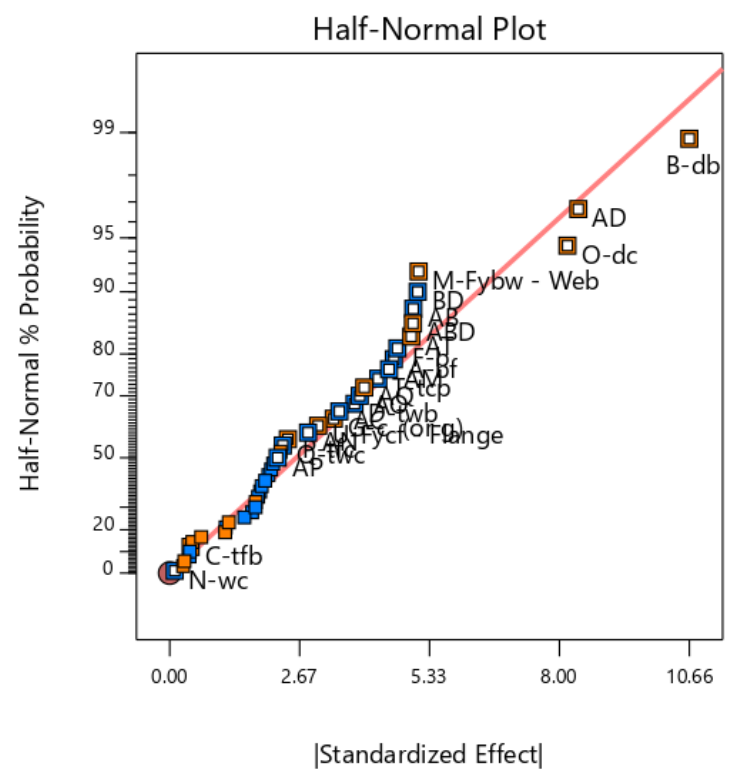

Figure 102: Half-Normal Probability Plot for Response R5 (Rupture Index @ 7.5\% Total Storey Drift)

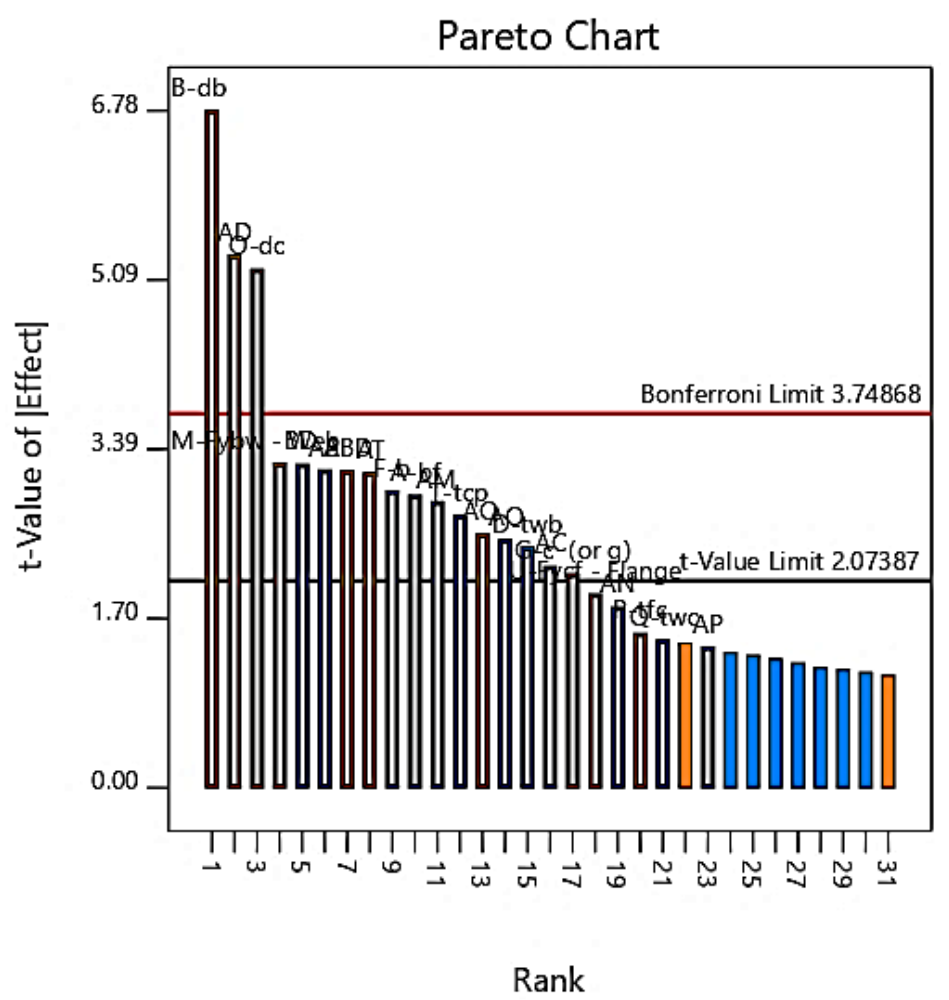

Figure 103: Pareto Chart for Response R5 (Rupture Index @ 7.5\% Total Storey Drift) 
It is evident that the most influential factor amongst these was factor B with a total contribution of $18.69 \%$ towards response $\mathrm{R} 5$ followed by $2 \mathrm{FI} \mathrm{AD}$ and factor $\mathrm{O}$ with contributions of 11.56\% and 10.95\% respectively as depicted in Figure 104.

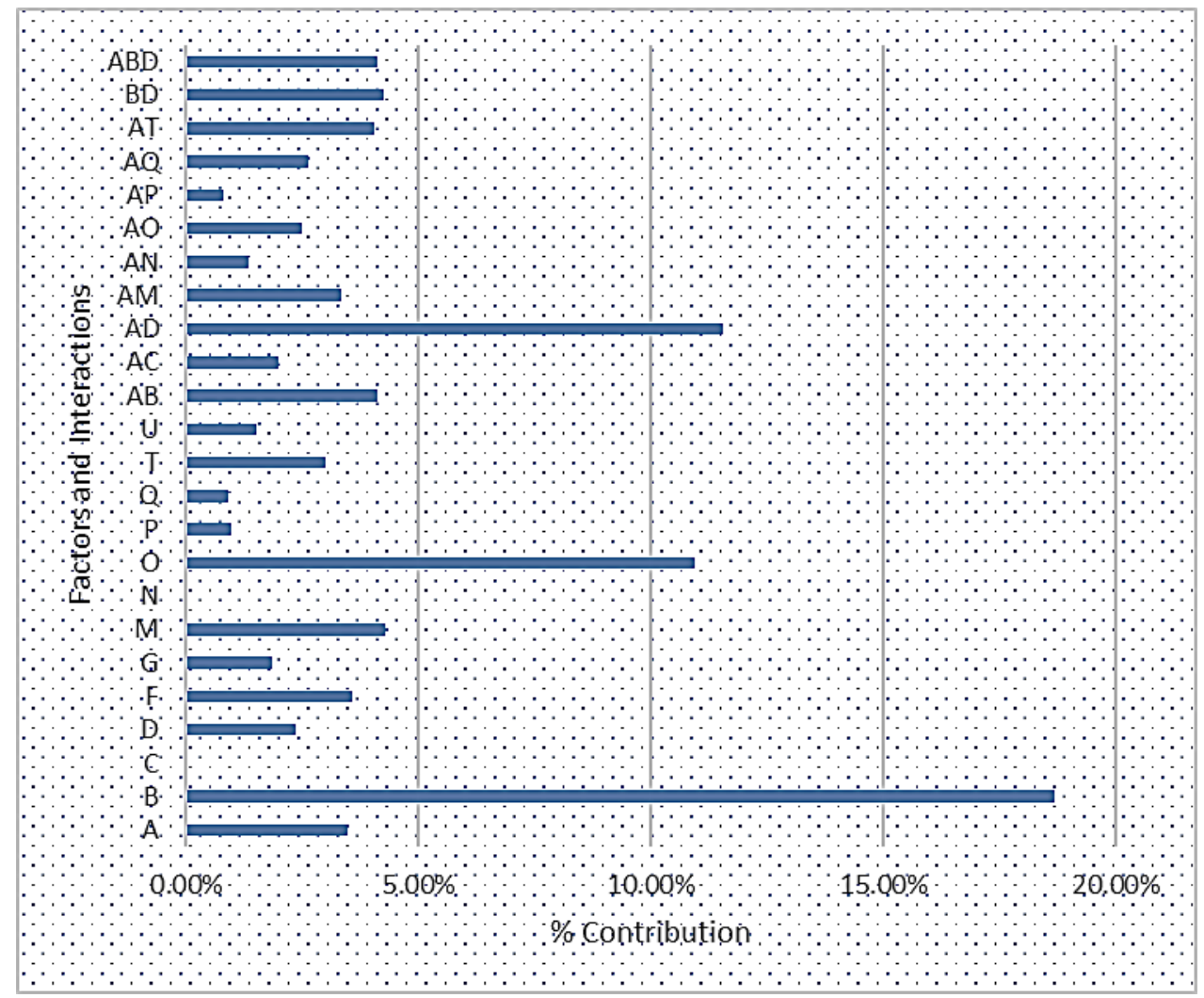

\section{Figure 104: Percentage Contributions of Factors and Interactions on Response R5}

The ANOVA for the selected model for response R5 as shown in Table 23 represents the significance of factor $\mathrm{B}$ over other factors with the highest F-value of 46.007 followed by 2FI of A and D (AD) and factor O with F-values of 28.461 and 26.961 respectively. 
Table 23: ANOVA of Selected Model for Response R5

\begin{tabular}{|l|r|r|r|r|r|l|}
\hline SOURCE & \multicolumn{1}{l|}{$\begin{array}{l}\text { SUM OF } \\
\text { SQUARES }\end{array}$} & \multicolumn{1}{l|}{ df } & $\begin{array}{l}\text { MEAN } \\
\text { SQUARE }\end{array}$ & F-VALUE & P-VALUE & \\
\hline Block & 248.978 & 1 & 248.978 & & & \\
\hline Model & 5830.810 & 24 & 242.950 & 8.522 & 0.000 & Significant \\
\hline A-bf & 244.050 & 1 & 244.050 & 8.561 & 0.008 & \\
\hline B-db & 1311.543 & 1 & 1311.543 & 46.007 & 0.000 & \\
\hline C-tfb & 2.129 & 1 & 2.129 & 0.075 & 0.787 & \\
\hline D-twb & 165.946 & 1 & 165.946 & 5.821 & 0.025 & \\
\hline F-b & 251.814 & 1 & 251.814 & 8.833 & 0.007 & \\
\hline G-c (or g) & 130.733 & 1 & 130.733 & 4.586 & 0.044 & \\
\hline M-Fybw - & 301.024 & 1 & 301.024 & 10.559 & 0.004 & \\
Web & & & & & & \\
\hline N-wc & 0.123 & 1 & 0.123 & 0.004 & 0.948 & \\
\hline O-dc & 768.597 & 1 & 768.597 & 26.961 & 0.000 & \\
\hline P-tfc & 67.904 & 1 & 67.904 & 2.382 & 0.138 & \\
\hline Q-twc & 62.156 & 1 & 62.156 & 2.180 & 0.155 & \\
\hline T-tcp & 211.229 & 1 & 211.229 & 7.410 & 0.013 & \\
\hline U-Fycf - & 107.000 & 1 & 107.000 & 3.753 & 0.066 & \\
Flange & & & & & & \\
\hline AB & 288.216 & 1 & 288.216 & 10.110 & 0.005 & \\
\hline AC & 139.834 & 1 & 139.834 & 4.905 & 0.038 & \\
\hline AD & 811.360 & 1 & 811.360 & 28.461 & 0.000 & \\
\hline AM & 233.698 & 1 & 233.698 & 8.198 & 0.009 & \\
\hline AN & 92.971 & 1 & 92.971 & 3.261 & 0.085 & \\
\hline AO & 175.538 & 1 & 175.538 & 6.158 & 0.022 & \\
\hline AP & 56.596 & 1 & 56.596 & 1.985 & 0.173 & \\
\hline AQ & 183.869 & 1 & 183.869 & 6.450 & 0.019 & \\
\hline AT & 283.282 & 1 & 283.282 & 9.937 & 0.005 & \\
\hline BD & 298.778 & 1 & 298.778 & 10.481 & 0.004 & \\
\hline ABD & 287.562 & 1 & 287.562 & 10.087 & 0.005 & \\
\hline Residual & 598.662 & 21 & 28.508 & & & \\
\hline Cor Total & 6678.450 & 46 & & & & \\
\hline
\end{tabular}

It was observed from the interaction plots of $2 \mathrm{FI} A D$ that higher value of factor $\mathrm{D}$ (20.32 mm) in combination with low-level value of factor A yields a lower value of rupture index as represented in Figures 105 and 106. In other words, at low-level value of factor D, factor A has an inverse effect on RI @ 7.5\% total storey drift that is explained by the decrease in the response when the value of factor A was 
increased from low- to high-level at low-level value of factor D. On the other hand, factor A has a direct effect on RI @ 7.5\% storey drift at high-level value of factor D.
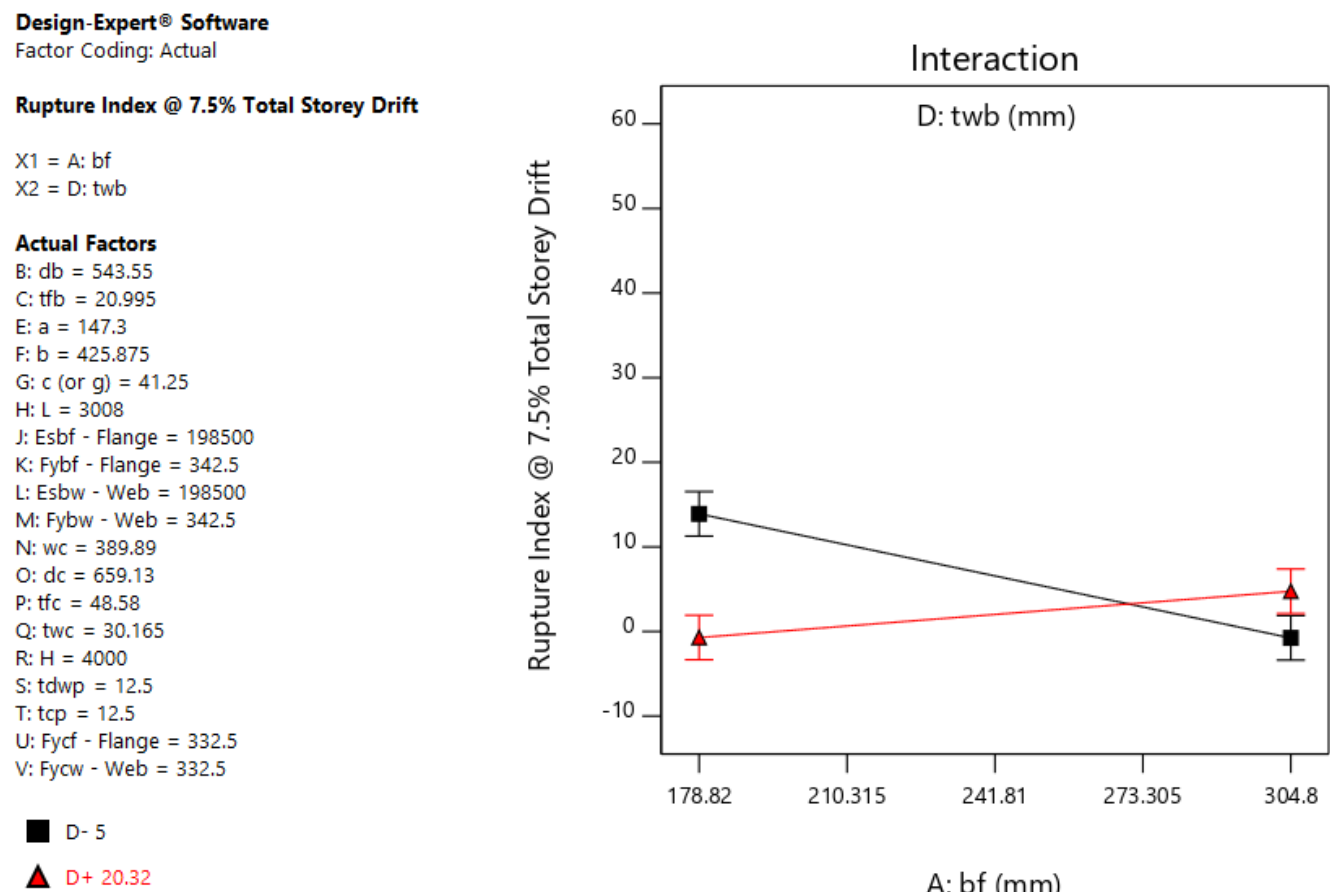

Figure 105: Plot of Marginal Means for Interaction AD in Selected Model for Response R5
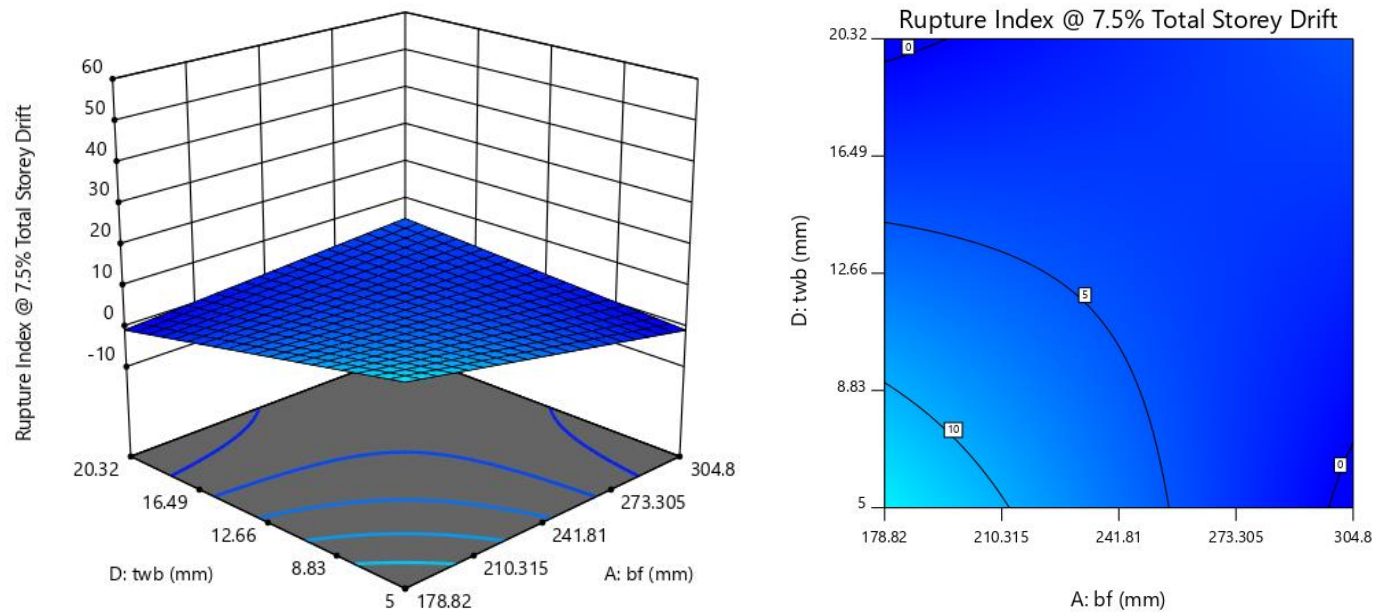

Figure 106: 3D Response Surface and Contour Plots for 2FI AD in Selected Model for Response R5 


\subsubsection{Overview of the Results}

The summary of actual percentage contributions for all factors of selected models is presented in Table 24. All of the rows were summed up and divided individually by grand total of all the values of $\%$ contribution for responses for all factors as given in Table 24 to get an aggregate overall percentage effectiveness which is graphically represented in Figure 107.

Table 24: Summary of Contribution of Factors for All Responses

\begin{tabular}{|c|c|c|c|c|c|c|c|}
\hline \multirow{2}{*}{ FACTORS } & \multicolumn{5}{|c|}{ \% CONTRIBUTION FOR RESPONSES } & \multirow{2}{*}{$\begin{array}{l}\text { SUM OF } \\
\text { ROWS }\end{array}$} & \multirow{2}{*}{$\begin{array}{c}\text { OVERALL } \\
\%\end{array}$} \\
\hline & $\mathbf{R 1}$ & $\mathbf{R 2}$ & $\mathbf{R 3}$ & R4 & $\mathbf{R 5}$ & & \\
\hline A & $3.82 \%$ & - & $0.92 \%$ & $0.73 \%$ & $3.48 \%$ & $8.95 \%$ & $1.93 \%$ \\
\hline B & $35.47 \%$ & $71.53 \%$ & $5.20 \%$ & $54.68 \%$ & $18.69 \%$ & $185.58 \%$ & $40.09 \%$ \\
\hline $\mathrm{C}$ & $5.70 \%$ & $3.37 \%$ & $6.60 \%$ & $4.47 \%$ & $0.03 \%$ & $20.17 \%$ & $4.36 \%$ \\
\hline $\mathrm{D}$ & $3.57 \%$ & $5.18 \%$ & $0.13 \%$ & $8.00 \%$ & $2.37 \%$ & $19.24 \%$ & $4.16 \%$ \\
\hline $\mathrm{E}$ & $0.09 \%$ & - & $0.00 \%$ & - & - & $0.09 \%$ & $0.02 \%$ \\
\hline $\mathrm{F}$ & $1.99 \%$ & - & $1.70 \%$ & $2.34 \%$ & $3.59 \%$ & $9.61 \%$ & $2.08 \%$ \\
\hline $\mathrm{G}$ & - & - & $3.70 \%$ & - & $1.86 \%$ & $5.56 \%$ & $1.20 \%$ \\
\hline $\mathrm{H}$ & - & $1.19 \%$ & $2.51 \%$ & - & - & $3.70 \%$ & $0.80 \%$ \\
\hline $\mathrm{J}$ & $0.01 \%$ & - & $7.34 \%$ & - & - & $7.35 \%$ & $1.59 \%$ \\
\hline $\mathrm{K}$ & $1.35 \%$ & - & $10.18 \%$ & - & - & $11.53 \%$ & $2.49 \%$ \\
\hline $\mathrm{L}$ & $1.83 \%$ & - & $2.16 \%$ & - & - & $3.99 \%$ & $0.86 \%$ \\
\hline $\mathrm{M}$ & $4.89 \%$ & $1.34 \%$ & - & $4.32 \%$ & $4.29 \%$ & $14.84 \%$ & $3.21 \%$ \\
\hline $\mathrm{N}$ & - & - & $0.01 \%$ & - & $0.00 \%$ & $0.01 \%$ & $0.00 \%$ \\
\hline $\mathrm{O}$ & $4.52 \%$ & - & $1.30 \%$ & $3.91 \%$ & $10.95 \%$ & $20.68 \%$ & $4.47 \%$ \\
\hline$P$ & - & - & $1.77 \%$ & - & $0.97 \%$ & $2.73 \%$ & $0.59 \%$ \\
\hline $\mathrm{Q}$ & $0.06 \%$ & - & $3.36 \%$ & $0.18 \%$ & $0.89 \%$ & $4.48 \%$ & $0.97 \%$ \\
\hline $\mathrm{R}$ & - & - & $3.08 \%$ & - & - & $3.08 \%$ & $0.67 \%$ \\
\hline$S$ & $0.01 \%$ & - & - & $0.25 \%$ & - & $0.26 \%$ & $0.06 \%$ \\
\hline $\mathrm{T}$ & - & - & - & - & $3.01 \%$ & $3.01 \%$ & $0.65 \%$ \\
\hline $\mathrm{U}$ & $0.00 \%$ & - & - & - & $1.53 \%$ & $1.53 \%$ & $0.33 \%$ \\
\hline $\mathrm{AB}$ & $2.96 \%$ & - & $0.99 \%$ & - & $4.11 \%$ & $8.06 \%$ & $1.74 \%$ \\
\hline $\mathrm{AC}$ & $0.12 \%$ & - & - & - & $1.99 \%$ & $2.11 \%$ & $0.46 \%$ \\
\hline $\mathrm{AD}$ & $3.26 \%$ & - & $2.03 \%$ & - & $11.56 \%$ & $16.86 \%$ & $3.64 \%$ \\
\hline $\mathrm{AE}$ & $2.47 \%$ & - & $0.12 \%$ & - & - & $2.59 \%$ & $0.56 \%$ \\
\hline $\mathrm{AF}$ & - & - & $5.56 \%$ & - & - & $5.56 \%$ & $1.20 \%$ \\
\hline AJ & $1.06 \%$ & - & $2.96 \%$ & - & - & $4.02 \%$ & $0.87 \%$ \\
\hline $\mathrm{AK}$ & - & - & $5.92 \%$ & - & - & $5.92 \%$ & $1.28 \%$ \\
\hline $\mathrm{AL}$ & - & - & $8.30 \%$ & - & - & $8.30 \%$ & $1.79 \%$ \\
\hline AM & - & - & - & - & $3.33 \%$ & $3.33 \%$ & $0.72 \%$ \\
\hline
\end{tabular}




\begin{tabular}{|l|c|c|c|c|c|c|c|}
\hline AN & - & - & $1.02 \%$ & - & $1.33 \%$ & $2.34 \%$ & $0.51 \%$ \\
\hline AO & - & - & - & - & $2.50 \%$ & $2.50 \%$ & $0.54 \%$ \\
\hline AP & - & - & - & - & $0.81 \%$ & $0.81 \%$ & $0.17 \%$ \\
\hline AQ & $3.08 \%$ & - & $0.86 \%$ & $1.70 \%$ & $2.62 \%$ & $8.25 \%$ & $1.78 \%$ \\
\hline AR & - & - & $6.78 \%$ & - & - & $6.78 \%$ & $1.46 \%$ \\
\hline AS & $2.57 \%$ & - & - & $1.54 \%$ & - & $4.11 \%$ & $0.89 \%$ \\
\hline AT & - & - & - & - & $4.04 \%$ & $4.04 \%$ & $0.87 \%$ \\
\hline AU & $5.71 \%$ & - & - & - & - & $5.71 \%$ & $1.23 \%$ \\
\hline BC & $4.33 \%$ & $2.66 \%$ & - & $3.05 \%$ & - & $10.04 \%$ & $2.17 \%$ \\
\hline BD & $3.08 \%$ & $5.04 \%$ & - & $6.53 \%$ & $4.26 \%$ & $18.91 \%$ & $4.08 \%$ \\
\hline BE & - & - & $7.19 \%$ & - & - & $7.19 \%$ & $1.55 \%$ \\
\hline ABD & $3.04 \%$ & - & - & - & $4.10 \%$ & $7.13 \%$ & $1.54 \%$ \\
\hline ABE & - & - & $1.96 \%$ & - & - & $1.96 \%$ & $0.42 \%$ \\
\cline { 7 - 8 } & & & & & Total & $462.88 \%$ & \\
\cline { 7 - 8 } & & & & &
\end{tabular}

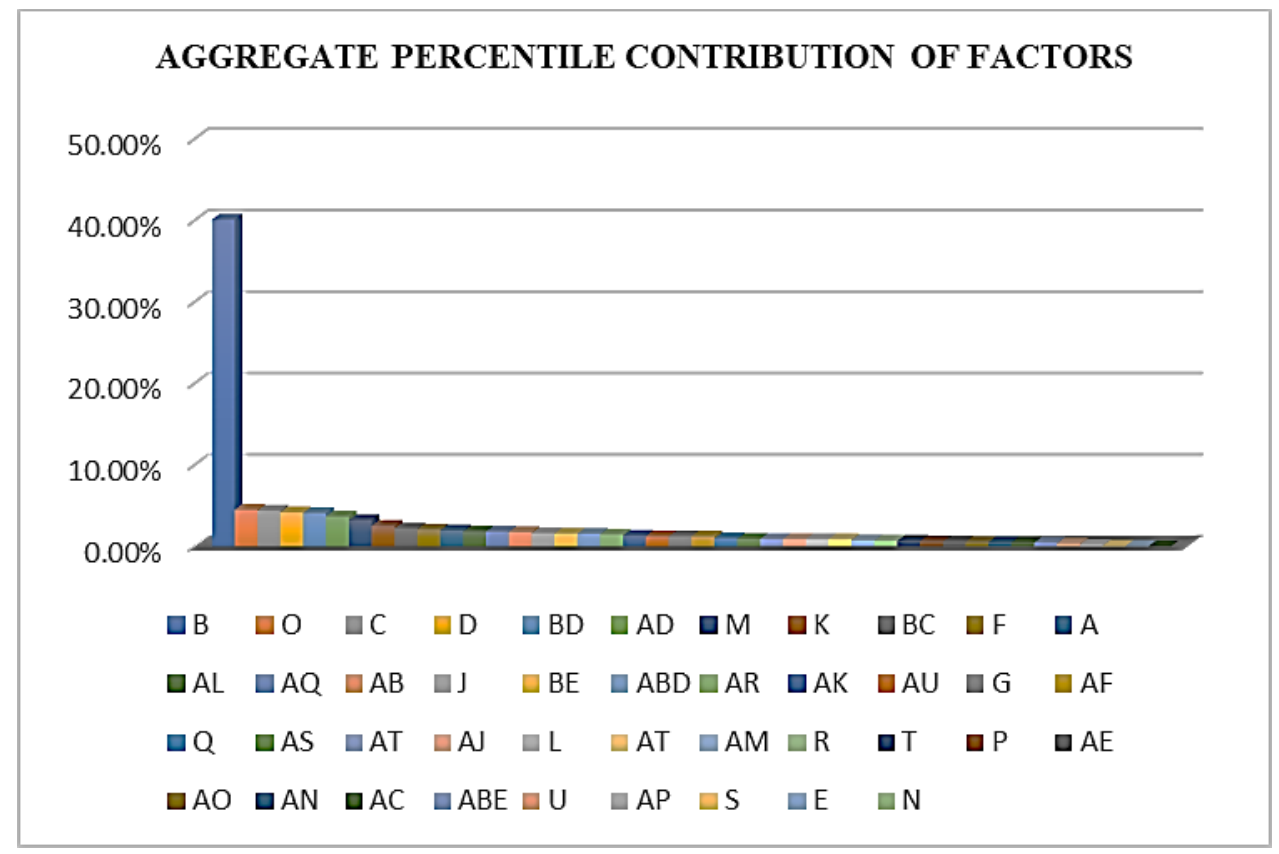

Figure 107: Graphical Representation of Aggregate Percentile Contribution of Factors

These factors were therefore ranked on the basis of their aggregate percentile effect for all 5 responses as presented in Table 25 . There were some factors that were significantly affective for all responses with a higher percentage contribution and hence were ranked higher than those factors that were effective just for certain responses. 
Table 25: Overall Ranking of Factors

\begin{tabular}{|c|c|c|}
\hline RANK & FACTOR(s) & $\begin{array}{c}\text { OVERALL } \\
\%\end{array}$ \\
\hline 1 & $\mathrm{~B}$ & $40.09 \%$ \\
\hline 2 & $\mathrm{O}$ & $4.47 \%$ \\
\hline 3 & $\mathrm{C}$ & $4.36 \%$ \\
\hline 4 & $\mathrm{D}$ & $4.16 \%$ \\
\hline 5 & $\mathrm{BD}$ & $4.08 \%$ \\
\hline 6 & $\mathrm{AD}$ & $3.64 \%$ \\
\hline 7 & $\mathrm{M}$ & $3.21 \%$ \\
\hline 8 & $\mathrm{~K}$ & $2.49 \%$ \\
\hline 9 & $\mathrm{BC}$ & $2.17 \%$ \\
\hline 10 & $\mathrm{~F}$ & $2.08 \%$ \\
\hline 11 & A & $1.93 \%$ \\
\hline 12 & $\mathrm{AL}$ & $1.79 \%$ \\
\hline 13 & $\mathrm{AQ}$ & $1.78 \%$ \\
\hline 14 & $\mathrm{AB}$ & $1.74 \%$ \\
\hline 15 & $\mathrm{~J}$ & $1.59 \%$ \\
\hline 16 & $\mathrm{BE}$ & $1.55 \%$ \\
\hline 17 & $\mathrm{ABD}$ & $1.54 \%$ \\
\hline 18 & $\mathrm{AR}$ & $1.46 \%$ \\
\hline 19 & $\mathrm{AK}$ & $1.28 \%$ \\
\hline 20 & $\mathrm{AU}$ & $1.23 \%$ \\
\hline 21 & $\mathrm{G}$ & $1.20 \%$ \\
\hline 22 & $\mathrm{AF}$ & $1.20 \%$ \\
\hline 23 & $\mathrm{Q}$ & $0.97 \%$ \\
\hline 24 & AS & $0.89 \%$ \\
\hline 25 & $\mathrm{AT}$ & $0.87 \%$ \\
\hline 26 & $\mathrm{AJ}$ & $0.87 \%$ \\
\hline 27 & $\mathrm{~L}$ & $0.86 \%$ \\
\hline 27 & $\mathrm{AT}$ & $0.87 \%$ \\
\hline 29 & $\mathrm{AM}$ & $0.72 \%$ \\
\hline 30 & $\mathrm{R}$ & $0.67 \%$ \\
\hline 31 & $\mathrm{~T}$ & $0.65 \%$ \\
\hline 32 & $\mathrm{P}$ & $0.59 \%$ \\
\hline 33 & $\mathrm{AE}$ & $0.56 \%$ \\
\hline 34 & $\mathrm{AO}$ & $0.54 \%$ \\
\hline 35 & AN & $0.51 \%$ \\
\hline 36 & $\mathrm{AC}$ & $0.46 \%$ \\
\hline 37 & $\mathrm{ABE}$ & $0.42 \%$ \\
\hline 38 & $\mathrm{U}$ & $0.33 \%$ \\
\hline
\end{tabular}




\begin{tabular}{|l|l|l|}
\hline 39 & AP & $0.17 \%$ \\
\hline 40 & S & $0.06 \%$ \\
\hline 41 & E & $0.02 \%$ \\
\hline 42 & N & $0.00 \%$ \\
\hline
\end{tabular}

\subsection{CONCLUSIONS AND RECOMMENDATIONS}

In this study, performance of radial flange cut type RBS connections was analyzed under cyclic loading conditions for different combinations of 21 factors. These combinations were designed by adopting 2-Level factorial design of experiment approach. The statistical analysis of the results suggested that:

1. The most significant factor in the performance of RBS connection under cyclic loading conditions is the depth of the beam (factor B) that had contributions of $35.47 \%$, $71.53 \%, 5.20 \%, 54.68 \%$ and $18.69 \%$ towards responses R1 (Total Dissipated Energy), R2 (Initial Stiffness), R3 (Strength Degradation Rate), R4 (Maximum Moment Capacity) and R5 (Rupture Index @ 7.5\% Total Storey Drift), therefore making the RBS connection most sensitive to this factor.

2. Strength degradation rate was influenced by various factors amongst which, yield strength of beam flange was the most significant one.

3. Width of beam flange (factor A) can not only impact total dissipated energy positively with higher value of elastic modulus of beam flange, but it can also affect strength degradation rate more significantly at higher values of factors $F$ (length of flange cut: b), L (elastic modulus of beam web: Esbw) and R (height of the column: H).

4. Depth of the column (factor $\mathrm{O}$ ) significantly affects rupture index.

The findings of this study can be useful for proceeding studies on a similar topic. Also, this study provides an insight of several factors effecting the cyclic response of RBS connections that might help the professionals in the design field to come up with more economical and optimal design solutions. 


\section{GLOSSARY OF ACRONYMS AND SYMBOLS}

2FIs $\quad 2$ Factor Interactions

a Distance from face of the column flange to starting point of beam flange cut (mm)

ANOVA Analysis of Variance

b Length of beam flange cut $(\mathrm{mm})$

bf $\quad$ Width of beam flange $(\mathrm{mm})$

c Depth of beam flange cut $(\mathrm{mm})$

$\mathrm{db} \quad$ Depth of beam section $(\mathrm{mm})$

dc Depth of column section (mm)

Esbf Young's modulus of beam flange (MPa)

Esbw Young's modulus of beam web (MPa)

Escf Young's modulus of column flange (MPa)

Escw Young's modulus of column web (MPa)

FEMA Federal Emergency Management Agency

Fybf Yield strength of beam flange (MPa)

Fybw $\quad$ Yield strength of beam web (MPa)

Fycf Yield strength of column flange (MPa)

Fycw $\quad$ Yield strength of column web (MPa)

$\mathrm{H} \quad$ Total height of column ( $\mathrm{mm})$

L Length of beam $(\mathrm{mm})$

MRF(s) Moment Resisting Frame(s)

PEEQ Equivalent Plastic Strain

PZ Panel Zone 


$\begin{array}{ll}\text { RBS } & \text { Reduced Beam Section } \\ \text { rfc } & \text { Radius of beam flange cut }(\mathrm{mm}) \\ \text { RI } & \text { Rupture Index } \\ \text { s } & \text { Distance from face of the column flange to middle of beam flange cut }(\mathrm{mm}) \\ \text { SDR } & \text { Strength Degradation Rate } \\ \text { tcp } & \text { Thickness of continuity plate }(\mathrm{mm}) \\ \text { tdwp } & \text { Thickness of doubler web plate }(\mathrm{mm}) \\ \text { tfb } & \text { Thickness of beam flange }(\mathrm{mm}) \\ \text { tfc } & \text { Thickness of column flange }(\mathrm{mm}) \\ \text { twb } & \text { Thickness of beam web (mm) } \\ \text { twc } & \text { Thickness of column web (mm) } \\ \text { wc } & \text { Width of column flange }(\mathrm{mm})\end{array}$


APPENDICES 


\section{APPENDIX A: FEA Models}



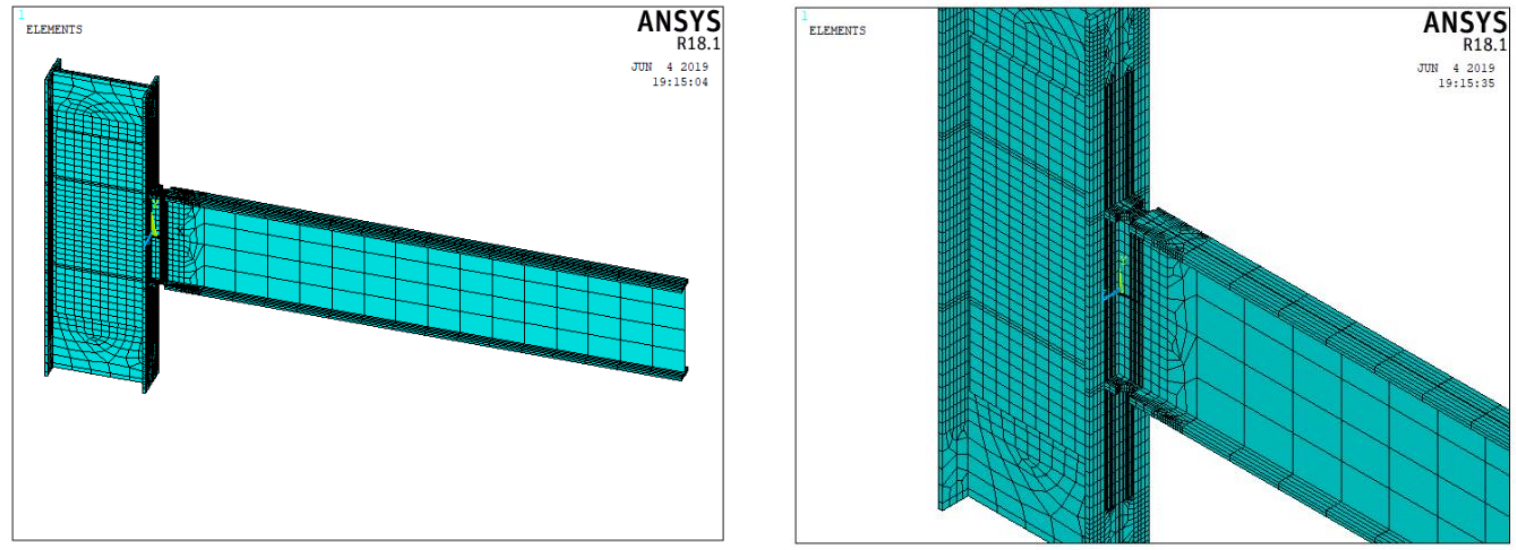

Figure A1: FEA Model for Specimen RBS-7
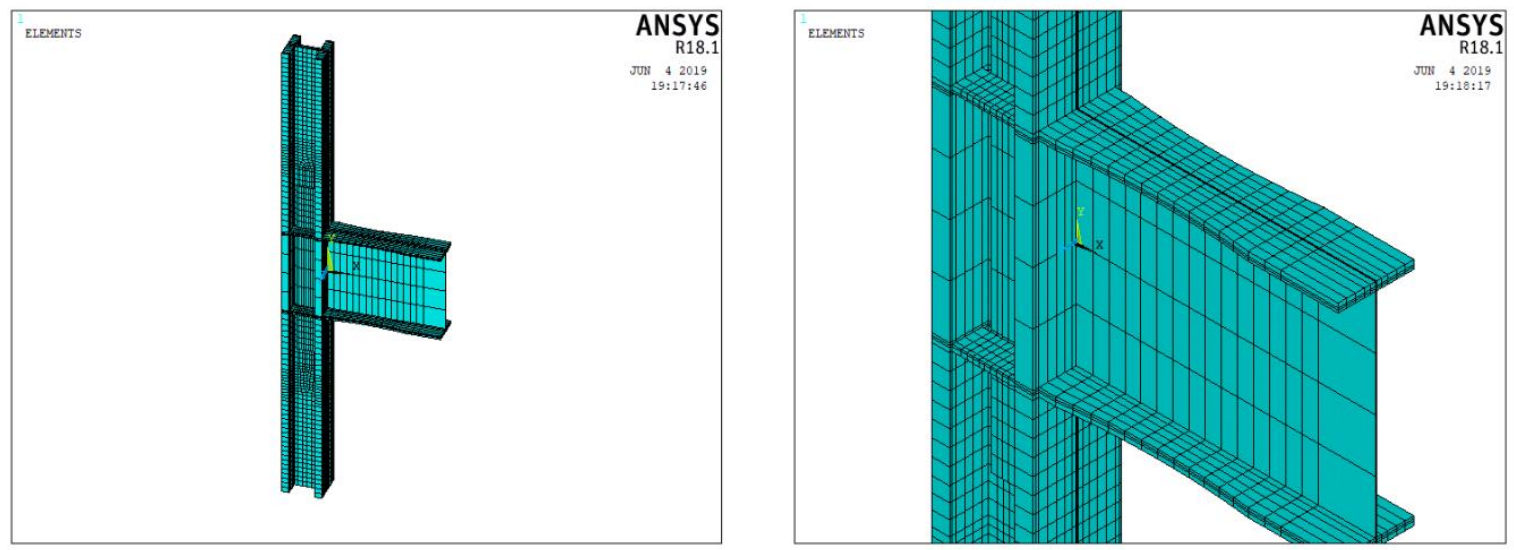

Figure A2: FEA Model for Specimen RBS-8
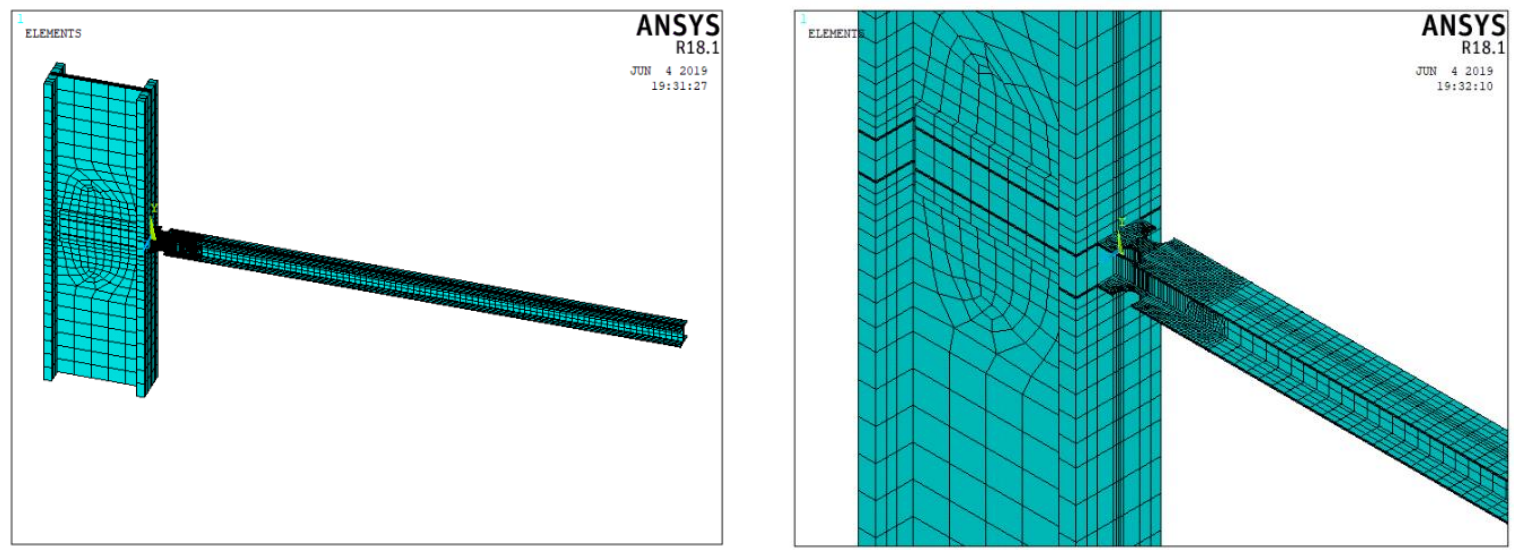

Figure A3: FEA Model for Specimen RBS-9 

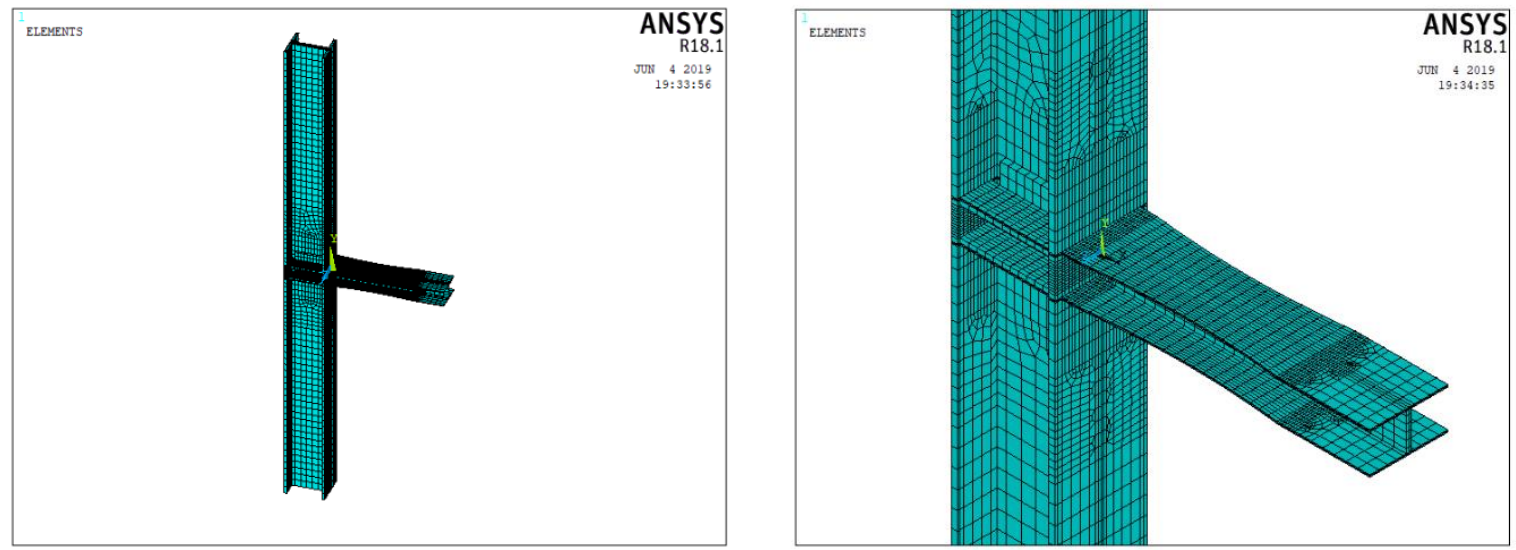

Figure A4: FEA Model for Specimen RBS-10
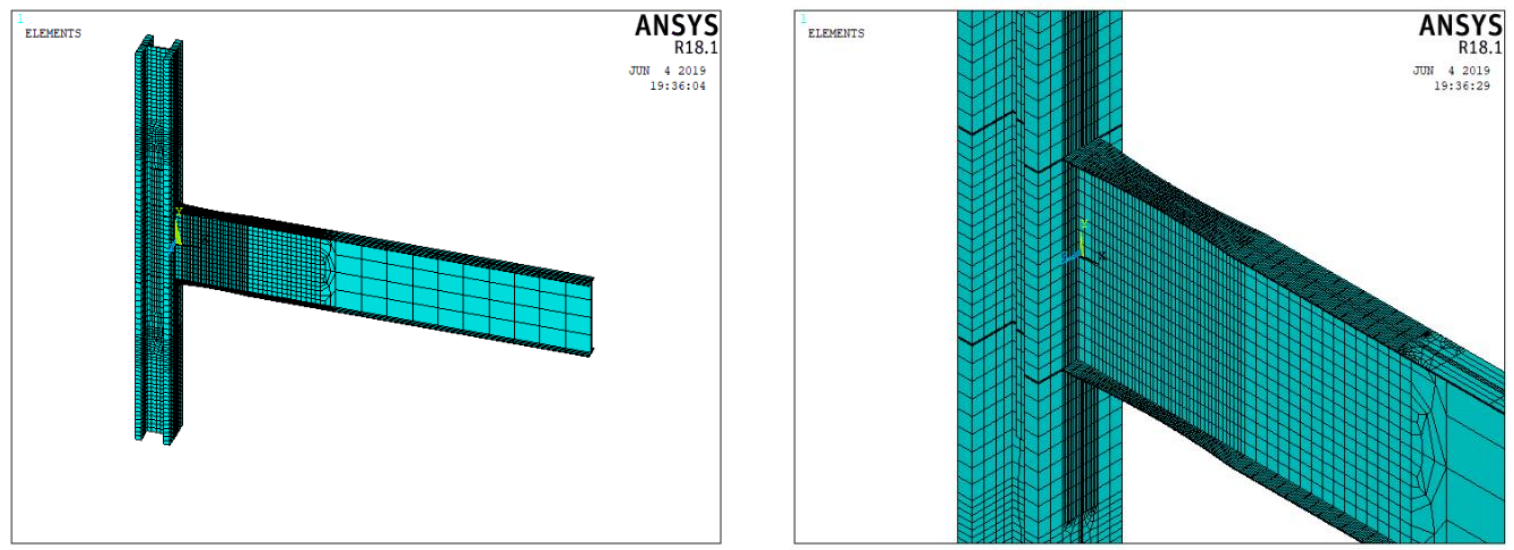

Figure A5: FEA Model for Specimen RBS-11
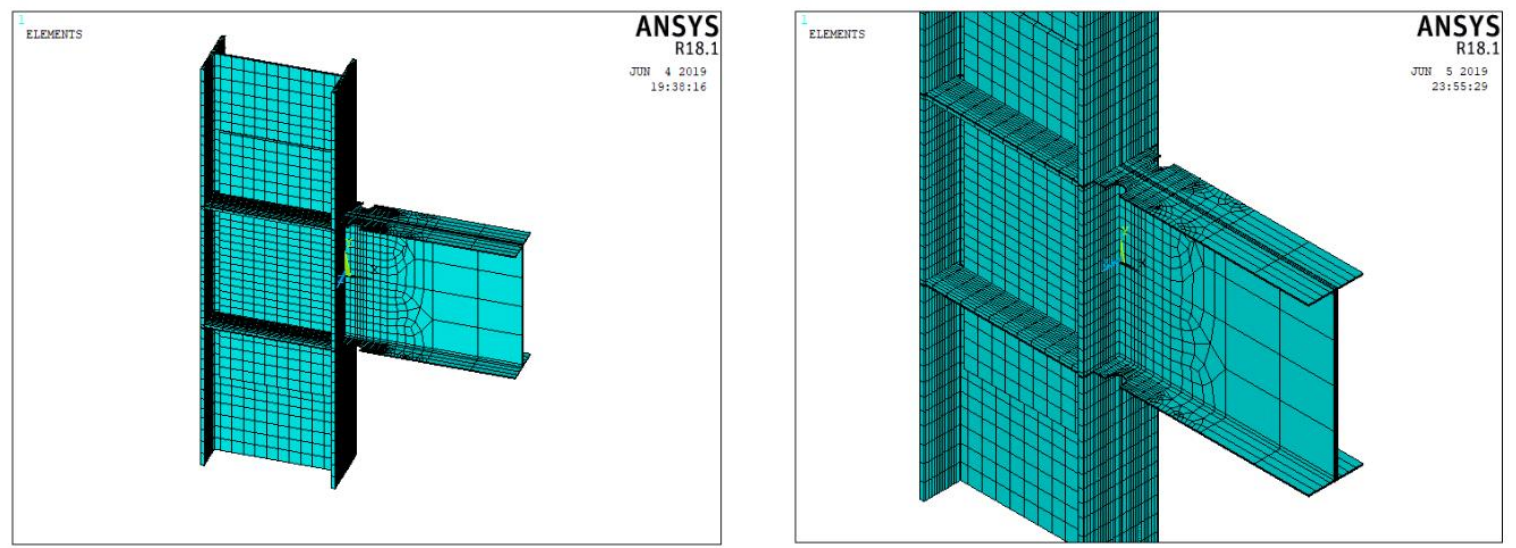

Figure A6: FEA Model for Specimen RBS-12 

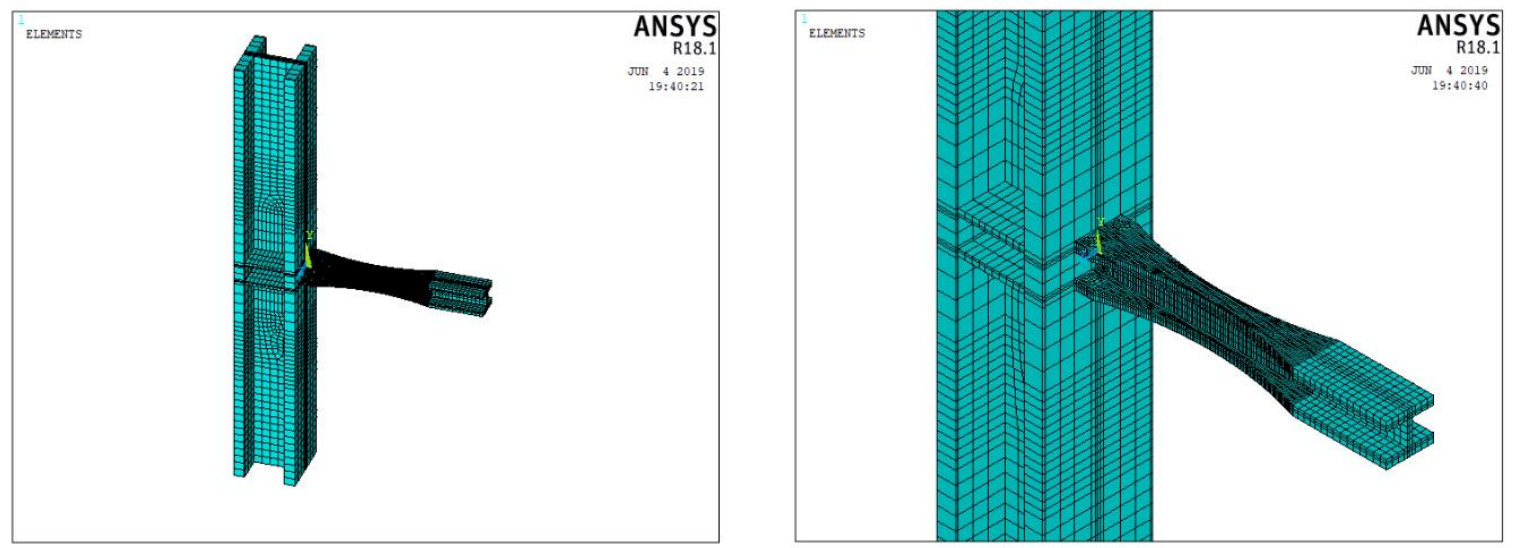

Figure A7: FEA Model for Specimen RBS-13
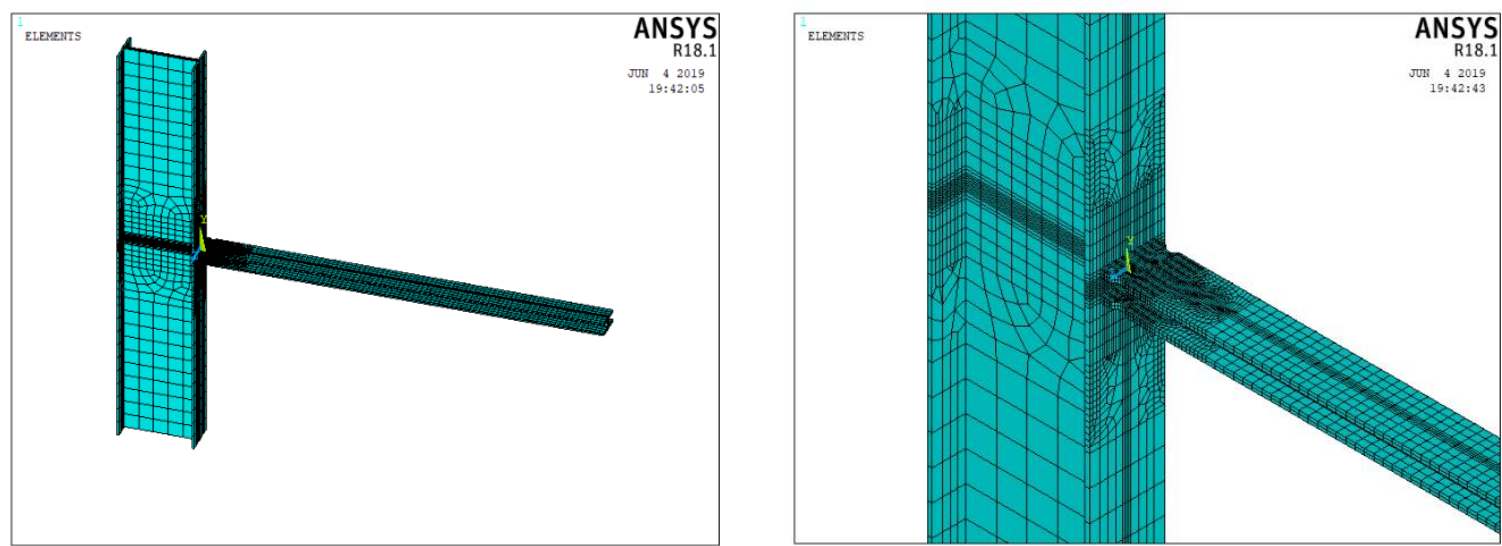

Figure A8: FEA Model for Specimen RBS-14
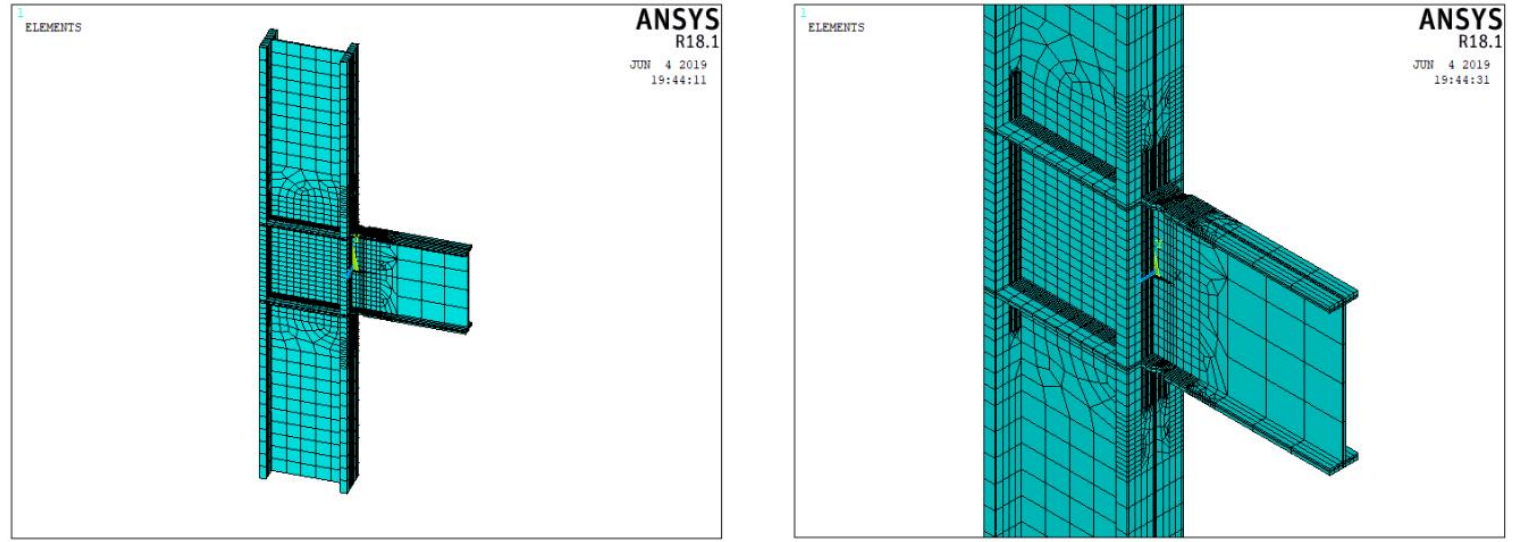

Figure A9: FEA Model for Specimen RBS-15 

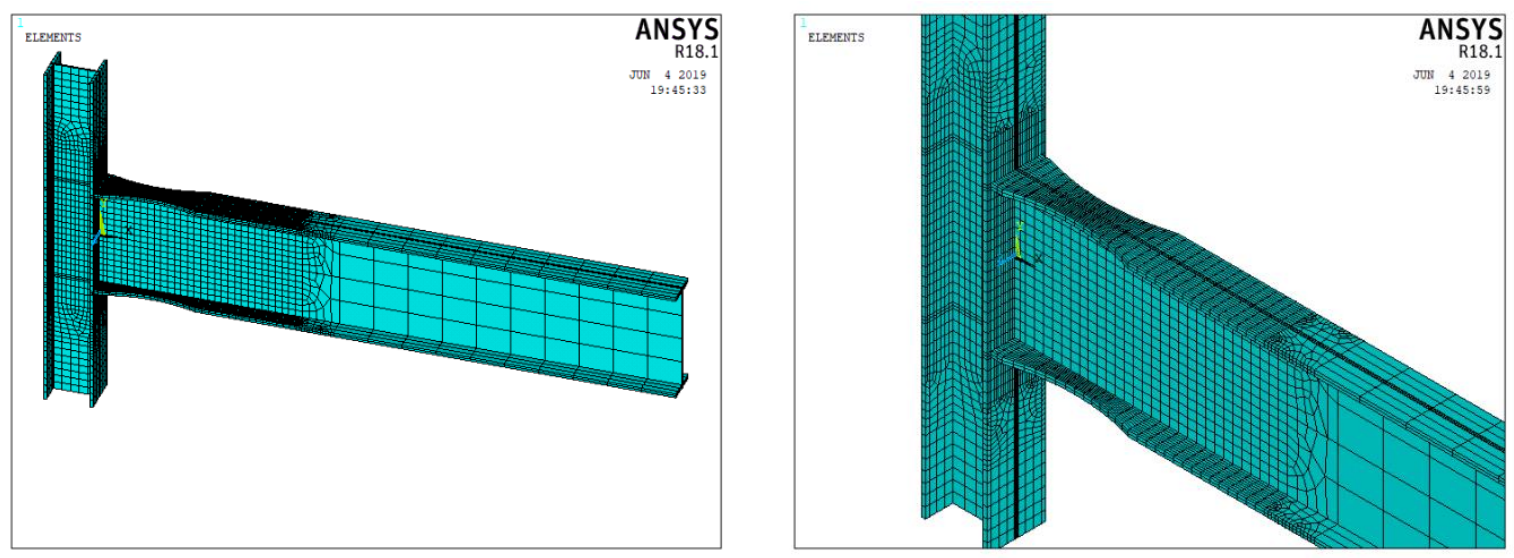

Figure A10: FEA Model for Specimen RBS-16
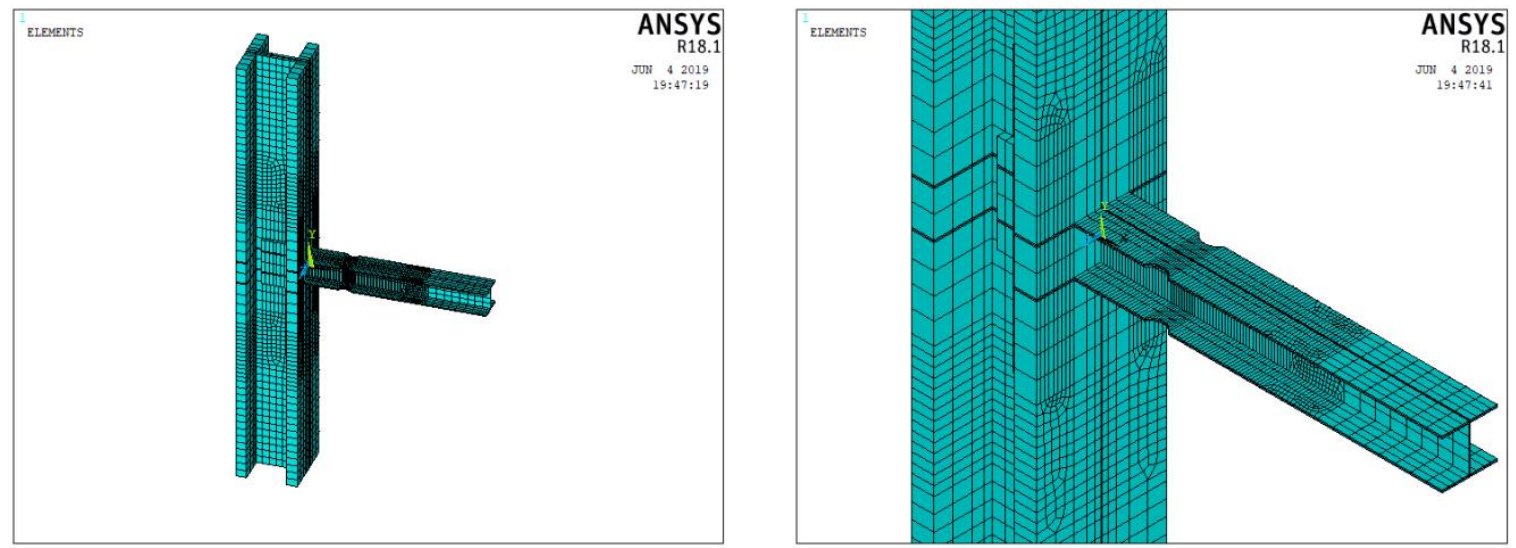

Figure A11: FEA Model for Specimen RBS-17
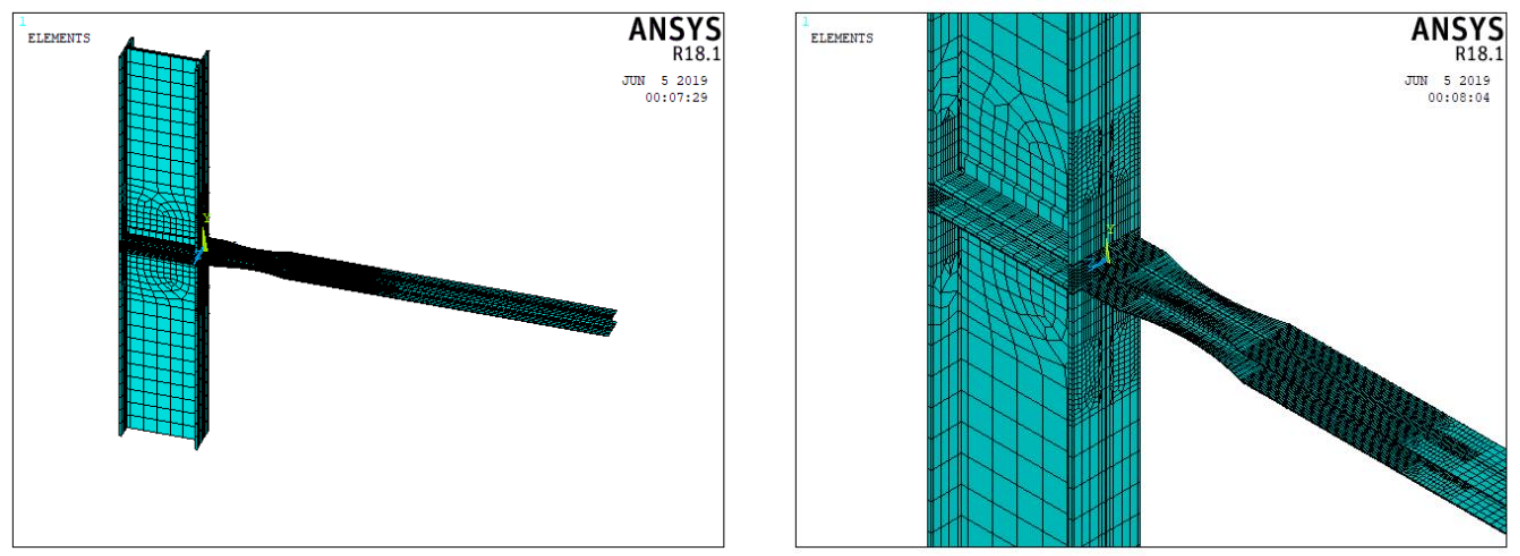

Figure A12: FEA Model for Specimen RBS-18 

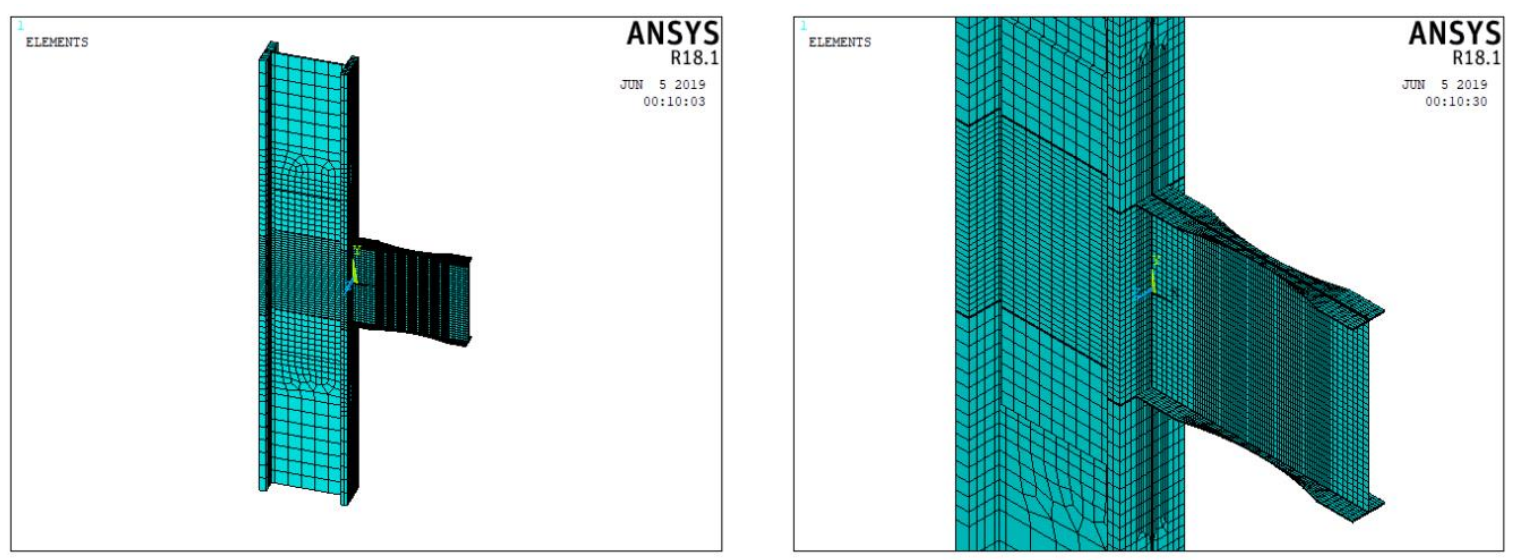

Figure A13: FEA Model for Specimen RBS-19
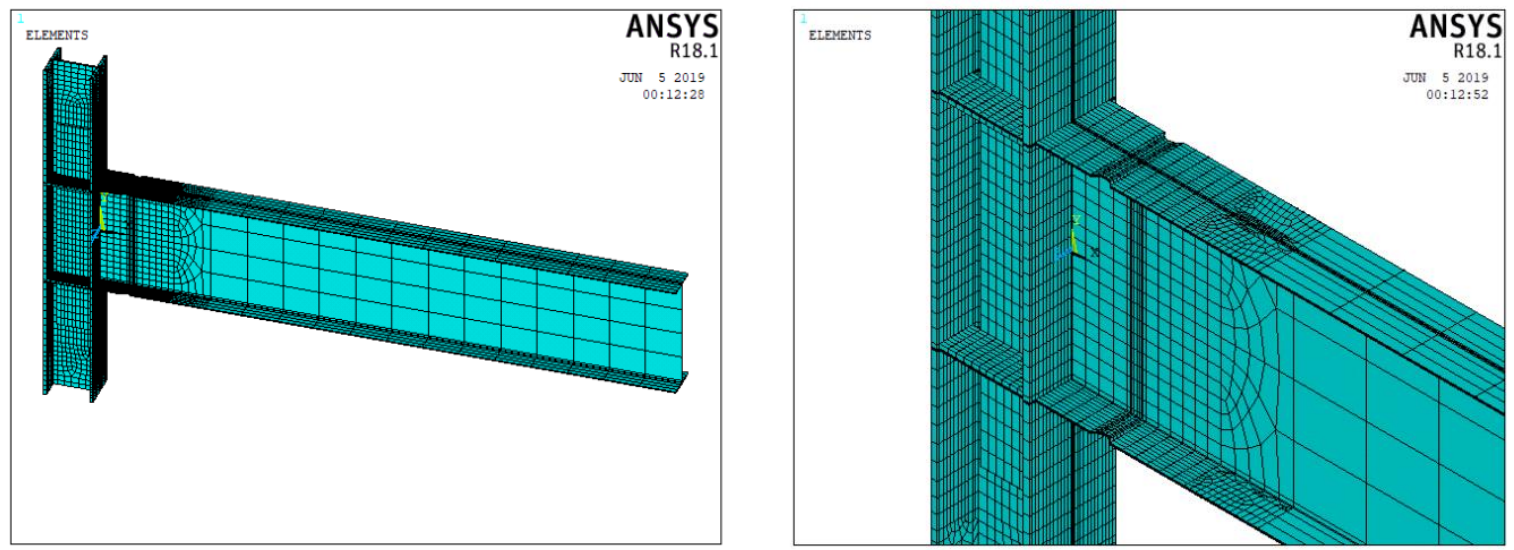

Figure A14: FEA Model for Specimen RBS-20
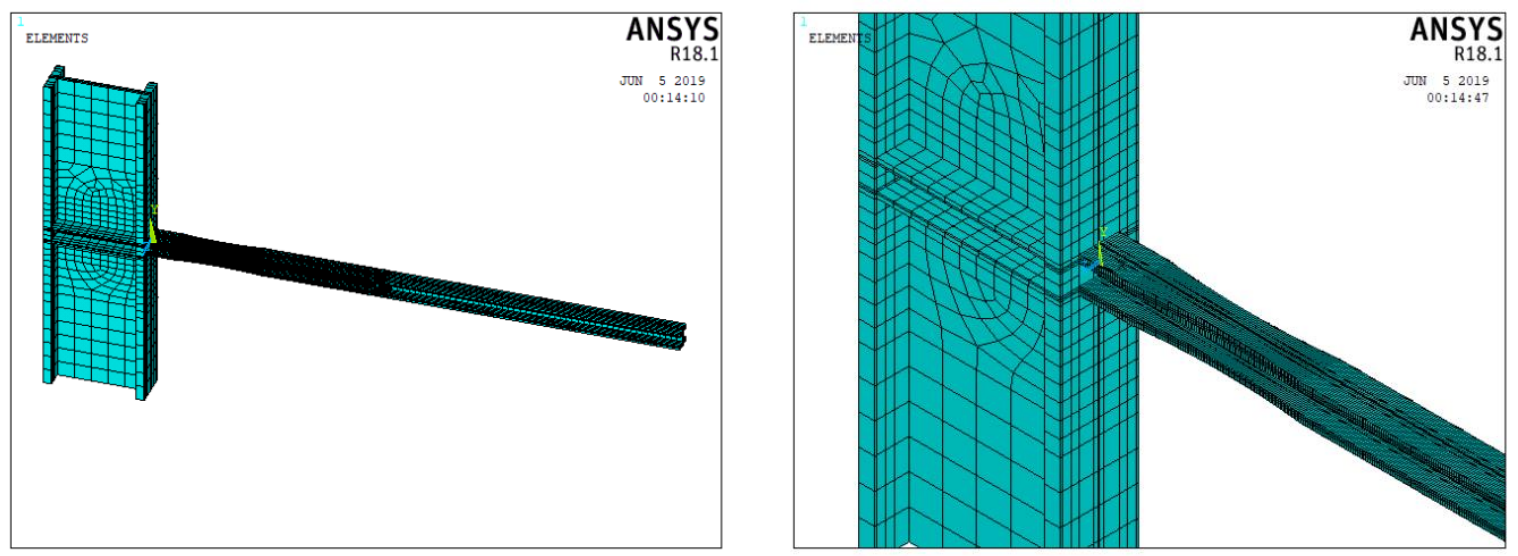

Figure A15: FEA Model for Specimen RBS-21 

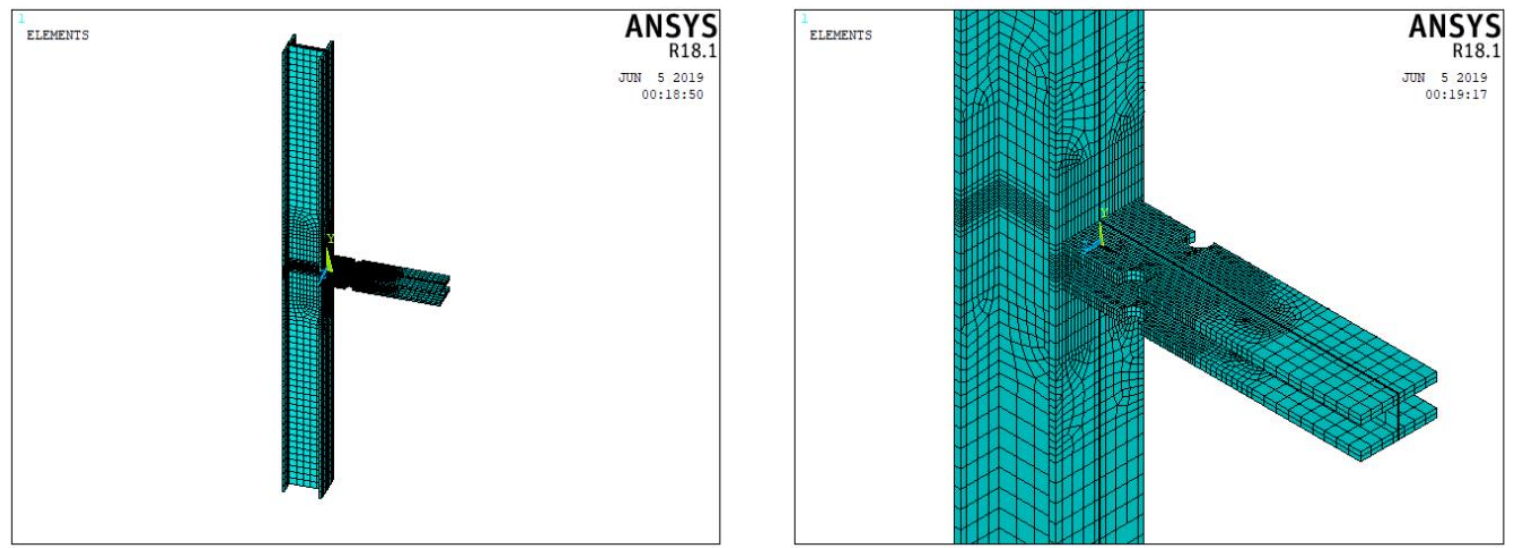

Figure A16: FEA Model for Specimen RBS-22
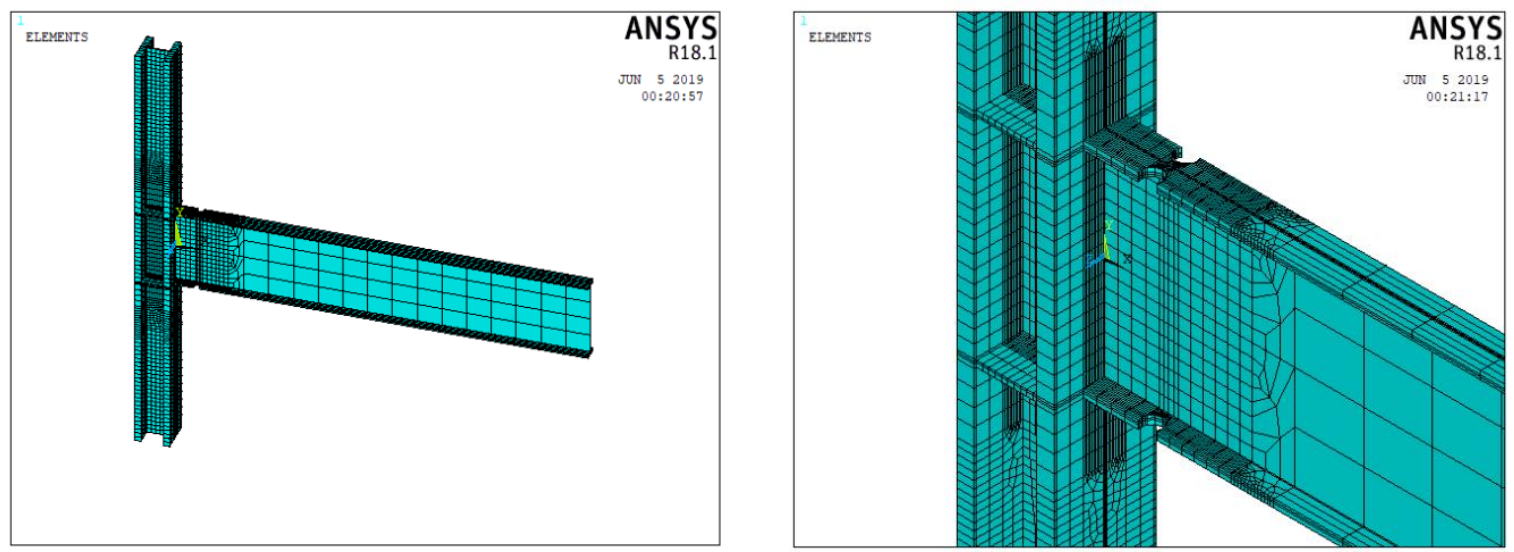

Figure A17: FEA Model for Specimen RBS-23
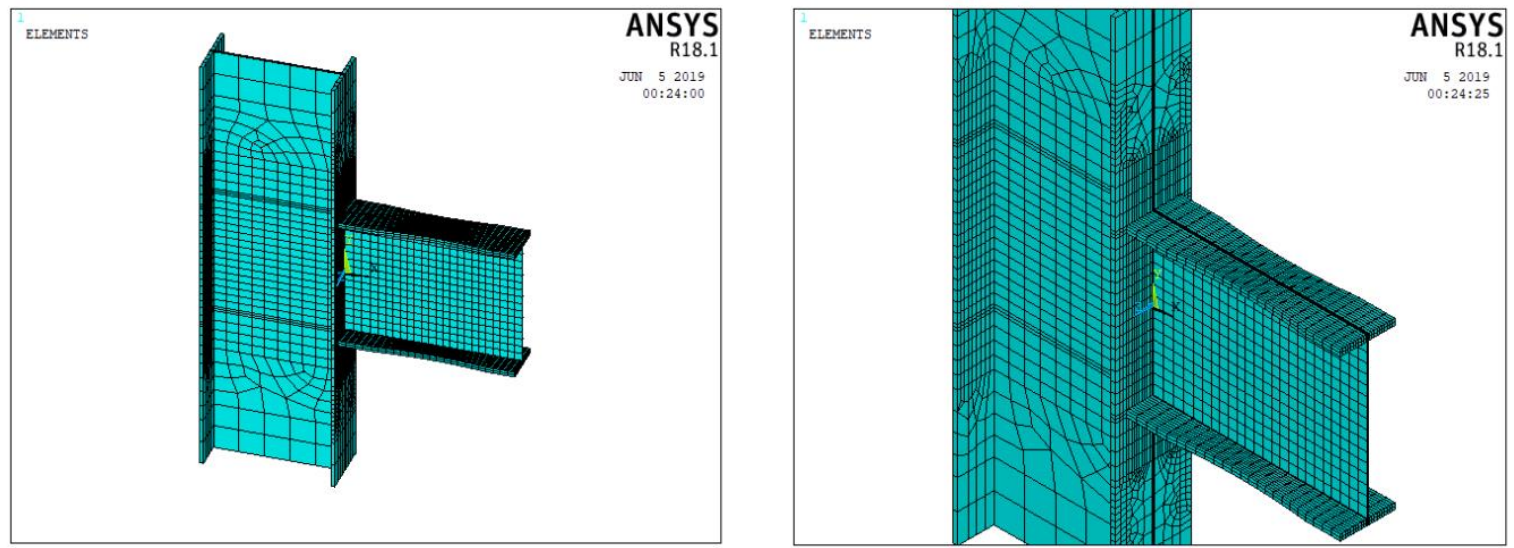

Figure A18: FEA Model for Specimen RBS-24 

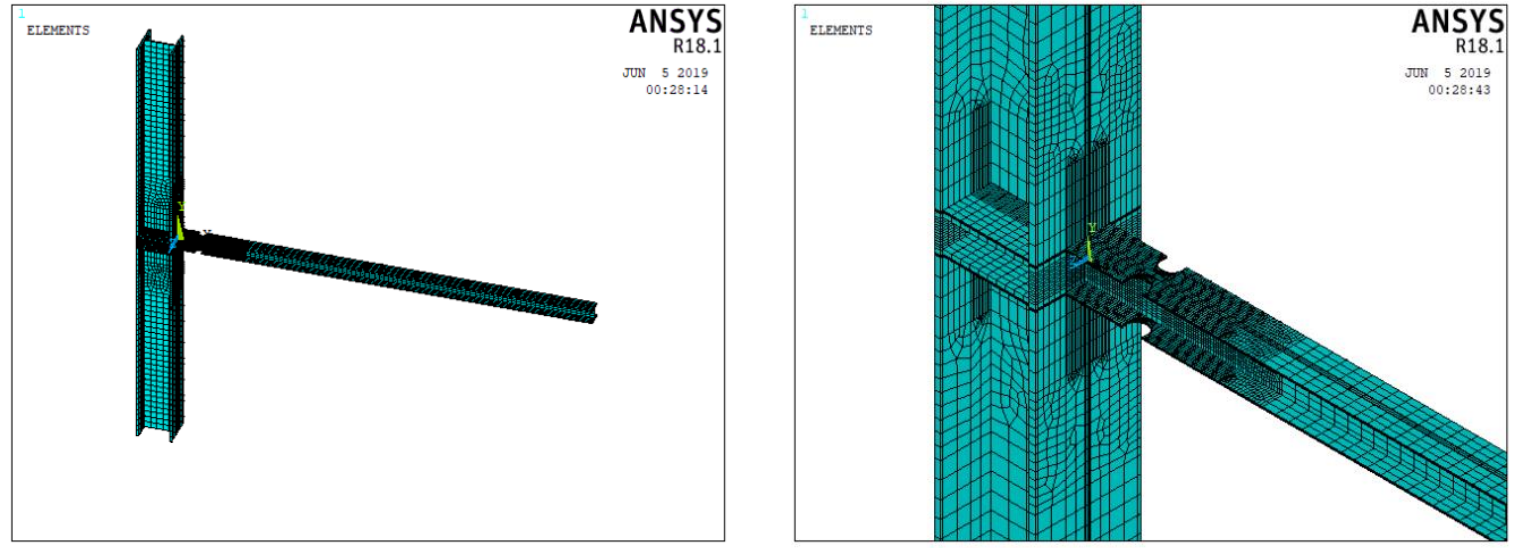

Figure A19: FEA Model for Specimen RBS-25
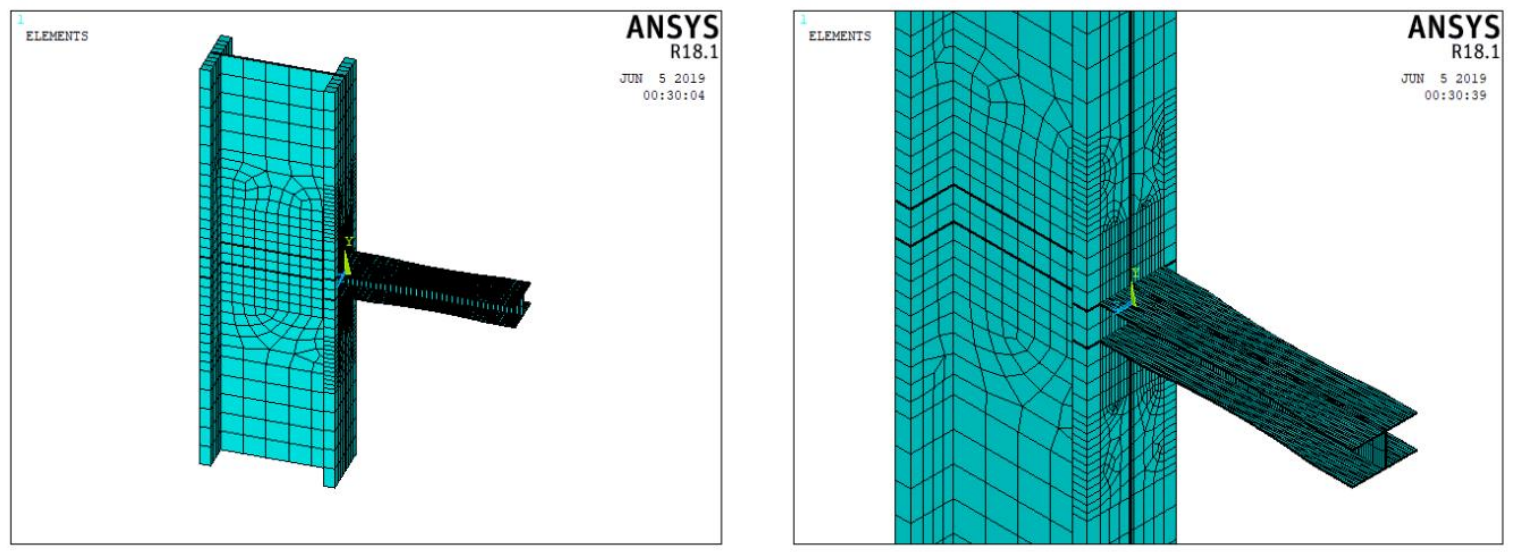

Figure A20: FEA Model for Specimen RBS-26
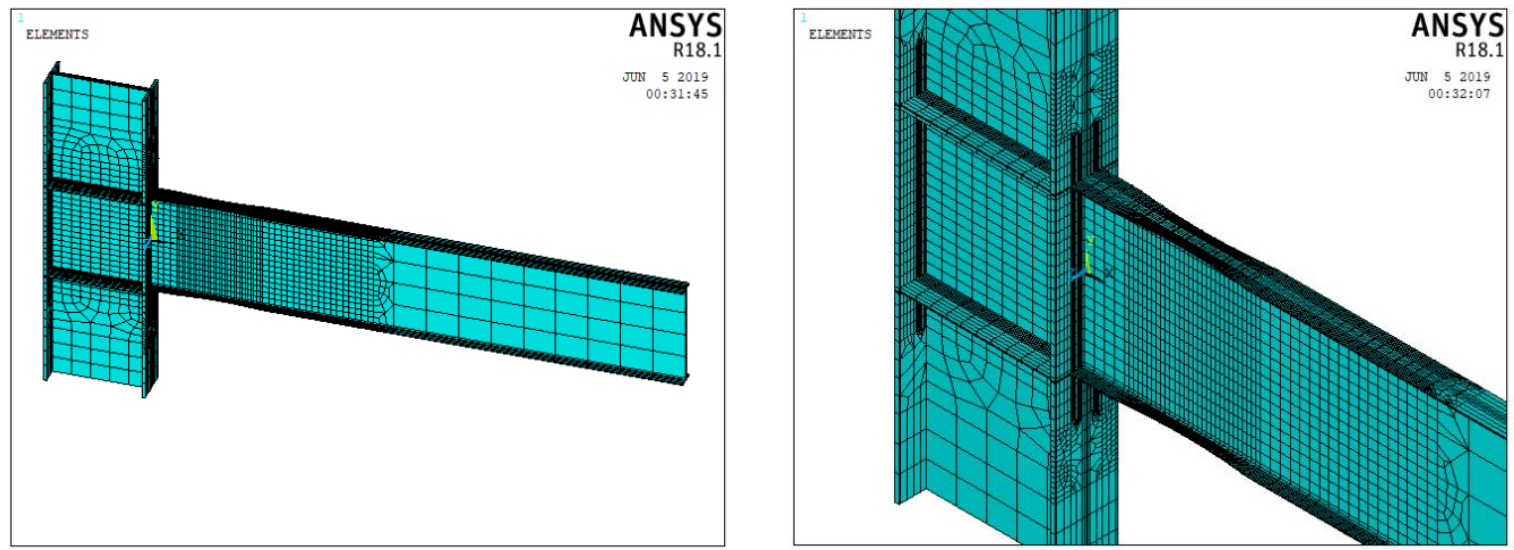

Figure A21: FEA Model for Specimen RBS-27 

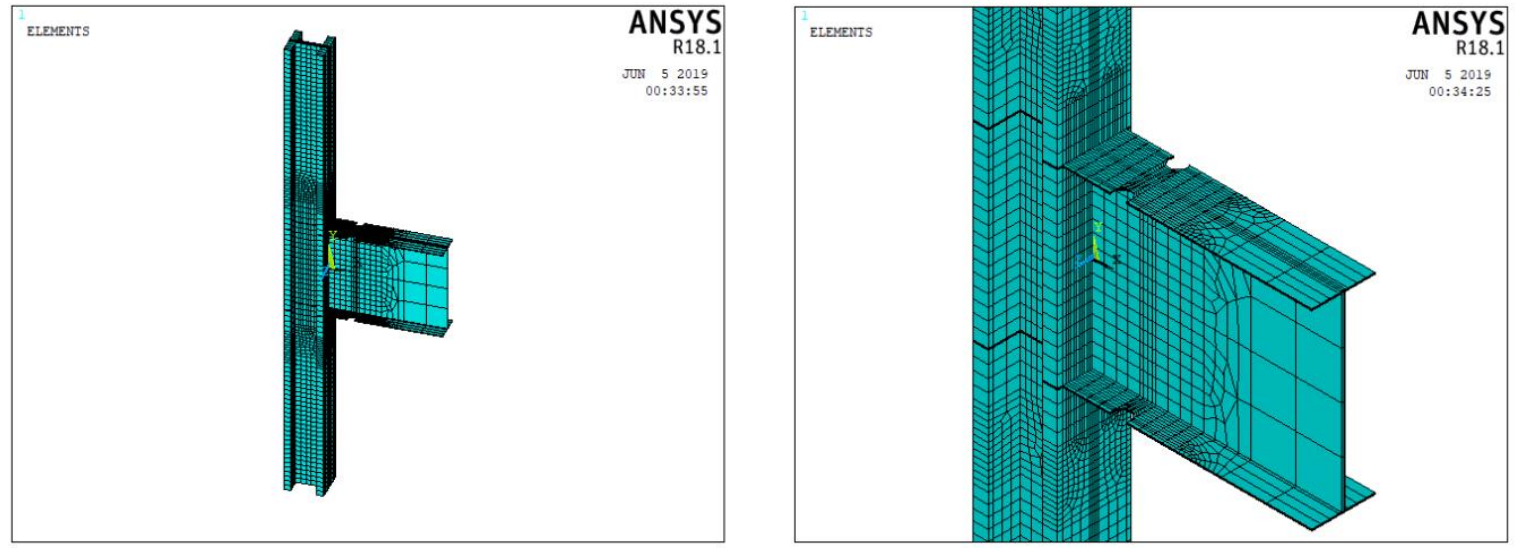

Figure A22: FEA Model for Specimen RBS-28
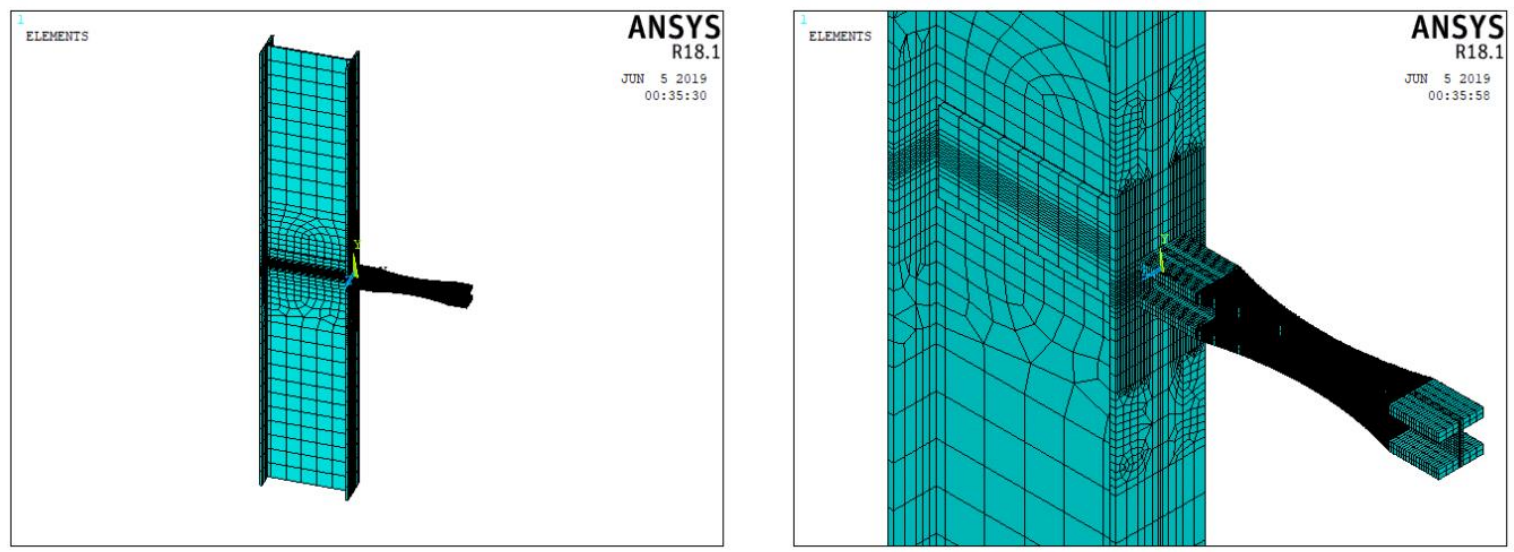

Figure A23: FEA Model for Specimen RBS-29
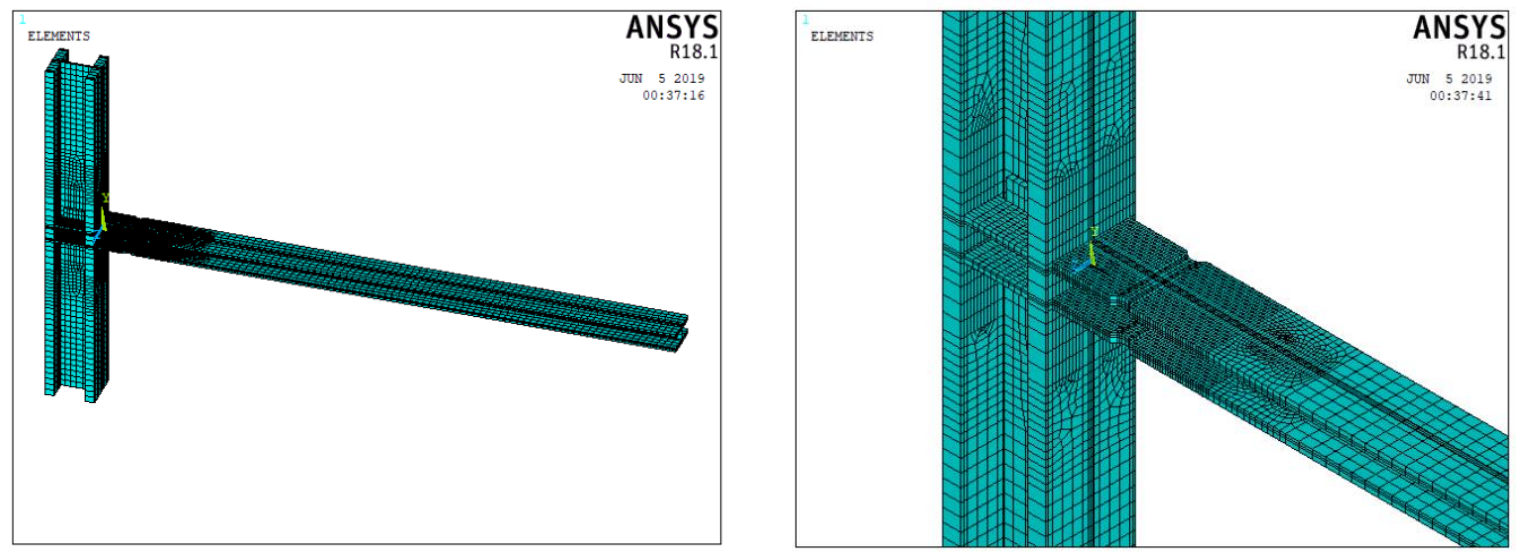

Figure A24: FEA Model for Specimen RBS-30 

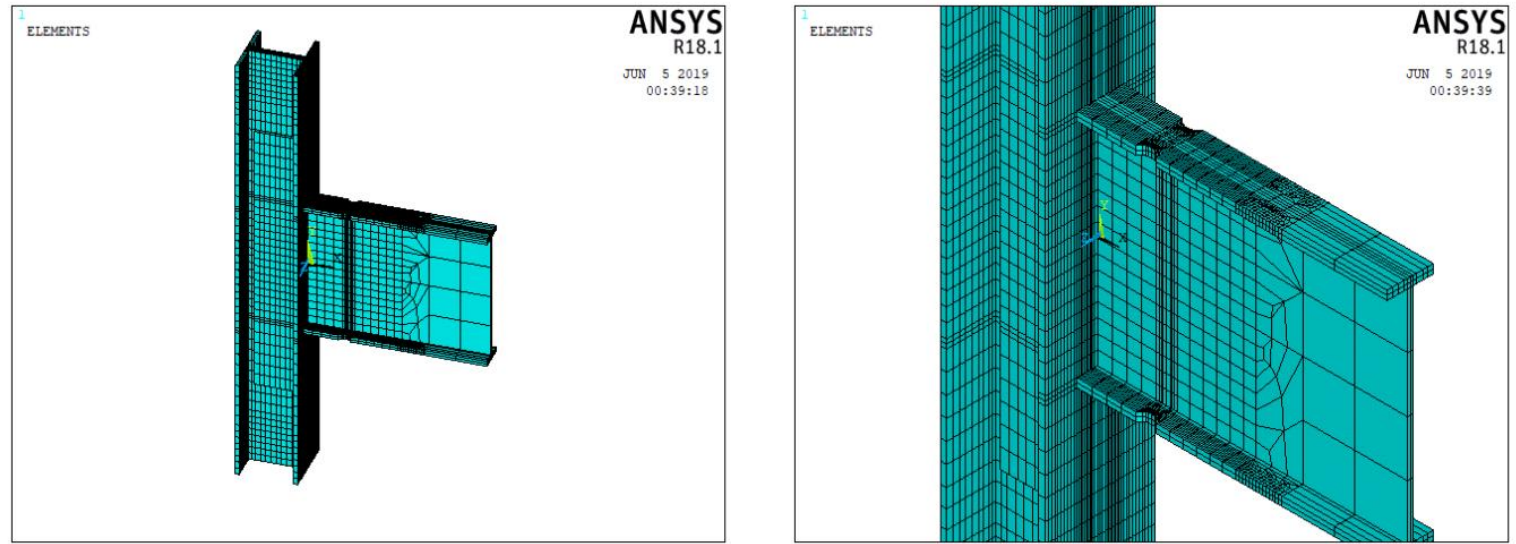

Figure A25: FEA Model for Specimen RBS-31
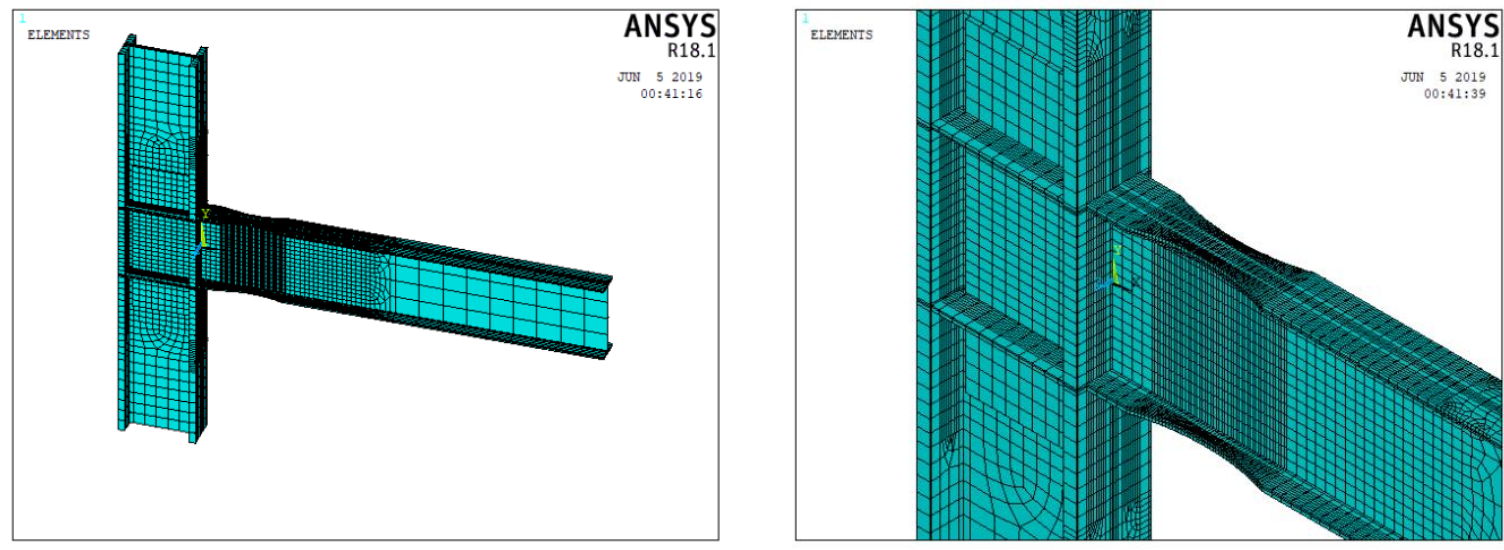

Figure A26: FEA Model for Specimen RBS-32
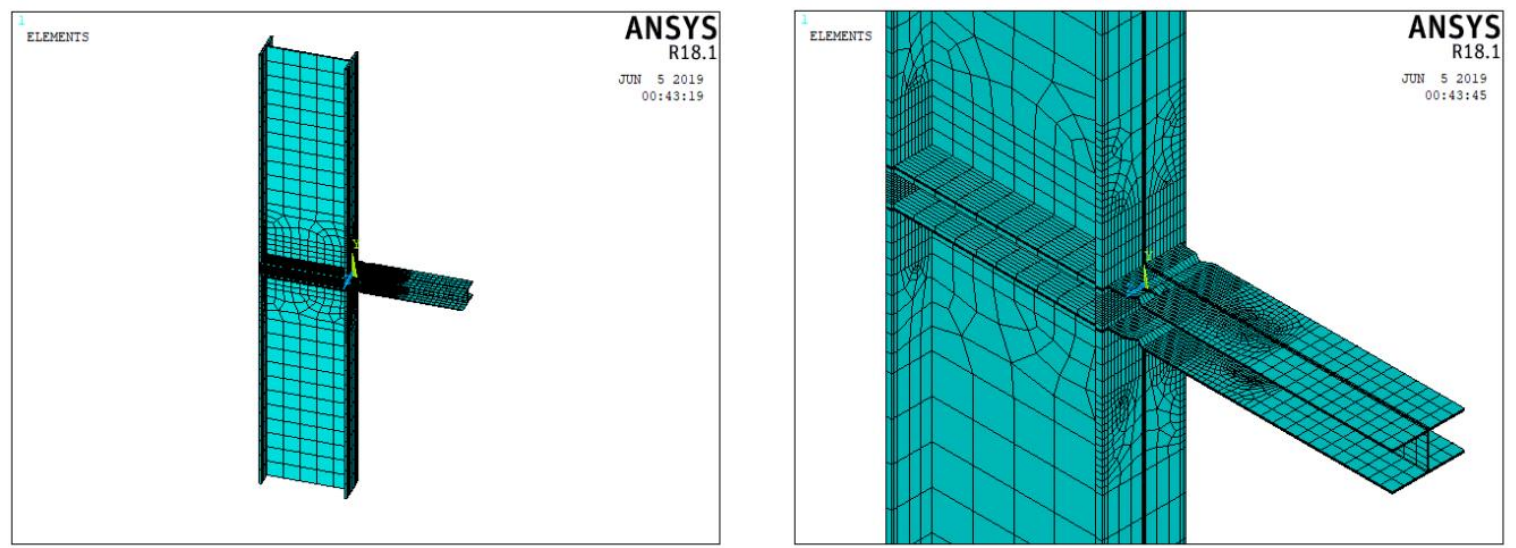

Figure A27: FEA Model for Specimen RBS-33 

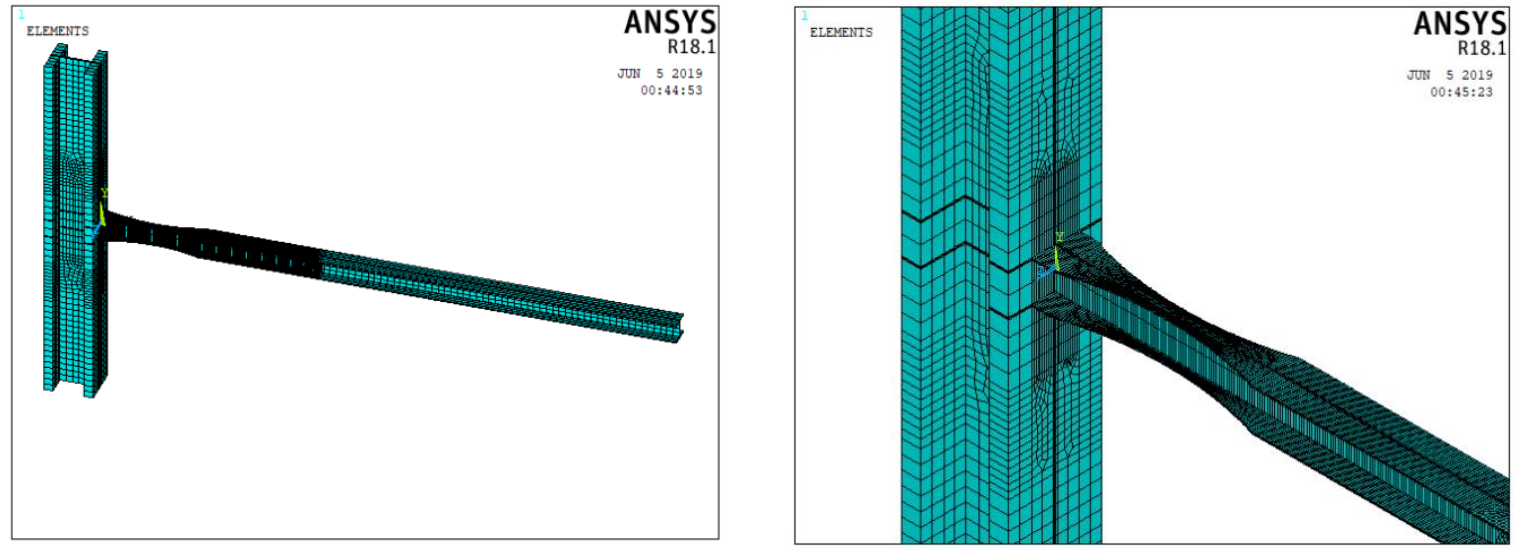

Figure A28: FEA Model for Specimen RBS-34
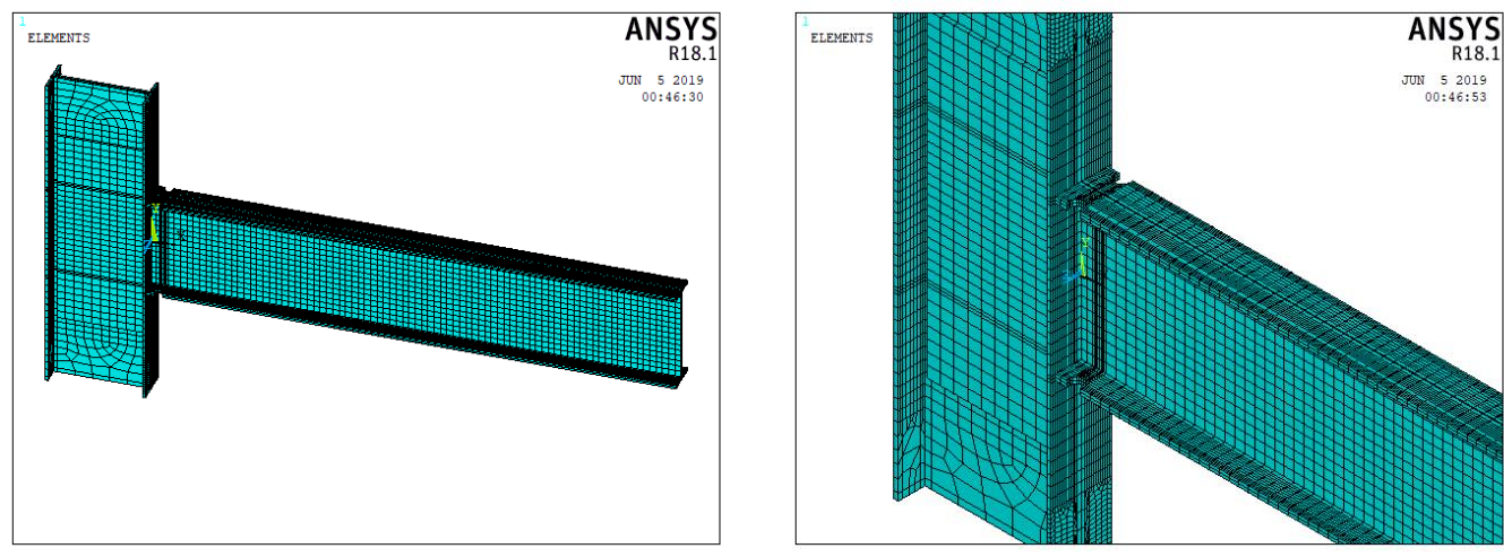

Figure A29: FEA Model for Specimen RBS-35
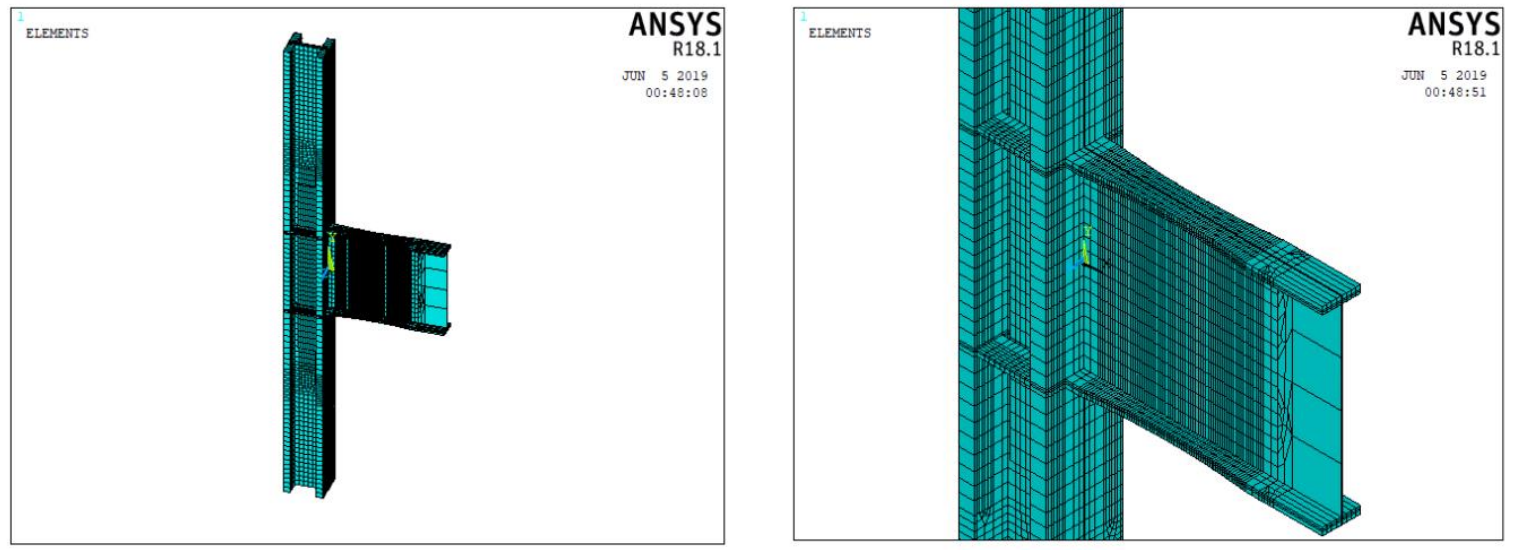

Figure A30: FEA Model for Specimen RBS-36 

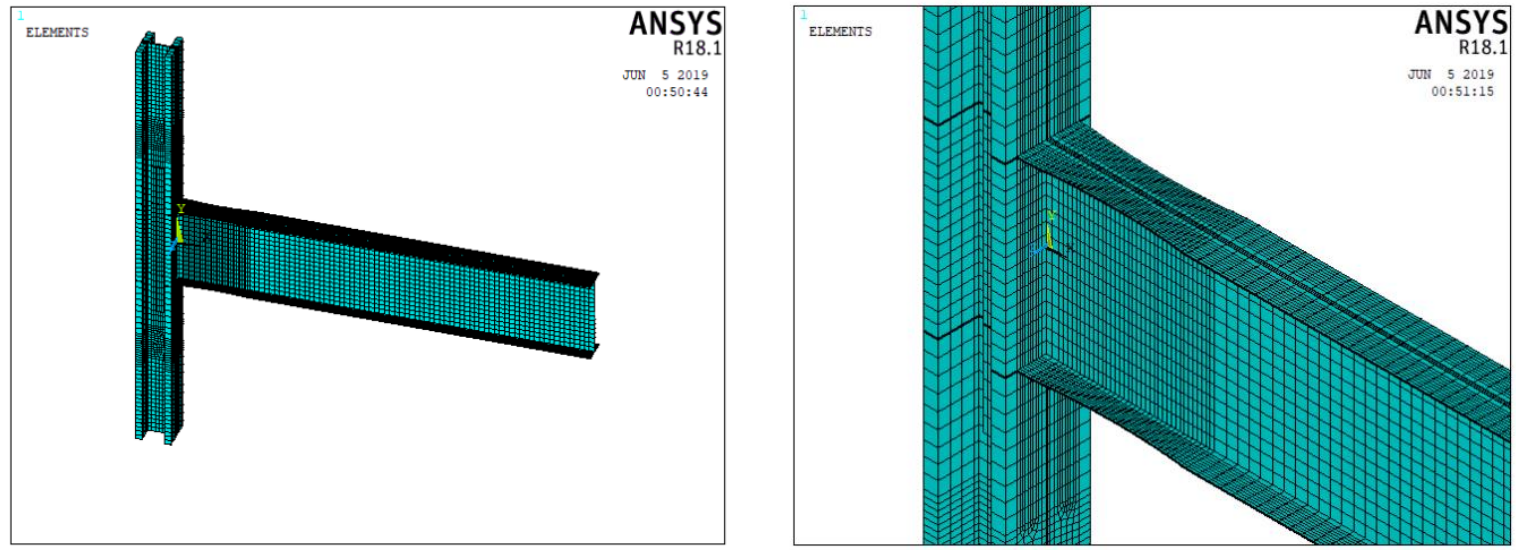

Figure A31: FEA Model for Specimen RBS-37
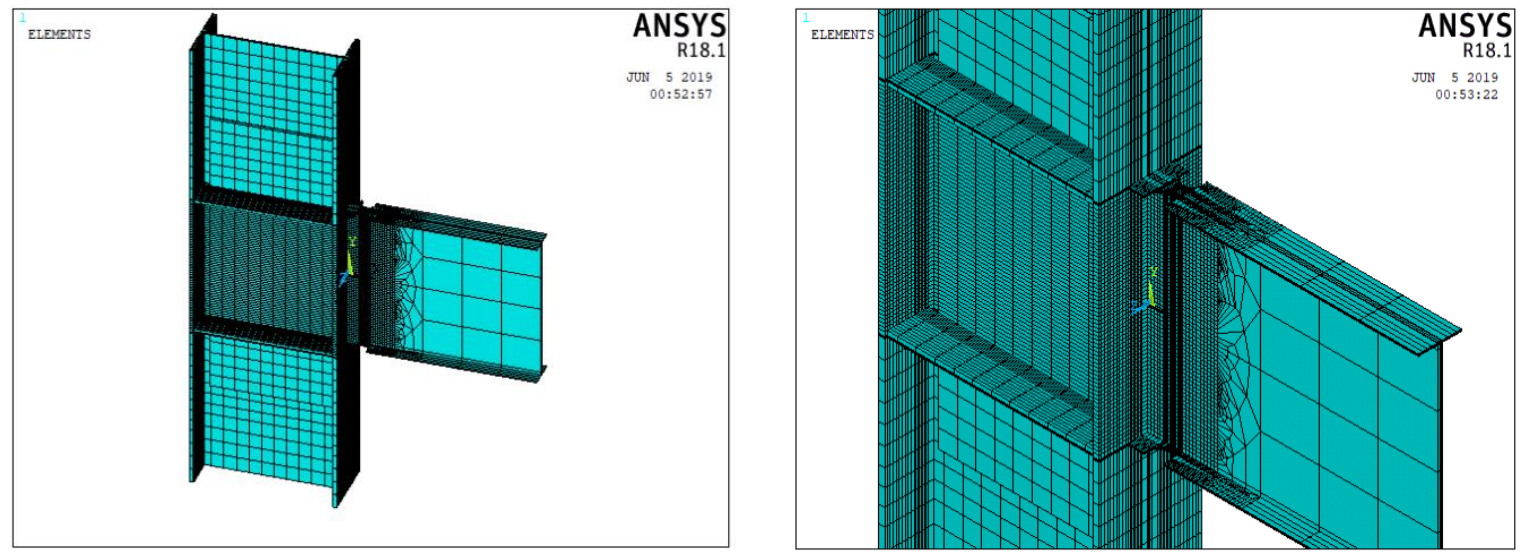

Figure A32: FEA Model for Specimen RBS-38
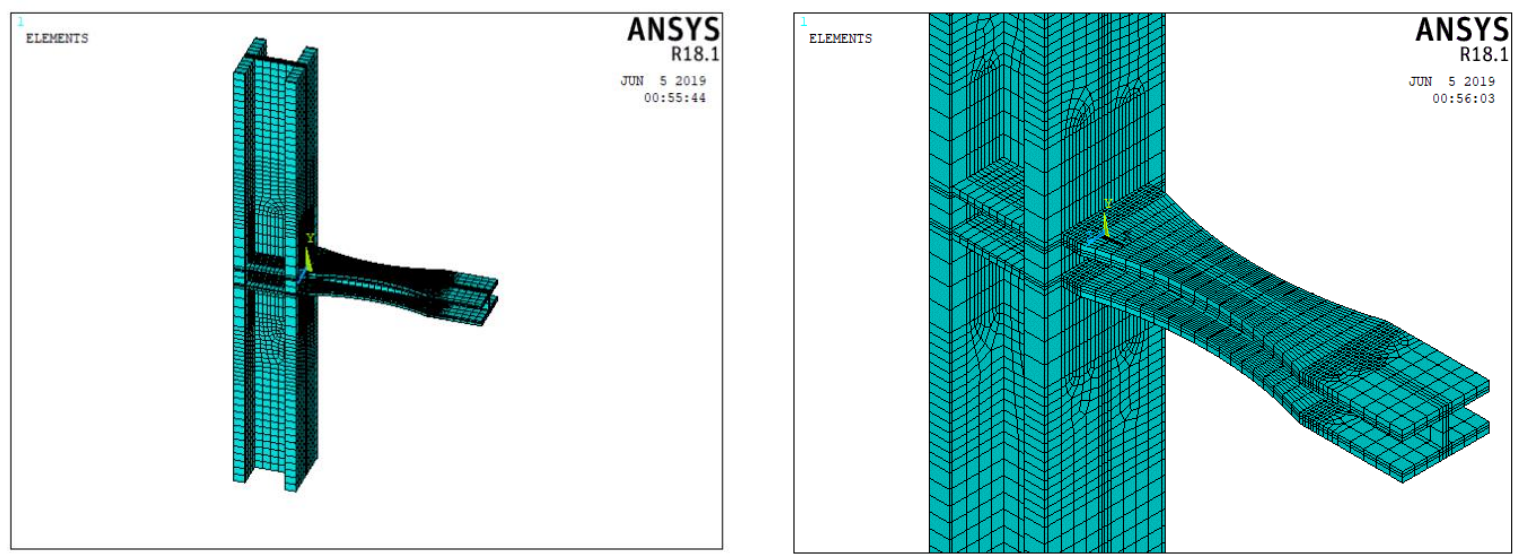

Figure A33: FEA Model for Specimen RBS-39 

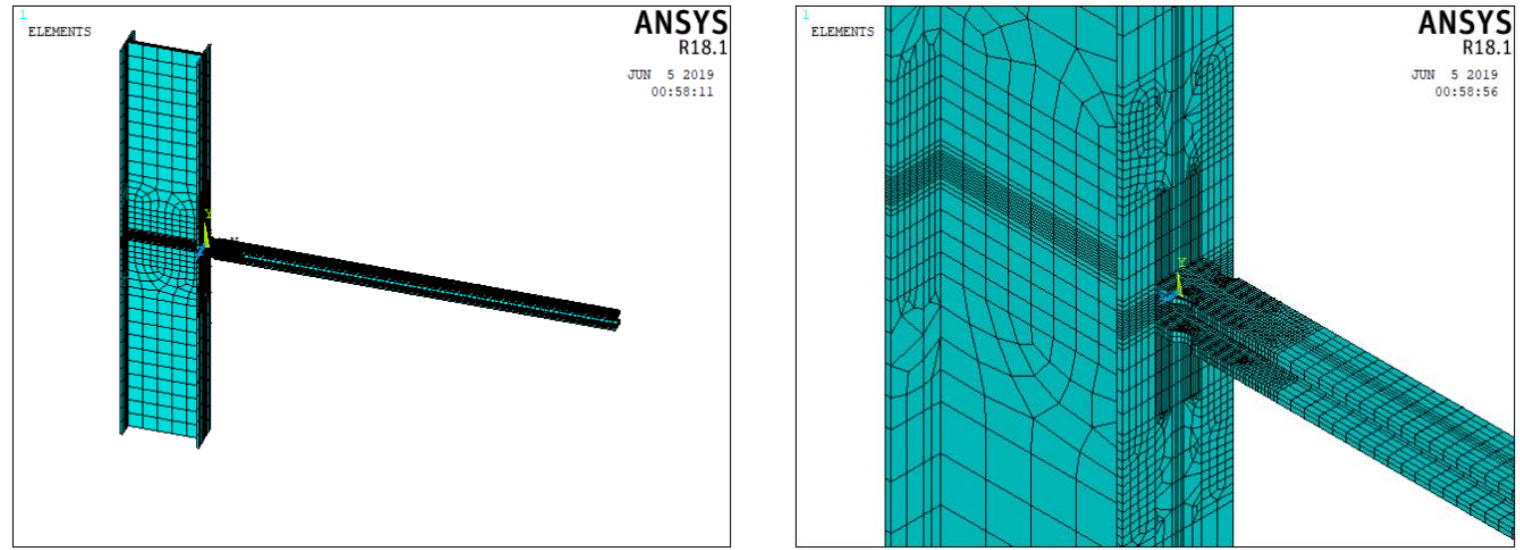

Figure A34: FEA Model for Specimen RBS-40
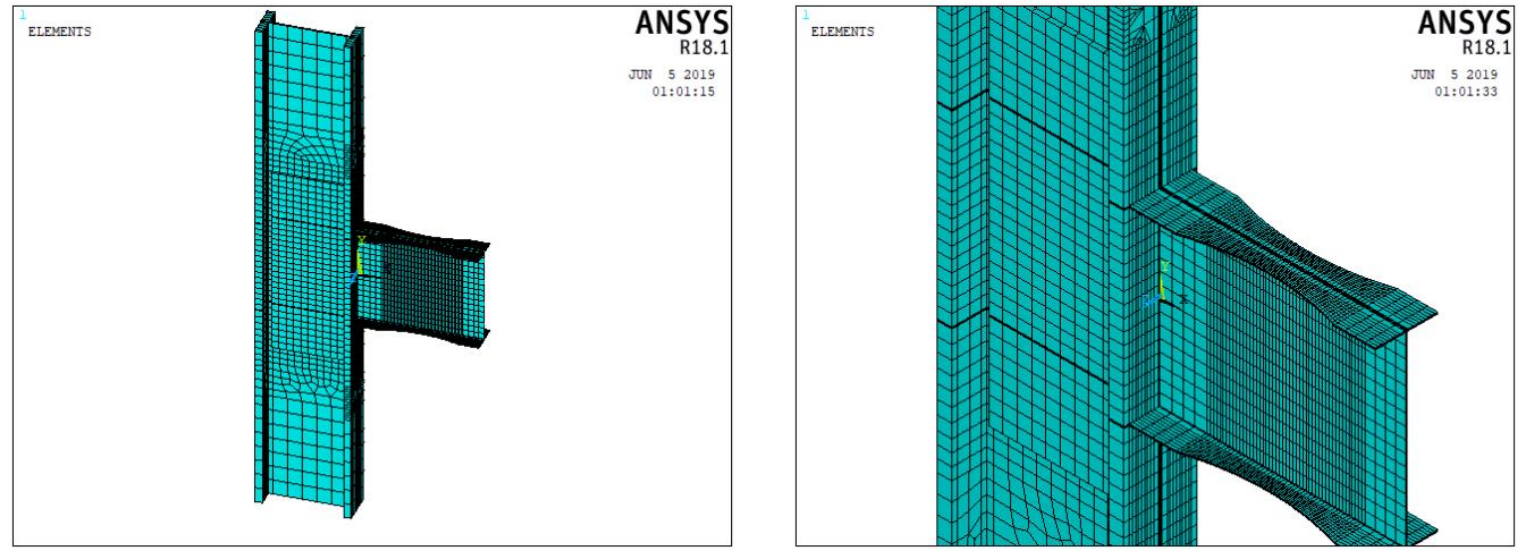

Figure A35: FEA Model for Specimen RBS-41
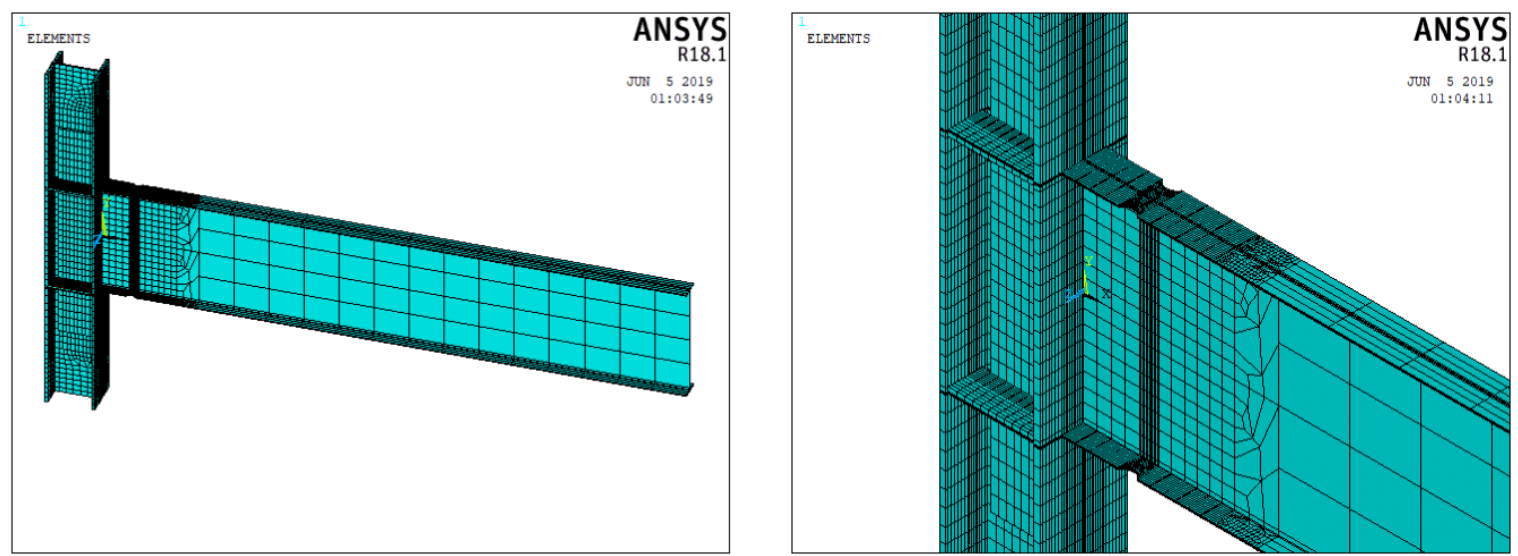

Figure A36: FEA Model for Specimen RBS-42 

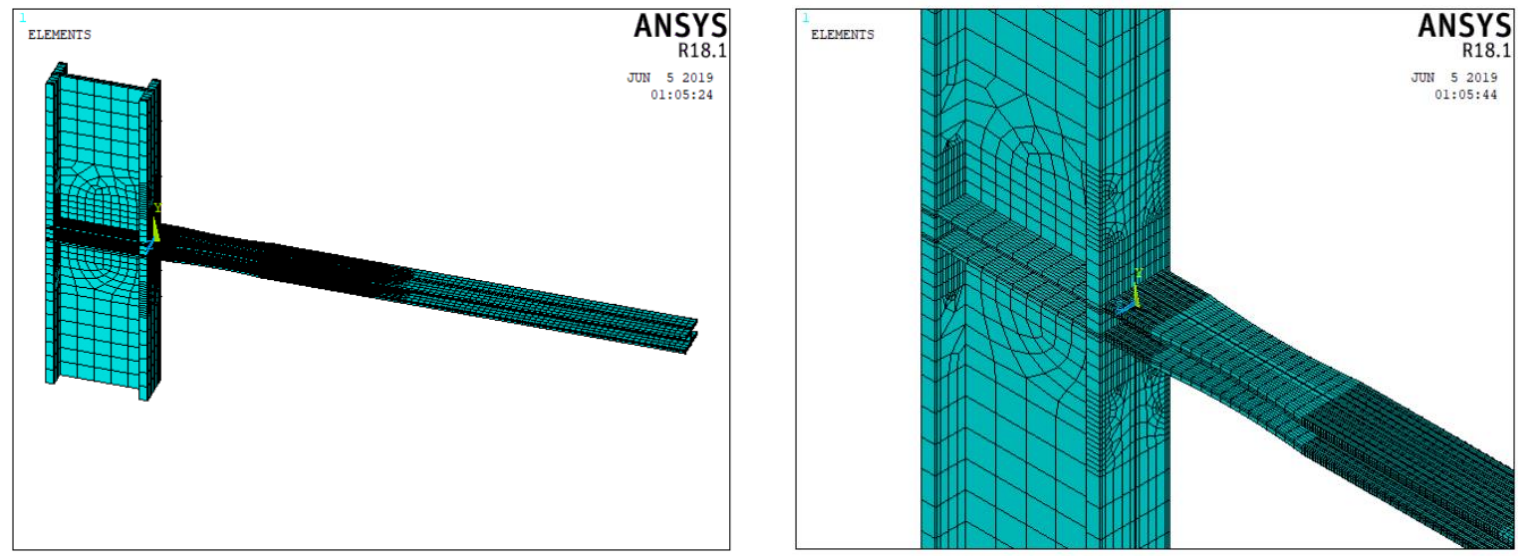

Figure A37: FEA Model for Specimen RBS-43
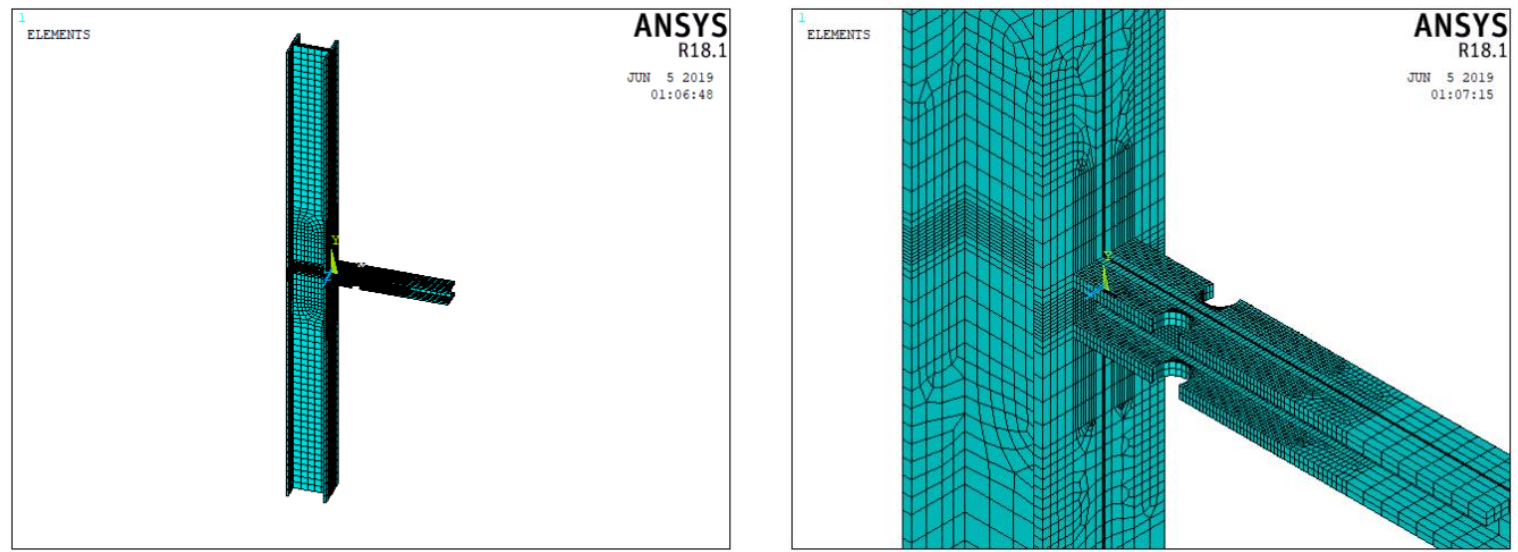

Figure A1: FEA Model for Specimen RBS-44
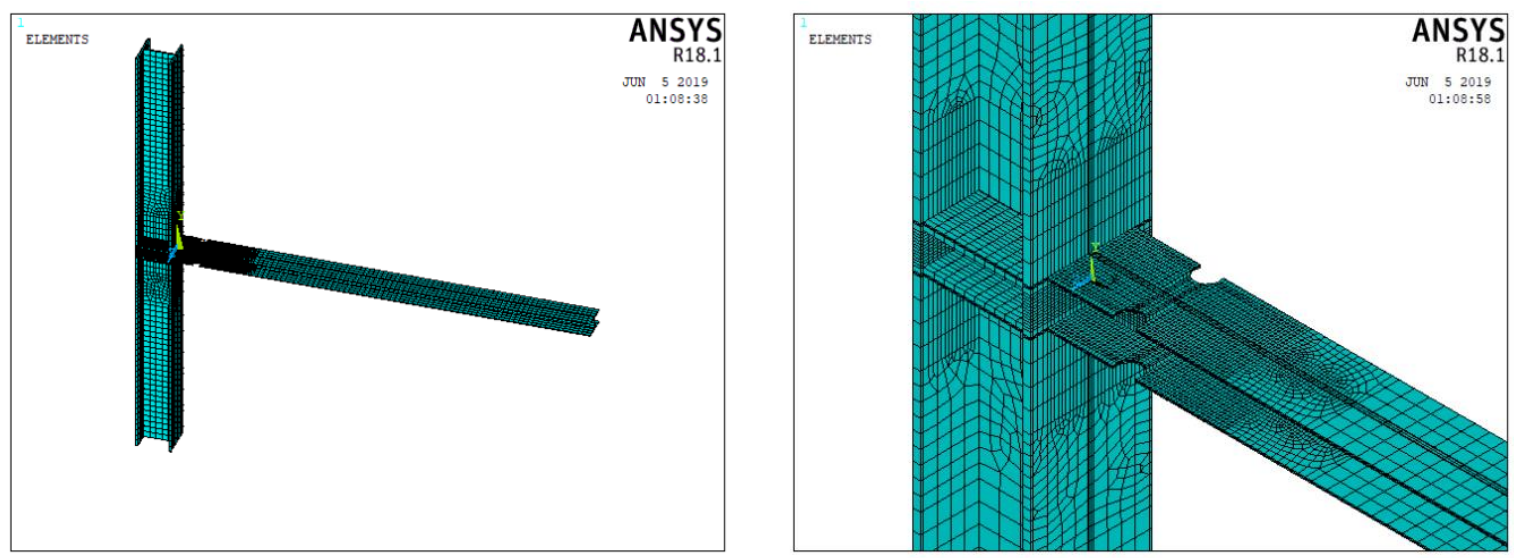

Figure A38: FEA Model for Specimen RBS-45 

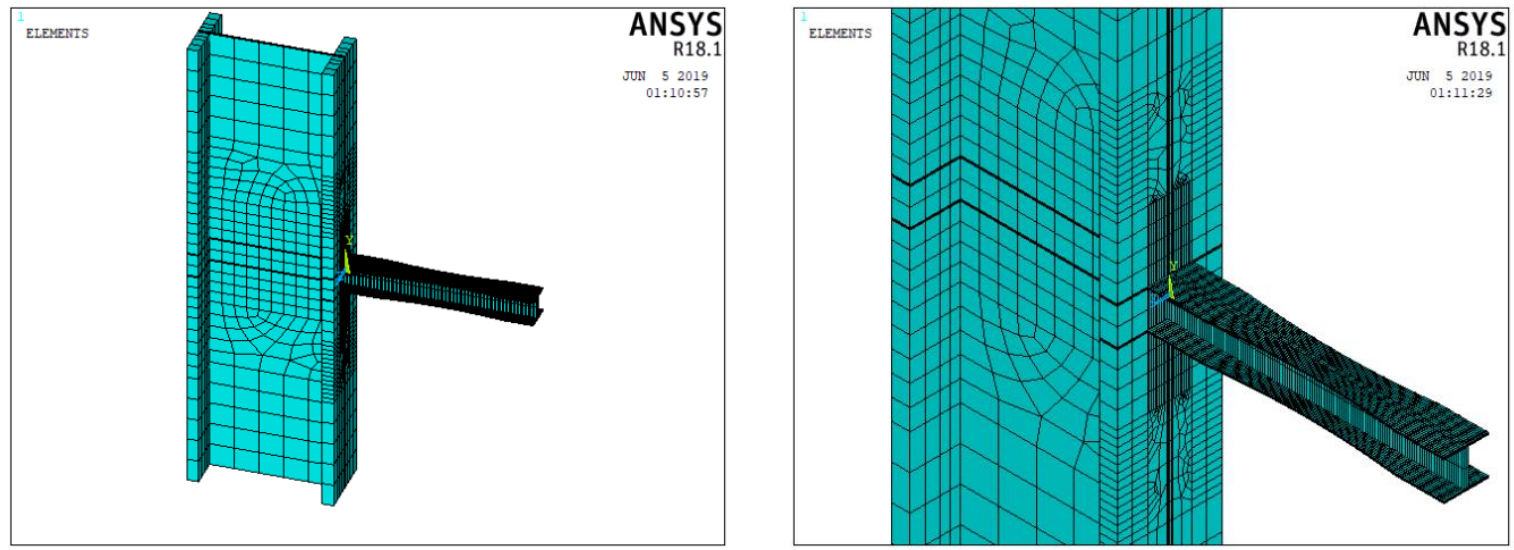

Figure A39: FEA Model for Specimen RBS-46
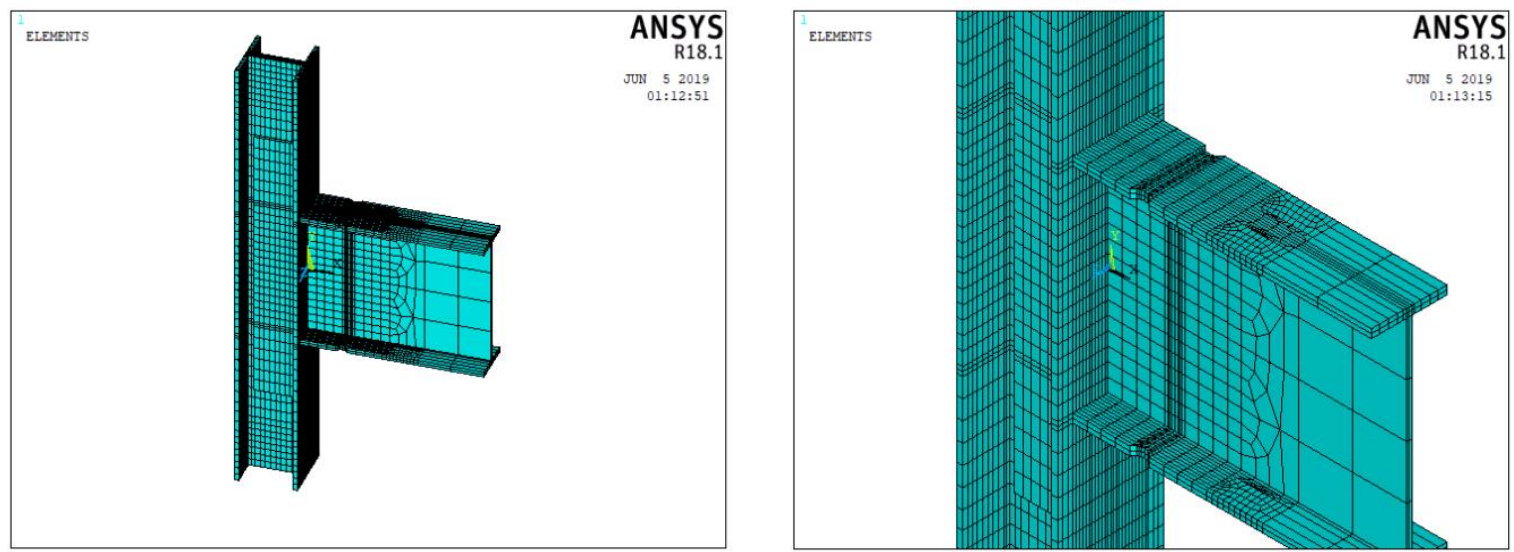

Figure A40: FEA Model for Specimen RBS-47
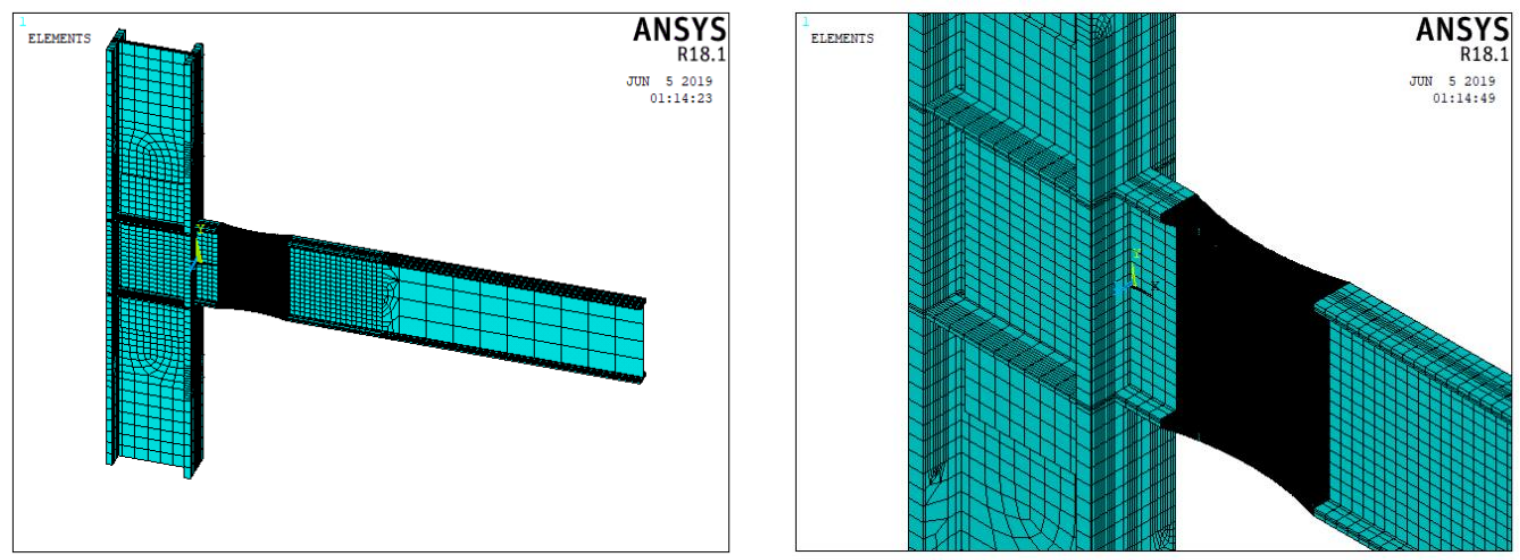

Figure A41: FEA Model for Specimen RBS 
APPENDIX B: Response Plots 


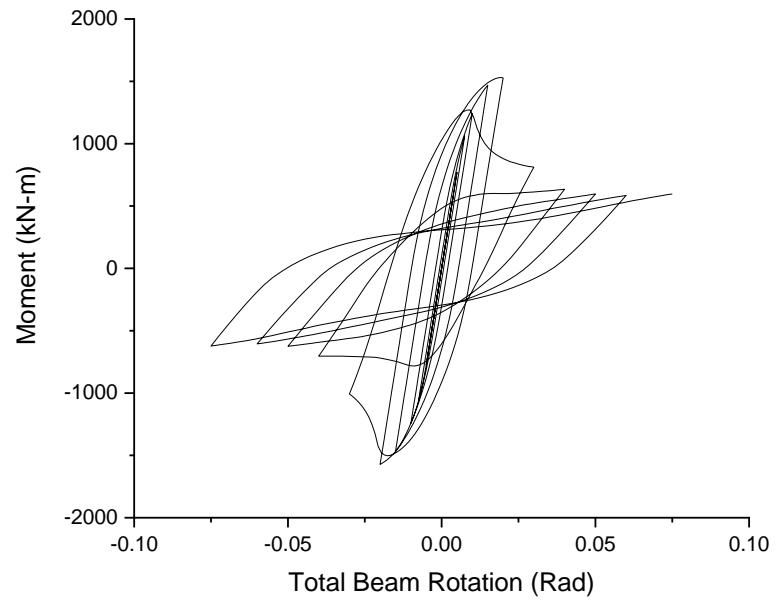

Figure B1: Experimental Moment vs Rotation Curve for RBS-11

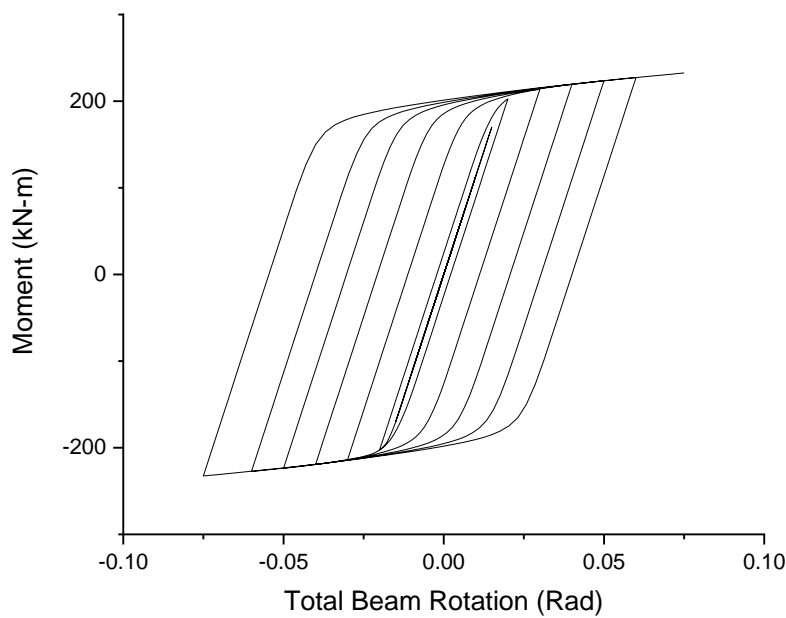

Figure B3: Experimental Moment vs Rotation Curve for RBS-13

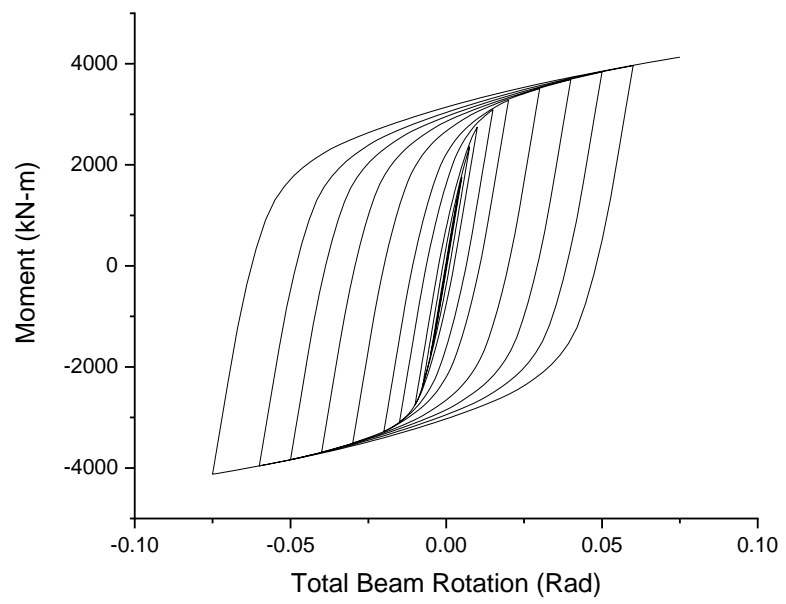

Figure B5: Experimental Moment vs Rotation Curve for RBS-15

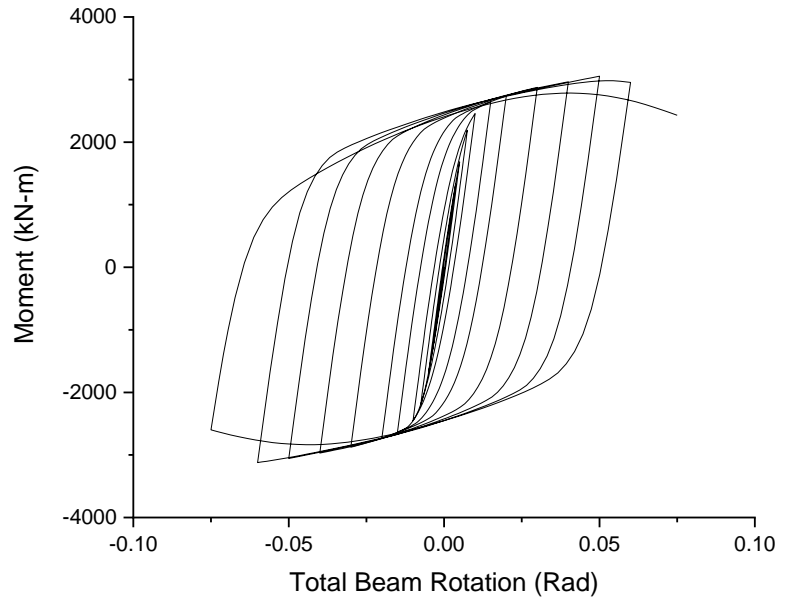

Figure B2: Experimental Moment vs Rotation Curve for RBS-12

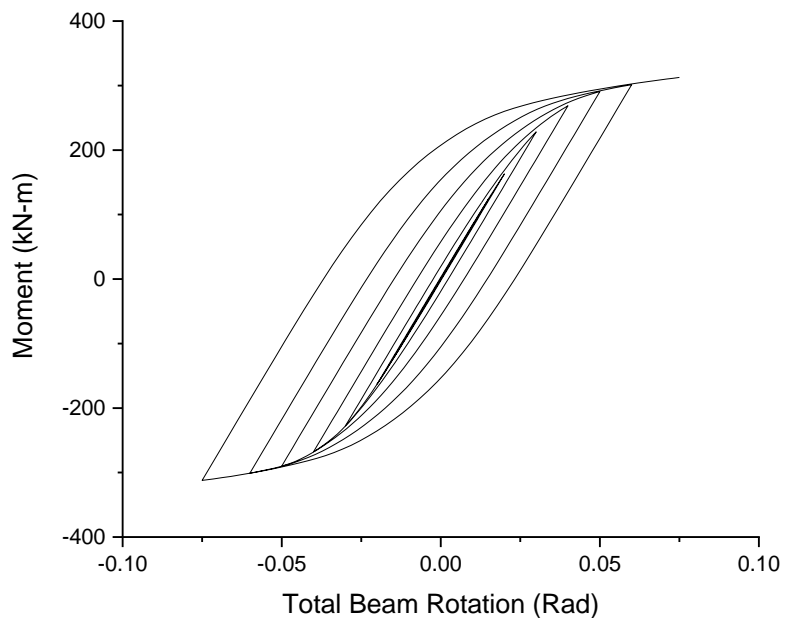

Figure B4: Experimental Moment vs Rotation Curve for RBS-14

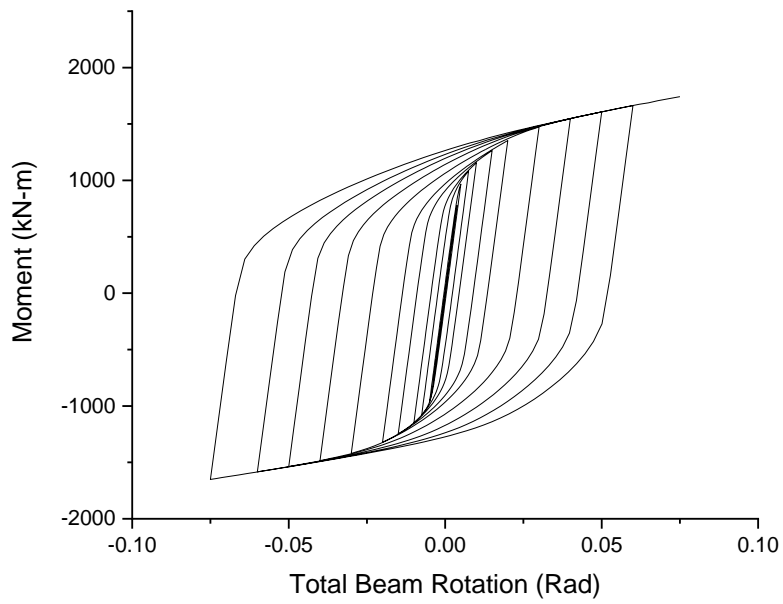

Figure B6: Experimental Moment vs Rotation Curve for RBS-16 


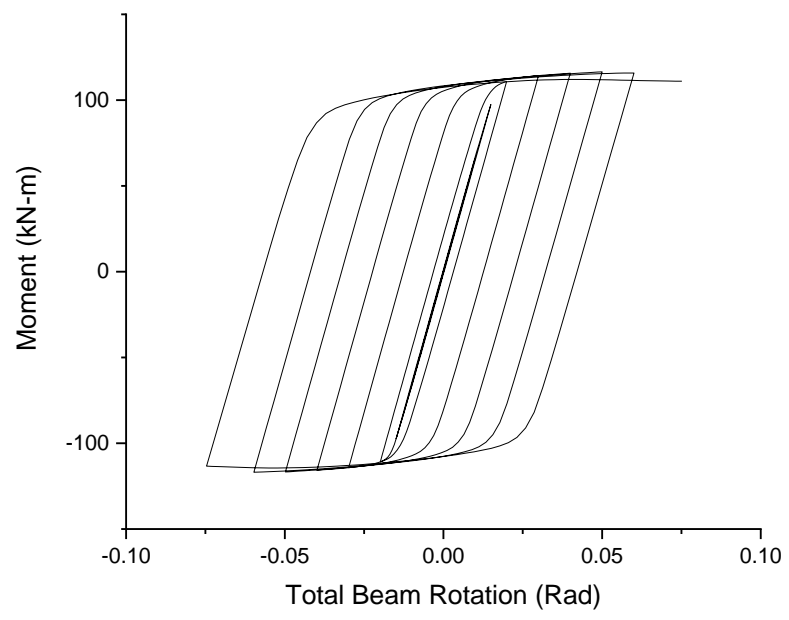

Figure B7: Experimental Moment vs Rotation Curve for RBS-17

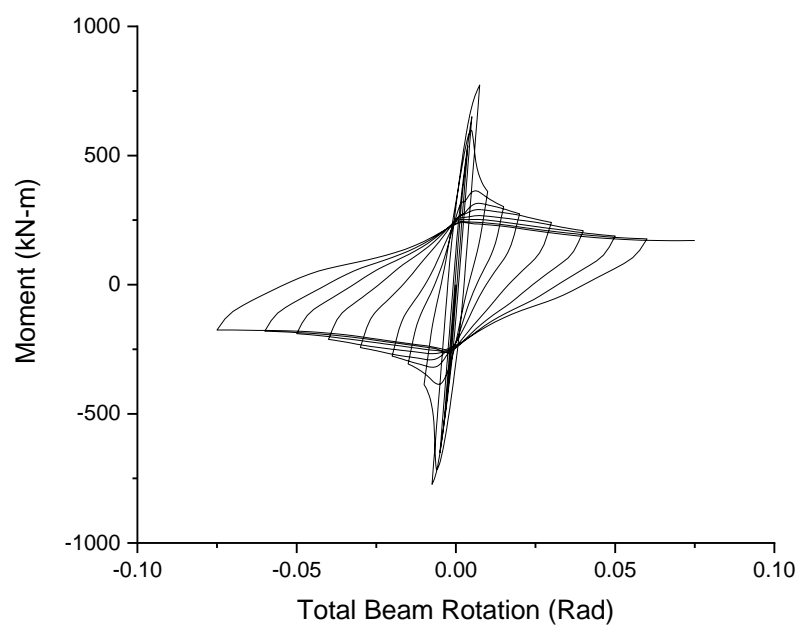

Figure B9: Experimental Moment vs Rotation Curve for RBS-19

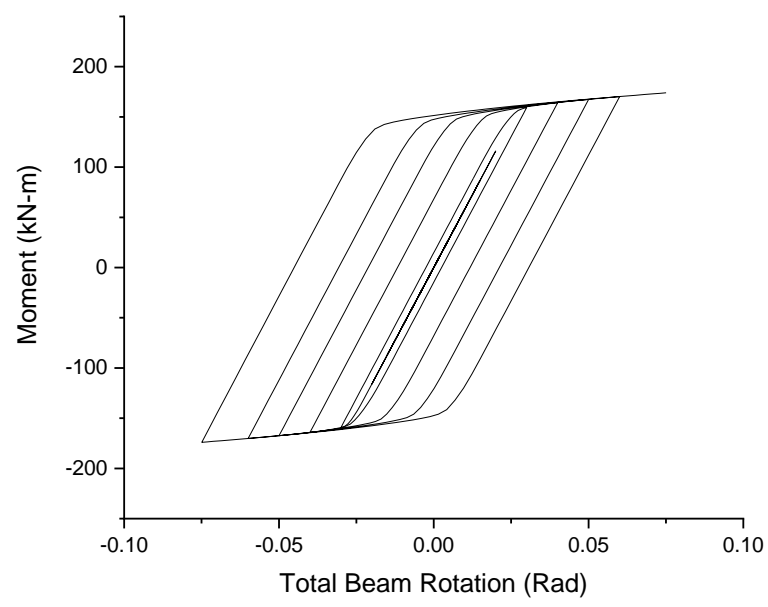

Figure B11: Experimental Moment vs Rotation Curve for RBS-21

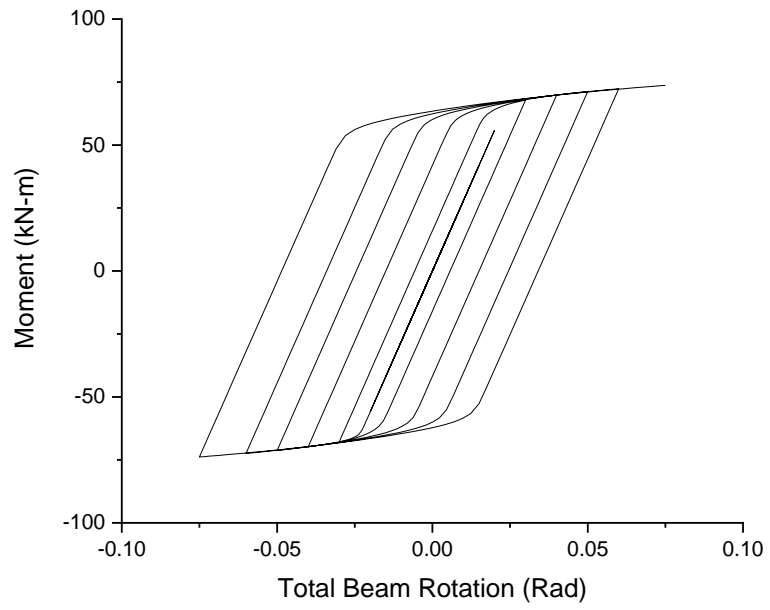

Figure B8: Experimental Moment vs Rotation Curve for RBS-18

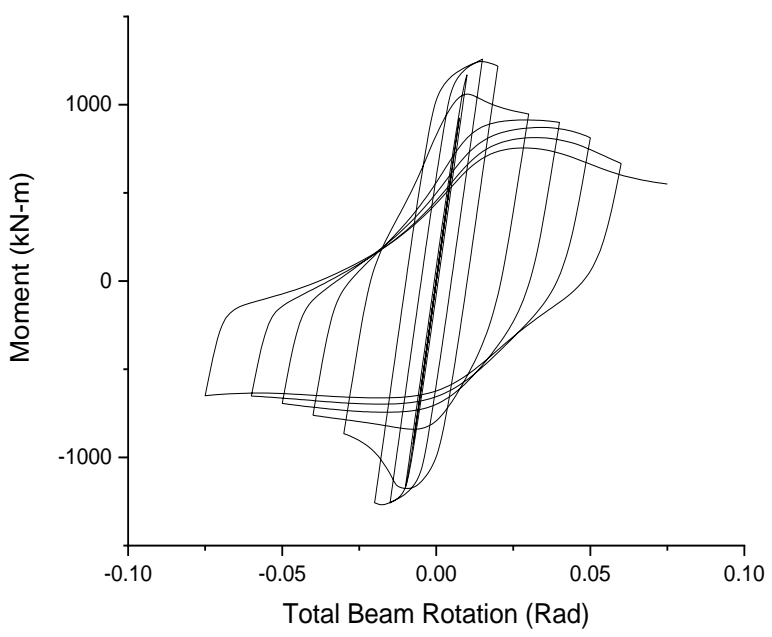

Figure B10: Experimental Moment vs Rotation Curve for RBS-20

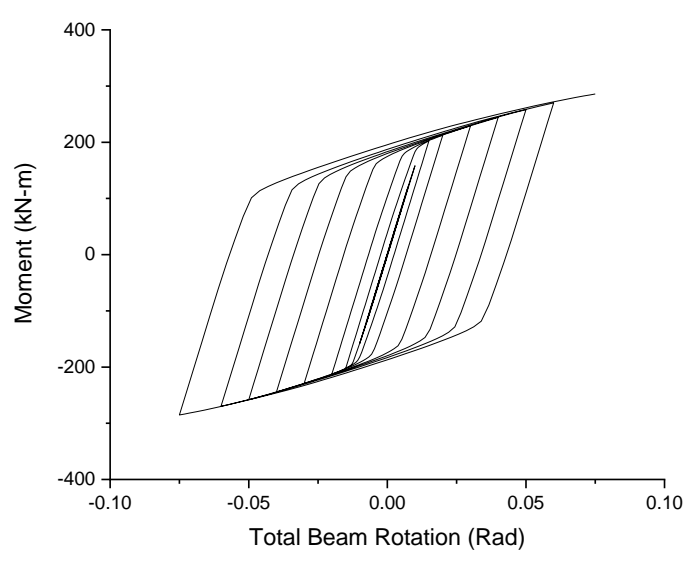

Figure B12: Experimental Moment vs Rotation Curve for RBS-22 


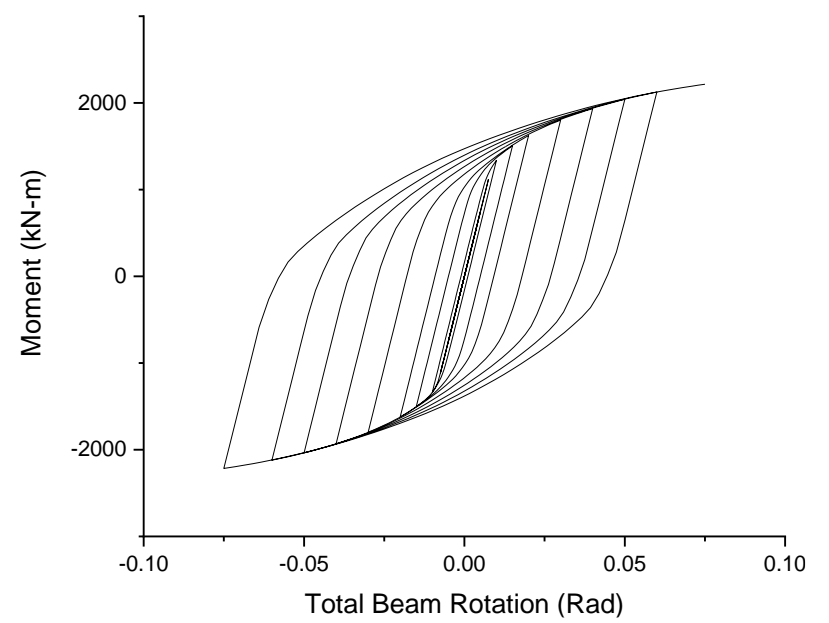

Figure B13: Experimental Moment vs Rotation Curve for RBS-23

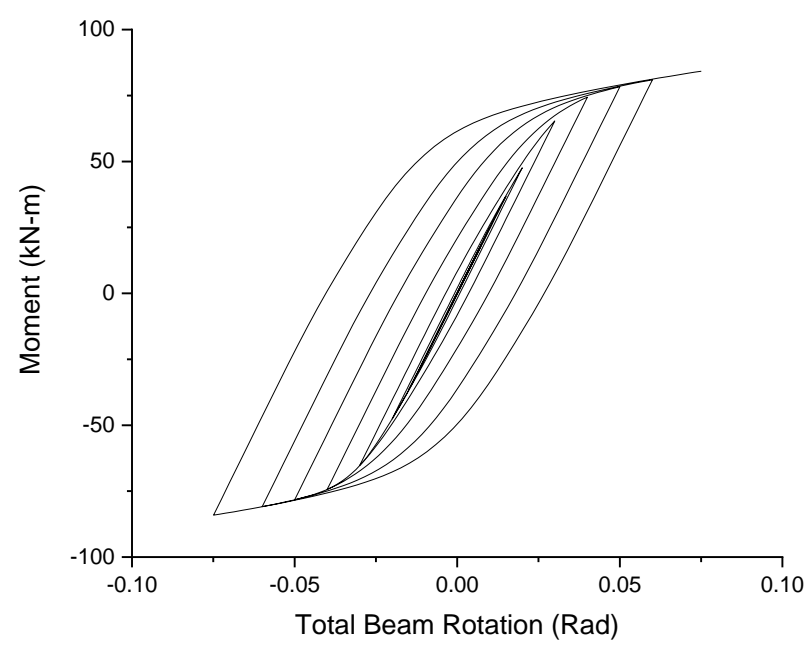

Figure B15: Experimental Moment vs Rotation Curve for RBS-25

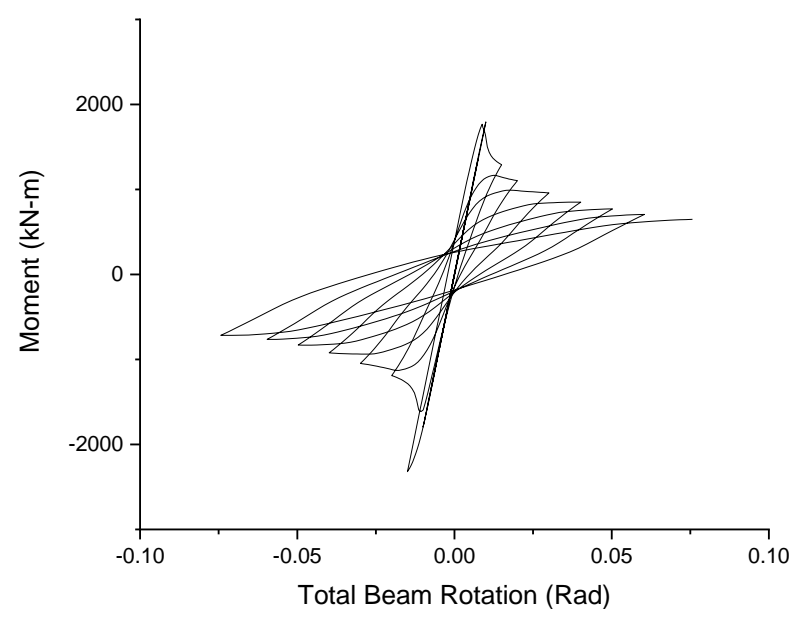

Figure B17: Experimental Moment vs Rotation Curve for RBS-27

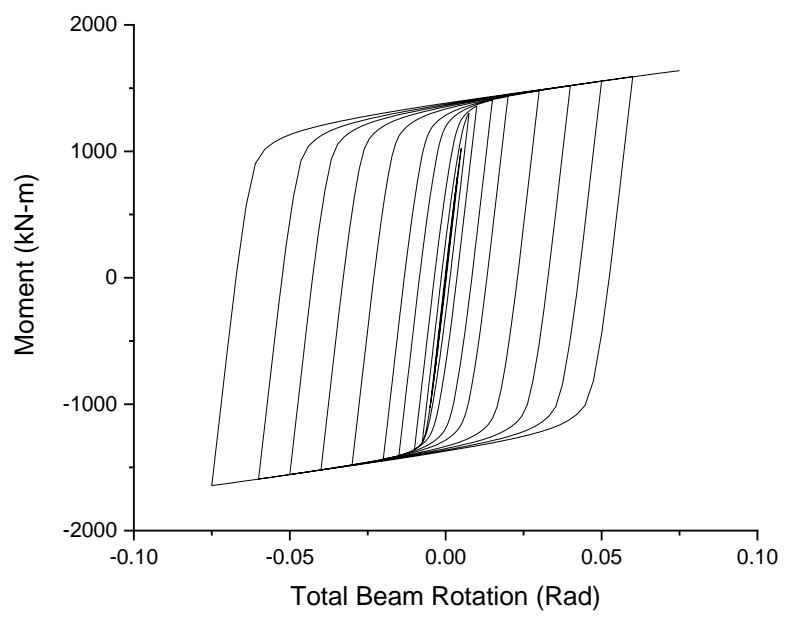

Figure B14: Experimental Moment vs Rotation Curve for RBS-24

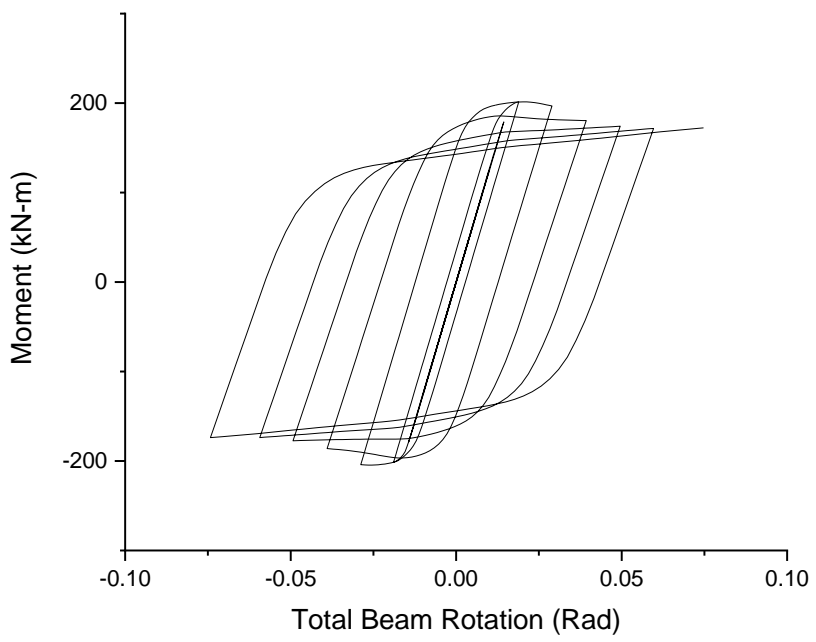

Figure B16: Experimental Moment vs Rotation Curve for RBS-26

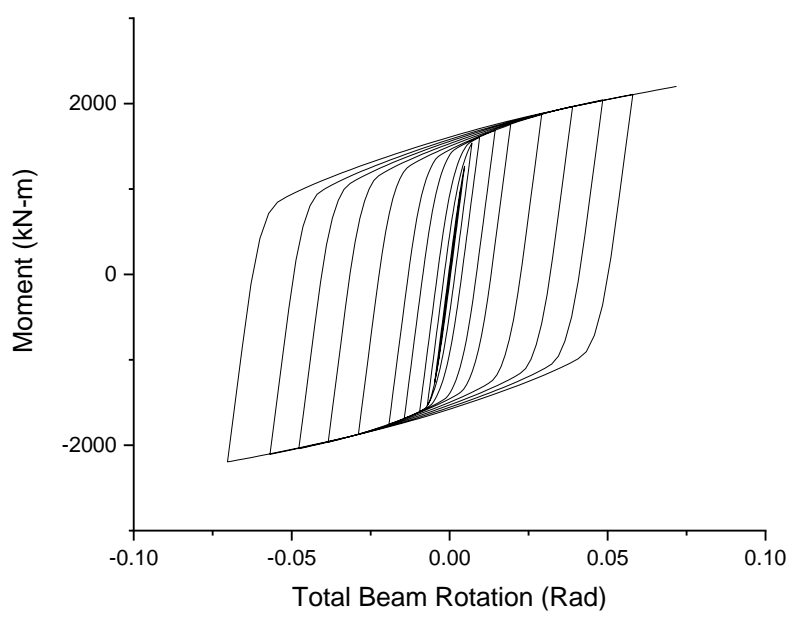

Figure B18: Experimental Moment vs Rotation Curve for RBS-28 


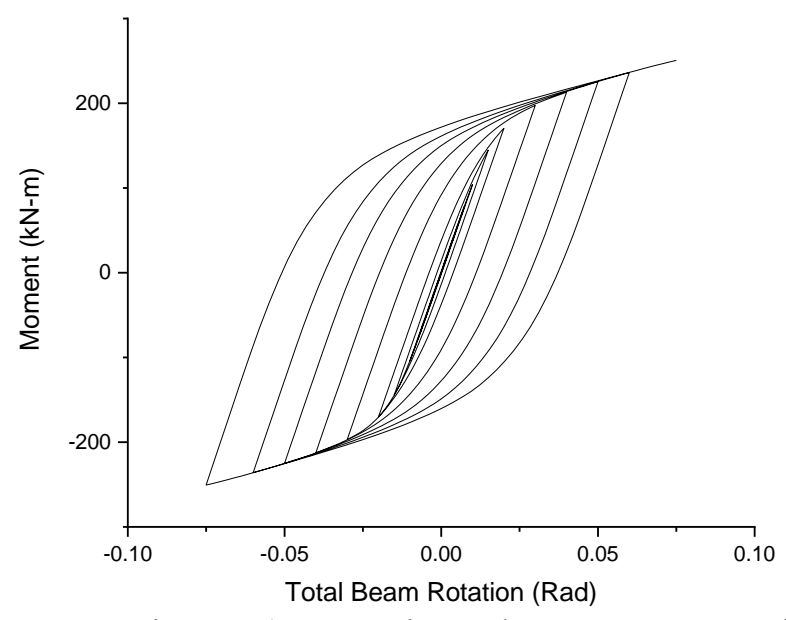

Figure B19: Experimental Moment vs Rotation Curve for RBS-29

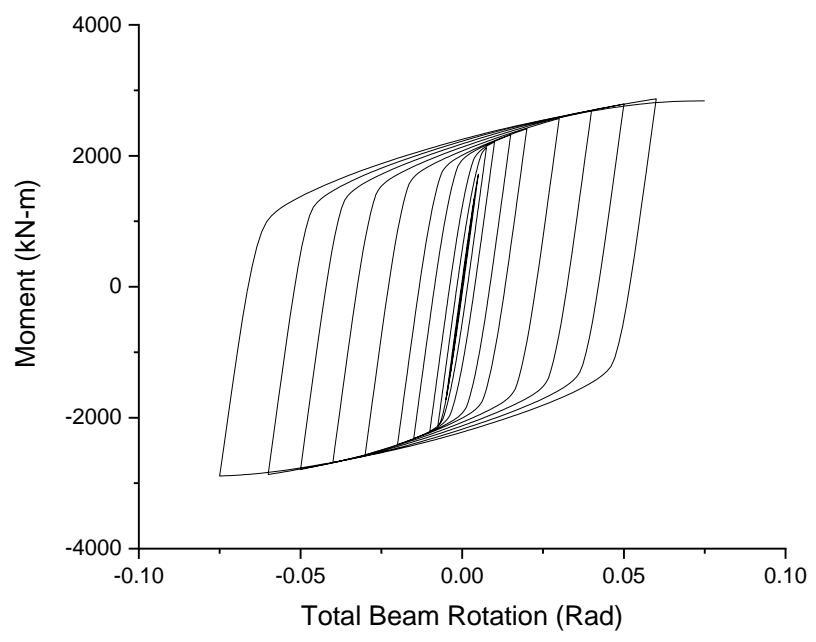

Figure 21: Experimental Moment vs Rotation Curve for RBS-31

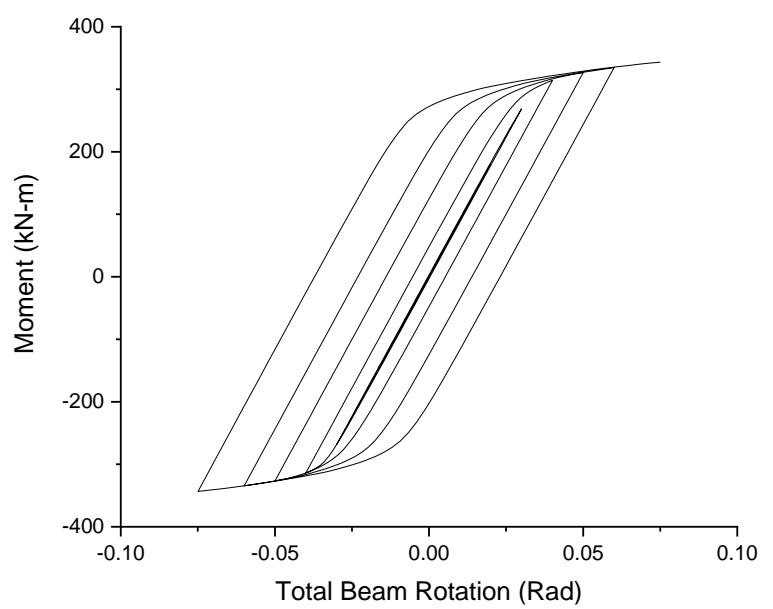

Figure B20: Experimental Moment vs Rotation Curve for RBS-30

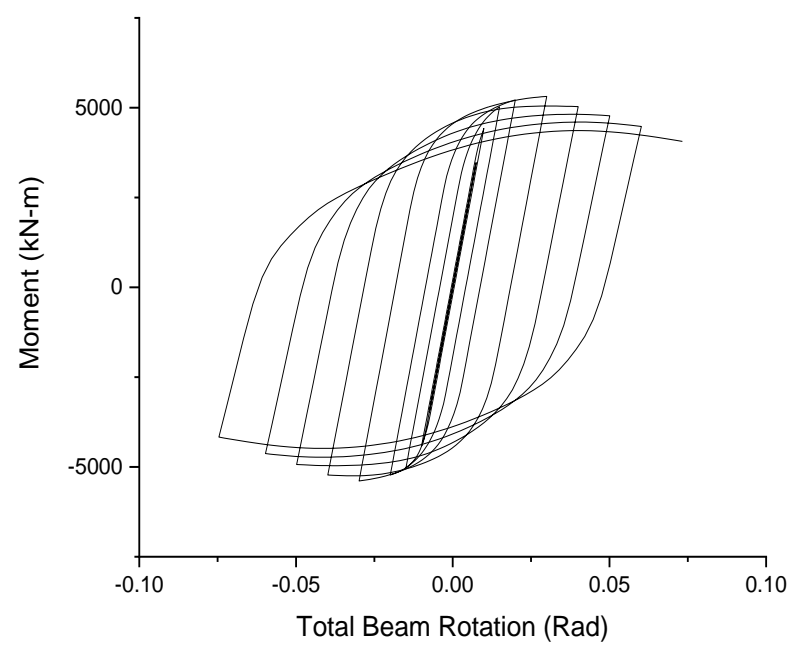

Figure 22: Experimental Moment vs Rotation Curve for RBS-32 


\section{APPENDIX C: Deflected Geometries of Specimen}



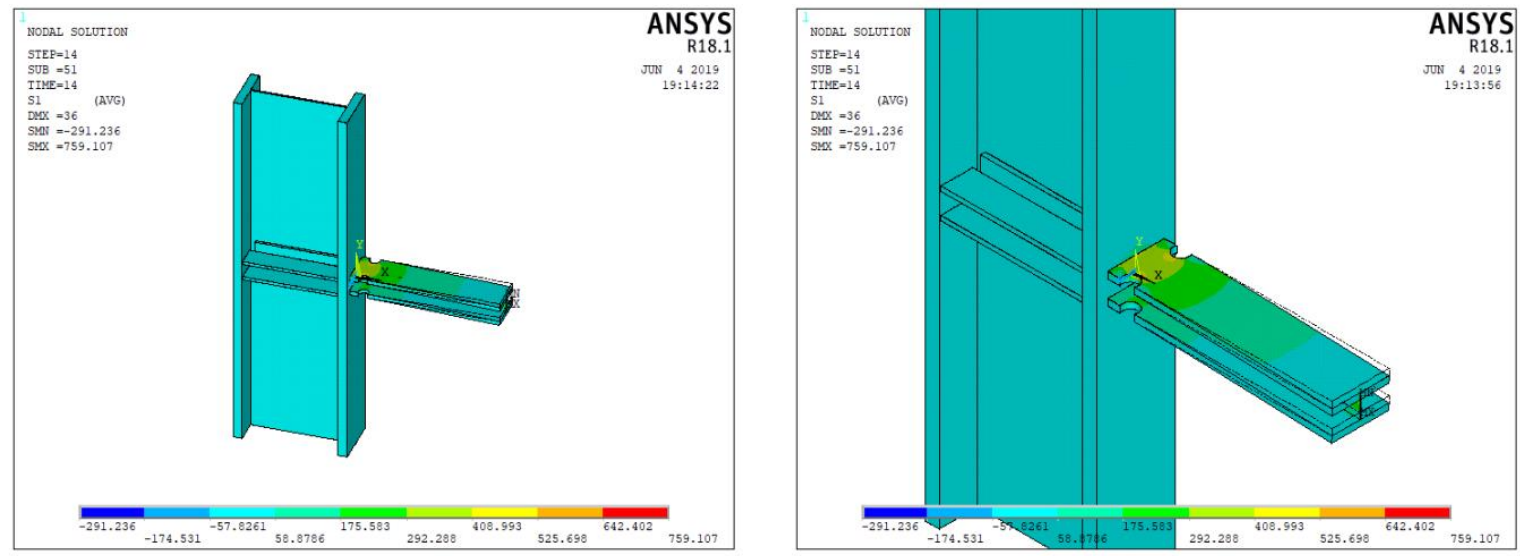

Figure C1: Deflected Geometry of Specimen RBS-6
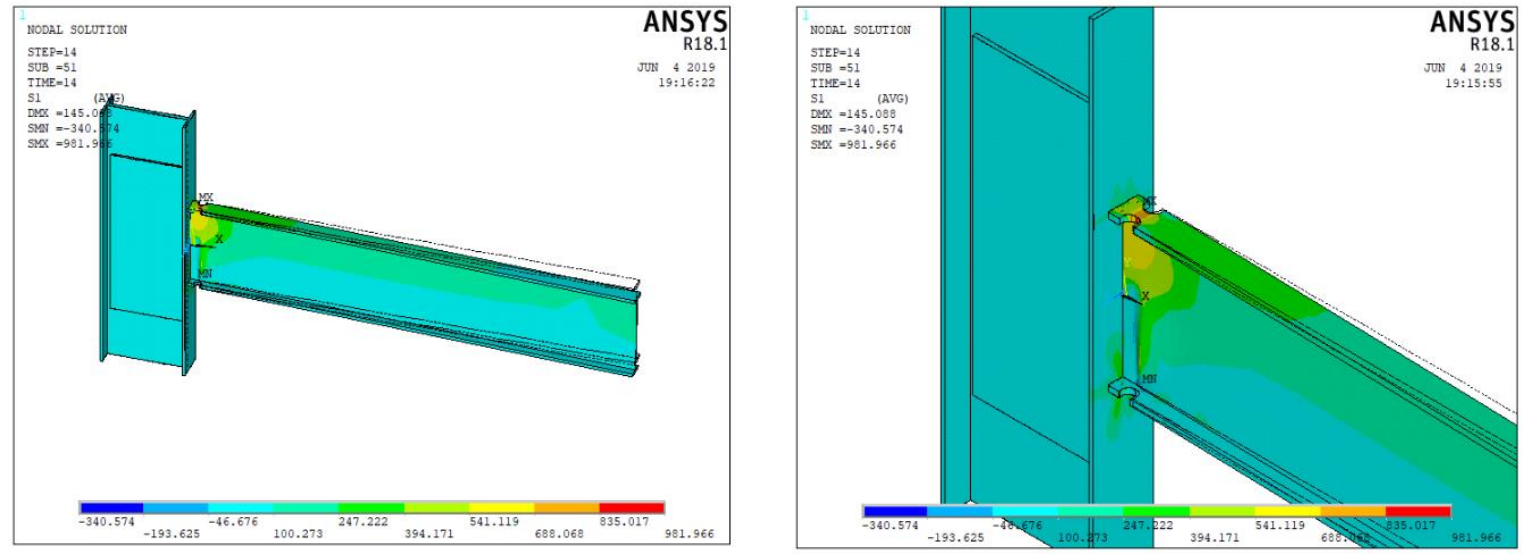

Figure C2: Deflected Geometry of Specimen RBS-7
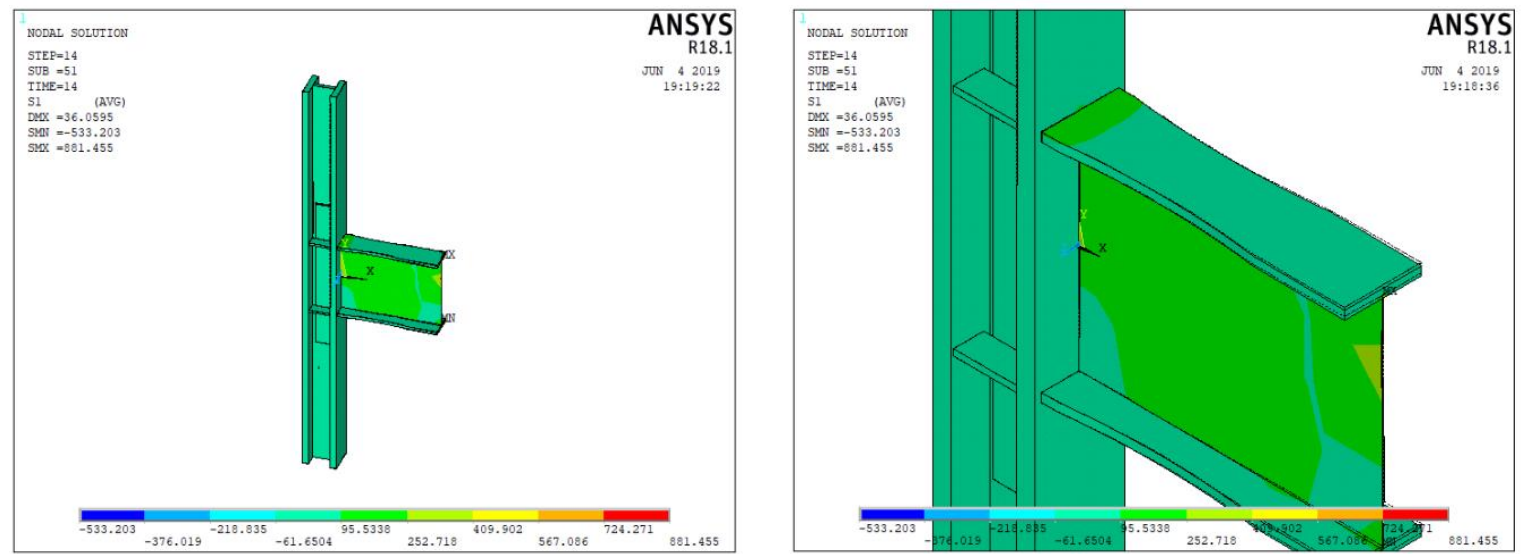

Figure C3: Deflected Geometry of Specimen RBS-8 

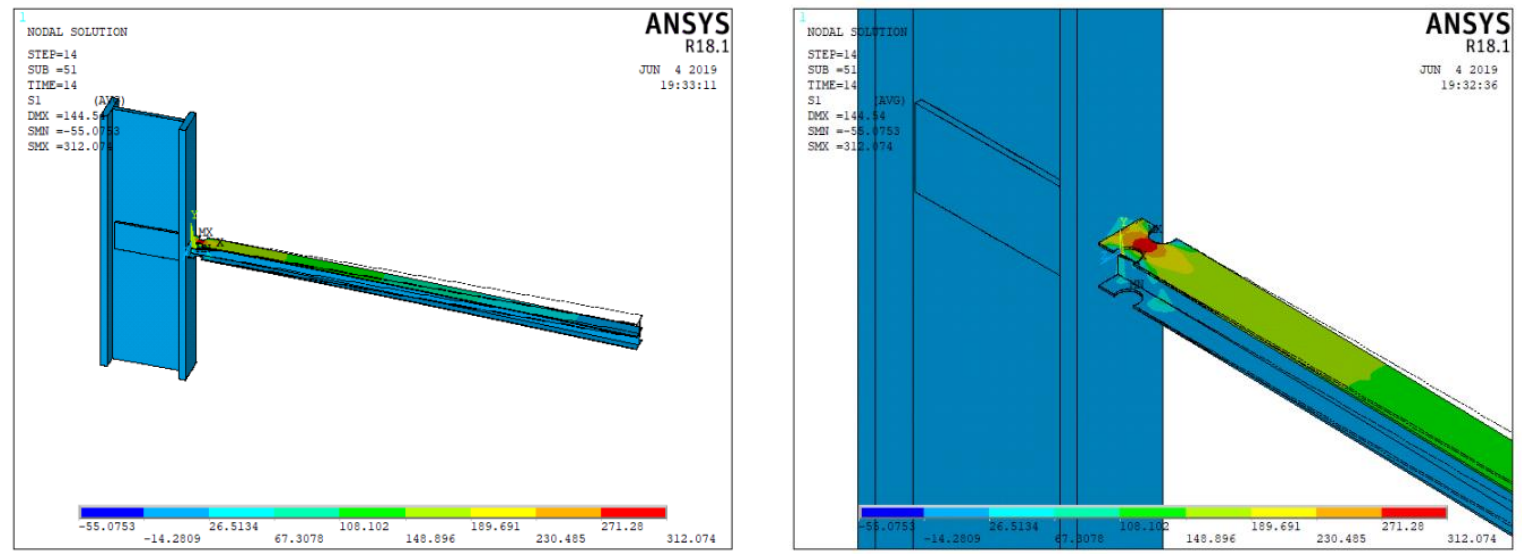

Figure C4: Deflected Geometry of Specimen RBS-9
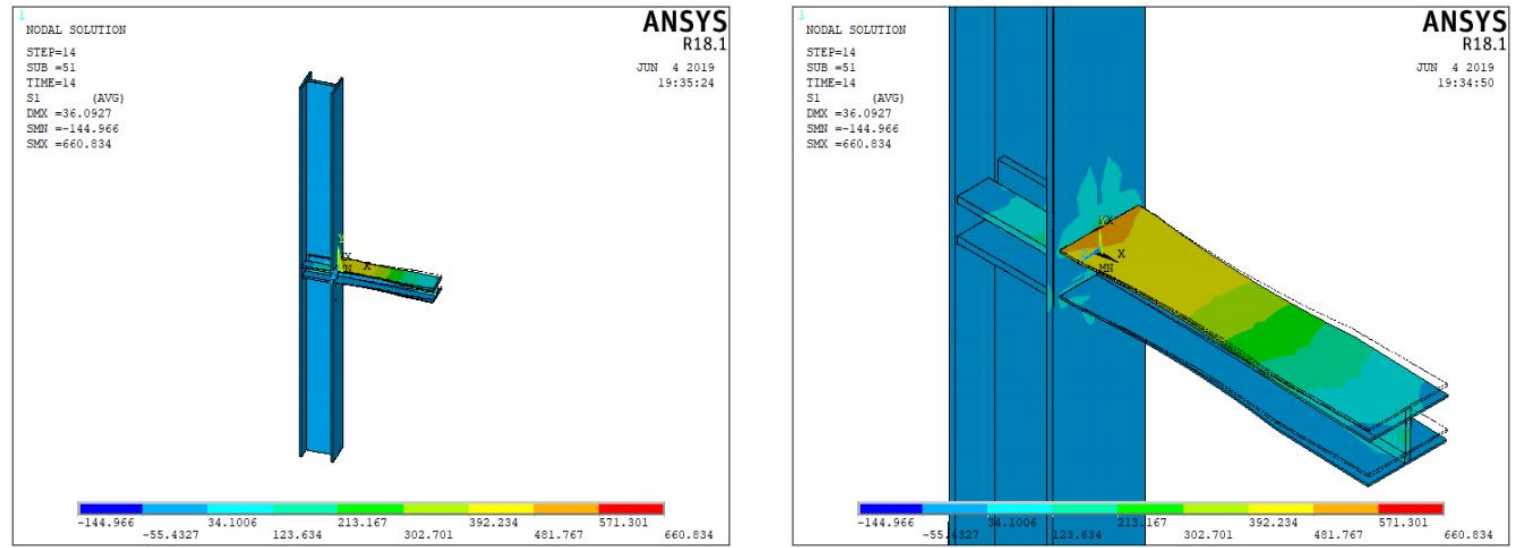

Figure C5: Deflected Geometry of Specimen RBS-10
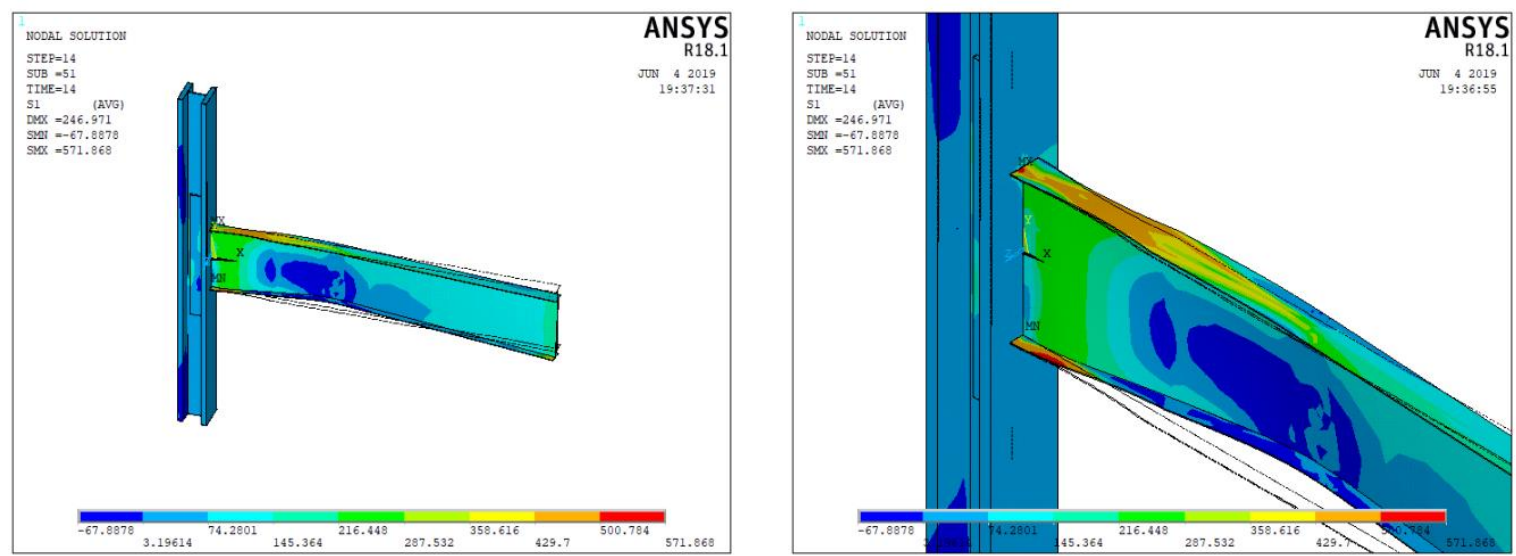

Figure C6: Deflected Geometry of Specimen RBS-11 

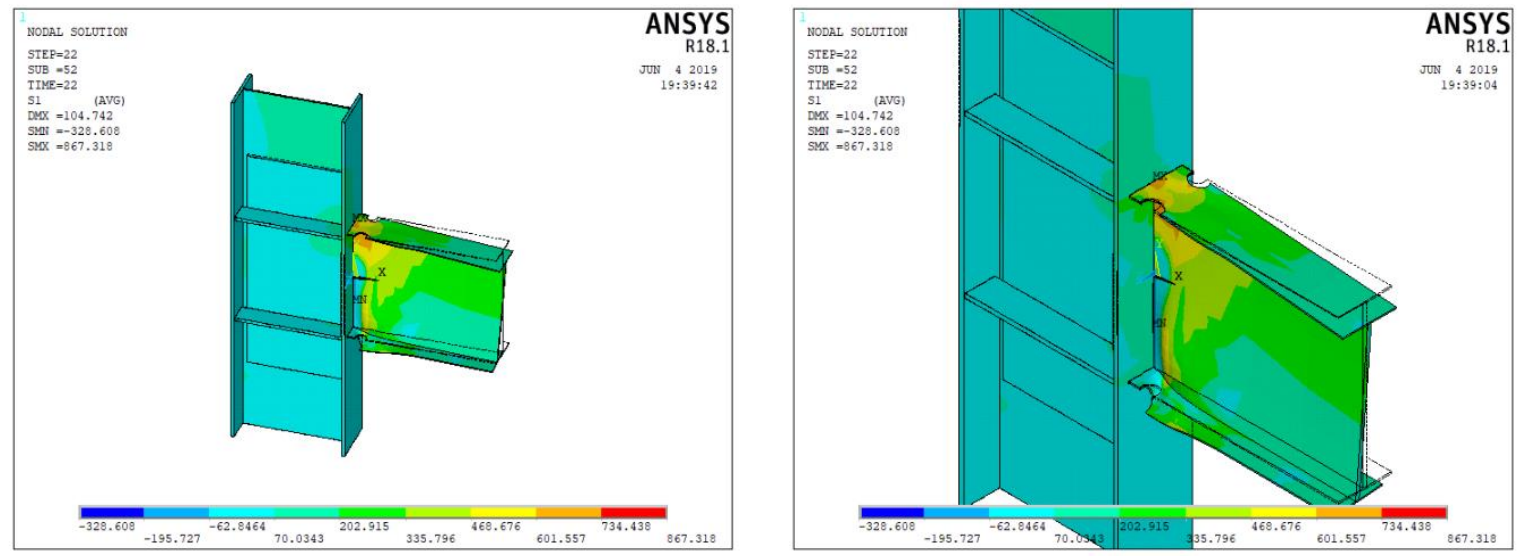

Figure C7: Deflected Geometry of Specimen RBS-12
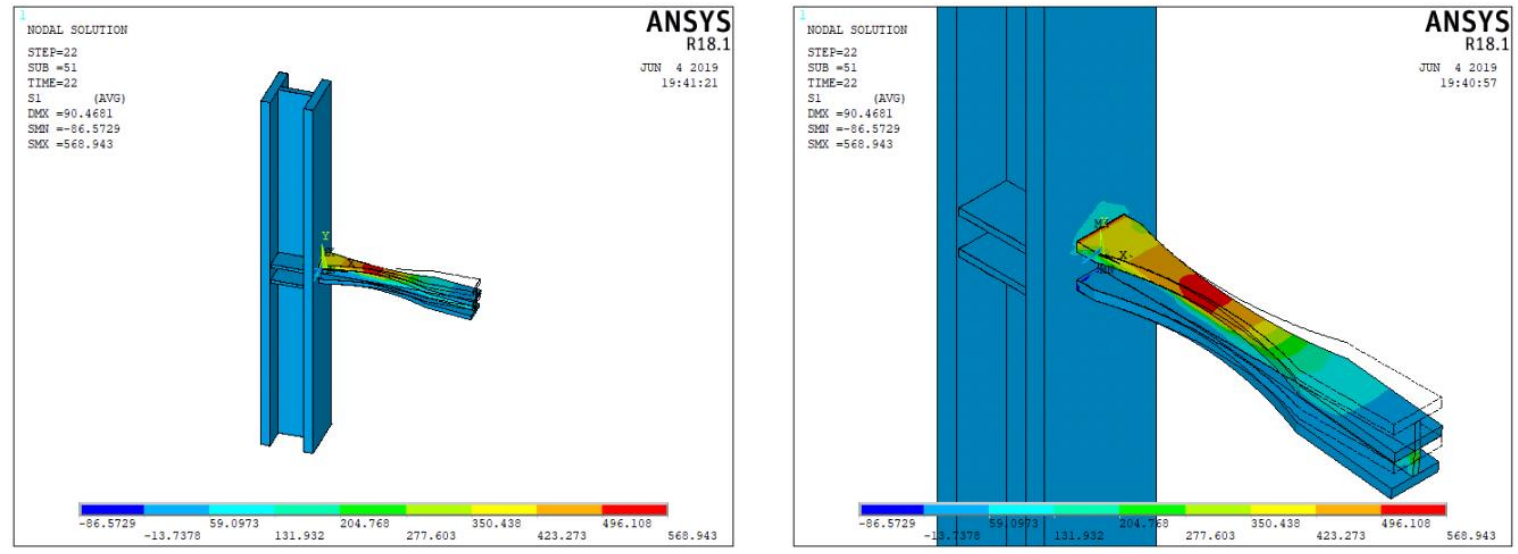

Figure C8: Deflected Geometry of Specimen RBS-13
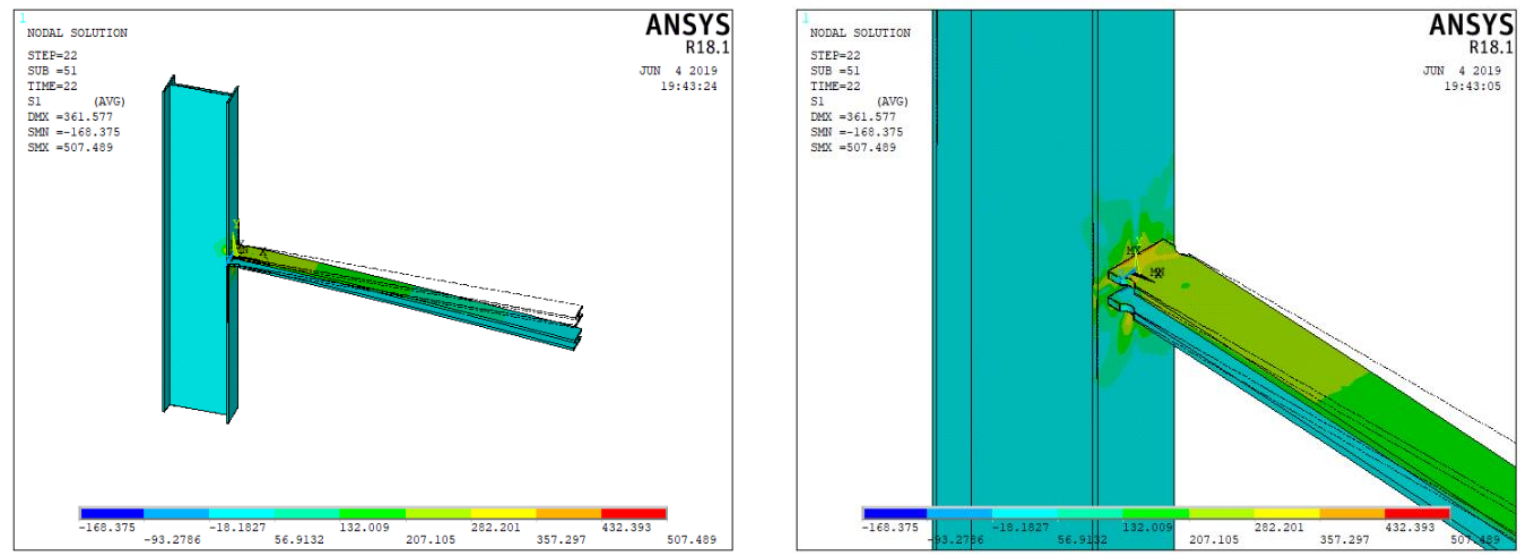

Figure C9: Deflected Geometry of Specimen RBS-14 

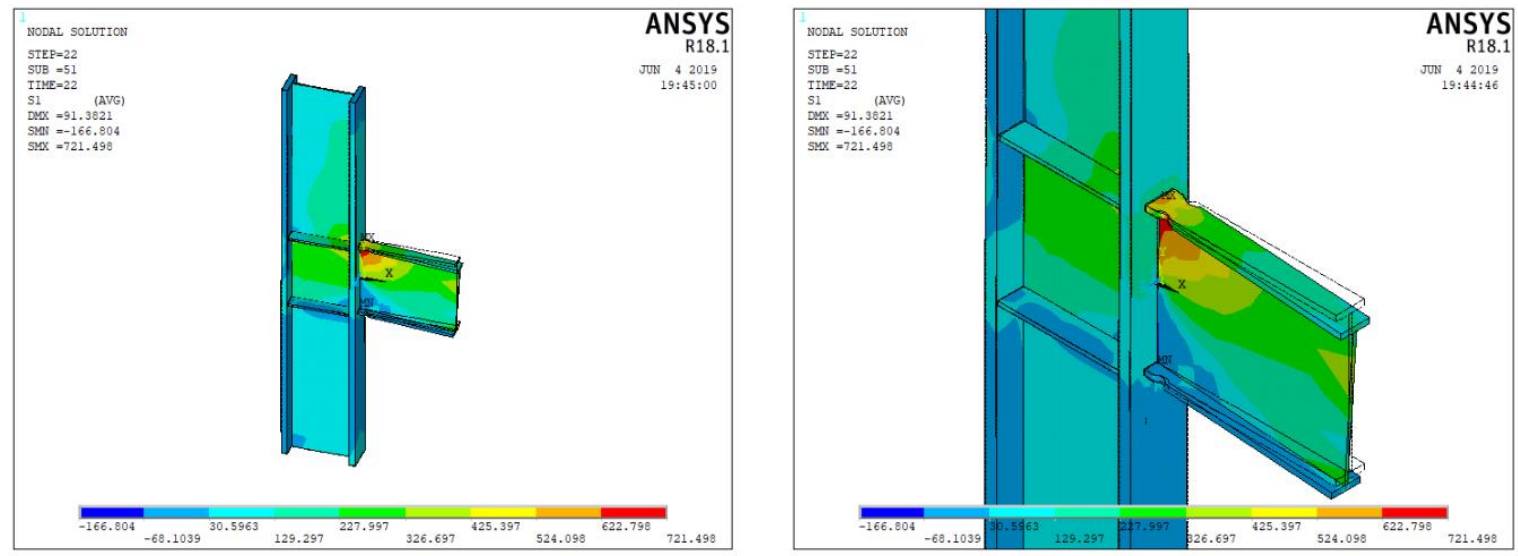

Figure C10: Deflected Geometry of Specimen RBS-15
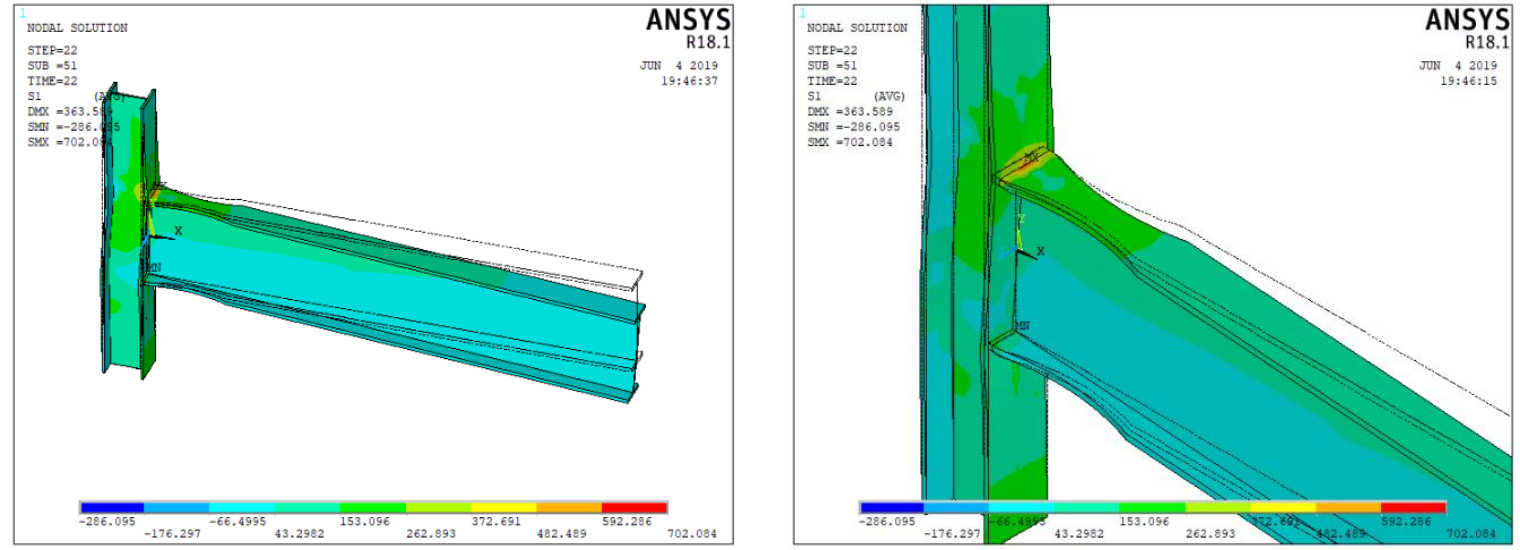

Figure C11: Deflected Geometry of Specimen RBS-16
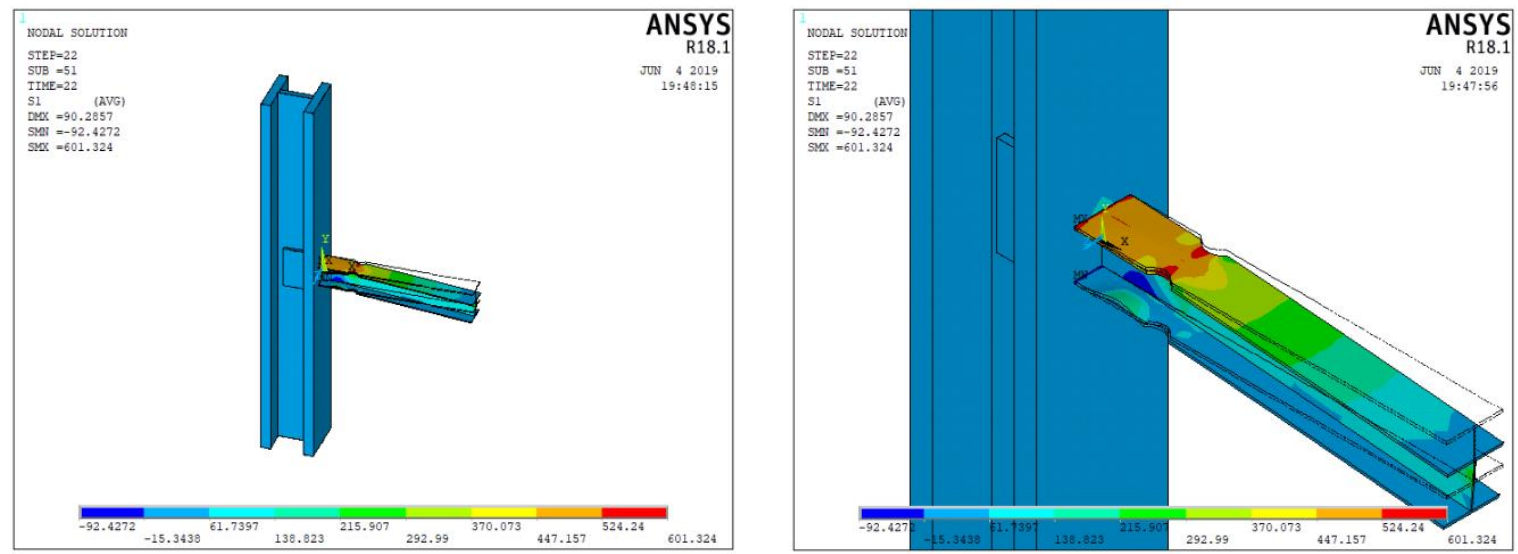

Figure C12: Deflected Geometry of Specimen RBS-17 

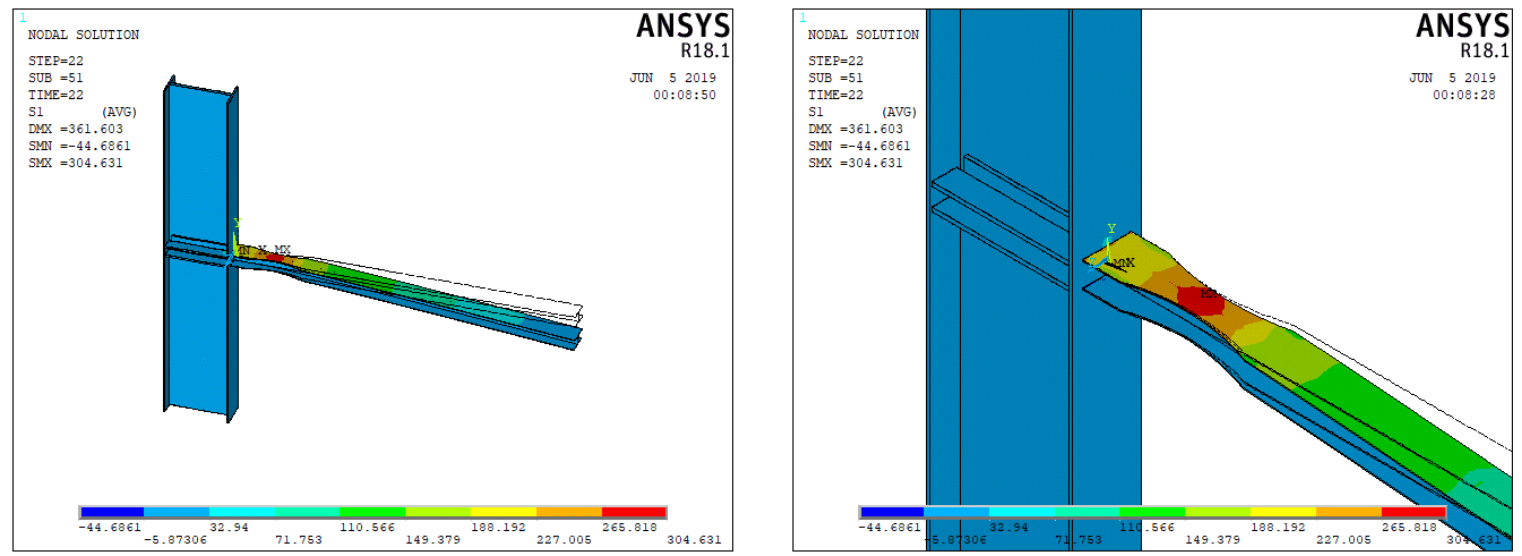

Figure C13: Deflected Geometry of Specimen RBS-18
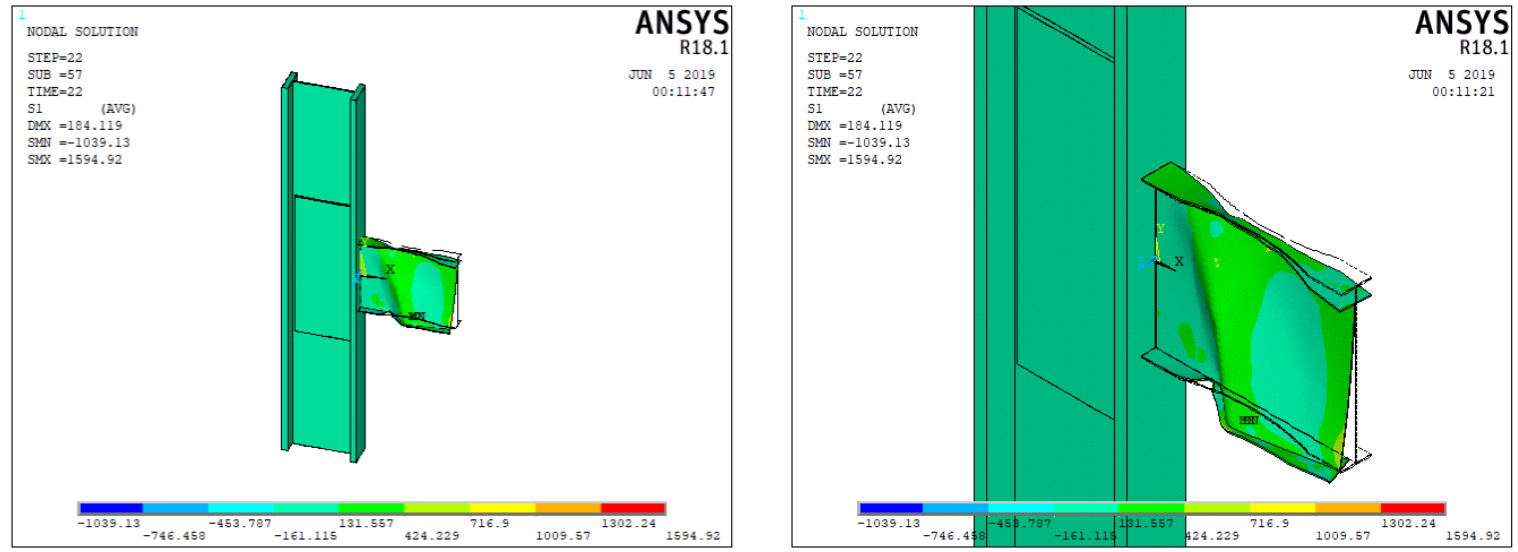

Figure C14: Deflected Geometry of Specimen RBS-19
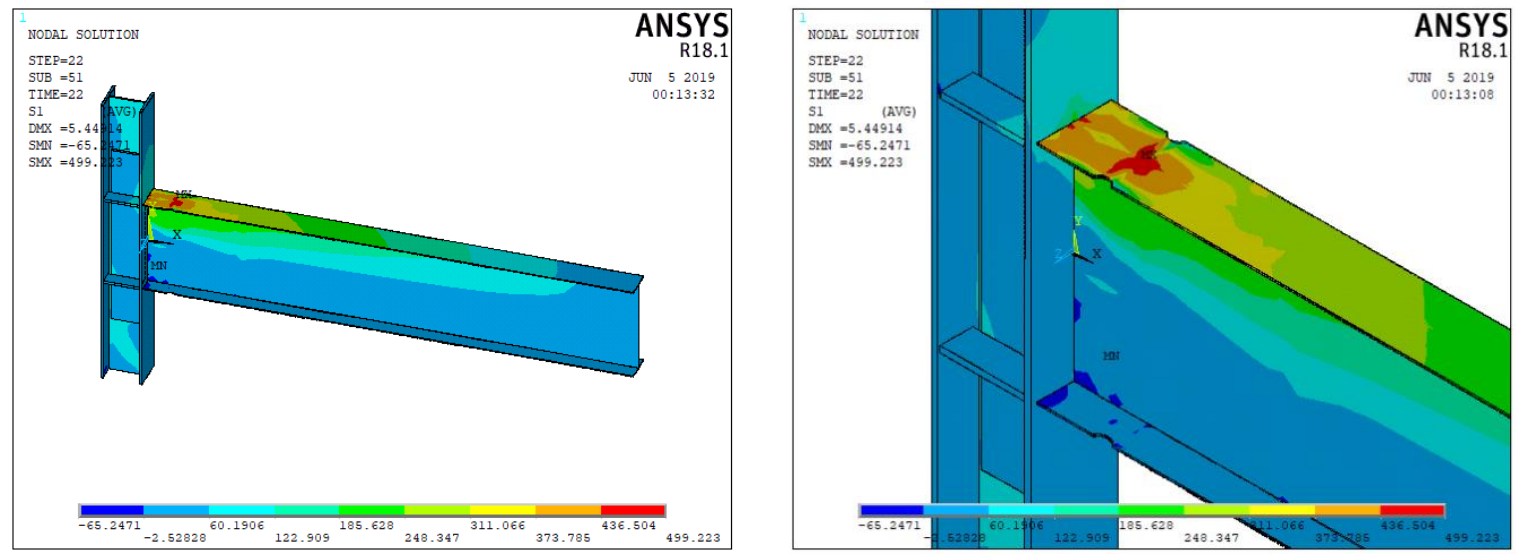

Figure C15: Deflected Geometry of Specimen RBS-20 

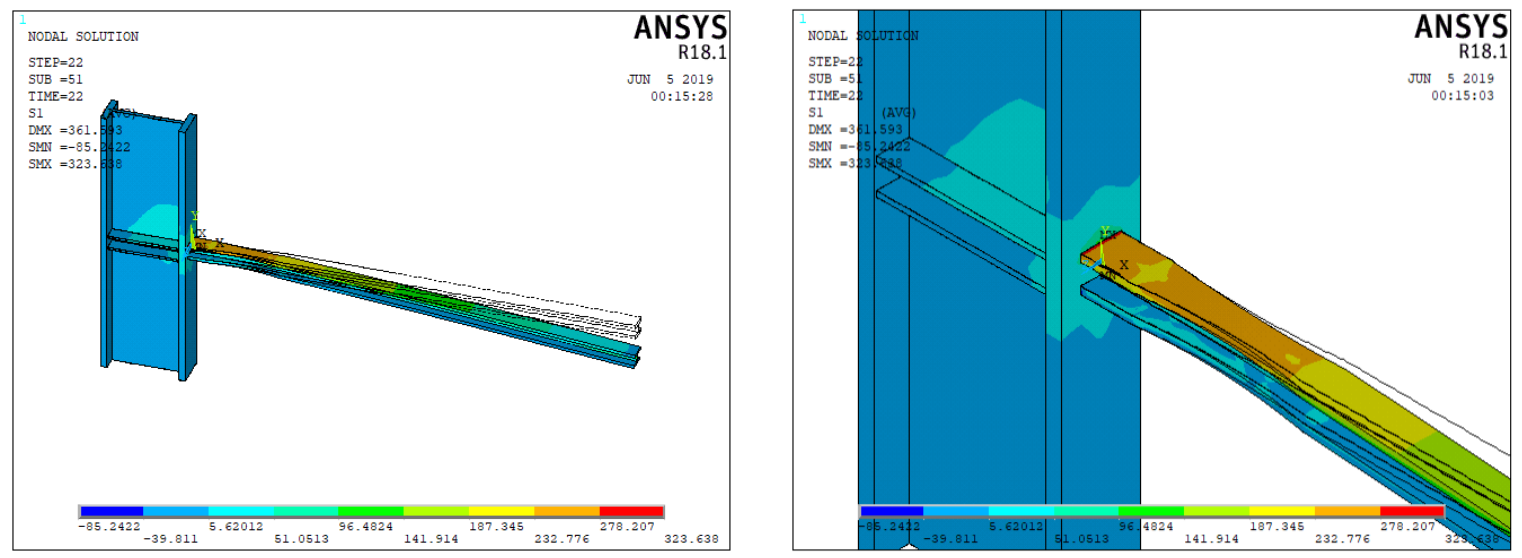

Figure C16: Deflected Geometry of Specimen RBS-21
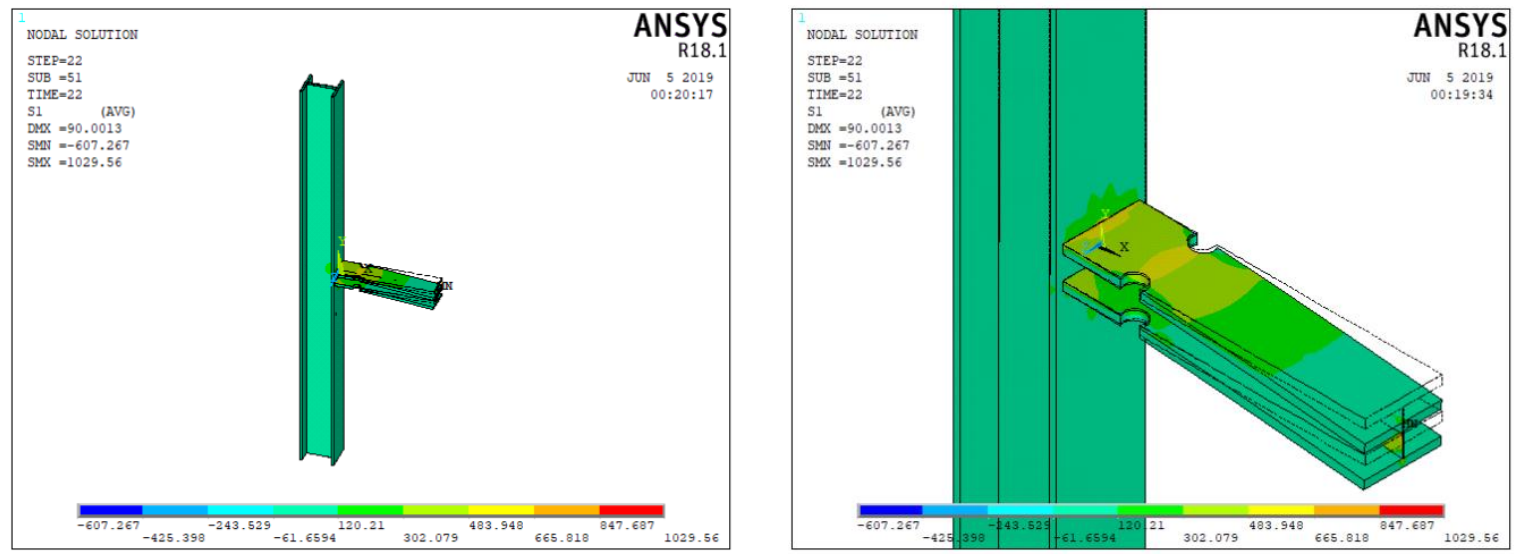

Figure C17: Deflected Geometry of Specimen RBS-22
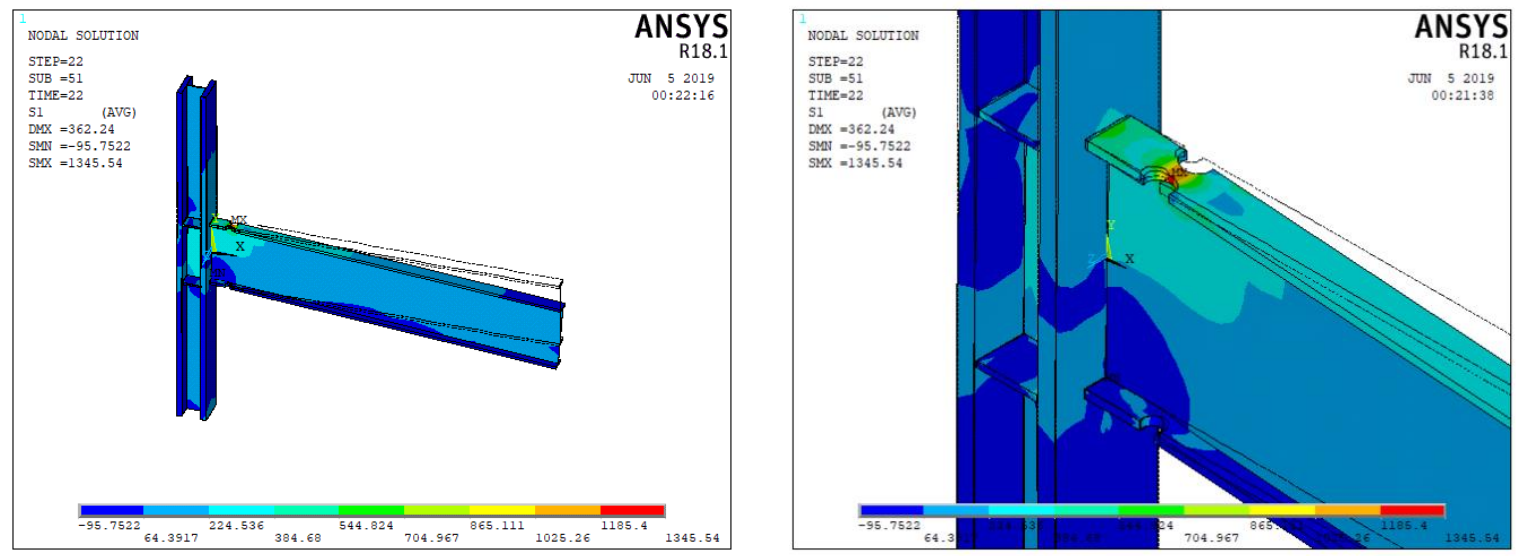

Figure C18: Deflected Geometry of Specimen RBS-23 

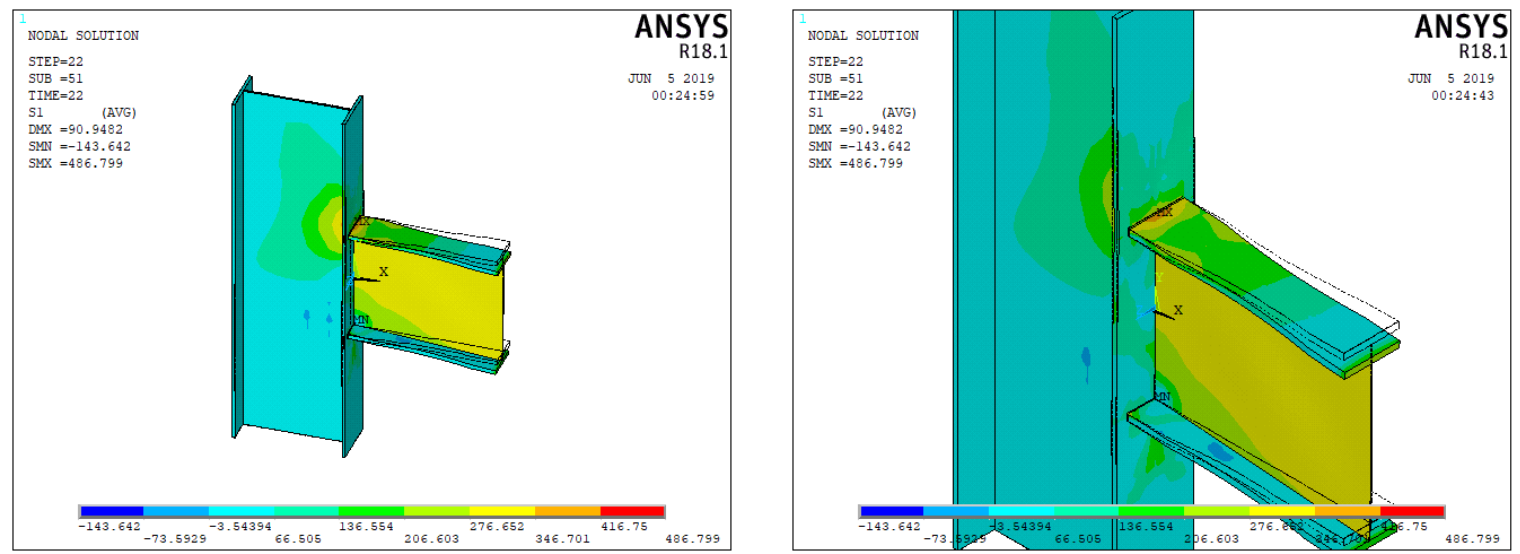

Figure C19: Deflected Geometry of Specimen RBS-24
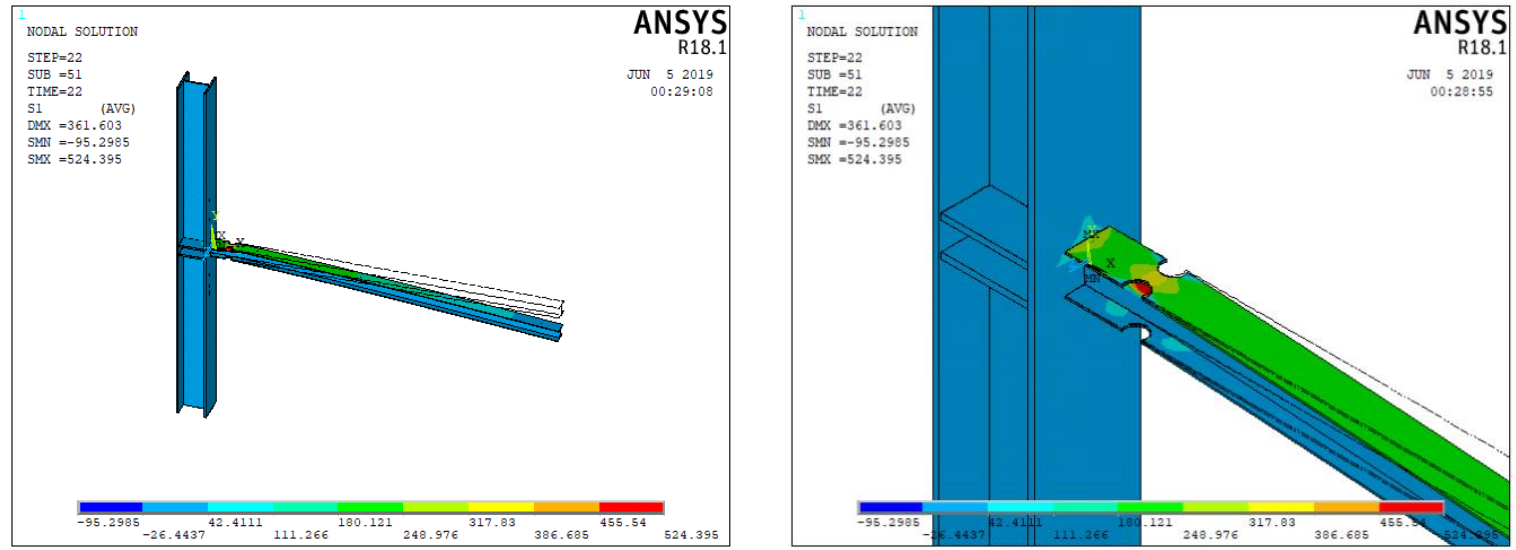

Figure C20: Deflected Geometry of Specimen RBS-25
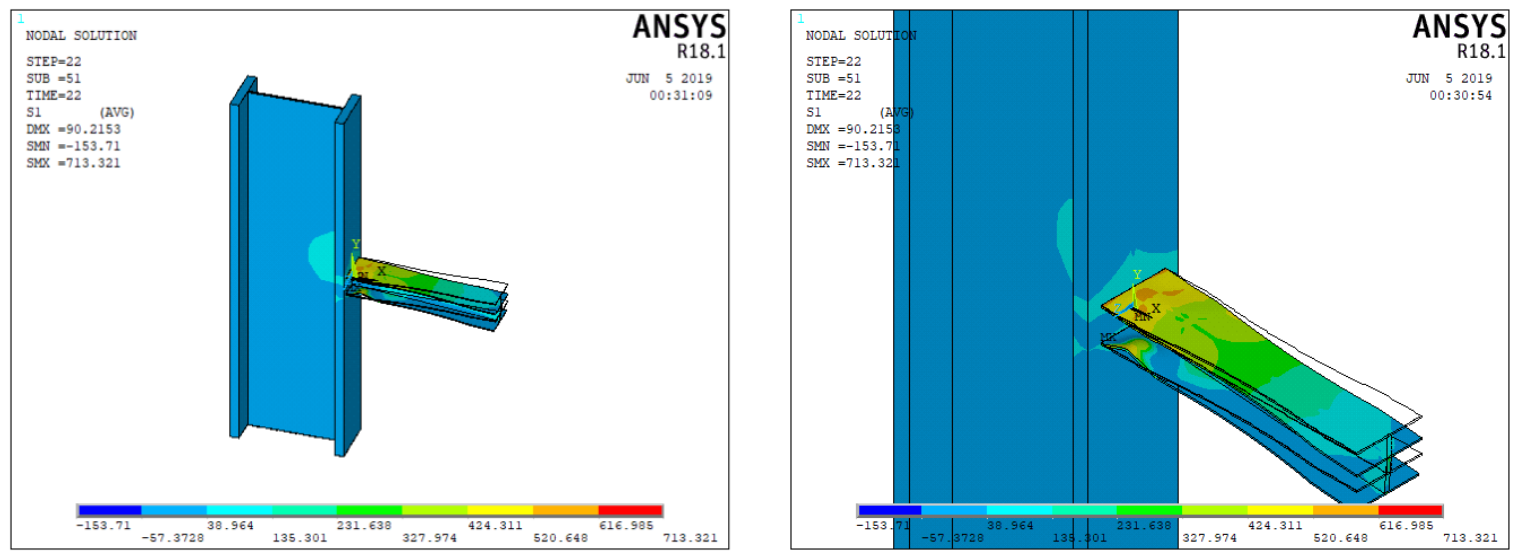

Figure C21: Deflected Geometry of Specimen RBS-26 

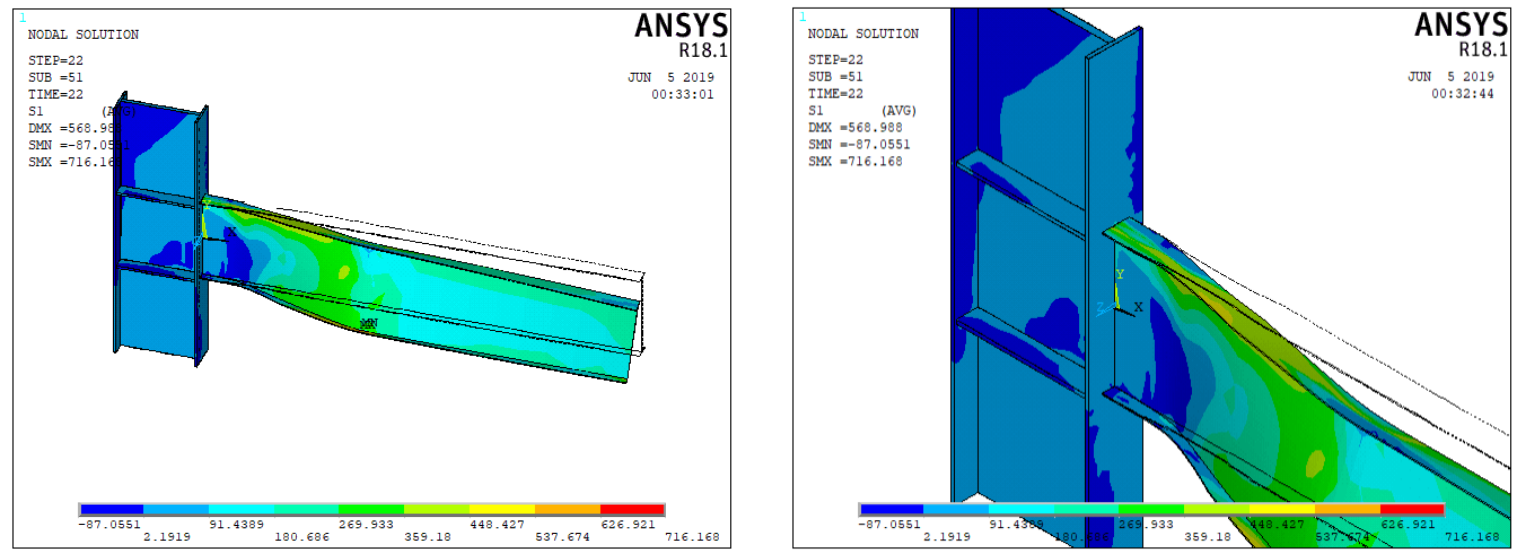

Figure C22: Deflected Geometry of Specimen RBS-27
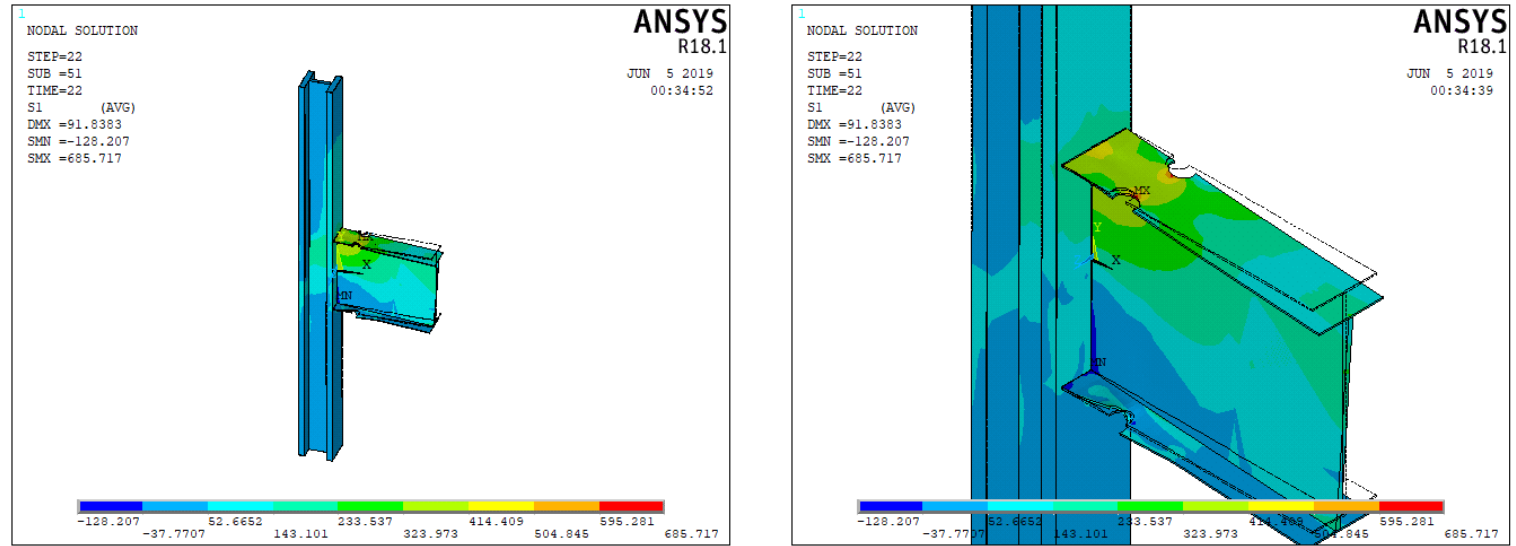

Figure C23: Deflected Geometry of Specimen RBS-28
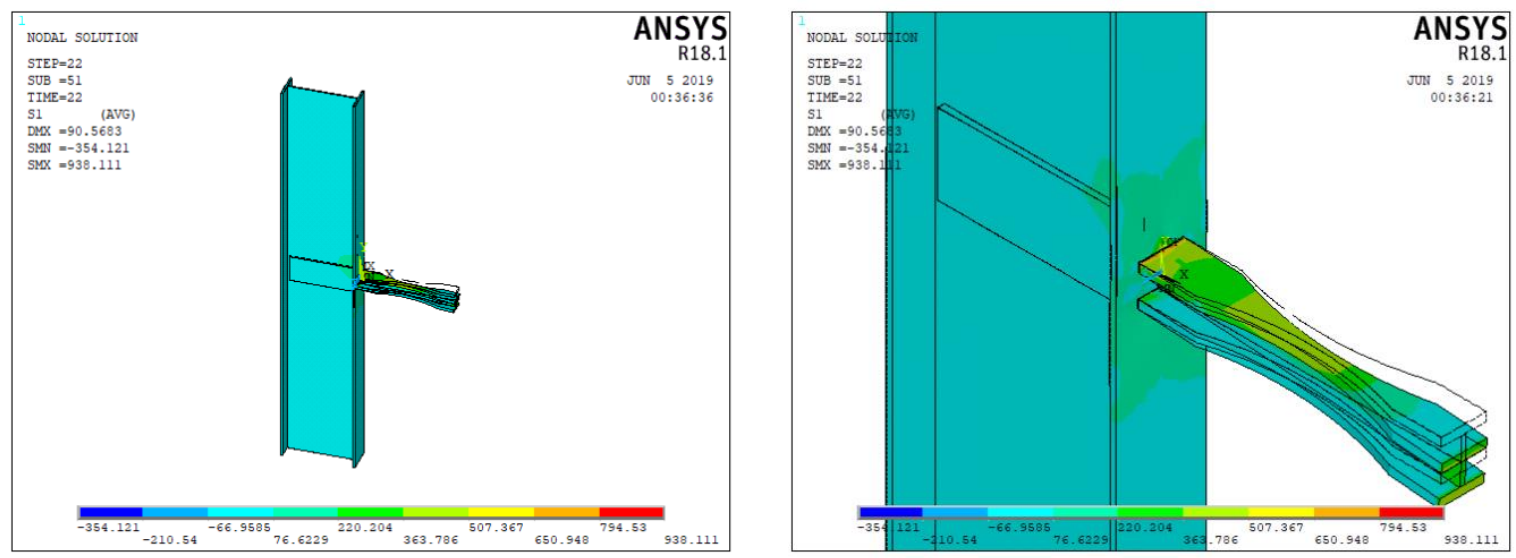

Figure C24: Deflected Geometry of Specimen RBS-29 

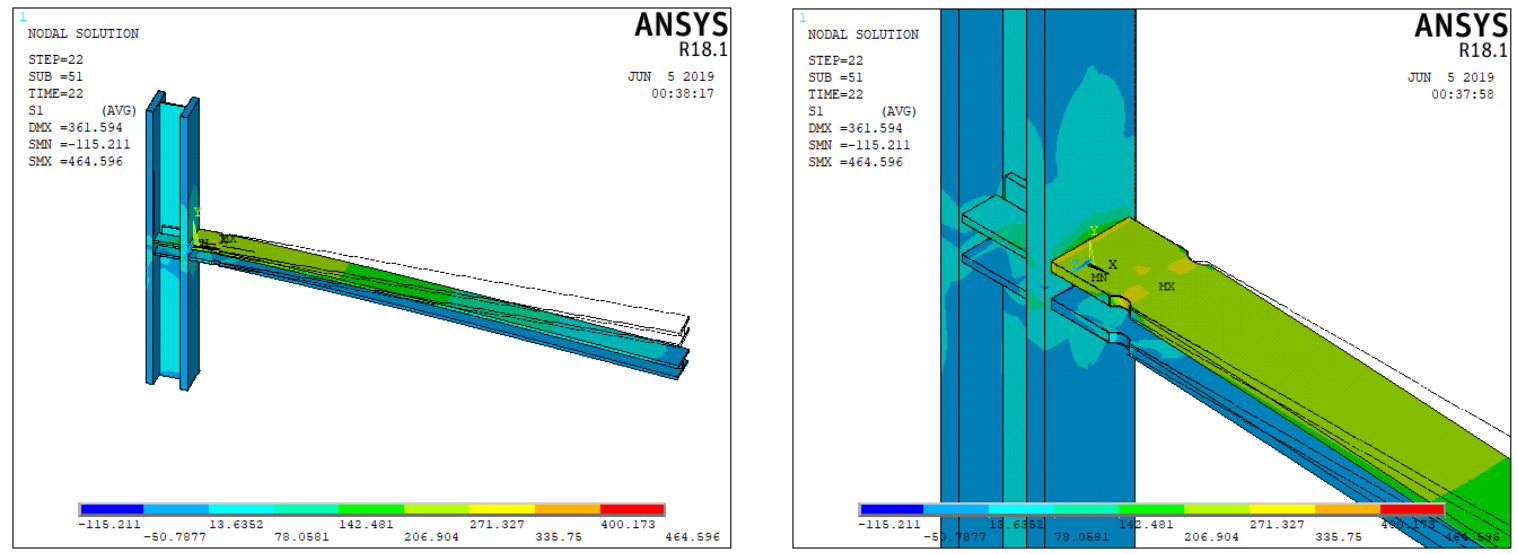

Figure C25: Deflected Geometry of Specimen RBS-30
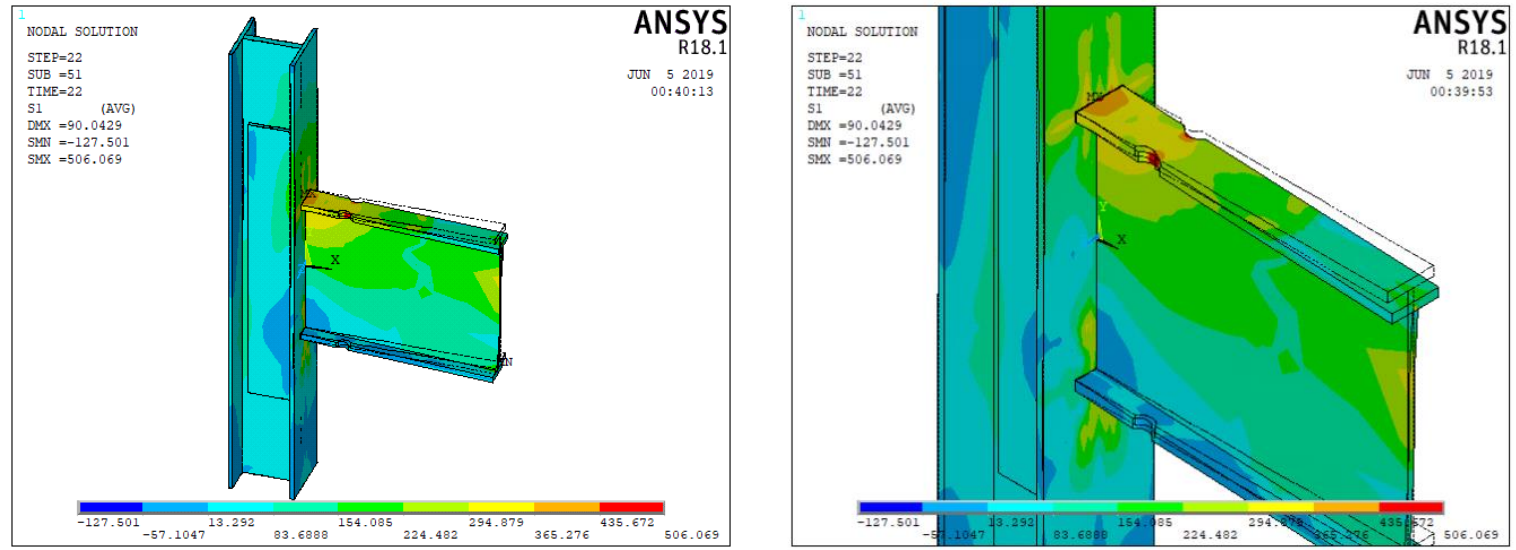

Figure C26: Deflected Geometry of Specimen RBS-31
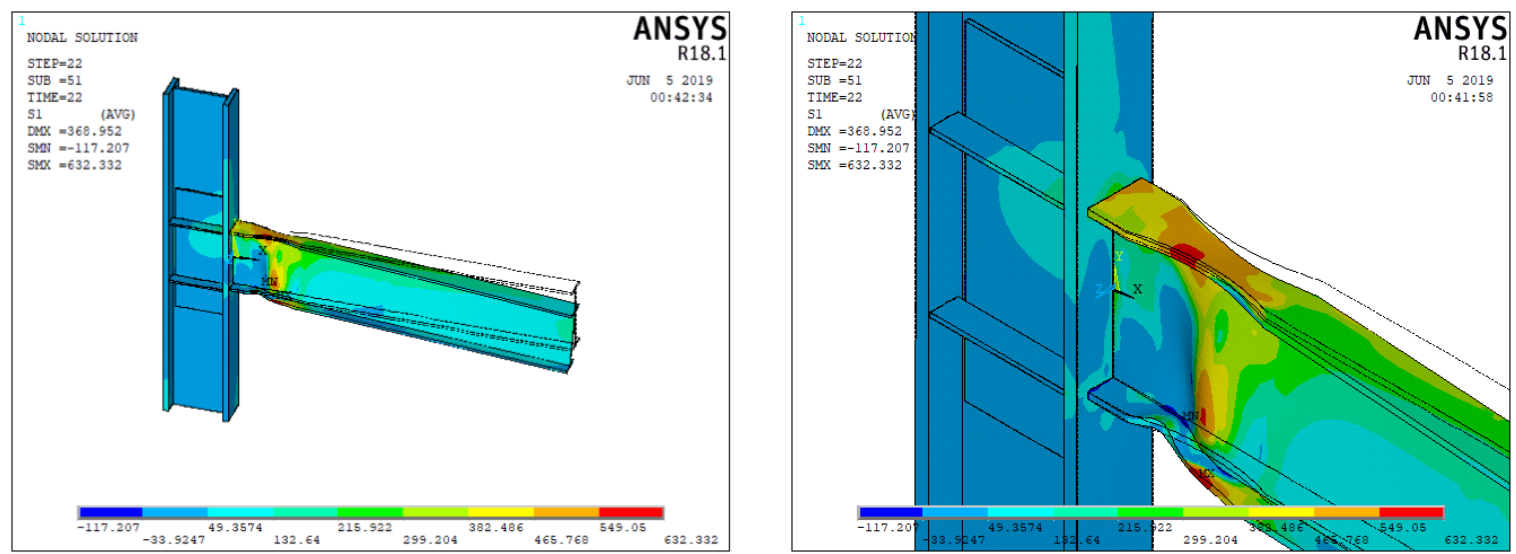

Figure C27: Deflected Geometry of Specimen RBS-32 

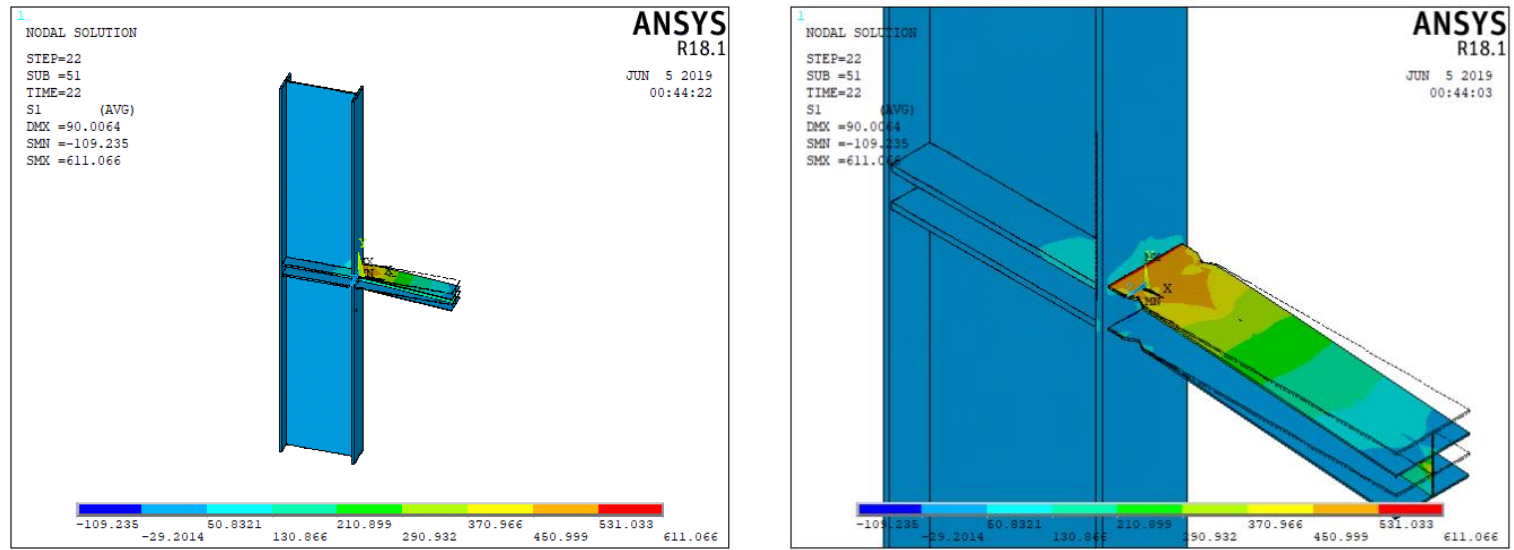

Figure C28: Deflected Geometry of Specimen RBS-33
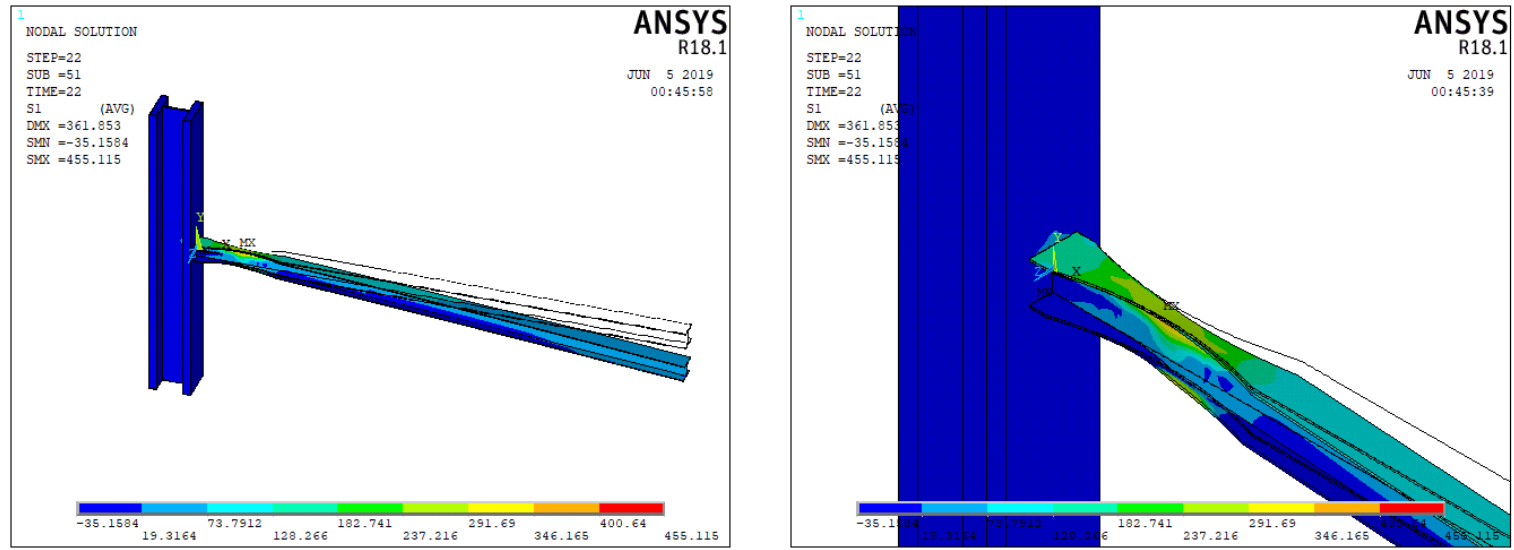

Figure C29: Deflected Geometry of Specimen RBS-34
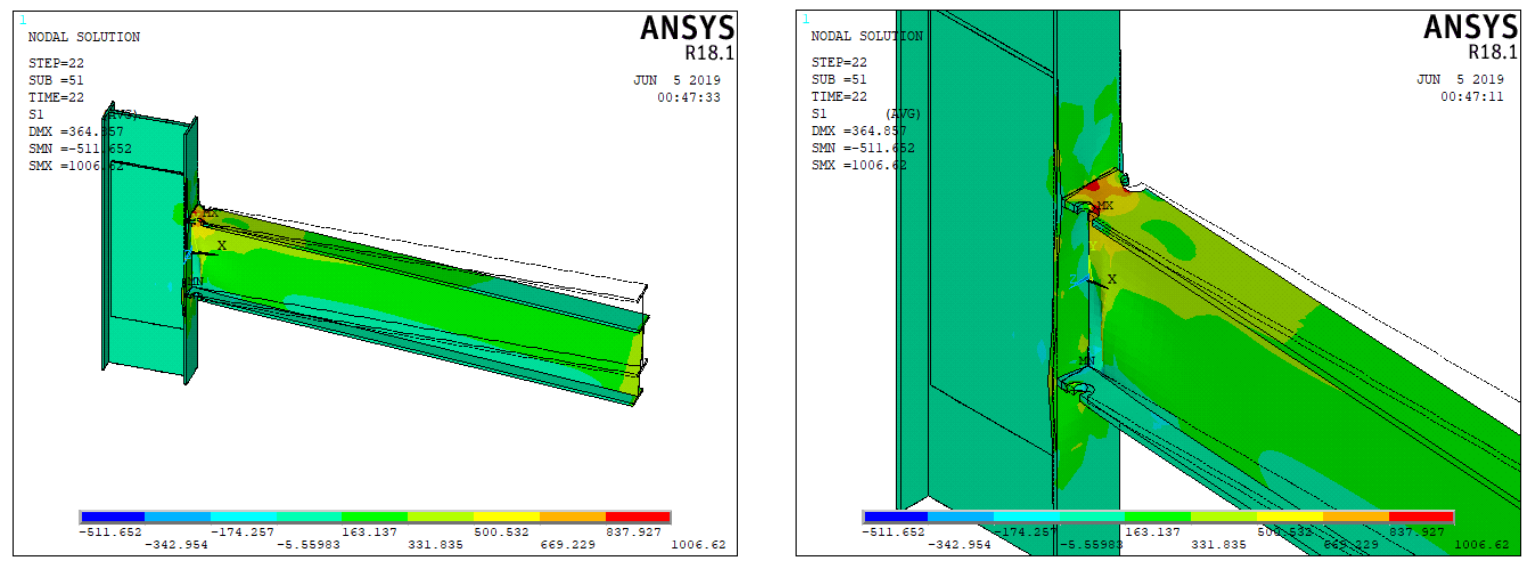

Figure C30: Deflected Geometry of Specimen RBS-35 

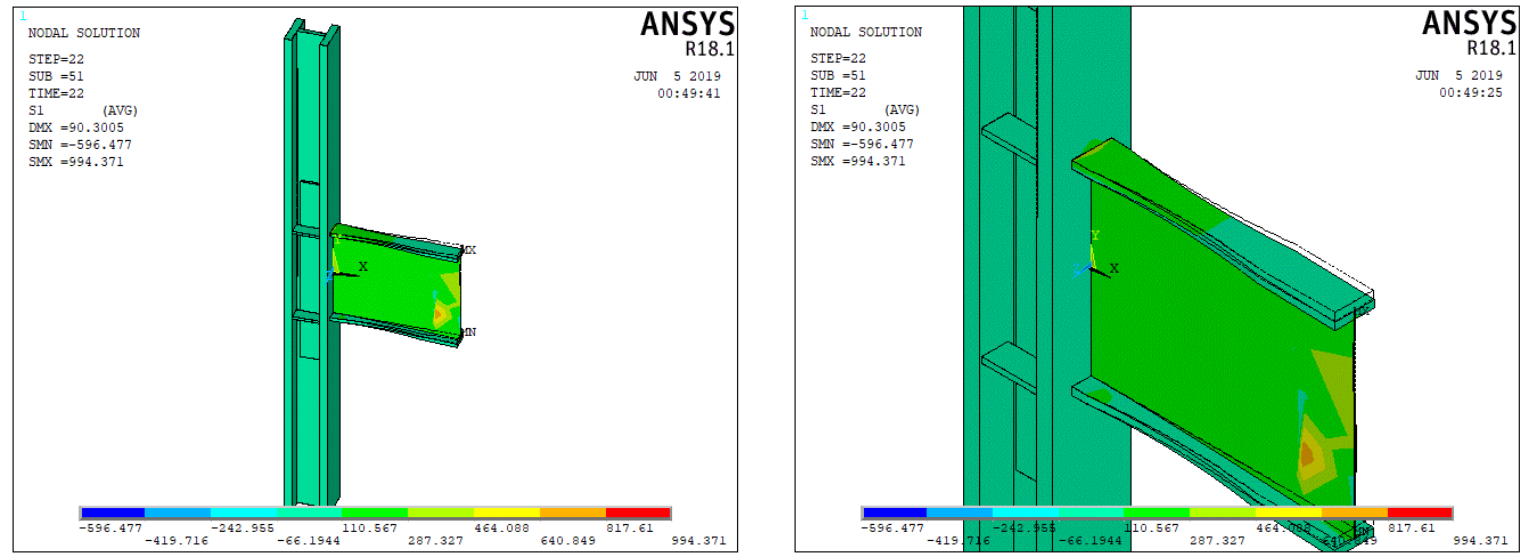

Figure C31: Deflected Geometry of Specimen RBS-36
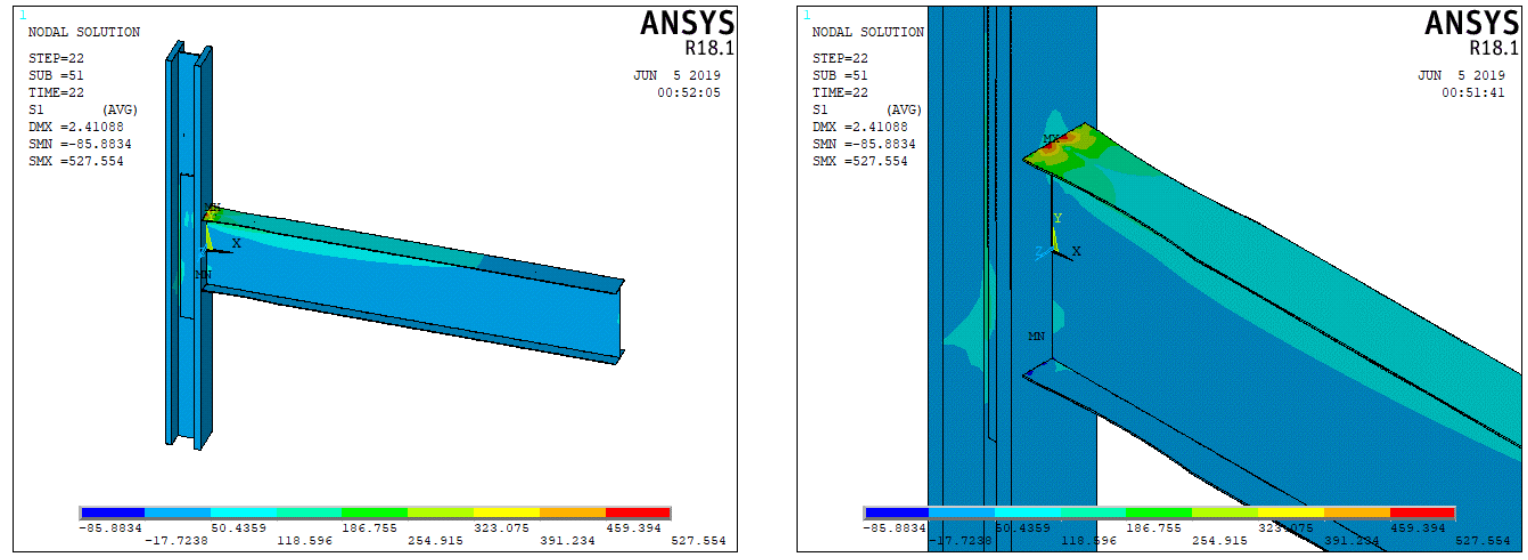

Figure C32: Deflected Geometry of Specimen RBS-37
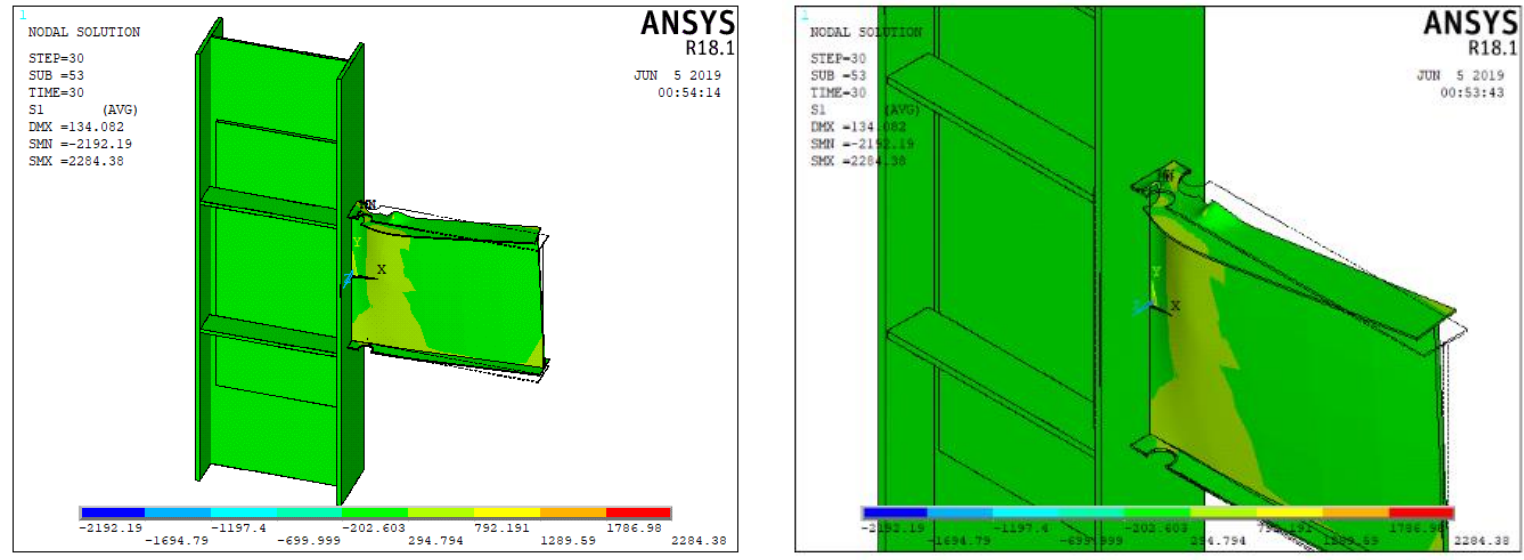

Figure C33: Deflected Geometry of Specimen RBS-38 

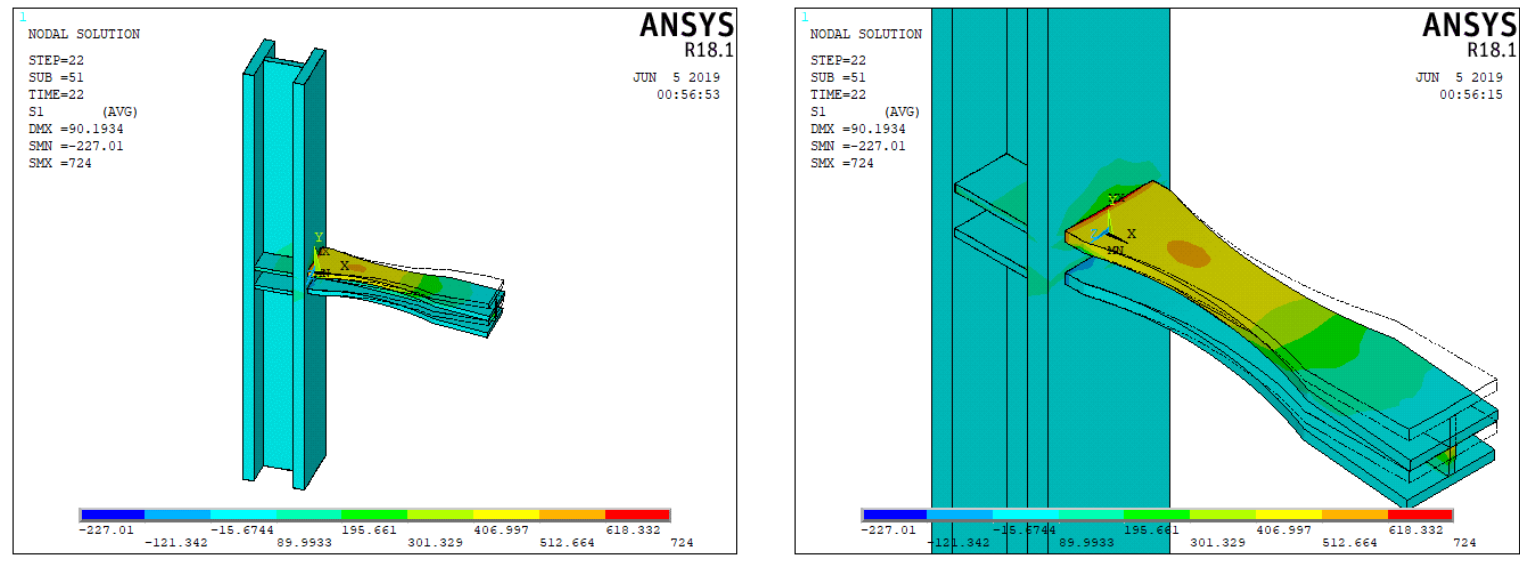

Figure C34: Deflected Geometry of Specimen RBS-39
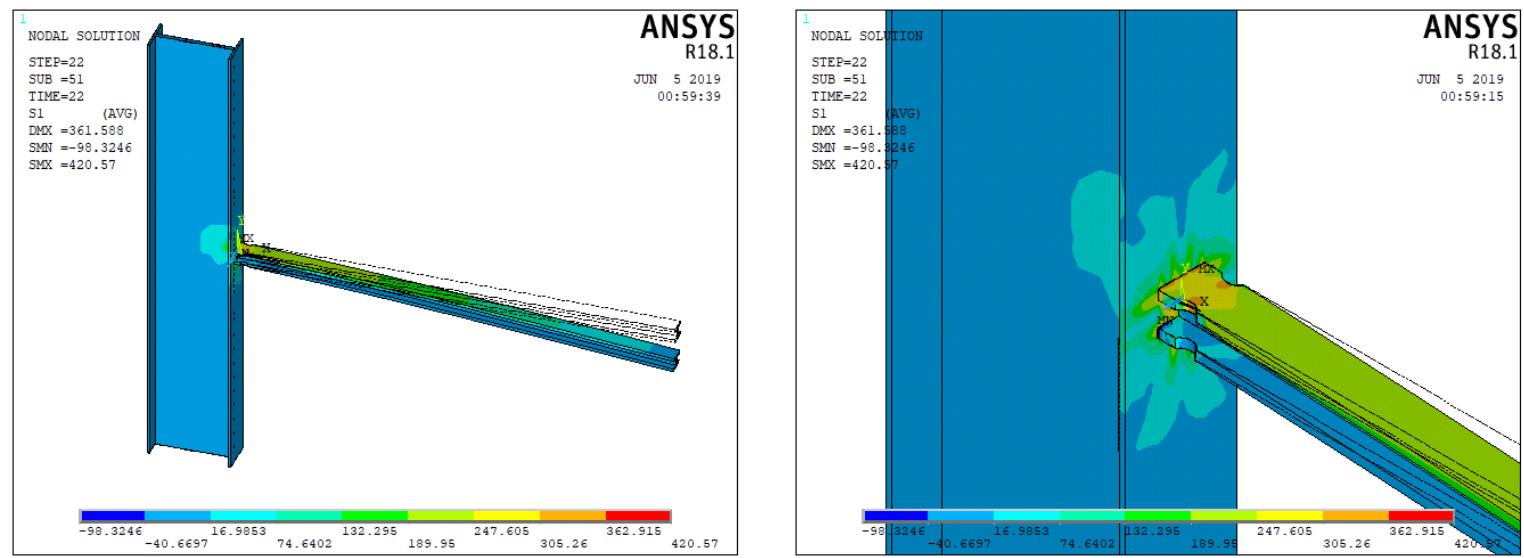

Figure C35: Deflected Geometry of Specimen RBS-40
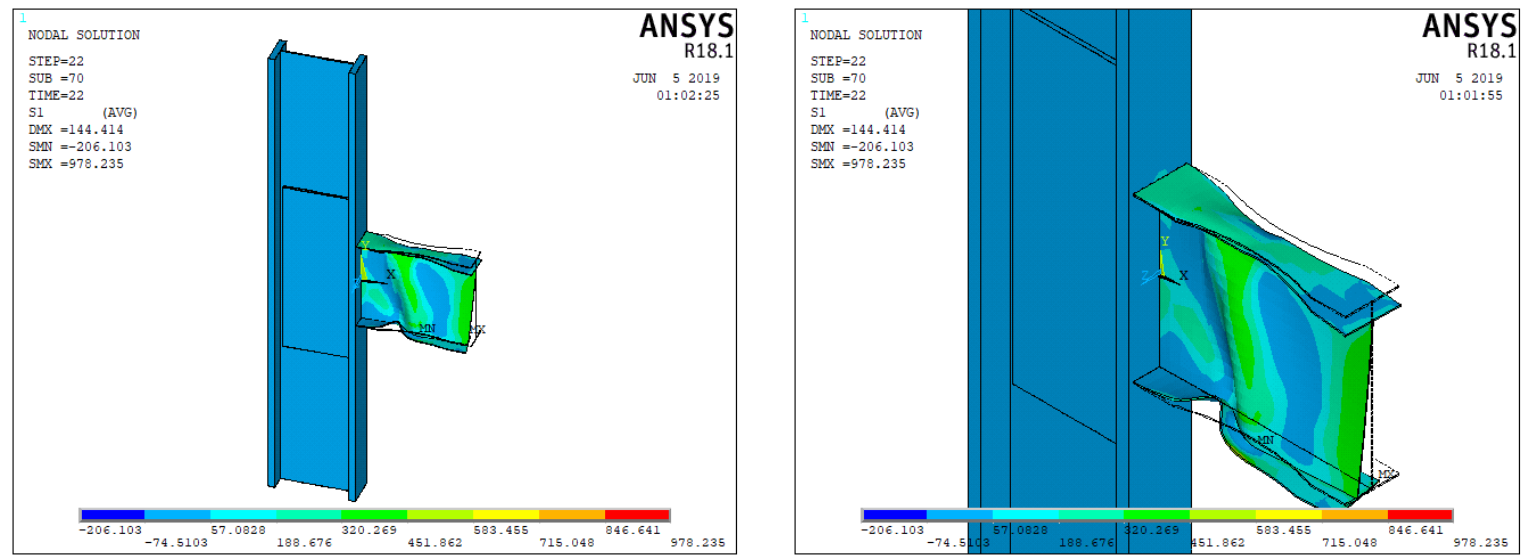

Figure C36: Deflected Geometry of Specimen RBS-41 

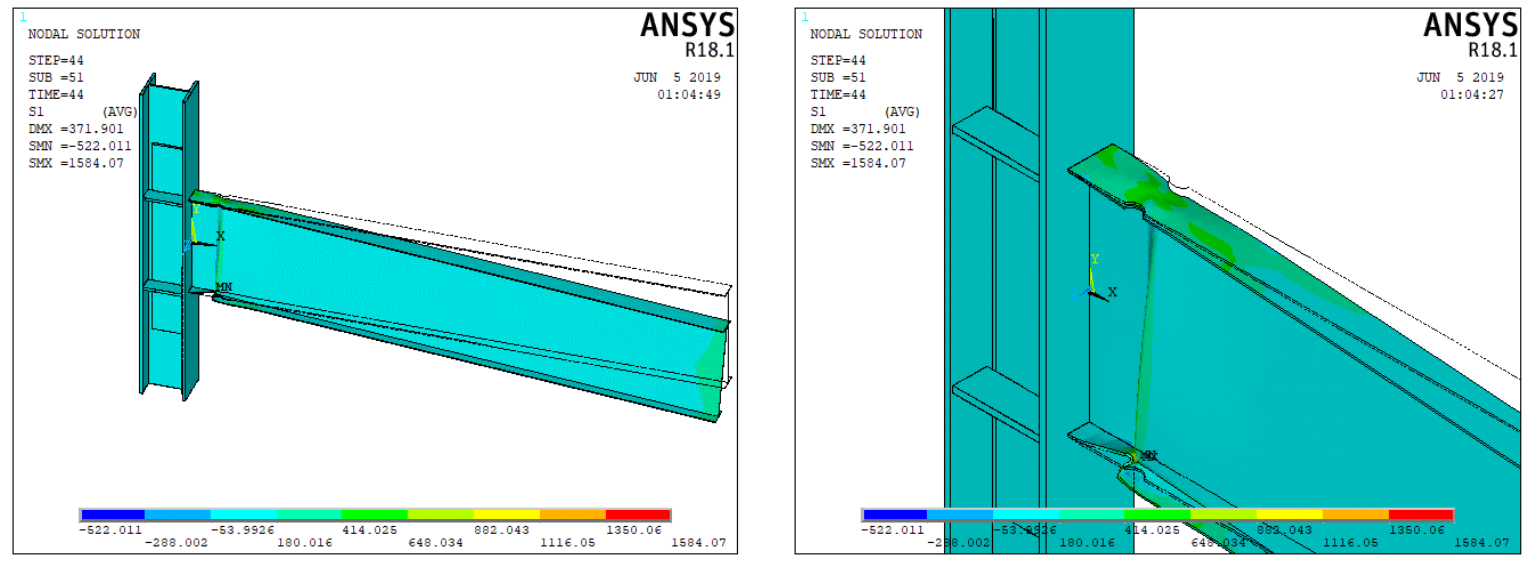

Figure C37: Deflected Geometry of Specimen RBS-42
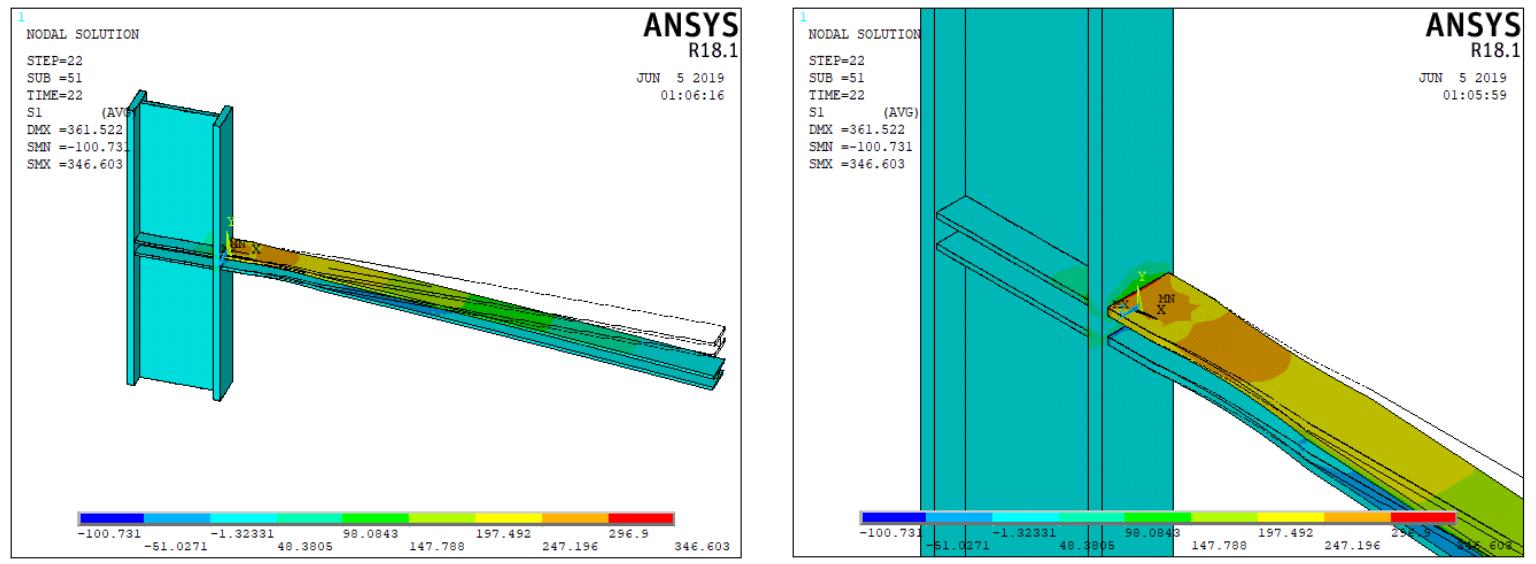

Figure C38: Deflected Geometry of Specimen RBS-43
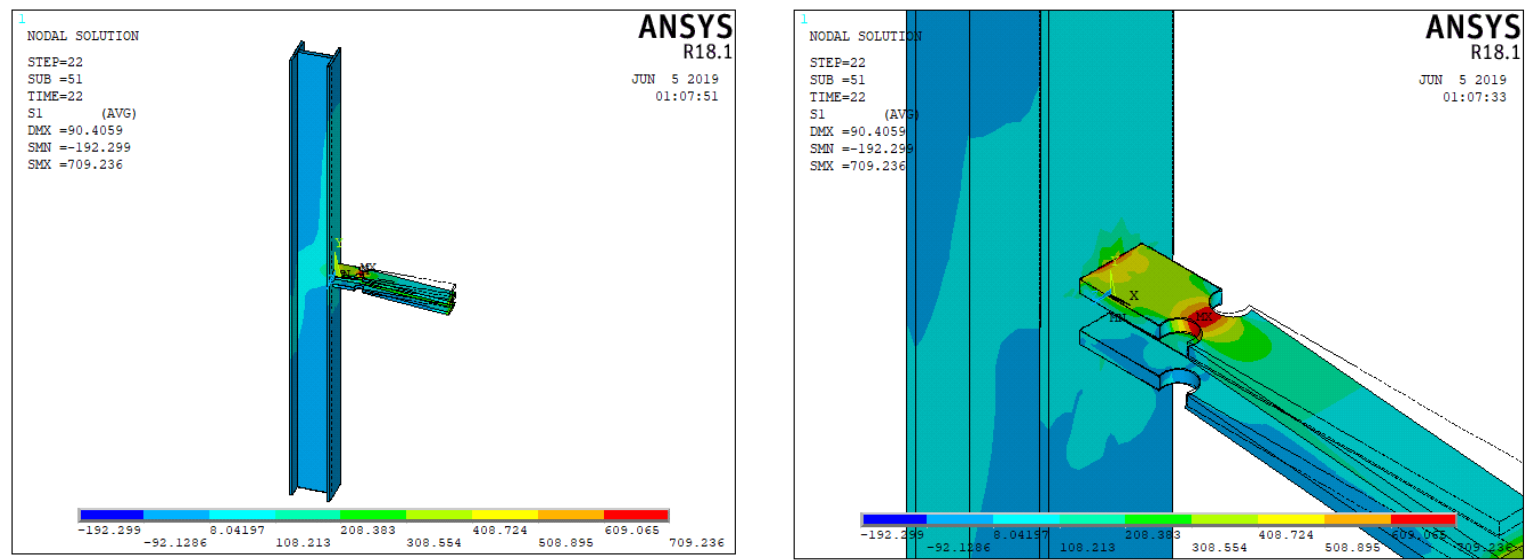

Figure C39: Deflected Geometry of Specimen RBS-44 

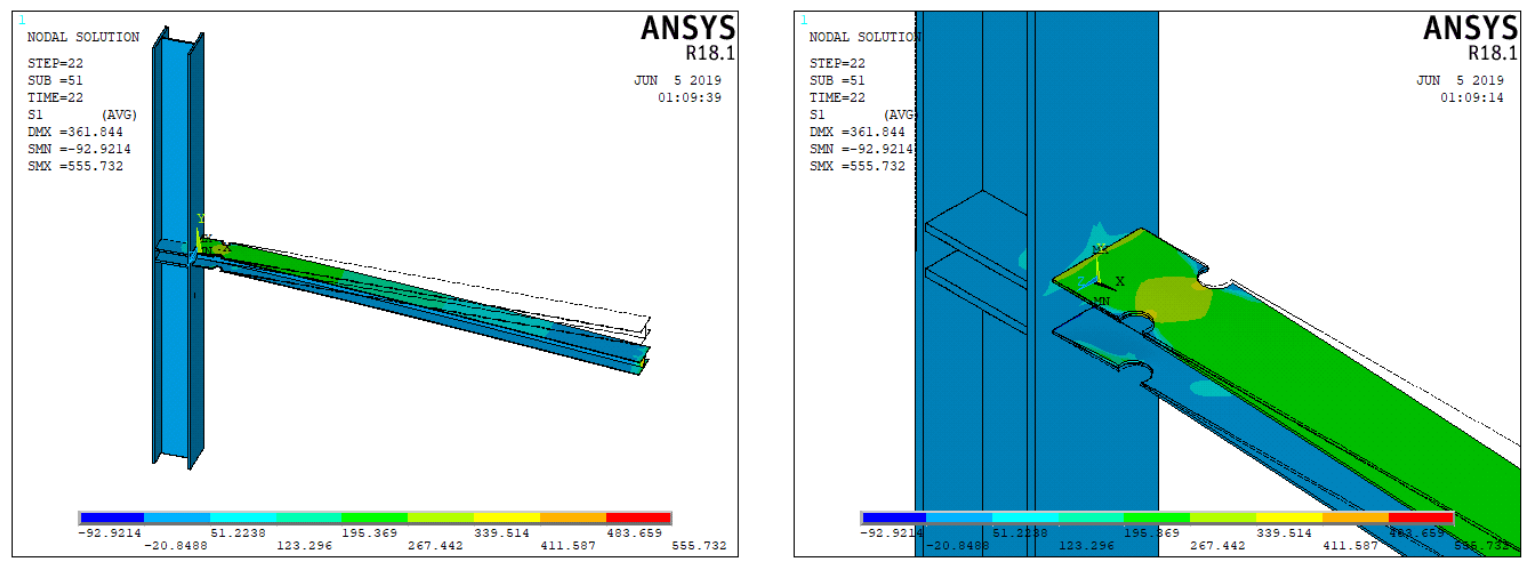

Figure C40: Deflected Geometry of Specimen RBS-45
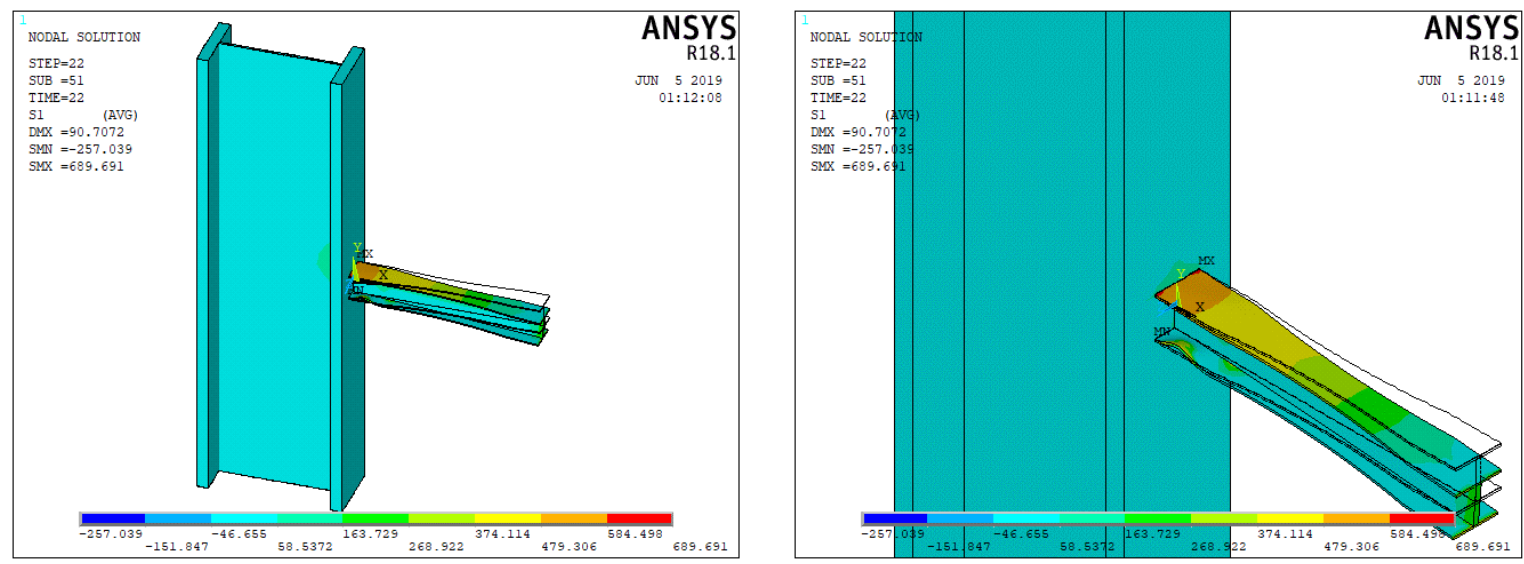

Figure C41: Deflected Geometry of Specimen RBS-46
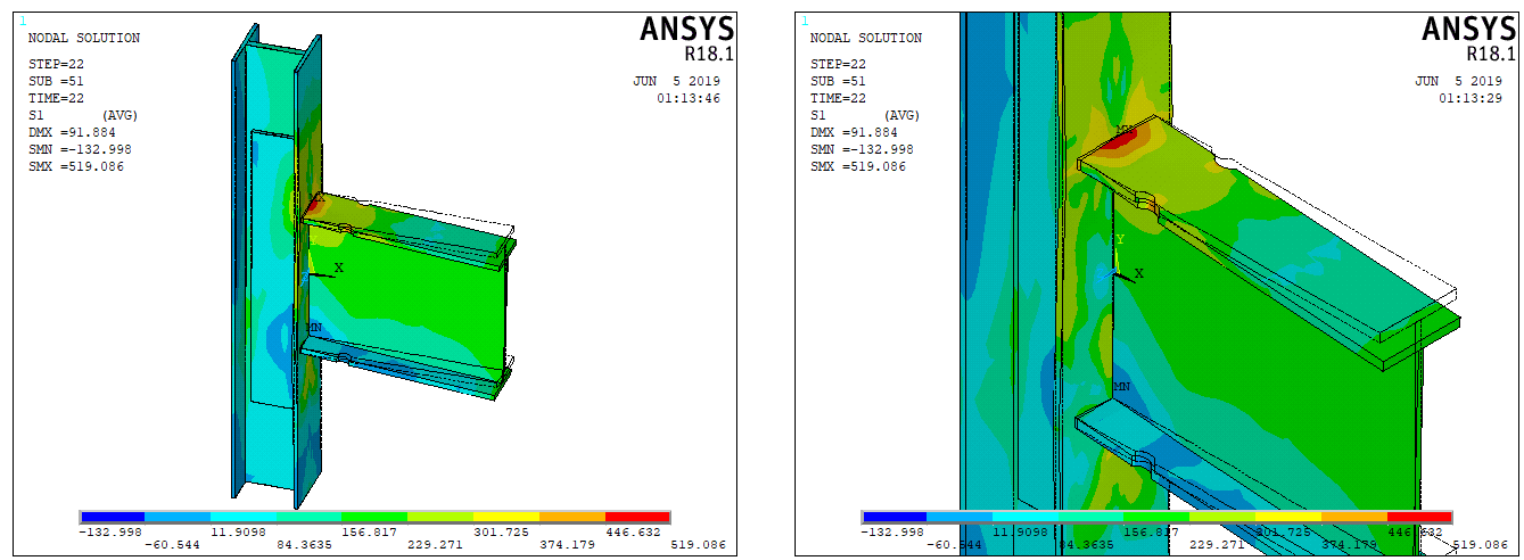

Figure C42: Deflected Geometry of Specimen RBS-47 

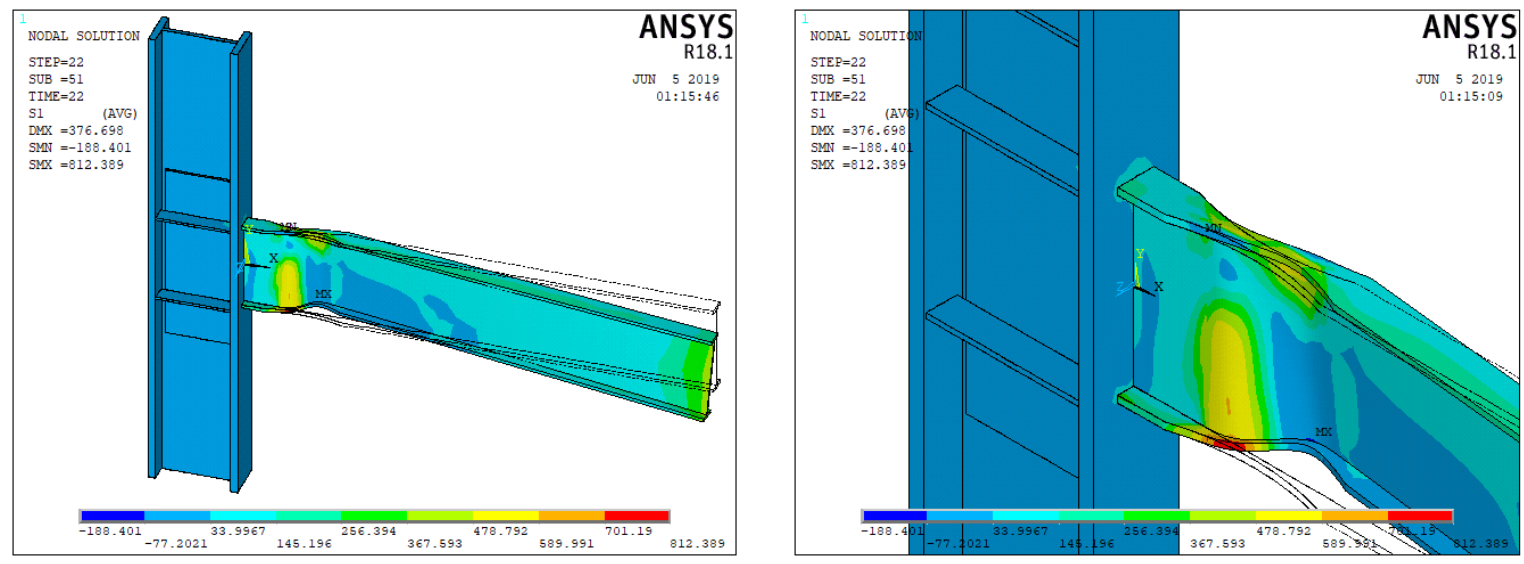

Figure C43: Deflected Geometry of Specimen RBS-48 


\section{REFERENCES}

Anderson, M.J., Whitcomb, P.J., Kraber, S.L., and Adams, W. 2017. Stat-Ease Handbook for Experimenters. Stat-Ease,Inc., 11(27): 1-5.

Bruneau, M., Uang, C.-M., and Rafael Sabelli. 2011. Ductile Design of Steel Structures.

Canonsburg, T.D. 2012. ANSYS Mechanical APDL Verification Manual. Knowledge Creation Diffusion Utilization, 15317(October): 724-746. doi:www.ansys.com.

Chen, B.S., and Chu, M. 1996. DUCTILE STEEL BEAM-TO-COLUMN CONNECTIONS FOR SEISMIC RESISTANCE. 122(11): 1292-1299.

Chi, B., and Uang, C. 2002. Cyclic Response and Design Recommendations of Reduced Beam Section Moment Connections with Deep Columns. 128(April): 464-473.

Chou, C., and Wu, C. 2007. Performance evaluation of steel reduced flange plate moment connections. (June): 2083-2097. doi:10.1002/eqe.

Dastfan, M., Asce, A.M., Driver, R., and Asce, M. 2018. Test of a Steel Plate Shear Wall with Partially Encased Composite Columns and RBS Frame Connections. 144(2): 1-9. doi:10.1061/(ASCE)ST.1943-541X.0001954.

Engelhardt, M.D. 1999. The 1999 T. R. Higgins lecture: design of reduced beam section moment connections. 1999 North American Steel Construction Conference(NASCC),: 1999.

Gilton, C.S., and Uang, C.M. 2002. Cyclic response and design recommendations of weak-axis reduced beam section moment connections. Journal of Structural Engineering-Asce, 128(4): 452-463. doi:Doi 10.1061/(Asce)0733-9445(2002)128:4(452).

Jones, S.L., Fry, G.T., and Engelhardt, M.D. 2002. Experimental Evaluation of Cyclically Loaded Reduced Beam Section Moment Connections. Journal of Structural Engineering, 128(4): 441-51. doi:10.1061/ASCÊं0733-94452002128:4441\%

Kim, K., Engelhardt, M.D., and Asce, M. 2007. Nonprismatic Beam Element for Beams with RBS Connections in Steel Moment Frames. 133(February): 176-184.

Lee, C., Jeon, S., Kim, J., and Uang, C. 2005. Effects of Panel Zone Strength and Beam Web Connection Method on Seismic Performance of Reduced Beam Section Steel Moment Connections. 131(December 2005): 1854-1865. 
Lee, C.H., and Kim, J.H. 2007. Seismic design of reduced beam section steel moment connections with bolted web attachment. Journal of Constructional Steel Research, 63(4): 522-531. doi:10.1016/j.jcsr.2006.06.030.

Li, F.-X., Kanao, I., Li, J., and Morisako, K. 2009. Local buckling of RBS beams subjected to cyclic loading. Journal of structural engineering, 135(12): 1491-1498. doi:10.1061/(ASCE)ST.1943$541 X .0000073$.

Li, R., Samali, B., Tao, Z., and Kamrul Hassan, M. 2017. Cyclic behaviour of composite joints with reduced beam sections. Engineering Structures, 136: 329-344. Elsevier Ltd. doi:10.1016/j.engstruct.2017.01.025.

Montgomery, D.C. 2013. Design and Analysis of Experiments Eighth Edition.

Moradi, S., and Alam, M.S. 2017. Lateral load-drift response and limit states of posttensioned steel beamcolumn connections: parametric study. Journal of Structural Engineering (United States), 143(7): 113. doi:10.1061/(ASCE)ST.1943-541X.0001772.

Oh, K., Lee, K., Chen, L., Hong, S., and Yang, Y. 2015. Seismic performance evaluation of weak axis column-tree moment connections with reduced beam section. JCSR, 105: 28-38. Elsevier Ltd. doi:10.1016/j.jcsr.2014.10.005.

Pachoumis, D.T., Galoussis, E.G., Kalfas, C.N., and Christitsas, A.D. 2009. Reduced beam section moment connections subjected to cyclic loading: Experimental analysis and FEM simulation. Engineering Structures, 31(1): 216-223. Elsevier Ltd. doi:10.1016/j.engstruct.2008.08.007.

Pachoumis, D.T., Galoussis, E.G., Kalfas, C.N., and Efthimiou, I.Z. 2010. Cyclic performance of steel moment-resisting connections with reduced beam sections - experimental analysis and finite element model simulation. Engineering Structures, 32(9): 2683-2692. Elsevier Ltd. doi:10.1016/j.engstruct.2010.04.038.

Pantelides, C.P., Eeri, M., Okahashi, Y., Eeri, M., Reaveley, L.D., and Eeri, M. 2004. Experimental Investigation of Reduced Beam Section Moment Connections without Continuity Plates. 20(4): 1185-1209. doi:10.1193/1.1814369.

Paul Popov, E., Yang, T.S., and Chang, S.P. 1998. Design of steel MRF connections before and after 1994 Northridge earthquake. Engineering Structures, 20(12): 1030-1038. doi:10.1016/S01410296(97)00200-9.

Prinz, G.S., and Richards, P.W. 2016. Demands on Reduced Beam Section Connections with Out-of- 
Plane Skew. Journal of Structural Engineering, 142(1): 04015095. doi:10.1061/(ASCE)ST.1943$541 X .0001360$.

Rahnavard, R., Hassanipour, A., and Siahpolo, N. 2015. Case Studies in Structural Engineering Analytical study on new types of reduced beam section moment connections affecting cyclic behavior. CASE STUDIES IN STRUCTURAL ENGINEERING, 3: 33-51. Elsevier Ltd. doi:10.1016/j.csse.2015.03.001.

Sofias, C.E., Kalfas, C.N., and Pachoumis, D.T. 2014. Experimental and FEM analysis of reduced beam section moment endplate connections under cyclic loading. Engineering Structures, 59: 320-329. Elsevier Ltd. doi:10.1016/j.engstruct.2013.11.010.

Sophianopoulos, D. 2011. Parameters affecting response and design of Steel Moment Frame Reduced Beam Section connections : An overview Parameters Affecting Response and Design of Steel Moment Frame Reduced Beam Section Connections : An Overview. (June 2011). doi:10.1007/s13296-011-2003-5.

Sophianopoulos, D.S., and Deri, A.E. 2017. Steel beam-to-column RBS connections with European profiles: I. Static optimization. Journal of Constructional Steel Research, 139: 101-109. Elsevier Ltd. doi:10.1016/j.jcsr.2017.09.028.

Tabar, A.M., and Deylami, A. 2005. Instability of beams with reduced beam section moment connections emphasizing the effect of column panel zone ductility. Journal of Constructional Steel Research, 61(11): 1475-1491. doi:10.1016/j.jcsr.2005.05.006.

Uang, B.C., Yu, Q.K., Member, S., Noel, S., and Gross, J. 2000. Cyclic Testing of Steel Moment C onnections With RBS or Welded H aunch. Journal of Structural Engineering, 126(January): 57-68. doi:10.1061/(ASCE)0733-9445(2000)126:1(57).

Uang, C., and Fan, C.-C. 2001. CYCLIC STABILITY CRITERIA FOR STEEL MOMENT CONNECTIONS WITH REDUCED BEAM SECTION. 126(January): 69-78.

Zhang, X., and Ricles, J.M. 2006. Experimental Evaluation of Reduced Beam Section Connections to Deep Columns. Journal of Structural Engineering, 132(3): 346-357. doi:10.1061/(ASCE)07339445(2006)132:3(346).

Zhang, X., Ricles, J.M., and Asce, M. 2006. Seismic Behavior of Reduced Beam Section Moment Connections to Deep Columns. 132(March): 358-367. 